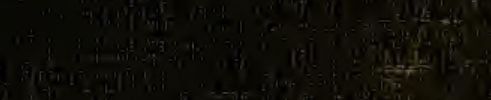




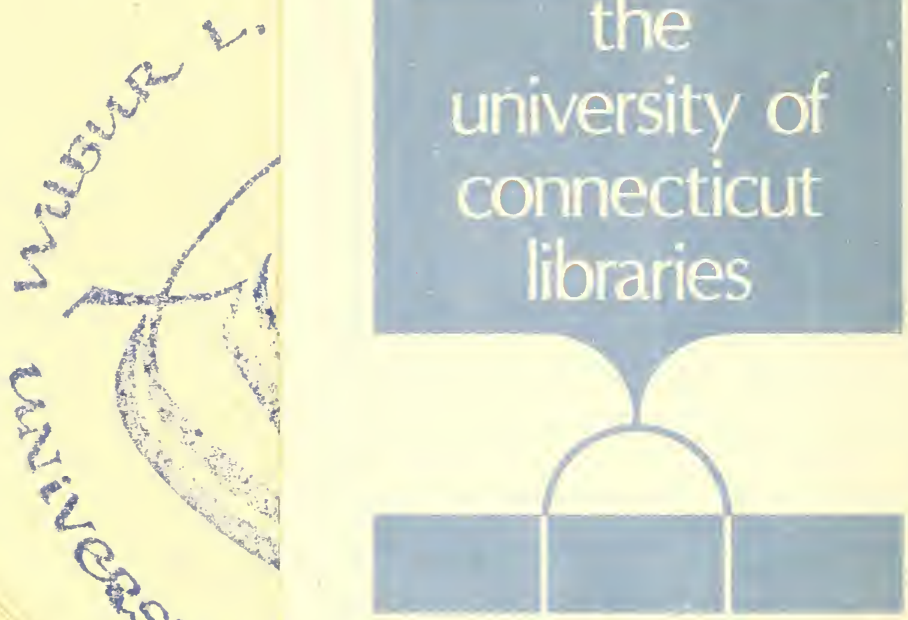

BOOK 595.7.B669P c. 2

BOUVIER \# PSYCHIC LIFE OF INSECTS

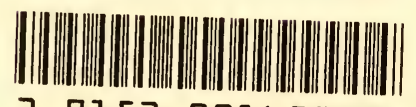

$\begin{array}{lll}3 & 9153 \quad 00145559 \quad 3\end{array}$ 



\section{The Psychic Life of Insects}





\title{
The \\ Psychic Life of Insects
}

\author{
BY \\ E. L. BOUVIER
}

Vice-President of the Academy of Agriculture of France

Member of the Institute

Professor at the Museum d'Histoire Naturelle

TRANSLATED BY

L. O. HOWARD, M.D., Ph.D.

IIIustrateo

T. Fisher Unwin, Ltd.

London: Adelphi Terrace

1922 

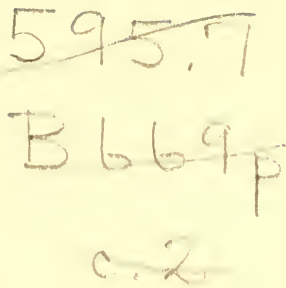

First Published in England 1928

(All rights reservod) PRINTED IN U. S. A. 


\section{TRANSLATOR'S PREFACE}

Professor Bouvier is one of the well-known personalities in the scientific world of Paris. His tall, spare, distinguished form and his keen, intellectual face are seen at the ceremonies of the Institut, at the meetings of the Académie des Sciences, the Société de Biologie and the Académie d'Agriculture; and at other times one will find him, in his long linen laboratory coat, working among his specimens in the old zoölogical workrooms at No. 55 Rue de Buffon, just across the street from the Jardin des Plantes. $\mathrm{He}$ is a very broad zoölogist. An old student of the late Edmond Perrier, he really began his active career at the period when evolutionary doctrines were being ardently contested, and he has fought valiantly at the side of Perrier, Gaudry, and Giard. His life has been a very productive one, and he has published a long list of important papers devoted for the greater part to marine articulates and especially to the Crustacea. He has produced, moreover, a magnificent monograph on the Onychophora, those extraordinary animals whose zoölogical position was so long disputed, 
and his studies on evolutionary mutations with certain sea forms of the family Atyida have been of the first importance. Moreover, his work on the remarkable sea animals known as the Pycnogonide, which are related in a broad way to the spiders, has made him a world authority on this group.

Bouvier, a quarter of a century ago, was appointed to the chair of articulate animals at the Museum d'Histoire Naturelle and from his laboratory has come a constant stream of important papers. Although working constantly with arthropods and having supervision of the labors of a number of famous entomologists and charge of the great entomological collections of the museum, for many years he personally did little work with insects, but in 1900 he became interested in the habits of certain nest-building Hymenoptera, and in that year and the next published three papers of very great interest as bearing on questions of instinct and behavior. Since the war he has retired from his official post, but it is impossible for a true naturalist like Bouvier to interrupt his work, and, curiously enough, he has gone back to the insects and is engaged at present upon a monograph on the great Saturnian moths whose larvæ are the most famous silk-spinners in the world. During the war he remained at his post, 
caring for the collections, except for a journey which he took quite to Toulouse in the South of France to carry a large series of the most precious specimens away from the dangers of bombardment. In the course of the war he lost two of his children, and the present volume was written during those trying times, in the effort, as he wrote me in sending me a presentation copy, "pour oublier les angoisses de patriote et de père."

I find this book, as I expected from a personal acquaintance with Bouvier for more than twenty years, to be a broad summary of an interesting field in which much work has been done by many men of many nations, but which is as yet almost unexplored. It has interested me enormously, and I feel sure that it will have the same interest, not only for students of some one restricted field of biology, but also for all nature-lovers, especially those to whom the constant question "why?" occurs.

Dr. W. M. Wheeler of Harvard University, in his appreciative review of the French edition of this book (published in the journal "Science" for November 13, 1920), called attention to several articles which should be read to supplement the consideration of certain topics in the book. Referring, for example, to the egg-laying of Cero- 


\section{viii}

\section{TRANSLATOR'S PREFACE}

pales, he mentions the very interesting observations of Adlerz (Bik. K. Svensk. Vet. Akad. Hand., 1902) on the surreptitious oviposition of this parasite in the lung-books of the spiders that have been captured by the host pompilid. He also refers to the important experimental contributions of Brun (1914) to the subject of the orientation and homing of ants and other animals. Further, he quotes from Needham and Lloyd's "Life of Inland Waters" (1916) in reference to the extraordinary habits of one of the American pompilids, as follows:

There is a black wasp, Priocnemis flavicornis, occasionally seen on Fall Creek at the Cornell Biological Field Station, that combines flying with water transportation. Beavers swim with boughs for their dam, and water striders run across the surface carrying their booty, but here is a wasp that flies above the surface towing a load too heavy to be carried. The freight is the body of a huge black spider several times as large as the body of the wasp. It is captured by the wasp in a waterside hunting expedition, paralyzed by a sting adroitly placed, and is to be used for provisioning her nest. It could scarcely be dragged across the ground, clothed as that is with the dense vegetation of the waterside; but the placid stream is an open highway. Out on to the surface the wasp drags the huge limp black carcass of the spider and, mounting into the air with her engines going and her wings steadily buzzing, she sails away across the 
water, trailing the spider and leaving a wake that is a miniature of that of a passing steamer. She sails a direct and unerring course to the vicinity of her burrow in the bank and brings her cargo ashore at some nearby landing. She hauls it upon the bank and then runs to her hole to see that all is ready. Then she drags the spider up the bank and into her burrow, having saved much time and energy by making use of the open waterway.

Doctor Wheeler appends to this quotation the statement that "additional peculiarities of habit among the Pompilids have been described by other authors, notably by $\mathrm{F}$. $\mathrm{X}$. Williams in a recent work on wasps of the Philippines (Bulletin No. 14, Experiment Station of the Hawaiian Sugar Planters' Association, 1919)."

Wheeler adds, "Most readers will be delighted with Bouvier's book as it stands, with its lucid diction, its lack of dogmatic assertion, its kindly and stimulating tone and its frank acknowledgment of our ignorance in regard to many matters of fundamental importance."

To some readers the early chapters of the book may seem, in comparison with the later ones, somewhat dull and possibly irrelevant, but they are a necessary part of an admirably elaborated discussion leading from the earliest reactions of living matter to the acquisition of instinct, and so 


\section{TRANSLATOR'S PREFACE}

to the consideration of the characteristics of that sort of psychism that insects possess.

L. O. Howard

Washington, D. C., October 1, 1921. 


\section{INTRODUCTION}

Insects are creatures which seem to defy the imagination with the strangeness of their form and their extraordinary habits. In the "War of the Worlds," Wells the novelist surprises us with his belligerent Tripods which descend as conquerers upon our planet, where they terrify and exterminate poor humanity. This fiction appears bizarre, but it falls far short of what Nature herself shows us in the world of the articulates! Among them, it is true, we do not meet with Tripods, but the hexapods or insects have invaded the entire terrestrial domain, where they make their power terribly felt; the octopods or arachnids share this domain with them and with the myriapods, which have more than a hundred pairs of legs; while the waters swarm with crustaceans which rival the myriapods in the number of their appendages. And what are the organs with which Wells endows his Tripods compared with those which serve as arms or ornaments to a host of articulates,- - the enormous pincers of the lobster and the crab, the toothed saber-like beak which projects 
from the forehead of shrimps, the wonderful sting at the end of the abdomen in female Hymenoptera, the great horns on the head and thorax of many scarabs, the numerous spines on the body of the thorny spiders, or the extremely elongate legs which give the house centipedes their swift gait and terrifying appearance!

And the habits of these animals are not less disconcerting than their forms. What is the meaning of the atrocious courtship of the spiders and the mantids, when the female responds with cannibalism to the loving advances of the male? And what can we think of the predatory wasps which paralyze with dagger thrusts the victims intended for their larvæ; of the braconids and ichneumons which place their eggs either on or in the body of other insects? What, above all, can we think of the larvæ that hatch from these eggs and scientifically devour their host, leaving its most vital organs untouched until the last? The orb-weaving spiders have no peers in the art of weaving. They know how to fasten marvelously regular webs to the branches of trees, how to cross rivers on bridges of floating threads, and, when young, how to utilize similar threads to take flight through the air like aëronauts. The sacred scarab fashions the oily sheep dung into a pear-shaped ball and the coarse excrement of horses into a per- 
fect sphere of food; and certain wasps of the genus Eumenes mold earth into pottery of the most charming design. In the presence of these phenomena which are beyond him, man wonders and tries to understand, but especially does he try to guard himself against these strange creatures among which he finds more enemies than aids; prolific and multiform, the minute phylloxera has destroyed his vineyards ; voracious and migratory, the multitudinous locusts advance in innumerable legions to ravage his crops; clouds of flies and gnats sting and infect his cattle. And he himself does not escape the virus secreted by these terrible stingers; mosquitos menace him with malaria in the vicinity of marshes, tse-tse flies with sleeping sickness in the damp and shady jurgles of the African tropics; fleas transmit to him the germs of plague, and filthy lice the typhus fever which claimed so many victims at the beginning of the great war.

What a contrast to the vertebrates, which form the other culminating point of the animal kingdom! No doubt there are cruel and voracious species among the higher animals; some of them are frankly hostile to us, and many are remarkable for their instincts and their industry. But where do we find the forms and the singularity of habits which are the appanage of the articulates? 
Georges Maeterlinck ${ }^{1}$ gives this striking contrast in poetic words :

The insect does not belong to our world. The other animals, even the plants, despite their mute existence and the great secrets which they nourish, do not seem wholly strangers to us. In spite of all we share with them a certain feeling of terrestrial fraternity. They surprise us : even make us marvel, but they fail to overthrow our basic concepts. The insect, on the other hand, brings with him something that does not seem to belong to the customs, the morale, the psychology of our globe. One would say that it comes from another planet, more monstrous, more dynamic, more insensate, more atrocious, more infernal than ours.

It seizes upon life with an authority and a fecundity which nothing equals here below: we cannot grasp the idea that it is a thought of that nature of which we flatter ourselves that we are the favorite children.... There is, without doubt, with this amazement and this incomprehension, an, I know not what, of instinctive and profound inquietude inspired by these creatures so incomparably better armed, better equipped than ourselves, these compressions of energy and activity which are our most mysterious enemies, our rivals in these latter hours, and perhaps our successors.

Everything about these animals surprises us even when, in the present stage of their mental evolution, they seem to come near us and to engage

1 Georges Maeterlinck, J.H. Fabre et son Euvre (Annales politiques et littéraires, April 2, 1911). 
in activities which might be considered human, such as we frequently observe in the social species. We are confounded by the foresight of the harvesting ants, by the care other ants give to their plant-lice herds, by the horticultural skill of the fungus-growing species, and by the division of labor which reduces certain workers among the myrmecocysts to the condition of honey-bags. We prize our own abilities so highly that we think them unequaled, even when they are inspired by motives that are hardly commendable. We are bellicose ourselves, but it seems strange to us that colonies of bees and ants engage in battle. A $\dot{t}$ times we return to barbarism by making slaves of our enemies; yet we exclaim with surprise at the habits of slave-making ants.

It is the fact that these wonderful analogies are well calculated to emphasize the contrast between the world of the articulates and our own. We have a feeling that the psychic evolution of these animals is not less original than their structure, and that they are never so widely separated from us as when they appear to resemble us the most. The old anthropocentric school is, indeed, dead: we no longer attempt to explain insects by man; we rather try to grasp the mechanism that allows these animals to evolve mentally and to acquire activities which seem human. 
That was the end we had in view in writing this book. The material was extensive, but we have not used it all, because many reported observations are lacking in the necessary scientific accuracy. Moreover, ever since the work of Loeb and Jennings, research in animal psychology has been directed along a fruitful path, on which we have been happy to follow these biologists and their disciples, Bohn, Pieron, Roubaud, Turner, etc. We have also given a large place in the work to biological observations from Réaumur ("Memoires pour servir a l'histoire des Insects") to Fabre ("Souvenirs Entomologiques"), where one may richly glean from every page. In this group, in which France occupies such a high place, we wish to mention especially Commandant Ferton, ${ }^{1}$ whose work is singularly rich and precise. I wish finally to do justice to my dear pupil, Georges Bohn, for the value of his numerous papers and for the originality of his two books, "Naissance de l'Intelligence," and "Nouvelle Pisychologie Animale," as well as for the material he has sent me in the course of the present study.

1 The principal memoirs of Ferton (eight series) have been published in the Annales de la Sociéte entomologique de France (1901-14) under the title: Notes détachées sur l'instinct des Hyménoptères mellifères et ravisseurs. 


\section{CONTENTS}

CHAPTER

I Directive Action of Light: Phototropism - . 3

II The Different External Stimuli and the TroPisms which They Provoke . . . . 21

III Vital Rhythms and the Organic Memory • . 46

IV Differential Sensitiveness . . . • . • . 65

V Differential Sensitiveness,-Species Memory

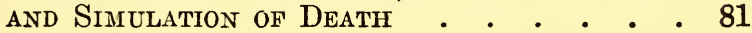

VI Individual or Associative Memory . . . . 104

VII Spontaneous Modifications of Habits . • 125

VIII Evolution of Instincts . • . . • . 140

IX Comparative Psychology. History of the PomPILIDS . . . . . . . . . . . . . 175

$\mathrm{X}$ Insects and Flowers . . . . . . . . 200

XI The Faculty of Orientation . . • • . . 231

XII The Faculty of Orientation with Terrestrial Articulates . . . . . . . . . . . 251

XiII The Division of Sexes with Nest-Making HYMENOPTERA . . . . . . . . . . . 287

XIV The Social Life of the Articulates . • . . 312 Conclusion • . • • . • . • • • • . 350 $\mathrm{INDEX}_{\mathrm{N}}$. . . . . . . . . . . . . 363 



\section{FUNDAMENTAL PART}





\section{The \\ Psychic Life of Insects FUNDAMENTAL PART}

CHAPTER I

DIRECTIVE ACTION OF LIGHT: PHOTOTROPISM

The pyralids of Pliny. In the eleventh volume of his "Natural History," Pliny the elder tells a strange story. "In the forges of Cyprus," he says, "one sees a large four-legged fly flying in the midst of the flames. Some call it Pyralis, others the Pyrausta. It lives as long as it remains in the fire ; if it flies out for a short distance, it dies." It is not necessary to go to Cyprus to see this strange creature. Pliny could have found it in the Roman Campagna with many others which possess the same title to these fabulous habits, and the summer gives us superabundantly the spectacle to which the Roman naturalist alludes in his account.

Like Pliny, we are sometimes in the fantasies of legend, but many legends touch strongly on real- 


\section{THE PSYCHIC LIFE OF INSECTS}

ity, and here the truth will appear singularly instructive. Pliny gave the name "fly" to different insects that fly more or less well and, like all insects, his Cyprus fly should possess three pairs of legs. But with certain insects the front legs are scarcely visible, since they are reduced in size and are brought forward toward the head, so that at first glance one would believe that the insect was "four-legged." This character is especially marked with most of the night-flying moths (tineids, tortricids, geometrids, noctuids etc.) and it is well known that these insects are attracted by flame and that they fly straight toward it and perish in it, victims of its destructive attraction. There was no entomologist at the forges of Cyprus, but the observation was not faulty. The four-legged flies of Pliny surely belonged to the nocturnal Lepidoptera, and among them were undoubtedly certain species which we designate today as pyralids or butterflies of the fire-the true Pyralida of the systematic zoölogists and the species popularly known as the "Pyralis of the Vine," which, however, is a tortricid (Enophtira pilleriana). Jacques Loeb has very exactly observed the attitude of these insects and others which fly toward the flame. The rapid flyers reach the flame before its heat has had time to stop their flight; but those that move slowly are 
affected by the increasing heat in the measure of their approach, the high temperature lessens this movement and they walk or fly about the light, burn their wings, and fall dying on all sides. This is the truth of the fabulous story of the old naturalist.

Directive orientation toward the light: positive phototropism. The observation of Pliny has passed into current practice. For a long time light traps have been used to capture the destructive Vine Pyralis and it is with traps of this kind or with simple lanterns that collectors of noctuids work during the night in the edges of the woods. However, the night-flying moths are far from being the only insects that fly to light. Very many others have similar habits, as one is easily convinced in the country on beautiful summer nights. Indeed, insects gather in swarms about lighthouses and street lamps, and if one wishes to have some repose in a lighted spot it is necessary to prevent the approach of all tineids, noctuids, June-beetles, scarabs, crane-flies, mosquitos, and other representatives of the entomological class which assemble there. It is at the table in the open air, around the lamp, that travelers in warm countries often collect the most interesting species of insects. All caterpillars-sawfly larvæ as well as the larvæ of butterflies and moths-are 
more or less sensitive to light and direct themselves directly toward it. If they are obliquely placed on a plane surface opposite to the source of light they quickly turn their heads, following the axis of the light ray and then the rest of the body moves in this direction.

The same faculty of directive orientation is seen with a great number of animals, even with lower forms which have no eyes. Who does not know the classical experiments with the Euglenes. These flagellate Infusoria progress by turning themselves over and it is by describing a helicoidal trajectory that they direct themselves toward the source of light. Moreover, the directive orientation which we are considering is not at all confined to animals. It is observed in the motile algæ of the genus Volvox and we know that with all plants the branches bend and grow toward the light when they are kept in the shade or in the house.

The scientific study of these phenomena was begun with the plants, and the botanists have given the name tropisms to the directive action exerted upon plants by external stimulating agents. To Jacques Loeb ${ }^{1}$ must be credited the first proof

1 Loeb has synthetized his work in the two volumes: Studies in General Physiology (1905), and The Dynamics of Living Matter (1906). 
that the law of tropisms applies to animals as well as plants. In the two kingdoms these phenomena are as varied as the forces that produce them and each one of them has received a special name in relation to the stimulating agent from which it draws its origin. The directive action of light is called phototropism (also heliotropism when it is caused by the sun), and one says that the organism is endowed with positive phototropism when it directs itself toward the source of light as with all the species cited above.

Directive orientation away from the light; negative phototropism. All animals are not equally sensitive to light; many do not appear to be phototropic, others are very slightly so, and the degree of attraction grows less and less until a good many direct themselves away from the light rays; their phototropism is negative.

This phenomenon was placed in evidence in a masterly way by Georges Pouchet (1872) with the larvæ or maggots of the green blow-fly (Lucilia casar) and the bluebottle or meat-fly (Calliphora erythrocephala), also with rat-tailed maggots of the drone-fly (Eristalis tenax). Upon a square of black or white paper spread on a horizontal table before a window, the larvæ were scattered promiscuously, and all drew away from the daylight. Pouchet also employed artificial lights 


\section{THE PSYCHIC LIFE OF INSECTS}

which he moved about and which always brought about an inverse displacement of the larvæ. Loeb gave the experiment a simple and elegant form. "If a shadow," he says, "is thrown upon the table by means of a pencil, the larvæ move parallel to the shadow, away from the light." The bedbug and the meal-worms (larvæ of Tenebrio molitor) lend themselves equally well to experiments of this kind. I have often made analogous experiments with Peripatus capensis, a curious and very primitive species which is a link between the articulates and the annelids. This wormlike animal is endowed with a very energetic negative phototropism. It directs itself in a straight line away from the light rays, and if one suddenly turns the sheet of paper on which it is walking at an angle of 180 degrees it immediately executes an equal reverse rotation.

Character of phototropism. Be it positive or negative, phototropism appears to us as a purely physical directive reaction; that is to say, innate, automatic, independent of all choice and consequently of all psychic phenomena.

It is innate because all sensitive animals are phototropic from birth, and the reactions which they present are not the result of an individual education. Neither do they seem to result from the education of the species in the course of its 
history. Loeb cites on this subject the examples of the tree-boring caterpillars of Cossus ligniperda and a little marine crustacean, Cuma rath$k e i$, common on our shores. Both are endowed with a very strong positive phototropism, but live, in complete obscurity, the first in the long galleries it makes in willow, apple, and a number of other trees which it kills, while the other is a burrowing animal which nests deep within the ooze.

The phototropic animal is not guided by choice, it acts like an automaton. In the presence of two sources of light, says Georges Bohn, it orients itself toward neither the one nor the other, but in an intermediate direction, so that the two sides of its body receive the same light. It is incapable of resisting the luminous reaction and one can point out in advance how it will behave during the reaction. This is pure automatism. As Loeb has shown by many experiments, the phototropic phenomena of animals differ not at all from those of plants, and they carry no more psychism in a polyp or in a pyralis than in a geranium or in a volvox.

It is not, then, from curiosity, as is often said, that certain animals come to the light, and Pouchet is surely self-deceived when he attributes the retreat of the maggots before the light to a dazzled condition. Phototropic creatures are neither drawn toward the light nor repulsed by it; they 
go or they come by a simple physical mechanism. The fly larvæ, says Loeb, are no more frightened by the light than the negatively phototropic end of a tree branch. He adds :

One can show this by putting the larvæ on a table, near the window, in such a position that the half of the table nearest the window is lighted by the diffused daylight and the other half by the direct rays of the sun. If at the beginning of the experiment the animals are in the shade, on the window side, they will mechanically bend their heads to leave the influence of the diffuse light and will begin to move in the direction of the light rays. They will also depart from the window, the source of light, which will lead them "from the shade into the sunlight."

Occurring among the plants and among the lower animals, as well as among those in which eyes are well developed, phototropism is not bound up with the existence of eyes, which serve only as propeller centers when they exist. At times, as in fly larvæ, eyes are totally lacking, but then the phototropic sensitiveness is localized in the anterior region of the body in the cerebral centers, which is truly an inheritance, since the insects with blind larvæ have developed from more primitive forms whose larvæ possessed sight. In all cases the sensitive articulates usually orient themselves according to the luminous source, so that 
the front end of the body (that which carries or should carry the eyes) faces the source or is opposite to it according as the phototropism is positive or negative. This rule is very general, and probably constant. Georges Bohn (1905) showed that the larvæ of the European lobster are endowed with positive phototropism on hatching and become negatively phototropic; but the larvæ always hold themselves with their eyes away from the light, so that they direct themselves toward the source or depart from it swimming backward. According to the researches of Hadley, the larvæ of the American lobster act in exactly the same way.

Physical interpretation of phototropism. Jacques Loeb has given the following interpretation of these phenomena: When the rays coming from a luminous center strike asymmetrically one side of the sensitive region (the head with the articulates) of a symmetrical animal endowed with positive phototropism, the muscles of that side of the body become more active than those of the opposite side, so that the axis of the body is finally turned in the same direction as the luminous rays. Then, "the luminous intensity being the same on both sides, there is no reason for the animal to turn from this direction either to the right or to the left. It therefore directs itself toward the 
source of light." When the animal is negatively phototropic the muscles of the illuminated side are less active, which has the result of turning the animal away from the source. The law common to the two cases may be expressed by saying that "with sensitive symmetrical animals, an asymmetry of lighting clearly provokes an asymmetrical muscular activity which results in a symmetry of activity and of lighting."

If the explanation of Loeb is well founded, if, in other words, it is to the asymmetry of lighting that the asymmetrical muscular activity of sensitive animals is due, an insect deprived of one eye should move in a circle to the opposite side if it is positively phototropic, and, deprived of both eyes, it should cease to react to the light by a directive orientation. This is, in fact, what was shown by the experiments of Parker (1903) with a butterfly, the mourning-cloak (Vanessa antiopa), which has a very strong positive phototropism. When one of the eyes is covered with black paint, the butterfly turns in a circle to the opposite side and little by little approaches the light. The recent experiments of Dolley (1916), on the same species, largely confirm the preceding, while this author does not consider them favorable to the views of Loeb. Under normal lighting conditions, or where there is an open window, the Vanessas of the 
American biologist behave always like Parker's when one of its eyes are covered with asphalt; but under the influence of a powerful light ray, sometimes they turn in a circle, sometimes they move obliquely in a straight or sinuous line toward the side of the sound eye, which shows that the muscles are always more active on that side. Dolley's memoir will be read with profit, for it adds a good chapter to this discussion; but, as we shall shortly see (page 78), it does not sufficiently indicate the difference between tropisms and the phenomena of differential sensitiveness.

Physicochemical interpretation of phototropism. It may be said that the preceding interpretation is a simple statement of facts. But Loeb has not contented himself with the establishment of a formula; he has wished to establish the relations which exist between the light and the movements that it provokes.

Admitting that phototropism is characterized by an asymmetrical motive activity when the body is asymmetrically struck by the luminous rays, it seems natural to admit that more or less intense chemical reactions have caused this activity. These reactions will be provoked by the light, either in the visual organs of animals provided with eyes, or on all or a part of the body with blind organisms. This conception of phototropism can. 


\section{THE PSYCHIC LIFE OF INSECTS}

doubtless be submitted to the control of experiments. In any event, it is strictly rational, for rays of light are among the most powerful chemical reagents. They are not limited to the transformations of mineral substances in the laboratory, as we see in photography, but they act with still greater energy in the heart of living matter, and, notably in plants, they play a nutritive rôle of the first importance in decomposing carbonic acid by the help of a photochemical green substance, chlorophyl.

It cannot be doubted that photochemical substances exist in animals and we know that in the vertebrate eye a substance of this kind impregnates the distal ends of the optic rods, where it constitutes the retinal purple. With the articulates there probably exist analogous substances in the retinal region where they provoke reactions which excite the optic elements and, through them, the different parts of the body. With the blind species they seem to be symmetrically distributed through the anterior or cephalic end of the organism. Thus, phototropism has for its start chemical modifications produced by light. We are here in the presence of an hypothesis, but this hypothesis appears to be an expression of the truth. It is, moreover, justified by the fact that the most refractive of the visible solar spectra, which are 
especially efficacious in the chlorophyl action of green plants, are also much more active in directive orientation with all organisms that are sensitive to light.

The preceding hypothesis is equally justified by the influence of certain chemical agents on the development or the suggestion of phototropism. In their normal condition, Gammarus pulex, the Cyclops, the Daphnias, and other small crustaceans of fresh water do not seem entirely phototropic, or are very slightly so. But, says Loeb, it is possible to confer upon them immediately an intense positive phototropism, by adding certain chemical substances to the water, ether or acids, especially carbonic acid. Dispersed at the beginning of the experiment, they direct themselves quickly to the light face of the aquarium. One gets this identical result with the green algæ of the genus Volvox. In both cases Loeb suggests with great truth that the ethers or the acids act as sensitizers, causing, by catalysis, an increase of the photosensitive substances and provoking the phototropic phenomena.

To this idea of sensitizing substances should be added another. The vinegar-fly (Drosophila ampelophila) is normally positively phototropic, but, as Carpenter has shown (1905), it ceases to react when the luminous rays are too strong. It then 


\section{THE PSYCHIC LIFE OF INSECTS}

turns away from the rays and appears to become negatively phototropic, but is really struck with directive incapacity. The larvæ of the lobster in their first stage direct themselves at first toward the light; but at the end of a day or two they leave and group together in the dark places. But Georges Bohn has shown that these last larvæ are very sensitive to the action of dilute sulphuric acid, that they return to the light, and that, having remained there one or several hours, they vigorously return to the shady spots they had quitted. Thus, under the sensitizing influence of the acid, their negative phototropism changes its character momentarily, to become again more strongly negative. Alkaline soda solutions produce a similar result. To what must we attribute the attenuation or the change of character of the phototropism in these two experiments? It is not muscular fatigue, for the animal preserved all its activity; neither is it a matter of memory, for the sensitiveness reappears. We must believe with Bohn that an intense functioning has caused more or less wear and tear of the photosensitive substances and that these last, before they are reformed, functionally give way to antagonistic chemical reactions.

Other factors which may modify the phototropism. If this be so, one conceives that, aside from 
light, phototropism may be modified by all the factors, either external or internal, which are capable of acting on the photochemical substances of the organism. This is shown, in fact, by observation and experiment.

If a too strong light can suppress phototropism, movements forced upon the animals can make it change in character. The maggots of the green blow-fly are normally, as we have seen, negatively phototropic, but Pouchet has shown that their phototropism becomes positive when one moves them previously in a box. The pelagic copepods, notably Temora longicornis, direct themselves toward the light when they have just been captured and almost all of them move away immediately afterward. But, as Loeb's experiments have shown, an agitation brings back to positive phototropism those which had become negatively phototropic.

Following up his experiments, Loeb has found that these same copepods are very sensitive to changes in temperature. Should this pass a certain point, the phototropism of positive individuals changes rapidly to negative phototropism, which increases with the temperature. If it lowers, on the contrary, below a certain limit the reverse phenomenon occurs.

Hindering the movements leads sometimes to 


\section{THE PSYCHIC LIFE OF INSECTS}

the same result as a mechanical agitation. So it is at least, according to Ostwald (1907), with the little fresh-water Crustacea of the genus Daphnia, known popularly as water-fleas. Indifferent to normal light or having a feeble negative phototropism, these organisms acquire an intense positive phototropism when one increases the viscosity of the water in which they move, by adding a little gelatine.

In the last experiment, as in that where mechanical agitation was used, there is evidently put in play an internal factor, the locomotive activity, which becomes greater from the opposition of the displacement or viscosity of the water or the contractions of the animal. But one of the results of the muscular activity is to render the internal reactions stronger and especially to increase the production of carbonic acid; and we have seen how this gas acts as a sensitizer in phototropic phenomena. In this way can be explained the change of phototropism in Ostwald's experiment and in those produced by mechanical agitation.

But locomotive activity is only one of the forms of work of the body; the organism develops others quite as important from the point of view of the modifications which they provoke, and which, like locomotion, powerfully affect phototropism. 
This is especially true of phenomena of nutrition and of reproduction.

The experiments of Loeb on the young caterpillars of the Brown-tail Moth (Euproctis chrysorrhea) show very plainly the influence of the nutritive phenomena upon phototropism. Loeb says :

These caterpillars hatch in the autumn and pass the winter in their webs; in the spring, and even in the winter when the temperature is raised, they come out, influenced by the warmth. They then show a very perfect positive phototropism, and I have never found under natural conditions any animal with a more pronounced heliotropism. But, as soon as they have eaten, their positive heliotropism disappears and reappears no more even when they fast again. It is evident that the chemical changes connected with nutrition have acted, directly or indirectly, as an inhibition or a definite suppression of the photochemical reactions which the insect formerly possesed.

It is probably to chemical phenomena dependent on nutrition that we must attribute the change of character of phototropism in the evolution of the individual.

Loeb has shown that larvæ of Limulus polyphemus and of Balanus are positively phototropic immediately after birth and that soon afterward they are changed in character. We have seen 


\section{THE PSYCHIC LIFE OF INSECTS}

that larval lobsters act in exactly the same way. We know, however, from the experiments of Pouchet that maggots do not react to the light when just hatched and that their negative phototropism develops with their growth.

The influence of the phenomena of reproduction on phototropic sensitiveness is especially shown with the fertile individuals of most ants and of the domesticated honey-bee. With these insects the fecundated females, or queens, pass their whole existence in the obscurity of the nest, where their rôle is to lay egg's almost continuously. But at the moment when they shed the nymphal skin and acquire sexual maturity they are positively phototropic and leave the nest, to dart toward the light. This flight coincides always with the sexual maturity of the males, which, having the same phototropism, and, guided by the odor, hasten in pursuit of the females. Such is the origin of the nuptial flight of the honey-bee and of the swarming of the winged ants, - that is to say, of the sexual individuals. With these insects, as with all animals, there are found within the organism, at the moment of sexual maturity, special products which modify the physiological condition of individuals; and, according to Loeb, it surely is to the action of these products on the photosensitive substances that we must attribute the development of phototropism. 


\section{CHAPTER II}

THE DIFFERENT EXTERNAL STIMULI AND THE TROPISMS WHICH THEY PROVOKE

Organisms respond automatically to the luminous stimulus with an orientation and with determined movements. Whether they are provided with eyes or not, they react the same, and this reaction is not the result of sight, but a response of the living material, of the protoplasm which constitutes them, to the energy of the luminous rays. But sources of energy abound in nature and, aside from light, as Davenport has shown in his "Experimental Morphology," each one exercises a physicochemical stimulation on the living matter,-a stimulus which, acting on symmetrical organisms in the way light does, can produce, as it does, an orientation and determined automatic movements. It is to an examination of these tropisms, at least the most essential, that the first part of the present chapter will be devoted.

Action of heat: thermotropism. Heat is the result of molecular vibrations which increase in 
number in proportion as the temperature rises. We know that it is one of the principal agents of all chemical phenomena. In different ways it plays a part of the first importance in the modifications of living matter. Most insects perish when submitted to temperatures of $38^{\circ}$ to $43^{\circ}$ (Centigrade) and if they resist very low temperatures (Pictet states that the eggs of the silkworm moth stand $-40^{\circ}$ ), is it at the expense of their vitality, which is lessened to the most extreme limit. It is, then, not astonishing that organisms respond with a directive orientation to stimulations by heat, and this is due to thermotropism as it is called.

Like all tropic manifestations, this reaction is particularly apparent with the lower organisms, like the myxomycete fungi among the plants, and the Infusoria among the animals. But it is found equally in the articulates.

Loeb put the caterpillar of the Brown-tail Moth in a dark box one end of which was near a warm stove, and after some instants found them all together in the warm end of the box. Here the reaction is positive, although much more poorly marked than are the reactions caused by luminous stimuli, for the caterpillars do not form a straight line beside the source. As we shall see, very few insects escape this reaction to heat. Every one 
has noticed that most ants go into their nests when cold weather comes, and leave them when it becomes warmer. This varies somewhat with the species. At Royan I have seen the harvest ants retire to their nests during the hot hours of the day, just as in the cold spells, and then they return to work, even at night, in moderate temperatures. In this case the thermotropism is positive or negative according to the intensity of the heat rays.

Action of humidity: hydrotropism. No less than heat, water is necessary to living beings, for it constitutes the greater portion of their protoplasm and plays a part in almost all their internal changes. Also, all organisms are sensitive to variations of humidity in the space surrounding them, and with a great number this sensitiveness takes the form of a directive orientation which is called hydrotropism.

We know the famous experiments made by Stahl, in 1884, on the hydrotropism of the fungi of the genus Athalium (tanning fungus). The plasmodial mass of these plants, during the vegetation period, enters the tan, making for the humidity necessary to it, and remounts to the surface in a dry milieu when it is going to form its spores which serve its multiplication. Its hydrotropism is positive. This is the case with 


\section{THE PSYCHIC LIFE OF INSECTS}

the beetles of the genera Haliplus and Hydroporus. Wheeler (1899) had taken from a pool a tuft of aquatic plants where these insects swarm. He says :

As soon as the beetles could come out and disengage themselves from the plant they turned, with a common accord, toward the sea and to it directed their steps. As this was a distance of about twenty feet, the little creatures could not see the water, and I was led to believe that they had some means of perceiving a source of moisture and acted accordingly.

Aquatic bugs act the same way when they are taken from the place in which they live, and we know that the land crabs go a long distance to water when they are ready to place their progeny. The proper degree of humidity differs, moreover, with different species. Wheeler reports that Bembidium, Elaphrus, Omophron, and other small Coleoptera which bury themselves in the sandy beaches, leave their burrows and come out into the open air when one throws a little water on their strand. This is negative hydrotropism. It is well known to collecting entomologists, who use it in making captures.

Action of chemicals: chemotropism. Protoplasm is not less sensitive to chemical agents; but its changing and complex nature varies according 
to the species and its response to the chemical excitant varies also. This response is again a directive orientation. It is called chemotropism. It does not show the absolute precision which one observes with phototropism, for chemical substances are not very regularly diffused.

As an example of chemotropism we may cite the directive orientation produced by oxygen on free lower organisms, animals or plants,-above all, the classic and very pretty experiments made in 1881 and 1894 by Englemann upon Bacterium thermo. This bacterium is very avid for oxygen. When one puts a thin cover-glass on a drop of culture of this species, the bacteria gather at the periphery, where the liquid is in contact with the air. So, also, in a culture charged with carbonicacid gas, when one introduces a filament of green alga whose chlorophyl, under the influence of light, decomposes carbonic acid and liberates oxygen. If the filament receives the light from a microspectrum the bacteria choose to mass themselves in the radiation absorbed by the chlorophyl; the red radiations in the less refrangible half of the spectrum, the blue and the violet in the opposite part.

Chemotropic reactions play a great part in the lives of insects, and it is believed that they have their seat in the antennæ. Thus, the vinegar-fly 


\section{THE PSYCHIC LIF'E OF INSECTS}

(Drosophila ampelophila) reacts positively to alcohol, the acids and ethers of fermented fruit. It flies directly to experimental liquids containing these substances. But Barrows has observed (1907) that it takes a manœuvering method when the terminal segment of one of the antennæ has been removed, just as does the mourning-cloak butterfly in the light, when one of its eyes has been covered. In both cases the asymmetry of excitation has resulted in an asymmetry of muscular action. Kellogg describes (1903) a similar phenomenon with the silkworm moth. As soon as it issues, the male seeks a female and succeeds in the dark as well as in the light. What guides it in its search is the emanation from the female perceived by the antennæ, and if one of these is cut off the male reaches its object only by describing circles to the side of the remaining antenna. It is led to the mating by a positive chemotropism. According to Loeb, it is a chemotropism of the same kind which directs maggots to the meat on which they feed, and the adult flies toward that on which they lay their eggrs.

It is equally well established that insects possess a negative chemotropism. Lubbock declares that ants flee from the essence of cloves and every one can make similar observations concerning other insects. "The backwoodsman (living in the vir- 
gin forest) who covers his hands with pennyroyal or who smokes his pipe," says Wheeler, is aware of the chemotropism of the terrible Culicida (mosquitos), even if he "is not familiar with the scientific name of the phenomenon."

Action of gravity: geotropism. Gravity acts on the protoplasm by its tendency to separate heavy substances from less dense elements. But, contrary to the ideas of Verworn, Davenport does not believe that this action is purely mechanical. It acts by stimulation in reducing the friction with the milieu in the species which follow its direction, increasing with those which act in an opposite manner. However it may be, it provokes in organisms a directive orientation which is currently called geotropism.

Geotropism manifests itself powerfully with plants, where it determines the form and manner of growth. It is positive for the action of roots, which it buries in the soil, negative for the main shoot, which it directs toward the sky. Well developed, also, in fixed animals, it is also seen with insects where one can easily demonstrate it by a very simple experiment devised by Loeb. Certain Coleoptera, coccinellids (or ladybirds) are placed in a closed box which has a dark compartment, in order to avoid all influence of light. The insects cling to the walls of their prison, and when the box 


\section{THE PSYCHIC LIFE OF INSECTS}

is opened they are found grouped at the highest points; their geotropism is negative. A geotropism of the same kind is common with many flying insects, notably with certain flies. Wheeler points out in this connection (1899) two Dolichopodids of the United States (Neurigona superbiens and Medeterus veles). Resting, or walking on a tree, he says, "these insects always hold the head directed upward, the main axis perpendicular to the ground and parallel to the long axis of the trunk. When they are disturbed, they fly away, but soon return, nearer the ground, and begin again to direct themselves upward whatever may be the condition of the light." It is easy to make similar observations in our country. When the physiological condition is modified by maturing, the geotropism of the insect may appear to become modified. Thus it is, according to Fabre, with the processionary caterpillars of the pine. In the month of March, when they are ready to transform, all leave the silken nest where they have lived together and proceed, more or less directly, to the ground, which they enter to transform to pupæ. They are, then, positively geotropic.

Actions of contact. Contacts and the pressure that results may irritate the protoplasm and, at least by contraction or extension, modify the physiological state of its substance. 
When contacts are produced by currents of air, the animal which reacts to their stimulation orients itself in their direction, even, and sometimes goes against them, sometimes with them.

In the two cases one finds oneself in the presence of anémotropism and we say that anémotropism is positive in the first case and negative in the second. Positive anémotropism is common with flying insects, above all with the flies and the midges. Wheeler has noticed numerous Diptera of these two groups:-in Bibio albipennis, which comes out in clouds in the spring, in the chironomids which gather in swarms to dance in the sunlight, with the syrphids, and with the male of an anthomyid, Ophyra leucostoma. All these Diptera face the wind and change direction with it. The males of Ophyra, especially, react to the aërial excitant with a military precision. As with all the tropisms, the orientation changes direction according to the intensity of the stimulus. The migratory locusts of the Rocky Mountains, and without doubt also those of other countries, face the wind when it is very strong, while their anémetropism becomes negative when the breeze is weaker.

The reaction to currents of water is not less evident, but is almost always negative. This form is seen in the plasmodes of the tannery 


\section{THE PSYCHIC LIFE OF INSECTS}

fungus, in many aquatic plants, in the spermatozoids of certain animals and notably in the Paludinas, and finally in numerous fish, especially in those which normally swim up the rivers from the sea (salmon, anguillas, lampreys, etc.). These phenomena of rheotropism are common with the articulates, which group Dewitz (1899) has studied in this regard with great care. They are very indefinite with the water-bugs of the genus Nepa and with May-fly larvæ, and they manifest themselves in negative form with Gammarus and in Notonecta glauca, which is a water-bug which swims upside down. Caddis-fly larvæ always react in the same way; since they live in fixed cases, they cannot mount the current and they content themselves with holding the opening of the case against it. But it is above all with the water-bugs of the surface that rheotropism is especially accentuated. Paddling upon the liquid mirror with their great legs, these Hemiptera, (Hydrometras, Velias, etc.) face the current and direct themselves in other ways only in places where the water is still. Dewitz writes:

When I saw a company of Hydrometras I sometimes carried out the following natural experiment, in order to put their rheotropism to the proof. In front of them I made a barrage with a plank, which turned the current 
and sheltered the water-bugs from its influence. Instantly there were no more efforts to swim against the current; behind the protecting barrier they turned irregularly in all directions. But, the plank lifted and the current liberated, the animals arranged themselves like soldiers and all together worked their legs again to react against the current.

These are observations and an experiment which it is easy to repeat anywhere.

With solids the result of the stimulus is to render the contacts shorter or to avoid them as much as possible. That is called stereotropism. It is negative with the amœbas, whose pseudopods are drawn in at the approach of a solid. As Dewitz has shown with cockroaches and Massart with frogs, it is positive for the spermatozoids; for in the fluid in which they move these reproductive elements rest against solid surfaces.

The researches of Münsterberg (1906) on an American crawfish, Cambarus affinis, have shown the positive stereotropism of this crustacean which seeks contact with solid bodies and holds it naturally in the galleries it has dug or under stones. Our European crawfish (Astacus fluviatilis) is surely endowed with the same tropism, for it has similar habits. Positive stereotropism is equally wide-spread among the nocturnal moths. In repose these insects hold themselves almost al- 


\section{2}

\section{THE PSYCHIC LIFE OF INSECTS}

ways close to walls and tree trunks in a plane on which it is not easy to see them. Ordinarily this attitude is attributed to negative phototropism, but Loeb has shown that it is not due to this. He says :

I placed some of these animals (noctuid moths of the species Amphipyra pyramidoides) in a box of which one-half was covered with an opaque substance and the other with transparent glass. I covered the bottom with fragments of similar glass which rested on little blocks and which were just far enough from the bottom to allow the Amphipyra to creep under them. But the moths got under these little bits of glass, where their bodies were entirely in contact with the solid bottom, and this not only in the dark parts of the box, where they were hidden from their enemies, but in the same way when exposed to the direct light of the sun. The same reaction occurred when the whole box was shaded. Nothing but stereotropism could bring this about.

\section{General Observations on Tropisms}

Association of tropisms among themselves. In the normal environment in which they live, organisms are almost always, if not always, subject to different external stimulations to which they may be more or lèss sensitive. They are therefore subject to many tropic reactions, and if one supposes that no other reaction manifests itself 
with them, it may be isaid that their behavior results from an equilibrium between these reactions, or rather from the predominance of one over the others.

That is what is perfectly shown by the pretty experiments of Mayer and Soule (1906) on the caterpillars of an American butterfly, Danais archippus. Under natural conditions these caterpillars feed extensively on the leaves of Asclepias, choosing the upper ones. They differ from the larvæ of Argynnis and of Catocala in that they seem incapable of searching far for their food, and, once put on the ground, they perish if a clump of Asclepias is not found in the immediate neighborhood. So each individual passes his whole life on the same plant. The behavior of these caterpillars is explicable, not by their tastes as one would be led to believe, but by their tropisms. (1) Placed in darkness on a vertical cord, the head below, they turn around to climb toward the top, and again make the turn when the cord is reversed. A potted Asclepias was suspended upside down and larvæ placed in the terminal leaves crawled upward and over the pot; when the plant was reversed, they walked up the pot and to the summit of the plant. In both of these experiments they are guided solely by their negative geotropism, for their behavior is the same whether they are young 


\section{THE PSYCHIC LIFE OF INSECTS}

or well grown. (2) In a horizontal tube closed at one end and open at the other they went to the open and thus showed positive phototropism. This tropism lasts through their life, but it is especially provoked by the ultra-violet rays, for it does not appear at all when the light is from a kerosene lamp or daylight passing through a bisulphide of carbon screen which excludes these rays. (3) The geotropism of these caterpillars is stronger than their phototropism, for if the tube is held vertically, the closed end upward, they go to this perfectly dark end. So much for the behavior of this species. They feed indifferently on the natural leaves of Asclepias and on those artificially colored, so that coloration does not guide them. They do not use associative memory, for they quickly renew attempts to eat unfit leaves which are offered them when they are on their proper food plant. They are poor creatures, badly endowed, which stay and feed in the place where the predominant power of their negative geotropism has placed them.

We have seen in the preceding chapter that a little burrowing crustacean, Cuma rathkei, although it passes all its life in its burrow, has a very intense positive phototropism, as intense as that of the Euglenas. To explain its behavior in a state of nature, Loeb tried the following experiment: 
I placed a little glass vessel filled with mud in the same jar which contained the crustaceans. The animals did not seem to notice the vessel, as none of them moved toward the mud which it contained. When I disturbed them (touching them with a pencil), they swarmed upward at first, then, if not too greatly excited, slowly fell back to the bottom. If one fell into the little vessel it became active as soon as it touched it. It dug in actively, after which it could not be induced to react to light. Thus we see that the effect of contact with a little receptacle predominates that of light. The stimulus of contact (stereotropism) is more intense than heliotropism (phototropism). It is thus that an animal, although a poor swimmer, lives far from the light in spite of its positive heliotropism.

Association of tropisms with other activities. On account of the irritability of living matter, we understand the sensitiveness which makes organisms respond to the excitation of stimuli and to react to them by movements and by more or less complex chemical phenomena. This sensitiveness is an essential property of living matter. It is found in all organisms, but it is especially apparent in those animals which respond by motion reactions.

With the lower animals and with the motile plants which form the contact betw'een the two kingdoms this sensitiveness may be very delicate, 


\section{THE PSYCHIC LIFE OF INSECTS}

but it is always diffuse, without special localization in organs where it is strongest, without nerve conductors which propagate its efforts. 'Also, tropisms play a predominant rôle with those beings with which the tropic manifestations seem simply due to internal physiological changes and to differences of excitants. But this subordination gives to the motive reactions of lower organ. isms a very characteristic suppleness which on $\theta$ especially notices when he examines one of these animals under the microscope. The infusorian advances, recoils, describes a circle, evolutes like a vortex, stops, or shivers, to go away immediately. One divines in this being an active sensitiveness always awake and, above all, infinitely complex. Without doubt, tropic manifestations belong to the domain of automatism, but animal automatism does not present the rigidity of mechanical automatism. Always complex in its nature, as in its manifestations, it shows a delicate play which indicates the complexity.

The subordination of tropisms becomes greater in the higher animals and notably in the articulates, where the sensitiveness is localized for the greatest part in special sensorial organs and the propagation of its effects in a well-differentiated nervous system. But it is not always easy to 
distinguish tropic excitations from sensorial impressions or sensations; and, in the same way that we can distinguish all the intergrades between diffuse sensitiveness and its localization in sense organs, it is probable that all the degrees may be established between these two kinds of phenomena. But there is more. We shall see in what follows (Chapter VI) that sensations can be graven on the memory and that these associated can induce new acts. From this conflicts often result between tropisms and the associative memory. Then the intellect and the automatism are in disaccord, and in this struggle of such an especial kind it is often the memory which carries the day. Bees go to the light, but this does not prevent them from working in the obscurity of the hive or from penetrating into the darkest places in search of their favorite honey. The house fly also loves the light, but it has passed its apprenticeship in our houses, and, less stupid than the big blow-fly, does not find its end in our artificial lights.

Character of tropisms. It may be said, of tropisms in general, as we have said of phototropism in particular, that they are automatic and, so far as they distinguish sensations, independent of any choice and consequently of all 


\section{THE PSYCHIC LIFE OF INSECTS}

psychic phenomena. The responses of the organism to the external stimuli are exactly determined by the nature and intensity of the excitant.

Stereotropism, especially a certain kind of stereotropism, manifests itself under the form of an orientation in which the great axis of the symmetrical organism is brought into the direction of the stimulating forces, so that the subject, which is incapable of deviation, proceeds toward the stimulating source or the reverse, according as the tropism is positive or negative. It receives, then, from each side and at the same angle the influence of the stimulus. When this is represented by two distinct sources, the organism oscillates to an intermediate position where both sides are equally excited. This last character, placed in evidence by Bohn, is a criterium of tropisms which distinguishes them from psychic acts, properly so called, where the faculty of choice comes in. In many cases, and notably with the articulates, where the stimulus is received in the cephalic region of the body (eyes, antennæ) another character of tropisms is furnished by the functional suppression of one of the two symmetrical receptive centers. Then the stimulus acts only on one side and the animal turns after manœuvering.

Such, according to observation and experiment, is the objective side of these phenomena. To 
know the mechanism, to know how they are released by the excitation of external forces, it is necessary to study the constitution of the organisms. These, says Loeb,

show usually a symmetrical structure, not only morphologically, but chemically and dynamically. By this I mean that the symmetrical parts of the body possess the same chemical substances, qualitatively and quantitatively, so that the rapidity and the nature of the chemical reactions are the same in the symmetrical parts. On the other hand, the asymmetrical parts of the organism have an entirely different chemical composition, so that the nature and the rapidity of their reactions are not necessarily the same, and, generally speaking, are not the same.

One may suppose-and it is true, in all probabilitythat the forms of energy which influence the orientation, or the direction of the movements of an organism, act as they do because they alter the rapidity or the character of the reaction.

"Because of this 'symmetrical structure," he says, "organisms orient themselves automatically in the whole field of forces that affect their chemical reactions ... in such way that the symmetrical parts of the body surface meet the direction of the forces at the same angle" and receive the forces in the same degree. If the body turns aside in a certain direction, it receives more force on 


\section{THE PSYCHIC LIFE OF INSECTS}

the other side, which thenceforth brings a greater abundance of provocative movement reactions; the lost orientation is immediately recovered.

This physicochemical explanation of tropisms rests, as Loeb says, on an hypothesis, but "a probably true hypothesis," for tropisms are only the responses of living matter to the stimulations of external forces, and we know that protoplasm has a very great physicochemical sensitiveness. Our detailed study of phototropism, moreover, shows that this hypothesis is fully justified by the facts.

We are thus led to the origin of tropisms, a field open to research, which must be explored. It is the part of science to reach as far as possible toward the first cause of phenomena; but here, as always, it is the first cause that escapes us. Tropisms are essentially characterized by directive movements and it is necessary to know why a chemical phenomenon, provoked by external forces, has, as a corollary, a motive reaction,-in fact, a determined motive reaction,-because certain organisms appear insensible to these forces; also, why certain ones respond in one way to the stimuli and others in a way diametrically opposite. We are here in the presence of the enigma of living matter and if we deny that life manifests itself by an ensemble of physicochemical phenomena, we should recognize that the continuity of 


\section{DIFFERENT EXTERNAL STIMULI 41}

these phenomena and their coördination in their variability escape us completely. But this continuity and this coördination seem, indeed, to be the very essence of life. Living matter is a protean thing in perpetual evolution and constant change. One can grasp it, but not fix it. Piéron says :

If to-morrow, the chemists should produce a true protoplasm, do we know that this protoplasm would function and give us even a fugitive view of life, a passing glimpse? Would it continue to live, really live?for continuity is one of the principal characteristics of life. It could, if it possess this property, of which we are without doubt far away from the knowledge of the conditional formula, but which appears to us to be really the foundation even of psychism. ${ }^{1}$

Are tropisms adapted? As soon as they issue from the egg in the spring the larvæ of the Browntail Moth, urged by a powerful positive phototropism, climb the twigs and find there the young leaves necessary for their subsistence. The tropism which affects them responds fully to their immediate needs. It is the same with the negative phototropism which urges fly larvæ into the midst of the material in which they find nourishment,

1.H. Piéron, L'Evolution du psychismue (Revue du mois, 19as, v. 5. pp. 291-310). 


\section{THE PSYCHIC LIFE OF INSECTS}

with the positive chemotaxy which leads male insects after their females, with the hydrotropism which directs water-beetles and water-bugs, from far away, toward water. These are the tropisms which can qualify as useful, because they respond exactly to the needs of the species. Many others have the same character and they, in fact, appear to be in the majority.

However, there are tropisms that appear useless. What is the use, says Loeb, of the positive heliotropism of the mining larvæ of Cossus ligniperda which lives in darkness, and that of Cuma rathkei which burrows in the depth of sea ooze? A profound biological study of these creatures will perhaps make possible a reply to this question. But, according to Loeb and Maxwell, the shrimps of the genus Palamonetes are very sensitive to eletricity. They orient themselves in the direction of the currents which traverse their aquarium and head toward the anode. But this galvanotropism cannot be an adaptation. "Galvanotropism," says Loeb, "is purely a laboratory phenomenon. Outside the laboratory no animal would find itself in a situation demanding a galvanotropic response; nevertheless, galvanotropism is not rare with animals." If it is objected that mineral substances orient themselves in the same way under the influence of electrical cur- 
rents, it will be easy to cite numerous animals which react by chemotropism to chemical agents absolutely foreign to the environment in which they live and to which it has been, therefore, impossible to adapt themselves.

Finally, there are tropisms which are sometimes injurious, since they lead insects to their destruction. This is the case, for example, with the positive phototropism which every night leads thousands of insects into the flame. But fire is not an invention of man. Before human fire there was that of incandescent lava; and volcanic fire, from which man undoubtedly got his first flame, goes back to the origin of the earth. In spite of everything, insects continue to fly to lights, and should they perish, they are obeying the innate impulse of their positive phototropism.

If useless and destructive tropisms are not the result of adaptation, can we believe that the others have been able to modify themselves by a kind of physiological selection, by an active adaptation of the organism to their influences? This question is vigorously debated. Loeb and his disciples reply in the negative; but Jennings considers the varied movements of an animal in tropic reaction as a series of trials, correcting, little by little, previous errors. Jennings's theory will be discussed in Chapter IV, but here and now we wish to say 


\section{THE PSYCHIC LIFE OF INSECTS}

that it supposes an adaptation to chemical phenomena of which the living matter is the seat. This way of looking at it has recently been sustained by Piéron ${ }^{1}$ in a hypothetical form. This biologist observes:

It is not absurd to think that chemical properties are such, in living protoplasm, that a negative reaction in its simplest form-a contraction, a retreat-tends to develop a factor effective in dimishing the vitality of the protoplasm, that is to say, reducing its changes, modifying, in the sense of diminishing, its chemical equilibrium.

The protoplasm, in effect, accustoms itself to the influences of external factors. Davenport has given numerous examples and no one denies that man can inoculate himself against poisons. But, between this acquired non-sensitiveness, really temporary, and the adaptive modifications of tropic reactions is a gap,-I do not wish to say an abyss. I do not wish to call it an abyss because Piéron's proposition rests in the domain of possibilities although its author considers it "quite hypothetical." If one leaves the domain of hypothesis to enter that of facts, one may state that tropisms vary with the physiological state of the organism, or of parts of the organism, and that they invariably follow the modifications of this

$1 \mathrm{H}$, Piéron, Loc. cit. 
state without being the cause that provokes it. The adaptive selection of tropic reactions appears, indeed, to be absolutely null.

But insects which respond to tropic reactions are subject to natural selection. This does not give birth to tropisms any more than to other characters; it simply eliminates all the forms in which these phenomena, as Loeb says, "are incompatible with reproduction and conservation." And it is thus that the real utility of the very great majority of tropisms is explained. Without doubt certain disadvantageous tropisms have persisted, but it appears that these tropisms are useful in a number of cases, for they do not place the species in peril. The noctuids, the Maybeetles, the flies, and thousands of other insects which burn themselves in natural or artificial flame have an unusual power of multiplication; this positive phototropism can have no effect on that and it is simply a superabundance which is limited to the great advantage of the natural harmonies. 


\section{CHAPTER III}

VITAL RHYTHMS AND THE ORGANIC MEMORY

What influence is exerted upon the organism by external stimuli which make themselves felt at regular periods? That is what we are going to study in the present chapter.

The paradox of Réaumur; diurnal variations in excitability. "It is singular," says Réaumur, "that the Lepidoptera which avoid the light of day are precisely those which fly into lighted rooms and are attracted to light when it is carried into the garden."

This fact would really seem paradoxical, and it is readily understood that biologists have tried to explain it. Romanes contents himself with a word, attributing to nocturnal moths a curiosity regarding strange objects, but Loeb has studied the paradox more seriously and has made many experiments.

In a room which received the daylight through a window, he placed in a glass box two nocturnal moths, the Euphorbia sphinx (Celerio euphorbia) and the willow Bombyx (Eriogaster lanestris). 
These moths flew about, then all gathered on the side toward the window, in which direction they collected when the box was turned around. Moths issuing from pupæ acted in exactly the same way. Allowed to fly in the room with a kerosene lamp placed far from the window, they went toward the latter when they were at equal distances between the two luminous spots (the window and the lamp), but they went to the lamp when they were at least a yard nearer to it. Thus, nocturnal Lepidoptera do not flee from the light of day, as Réaumur believed, and they are positively phototropic, just as are the diurnal species, but, adds Loeb, we find with insects as with many plants, "periodical variations of irritability, and these variations correspond to the change of day to night. Just as certain flowers open their corollas only during the night and others only during the day, certain Leopidoptera fly only by day and certain others only by night."

This periodicity is independent of actual luminous stimulations. There are, in fact, with these insects, "periodic variations of irritability," but these variations can manifest themselves in the absence of all actual luminous stimulation.

Réaumur has already noted this phenomenon, which is not less curious than suggestive: 


\section{THE PSYCHIC LIFE OF INSECTS}

Most of the night-flying moths which are at liberty in the country, fly only at night or on the approach of night. Some, moreover, of the same class, when kept enclosed in boxes or cages, show the time when their inclination leads them to flight. During the day they are quiet in their prisons, passing hours and often days without moving, in the same place. But when night has come and sometimes even before the sun is ready to set, they move their wings and fly as much as the box will permit.

Loeb has tried this experiment with the Euphorbia sphinx, and has noted these periodic nocturnal movements during two or three days. He does not know if this periodicity will ultimately disappear after long confinement in the dark box, but he has noted that the sphinx in the clear day does not take its flight when a quick diminution of the intensity of the light occurs. This reaction is produced only in the morning a little after dawn, and toward evening when twilight begins, - that is to say, at hours close to those when the free insect ordinarily takes flight.

Thus, the periodicity appears to us to be manifest and independent of luminous variations.

Interpretation of this periodicity. Davenport interprets the experiments of Loeb and of Réaumur by saying that the diurnal butterflies are so constructed that they react only to a high luminous 
intensity, and the nocturnal moths to a feeble intensity, "so that the brilliant light of the sun which makes the butterflies come out causes the retreat of the others." This certainly has some reason and several experiments of Loeb prove it, notably that with a diurnal species, Papilio machaon, which, reposing in a diffused light, takes its flight when exposed to the sun's rays. But the explanation of Davenport does not oppose that of periodicity held by Loeb. In reality, these two theses complement each other. It is because their positive phototropism demands a high luminous intensity that the diurnal butterflies fly during the day and rest at night. It is because they demand more feeble luminosity that the nocturnal species fly at twilight or during the night, remaining quiet during the day. Thus understood, the periodicity shows itself to be a simple manifestation of phototropism with these insects.

But something else can happen, as Loeb and Réaumur have shown, aside from any luminous intervention. That is a periodicity acquired by the organism. This is graven upon the being in the course of generations under the phototropic influence of periodical luminous stimulations, and may show itself to-day without their intervention. It has separated itself from the stimulating actions which have produced it. 
The actual acquisition of a diurnal periodicity. That this is really so-that is to say, that the diurnal periodicity of butterflies has been acquired in the course of their history-is what the pretty experiments of Roubaud ${ }^{1}$ have shown concerning the actual acquisition of a similar periodicity by the larvæ of an African fly, Auchmeromyia luteola, which resembles our bluebottle, but is very different in habits. The larvæ of this fly are called "house-worms," because they are found exclusively in houses, and only in those in which people lie on the ground with or without mats. During the day the larvæ are to be found at a certain depth below the surface of the ground, which serves as the flooring of these primitive habitations. At night, while the sleepers are lying down, the larvæ crawl up toward them, wound them with their mandibles, and gorge themselves with their blood through the wound thus made. After this, they go back into the earthen floor to digest there in peace, and to await the following night. Here are temporary parasites whose periodicity is like that of nocturnal moths.

This periodicity is the result of their thermic sensibility. Experiments establish the fact that their optimum temperature varies between $25^{\circ}$

1 E. Roubaud, Les Producteurs de myiasis et agents similiares chez l'Homme et les animaux, 1916. 
and $30^{\circ}$, which they find at a certain depth in the soil of these houses, and that they are endowed with a positive thermotropism which leads them to the sleepers, whose temperature is $37^{\circ}$, and that, once they are filled, their thermotropism becomes negative, which leads them back underground. A temperature of $35^{\circ}$ is manifestly unfavorable to them when it is prolonged for some hours. Thus the nocturnal periodicity of these larvæ is produced by thermic irritability in conditions of determined hunger.

This rhythm not only is acquired in the course of the larval existence, but is changeable at the will of the experimenter. On their birth, says Roubaud, these larvæ, having taken no nourishment "are awake during the day as well as during the night." Fed from the egg stage regularly each day at the laboratory in the morning or afternoon, they "remain completely motionless during the night"; and when, after having been nourished periodically for several days, they are left to fast, "they awake irregularly," some during the day and others during the night. "Thus," says Roubaud, "the nocturnal awakening is above all a case of adaptation of the organism of the larva to a certain rhythm of nutrition," regulated under normal conditions by the habits of the sleepers, who return to the houses and sleep when 


\section{THE PSYCHIC LIFE OF INSECTS}

evening comes. It is a rhythm acquired in the course of the larval existence, experimentally modified with the young larvæ, and moderately tenacious with those in which it is well established, for it only slightly resists a long deprivation from food.

The work of Roubaud upon the larvæ of Chœromyia chœrophaga completely justifies the foregoing conclusions. These blood-sucking larvæ in nature are less completely nocturnal than the preceding, for they have as their hosts certain tropical pigs which leave their holes only in the cool hours of the morning, and in the afternoon when the great heat has passed. During the warm hours of the day they rest in their obscure lairs, where, just as during the night, they are bitten by their parasites. But the physiological plasticity of the larvæ of the Chœromyias is just as great as that of the house-worms: "gorged regularly with blood and only during the day, after their hatching they manifest only a slight diurnal activity during the meal hours, and when filled, pass the night in a condition of complete immobility."

The rhythm of the Auchmeromyias and the Chœromyias is acquired, but it is not yet innate, because it is not passed on to the progeny. That of the nocturnal moths is innate, for we observe it 
in moths issuing from chrysalids, but it was certainly acquired like the preceding, and there were ancestors who transmitted it to their descendants.

Other examples of diurnal periodicity. Many insects besides butterflies possess a periodicity which responds to the alternation of day and night. Most of the Hymenoptera are diurnal, among others the bees and the wasps. The predatory insects are also almost all diurnal, such as the robber flies (Asilida) among the Diptera, the Cicindelidw (tiger-beetles) among the Coleoptera, the Neuroptera of the genus Panorpa, (scorpionflies) the libellulids or dragon-flies, which belong: to the Pseudo-Neuroptera. Nocturnal insects are also very numerous. Among the commonest of these I will mention the June-beetle, the stagbeetle, the mosquitos, the bedbug, the cockroaches, and the white ants. It is during the night that the processionary caterpillars of the oak leave their silken nest to travel in processions over the branches until they reach the leaves on which they feed. It is during the night also that a great numbers of weevils shake off their daily torpor to climb on plants and to puncture the leaves or buds. Some very closely related species may have a different periodicity. The European click-beetles ordinary fly in full daylight, as is the case with the commonest form, Lacon murinus, but Perris ob- 


\section{THE PSYCHIC LIFE OF INSECTS}

serves that several of them are nocturnal, among others Athous rufus, Elater sanguineus, and E. crocatus.

Has periodicity with all these insects the rank of a definite acquirement, as with the group of nocturnal moths? We cannot tell, for the lack of experiments. But it is not to be doubted that many possess periodicity in this way. Perris (1853) noted, as a matter of fact, that the nocturnal clickbeetles of our regions remain asleep under the bark when the sun is bright, but "that when enclosed alive in boxes, they remain motionless during the day and begin to move when night comes." Dixippus morosus is an orthopteron often found in laboratories to which it has been brought from India, which is its original country. This curious phasmid (walking-stick) is remarkable not only on account of its form, but also on account of its mimetic attitude, in which, drawing its legs and antennæ together, it resembles a dry branch. But, according to Piéron (1910), "the mimetic attitude is assumed by the Dixippus only during a limited time. This time lasts exactly from the beginning of day until night. As soon as the darkness arrives the period of immobility ceases; the animal walks around on its six legs, its antennæ spread, sipping and exploring, and it feeds itself with ivy leaves which it chews with its mandi- 
bles." But here the acquirement of the rhythm does not as yet seem to be perfect. Piéron observes, in fact, that one "can keep Dixippus in continuous obscurity without their taking on the period of immobility with the mimetic attitude. Their activity is evidently not absolutely uniform," and everybody who has reared these insects knows that they are frequently active in the middle of the day.

Much more strongly fixed is the rhythm which produces the light with phosphorescent insects. In an interesting study on these insects, Professor Bugnion (1916) observes that their phosphorescence is always a nocturnal phenomenon, while with certain of them, like the Pyrophoras, it can be provoked in the daylight by mechanical excitations. But the specific differences are very great; with the Luciolas, or fireflies, which abound in tropical countries and in the South of Europe, the male is more luminous than the female, and "its phosphorescence is extinguished more or less completely" when it stops flying. With the Lampyrids on the contrary, the male is very slightly luminous even when flying, while the female (the glowworm), which is sedentary and wingless sends out a great phosphorescence. The luminosity of the latter, observes Bugnion, "is not intermittent like that of the firefly, but it is continuous or per- 


\section{THE PSYCHIC LIFE OF INSECTS}

sistent during a considerable length of time. Every one knows that one can take the adult Lampyris in the hand, turn it over, and put it in a tube, without fearing that it will extinguish its torch. The functioning of the luminous organs is, on the other hand, regularly periodical; it stops almost completely during the day and when the moment is favorable (the period of sexual maturity), begins each evening with its customary brilliance." It is possible that the luminosity of certain myriapods with long slender bodies (Orya barbarica and some other geophilids) has the same rhythm.

The phenomena of phosphorescence and their rhythm have been patiently studied by Raphael Dubois (1896) with a great American elaterid, namely, Pyrophorus noctilucus, known in the West Indies by the popular name of cucujo. As with the nocturnal moths, this curious beetle is positively phototropic to the lights which burn during the night, but this phenomenon is independent of its own luminosity. This latter is in close connection with muscular activity, so that it may be provoked at any time by exciting the insect. However, it has a closer relation to the nocturnal periodicity, for under normal conditions it shows itself only during the night. When the Pyrophorus is enclosed "for several days in a 
black cabinet" the temperature of which is nearly constant, it becomes "active every evening at the same hour," and soon gives out a bright light even when it has been fatigued during the day by experiments. This rhythm was doubtless acquired like that of the nocturnal moths, although it is of another kind. The Auchmeromyias and the Chœromyias have shown us how acquirements of this kind can be made. We may note, in passing, that the photogenic periodicity is not necessarily due to the existence of differentiating visual organs; according to Massart, as a matter. of fact, the protozoa of the genus Noctilucus become luminous at night when kept in a closed closet.

Convoluta and Littorina. All natural rhythms can develop an acquired periodicity in organisms. We know the suggestive observations of Bohn on the marine worms of the genus Convoluta which are found in masses on certain sandy shores on our coast. These minute planarians are colored green by the unicellular algi which live symbiotically in their tissues. When the tide goes out, they emerge on the surface of the strand and make on it a green fringe. When the tide comes back, they dig into the sand and completely disappear. But, says Bohn, these alternating movements, synchronous with those of the tide, 


\section{THE PSYCHIC LIFE OF INSECTS}

persist in the aquarium when these animals feel slight movements: in a glass tube containing moist sand and some of these Convolutas, the green ring rises and descends, occupying the high position at the moment of low tide and the low position at the moment of high tide. And-a still more curious thing,-the irregular. ities of the sea are followed by the Convolutas in the aquarium. The movements are slower in still water and more rapid in running water, and this continues for some days after they have been put into the aquarium.

Similar oscillating movements have been noticed by Bohn and Fauvel with Pleurosigma astuari, which is a littoral diatomaceous alga. According to Bohn, the gasteropods of the genus Littorina have a double series of oscillations which draw them toward shady surfaces or away from them: daily oscillations of thirteen hours, which correspond to the flux and to the reflux, and oscillations of fifteen hours, according to the running water and the still water. These two kinds of rhythms persist in the aquarium and consequently have been acquired.

The misanthropic Pagurus. Analogous phenomena have been observed by Drzewina (1907), in the charming little hermit crab of our coasts, the misanthropic Pagurus (Clibanarius misanthropus), which is found in abundance upon the littoral of the Gulf of Gascony and in the Mediterranean. 
In the harbor of Arcachon, near the wharf where Drzewina made his first experiments, the tide is high from noon to six o'clock during the eight hours of the tide, low for the same time during the eight following hours, which are those of low water, and it is stated that during the first period the Pagurus runs freely on the bottom, while it hides under the rocks during the second period. This phenomenon is undoubtedly due to the lighting of the sea-floor, which is only moderate during the first period on account of the depth of the water, and intense during the second, when the depth of the water, which softens the rays, i's greatly reduced. At any rate, it seems to be an acquired rhythm. If, as a matter of fact, one places these creatures in an aquarium partly covered with a black screen, they are seen in the light part during the period and at the time when the sea is at high tide, but under the black screen during the hours and at the period which correspond to the low tide. However, this acquired rhythm has not yet become specific and is closely related to the conditions of the environment, and in the Mediterranean, where the tides are not great, the observer has noticed that the Pagurus does not show the least periodicity.

Other rhythms. Periodic phenomena are common in organisms, from plants which show them 
by the diurnal or nocturnal attitudes of certain species, up to the human species and certain mammals, where they appear in the female sex in the form of menstruations.

Indeed, the phenomena of the life of articulates are explained, perhaps, by rhythms of shorter or longer duration. So it is with egg-laying, which comes about with many species at certain epochs; without doubt, also, the faculty which the queens of wasps and bees have of producing male eggs at certain times,- - that is to say, non-fecundated eggs. Roubaud (1915) reports that a certain coccid cared for by the ants is carefully carried under the ground and remains there during the time when the fruitage of the plant is being harvested. This is consequently a seasonal practice, and it will be interesting to know if it has left a trace in the behavior of the two kinds of insects.

Acquired periodicity and dependent periodicity. From a consideration of these phenomena, which have not been studied enough, it seems rather certain that acquired periodicity - that is to say, innate-has as an antecedent a dependent periodicity closely associated with the rhythm of the environment, and its autonomy, its independence of the stimulating actions, results from a longer or shorter exercise of this dependent periodicity. The periodicity is simply dependent 
with the blood-sucking larvæ of the Auchmeromyias and the Chœromyias, it seems already acquired with the misanthropic Pagurus of the Gulf of Gascony, and it is complete with the nocturnal moths and the fireflies. There are all kinds of intermediary steps between these two kinds of periodicity.

How can acquired periodicity come from dependent periodicity? Without doubt, on account of physicochemical phenomena which provoke the latter. Bohn attributes in large part the rhythmical movements of Convoluta, Littorina, and Pleurosigma "to alterations of desiccation and rehydration" which are produced in their organisms in the periods of flux and reflux. We know, also, that the periodical movements of plants are due to the same causes. On the other hand, the daily rhythms of diurnal or nocturnal insects and of phosphorescent articulates are in close dependence upon the intensity of the light rays, and we must not forget that these count among the most efficient chemical agents. As to the periodic movements of the blood-sucking larvæ, they are produced by heat, whose chemical action is not less than that of light.

Organic memory. Thus natural rhythms produce more or less profound periodical modifications in the organism. This periodicity leaves, in 
the long run, a trace in the tissues. It becomes engraved there and ends by manifesting itself aside from the causes which have produced it. It becomes a habit, and, like all habits, presupposes a memory.

Treating of the phenomena to which he gives the very appropriate name of vital rhythms, Bohn observes that they are frequent in organisms, and that he cannot see in them any manifestation of psychism. He is right, without a doubt, for psychic manifestations presuppose a choice, at least originally, and we are here in the presence of automatic movements equally wide-spread in the two kingdoms (animals and plants) and produced by inflexible stimuli to which the organism submits like a plaything. When we consider these phenomena, adds the distinguished biologist, "we are tempted to speak of 'memory,' but we are not exact in speaking so of vital rhythms, and simply risk arousing confusions, the word 'memory,' in fact, being employed in very different senses." I do not share this opinion of the original savant, to whom we owe so many interesting researches in periodicity. When the organism retains an impression, a memory of rhythmic influences to which it has been subject, one cannot deny to the manifestations of this memory the quality of 
phenomena of memory, and the appellation "vital rhythms," which is used to designate them, does not forcibly imply this character. This is not a futile play of words; it acts, in effect, to show $a$ suggestion of memory under a form which may be called organic memory, because it is engraved upon the tissues, and rules, in a way, the functioning of the being. This memory has an importance which cannot be disputed. Piéron has devoted a long study to it in one of his most interesting works. Bergson ${ }^{1}$ attributes to it the name which we have chosen, and Roubaud has applied to his blood-sucking larvæ the equivalent term physiological memory.

Organic memory is the result of external stimuli like tropisms, and like them, also, it is independent of the differentiation of tissues and manifests itself by automatic acts. But it is distinguished essentially by the fact that it can provoke reactions (motor or others) without the aid of the stimuli which originated it. This is its principal character, one which marks a first tendency of the organism to liberate itself from the environment which surrounds it. With the beings which possess it, observes Bohn, "the protoplasm remembers in some sort the stimuli which have acted

$1 \mathrm{H}$. Bergson, L'Evolution créatrice, 1907. 


\section{THE PSYCHIC LIFE OF INSECTS}

upon it"; it can act again without them, and by the simple effect of acquired habit. It is surely not yet psychism, but it is at least a stage on the road which leads to it. 


\section{CHAPTER IV}

\section{DIFFERENTIAL SENSITIVENESS}

Differential sensitiveness. What characterizes tropisms is a directive orientation which automatically leads the organism in the same axis of the stimulating force, this being invariable as long as the stimulation lasts. What will be the response of the organism if one abruptly varies the intensity of the stimulating force? Will the response still be a directive orientation, a tropic displacement?

It is quite otherwise, as Jacques Loeb observed in the course of his first experiments upon tropisms. Led by a remark of Wheeler's, the learned biologist had no trouble in showing that a worm, Planaria torva, having no phototropism, shows a greater activity when the luminous intensity increases and quiets down when it diminishes, so that if one puts a certain number of these Planarias into a cylindrical vessel in front of a window, they all gather at the points in the vessel which are lighted the most poorly,- that is to say, at the two 
extremities of the diameter parallel to the lighted glass. More sensitive still to variations in intensity is Serpula uncinata, a little tube-inhabiting annelid studied by Loeb in the laboratory at Naples. The branchiæ of this insect are spread out to the light of the sun, and form a graceful discoidal plume at the orifice of the tube, but if but the shadow of one's finger falls upon them, immediately the plume is withdrawn. It is drawn in, also, when the blinds of the window are closed. In these two cases the animal resumes little by little its first position, and when the branchiæ are reëstablished they are not drawn in if the light returns. Positively phototropic, the Serpula reacts only to negative radiations of the luminous intensity.

These phenomena do not enter into the formula of tropisms, because they are independent of the direction of the luminous rays, and do not provoke a directive orientation. Loeb gives them (1893) the barbaric name of Unterschiedempfidlichkeit, which Georges Bohn has happily translated "differential sensitiveness."

The phenomena of differential sensitiveness have been subjected to a minute study by the latter author, who has the honor of having established certain laws. It will be well to examine these rather closely, for they are almost always con- 
nected with tropisms and indicate a serious advance in the animal activity.

Relations between the differential response and the understanding of tropism. As we have just seen, it is by the responses of the organism to the variations of luminous intensity that work concerning differential sensitiveness began, and the responses to these variations have been the subject of very numerous and very profound studies. It is through these that we approach the present study in the group which we are considering, in order to examine afterward the responses to the variation of other stimulating forces.

The responses of the positively phototropic articulates to variations of light have been the subject of interesting observations in the work of Parker on the mourning-cloak butterfly (Vanessa antiopa). When resting on a surface in the bright sunlight, this diurnal butterfly turns its back to the light. In flight, or when walking, under the same conditions as to light, it shows, on the contrary, a positive phototropism, and directs itself with its face to the rays. If, then, a shadow is thrown upon the insect when it is walking, it stops, says Parker, momentarily closes its wings, and rapidly takes flight. Our thistle butterfly (Vanessa cardui) undoubtly reacts in the same way, for it is, according to Bohn, positively photo- 
tropic; but experiments do not give the same result with Vanessa io or with Satyrus janira, for the same author has observed that the phototropism of these two diurnal butterflies is negative.

One can get similar responses, or even more marked ones, with all insects whose positive phototropism is strong. The currant-worm (Nematus ribesi) is one of these. Captured in the garden, where it causes serious damage, there were many of the worms which, placed on a sheet of paper, directed themselves in a straight line toward the window of my room. I cast on them the shadow of a book held in the hand, and they immediately stopped, raised themselves up, and moved the anterior part of their body about, then made a half-turn, or less, and directed themselves to the side or in a reverse direction. Like Vanessa antiopa, these positively phototropic insects react by a half-turn to a quick diminution of the light.

Insects having negative phototropism show an identical reaction, but only when they are subjected to a rapid increase of light. The bedbug is, as we know, energetically photophobic; it hides in the darkest cracks and leaves only during the night. In the daytime, says Bohn, if an accident has brought it from the shade into the light, it im- 
mediately executes a rotation of 180 degrees, which brings it into the shadow. On a sheet of paper it walks away from the luminous rays and turns about immediately when one holds a candle toward it. "It is very difficult," adds Bohn, "to make a bedbug which is on black paper pass over upon a piece of white paper."

All the insects which are negatively phototropic lend themselves to similar experiments, among others, the meal-worms, or larvæ of Tenebrio molitor, and the maggots of different flies. Placed upon a sheet of white paper which receives the sun's rays from a window, these larvæ orient themselves in the direction of the rays and march the other way; they unhesitatingly enter a shadow thrown upon the sheet and they follow it until they reach its limit, when they walk in the shadow and make a half-turn if one throws a luminous ray before them. A negative variation of intensity has no effect upon them, while a positive variation makes them turn or reverse.

Thus, positively phototropic animals respond to a diminution of light, - that is to say, to a negative variation of luminous intensity,-and those whose phototropism is negative respond to a variation of positive intensity. Experiment shows also that animals having no phototropism (at least apparently none) respond, nevertheless, to variations of 


\section{THE PSYCHIC LIFE OF INSECTS}

intensity, but some to positive variations and others to negative ones.

In all cases the response is independent of the direction of the rays. It reacts especially to sudden variations and manifests itself by rotation of 180 degrees or a digression in this direction, and often, as with many swimming organisms, by one or several rotations of the individual upon itself.

Established for light, the preceding rule really applies to all external stimuli. Animals of negative geotropism climb vertical or inclined surfaces. When they are at rest, or marching, it suffices to diminish quickly the incline to make them stop, to make a turn, and almost always to go in the opposite direction. Bohn tried this experiment with the mollusks of the genus Littorina, with starfish, with the larvæ of the sand-dune butterfly (Tyria jacobace); I have tried it with the larvæ of Nematus ribesi, and always with the same result. Upon a glass plate Jennings (1887) exposed a drop of water charged with the common infusorian (Paramocium aurelia) and put in the center of the drop a droplet acidulated with carbonic acid. The infusorian, endowed with positive chemotropism by the influence of this acid, penetrated into the droplet, recoiled and tried to leave, but finished by staying imprisoned.

In fact, whatever the stimulations of external 
forces, the laws of differential sensitiveness remain the same, and the principle may be formulated by saying, with Bohn: "When the tropism is positive, the animal reacts only to a negative variation of the excitant; when the tropism is negative the reverse is true." One would say that the animal abhors variation. It results from this law that sensitive animals accumulate in the places favorable to the exercise of their tropism, but they depart from the opposite kind of places. Parker observes that he has never seen Vanessa antiopa fly in shady spots when the sun was brilliant, and every one has noticed that little flies, at the hour when they dance in swarms in the sun, avoid the shady places in the glades. When maggots or meal-worms flee from the light under a leaf traversed by a large dark spot, they penetrate into the spot and do not leave it, and are finally all gathered there together. When one puts them into an open box, one of the walls of which is in the light, they all cluster against the opposite side. One can, as Bohn justly says, compare these favorable areas to trapis. The shadow is a trap for maggots and meal-worms, and the light for Vanessa antiopa; and in the experiment of Jennings, cited above, the acidulated droplet plays the rôle of a chemical trap.

The other rules of differential sensibility. We 


\section{THE PSYCHIC LIFE OF INSECTS}

can go further into the study of the rules of differential sensibility.

To make the currant-worms give characteristic responses of differential sensitiveness, it is not necessary to put them in the presence of a shadow zone. If we bend the horizontal supporting plane a little to one side toward the light, they are quickly influenced by the force of gravitation; they stop, raise the anterior part of the body, change their route, and often turn at an angle of 180 degrees to reverse their way, and to walk for a time against the light. These reactions may be attributed to the positive phototropism of the creature, but it acts very like the meal-worm, which has a contrary tropism, and which nevertheless, when one inclines the plane on the side of the light, tends to direct itself toward the lower side. Similar results follow a breath of wind, a light shock, or the holding of a warm but not luminous object near the animal.

In the same way variations in the intensity of the light can provoke a kind of geotropism: "A starfish," says Bohn, "is motionless near the surface of the water; a diminution of the light, even slight, but quick, brings about a vertical descending movement." Here the positive geotropism appears to be a response of the differential sensitiveness to the light variation. 
This is enough to allow us to conclude with the same author that in the manifestations of differential sensitiveness "we need not take into consideration the specificity of the stimulus."

Let us go still further, and, in fact, return to our experimental subjects, the positively phototropic currant-worms, and also the meal-worms, or the maggots whose phototropism is negative. If the currant-worm encounters a shady ispot, when it is going toward the luminous source, it ordinarily makes a half-turn, directs itself abruptly away from the source, then stops, turns again, and resumes its direction toward the light. The mealworm and the maggots act in the same way when in the course of their progress they encounter a luminous place; they iturn around, proceed for a longer or shorter time towardis the source, then stop, half turn, and begin again to go away from it. One may say that, driven away from the natural course, they return at a gallop. In the phenomena of differential sensibility, it seems that stimulating variations bring about the development of a certain amount of energy, and that when this is once spent, the creature stops and once more takes its first direction. This is, according to Bohn, the law of the return to the state of repose, which we can better call the law of the return to the former state. 


\section{THE PSYCHIC LIFE OF INSECTS}

I have reached a fourth law which applies to the tropisms of differential sensibility. We know that the bedbug, strongly phototropic, makes a half-turn (Figure 1,a) when it is put in the presence of a window, $\mathrm{F}$, and leaves rapidly. While it was fleeing Bohn interposed the flame of a lamp, $\mathrm{L}$, between the insect and the window; this had the effect of provoking a new half-turn $\left(a^{1}\right)$, which brought the insect not only in the direction of the lamp, but into that of the window, for the two

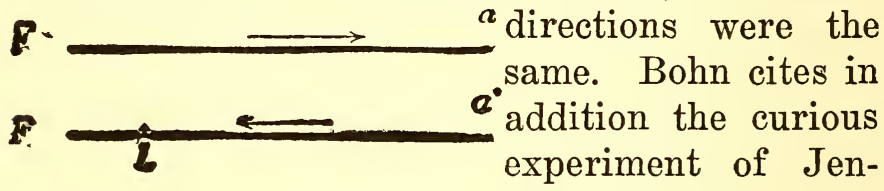

Fig. 1.-Bedbug leaving, at $a$, a nings, in which an inwindow $F$, and returning to $a^{1}$, fusorian, Spirostom-
when a light $L$ is interposed between it and the window. (After um ambiguum, when Bohn.)

a noxious droplet is placed in the liquid containing it, always retires, whatever the position of the droplet. To a variation of the excitant, concludes Bohn, the animal responds always in the same way, whatever be the "direction of the stimulus in relation to the axis of the body.'

The experiments of Max Morse (1909) oblige us to make the meaning of this conclusion more exact. A meal-worm was introduced by this biologist into a rubber tube five centimeters long and 
of such a diameter that the animal found itself tightly lodged. The head end of the worm was directed toward the sun, the rays of which fell obliquely on the tube. The creature tried to turn and finally the extremity of its abdomen came out of the tube to the length of four segments, which were exposed to the light. This brought about an inverse march and the worm reëntered the tube. A calorific screen had been placed between the sun and the tube, and a cold paper introduced under it, so that thermic influences were excluded. No response was obtained when the abdomen was exposed to the light and had received a coating of vasoline and lampblack. The author concludes that "all the surface of the body is sensitive to a light of great intensity."

I do not wish to dispute the existence of dermatoptic sensations which other authors have suggested, but it is proper to ask whether with insects these sensations are sufficiently strong to provoke on the abdomen the reactions of differential sensitiveness. Could it not have been the close imprisonment to which the worm was subjected which caused the response obtained by Morse, and would it not be wise to work under more normal conditions? This is what I have tried: When the larva was walking upon a sheet of paper in the shadow of a book, I have moved 


\section{THE PSYCHIC LIFE OF INSECTS}

the book so that the sun's rays quickly struck the animal, both on the sides and on the extremity of the abdomen, and I have never seen the least reaction. However, to the light rays is added the sun's heat. Parker reached the same negative result in working with Vanessa antiopa. We have seen that this insect presents a positive phototropism when it flies or walks in the sunlight, and that a shadow rapidly brings about the reactions of differential sensibility, but Parker has noticed that the reaction is produced at the end of from fourteen to seventeen seconds when the shadow of a finger or of a pencil reaches the eyes, and that there is none when this shadow is projected upon any other part of the insect. Then, if it is true to say that the responses of differential sensitiveness do not depend "on the direction of the stimulus in relation of the axis of the body," one cannot fail to add, as a general thesis more or less, that they are independent of the stimulated points; with the insects, with the articulates, the head end of the body, which is the ordinary seat of tropic phenomena, is also a preferred center for the phenomena of differential sensitiveness, but this conclusion cannot be applied to the lower animals, where an incomplete differentiation of the organs renders the sensitiveness diffuse. 
Combination of differential sensitiveness with the tropisms. As we have just seen, differential sensibility is subject to a certain number of laws which essentially distinguish it from tropisms, and on the other hand it is closely linked with them. Most often tropisms are associated with' phenomena of differential sensitiveness in order to determine what the American biologists have designated by the name "behavior," and what we call in France the "comportement" of the animal toward external forces. A currant-worm directs itself toward the light upon a horizontal plane; one inclines this plane and the animal stops by differential sensibility to gravity, and then, after a turn or a reverse, it moves obliquely toward the light, satisfying, so far as possible, the exigencies of its positive phototropism and its negative geotropism.

Bohn (1904) has carefully studied the combination and the variations of these two kinds of phenomena from the point of view of light in the larvæ of Tyria jacobae, which is common on the dunes of Wimereux, where, among the tufts of dune grass and the willow bushes, there grows in abundance the groundsel of Jacob which serves it as nourishment. For this caterpillar there is a lesser light above to which its phototropic reactions are negative, below positive, and this lesser 


\section{THE PSYCHIC LIFE OF INSECTS}

light corresponds to the shade of plants which are exposed to the sun. When the caterpillars find themselves upon the sunlit sand, their negative phototropism leads them to dark spots, that is, to the groundsels, or to the willows. They remain on the groundsels until they find the lighting which they like, but if they go to the willows where the shade is thicker, their differential sensitive-

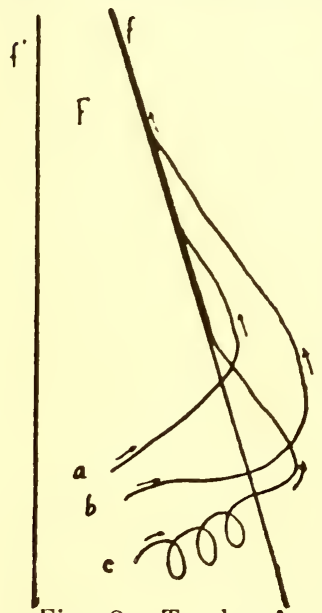

ness leads them to another more favorable point, so that the groundsels growing among the willows or in a shady place "are much less often attacked than those which grow upon the sand of the dunes." In addition, the light action varies with the physiological condition of the animals, and parasitized caterpillars, or fullgrown ones, go to obscure nooks to transform to chrysaFig. 2.-Track of a lids.

Vanessa antiopa blinded in the left eye and placed in a luminous recent experiments of Dolley placed in a luminous recent experiments of Dolley placed in a luminous recent experiments of Dolley
ray $F$. (Three experi-
mental diagrams $a, b$, upon the behavior of Vanessa
$c$, borrowed from Dol- antiopa, when this butterfly,
ley.) placed in a luminous recent experiments of Dolley
ray $F$. (Three experi-
mental diagrams $a, b$, upon the behavior of Vanessa
$c$, borrowed from Dol- antiopa, when this butterfly,
ley.)

More significant still are the deprived of the use of one eye, is placed in a 
shaft of light (Figure 2, F). The animal directs itself obliquely to the side of the well eye (right eye in the figure), either by a direct traject (a) or in a curved line (b), or by describing circles, which become a spiral (c). When by these movements it leaves the shaft of of light to pass into the shadow, which is very dark, it describes a curve in the direction of the obliterated eye, then proceeds toward the border $(f)$ of the shaft, which it reaches without ever crossing it. Its abrupt passage from the light into the shadow has resulted in completely changing its direction. It obliques now to one side, now to the other, as if it would avoid the direction which would lead it into the shadow. This is not all, for in its oblique march toward the side of the obliterated eye, the butterfly is led in the direction of the shaft of light. It reaches the border of this, but it is not able to cross it, for it penetrates at once into the light and immediately the sight of the intact eye leads it into the shadow, so it follows the border of the limit of the shadow and light. The numerous and interesting diagrams of Dolley are surely the most demonstrative which have been used in this study, and they have so much the more importance in that the author draws from them conclusions which are 


\section{THE PSYCHIC LIFE OF INSECTS}

contrary to the theory of Loeb. In fact, in his experiments Dolley has confused tropisms with differential sensibility without seeing the close bond between these two kinds of phenomena. 


\section{CHAPTER V}

DIFFERENTIAL SENSITIVENESS-SPECIES MEMORY, AND SIMULATION OF DEATH

The theory of trial and error. The numerous and interesting experiments carried on by Jennings ${ }^{1}$ to justify the theory of trial and error furnish striking examples of the combination of tropisms with the phenomena of differential sensitiveness. We think that it will be of use to note the following, which are among the most typical. The Infusoria of the species Oxytricha fallax are placed in water in a basin warmed at one end, $\mathrm{x}$, (Figure 3); an individual starts toward the warm part, arrives at 1 , recoils 2 , turns to the right 3 , from the effect of differential sensitiveness, then, returning not quite so far toward $\mathrm{x}$, finds itself again in the warm part 4, which produces a second recoil 5 , and a second turn to the right 6 . The same phenomena are reproduced at 8 and 9 , leading the infusorian more and more from the warm part, while it swims or moves directly into the

$1 \mathrm{H}$. S. Jennings, Contributions to a Study of the Behavior of the Lower Organisms, 1904. (Carnegie Institution of Washington Pub. No. 16.) 


\section{THE PSYCHIC LIFE OF INSECTS}

cold part 10. As we have just shown after Bohn, there is a combination of negative thermotropism with a differential sensitiveness to the heat.

This is evidently the explanation of these phenomena: the animal obeys the three simple laws which we have explained. But to Jennings, the behavior of Oxytricha fallax and lower organisms to external stimuli is the result of a series of trials. When these organisms, he says, "receive a stimulus which provokes a response, they try to go in different directions. If the direction followed leads them to a new stimulus, they try another, until the one found leads them to a proper stimulus." In other words, the animal makes a series of trials which correct the first errors, until a satisfactory result is reached. This is the theory of "trial and error," formulated by Lloyd Morgan after his work on the higher vertebrates. Jennings recalls, apropos of this, numerous experiments, fruitless at first, in which Morgan's dog tried to pass through the narrow opening in a barrier, his master's cane in his mouth: "Just as the dog for the first time carried the cane in his mouth across the opening in the barrier," the lower organisms "seek in all directions until one of them is found practicable. . . The problem is the same for the dog as for the lower organisms." With the one as well as with the 
other, it is necessary to consider as an "error" everything which produces a physiological state analogous to that which in men is characterized by a sensation of pain; after a trial, the organisms avoid what produces with them a condition of this kind.

It is difficult to dispute this analogy, for we know nothing of the sensations of pain or of pleasure which these organisms feel, especially the lower organisms, but what strengthens Jenning's theory is that the protoplasm has a primitive power of reaction against external stimulants (which is undoubted) and that lower animals are capable of making a choice between these reactions

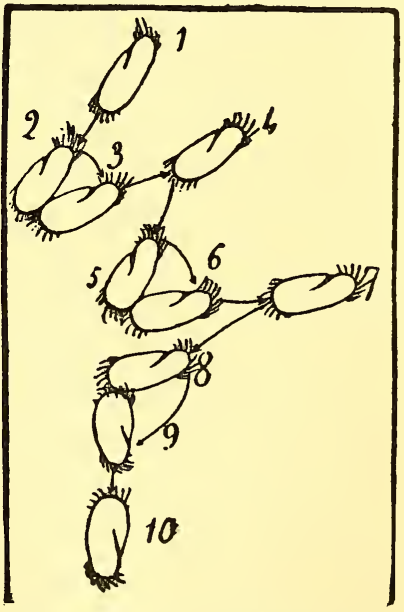

Fig. 3.-Movements of Oxytricha fallax in a beaker of water of which the wall $x$ is warmed. (After to direct themselves in Jennings.) ways which are favorable to them. So the advances, the turnings, and the recoils which are for us simple automatic responses of tropisms and of differential sensitiveness, represent to Jennings a sort of actual apprenticeship. 


\section{THE PSYCHIC LIFE OF INSECTS}

If this be so, it follows that this apprenticeship is singularly long and only slightly fruitful with the organisms which undergo it. In all the insects which we have studied from this point of view, as in Oxytricha fallax, the reactions produced by variations of intensity with stimuli are invariable, stereotyped, so to say, and inseparable from organic function. We notice them to-day as they will be seen to-morrow, and it is certainly no exaggeration to say that they go back to the origin of the species. If the Oxytrichas are capable of correcting their errors by trials, why do they return without pause to the warm side before once trying the opposite side of the aquarium? Moreover, there are animals which orient themselves directly when they are young and afterward by a series of oscillations due to differential sensitiveness; this is the case with the starfish studied by Bohn; when little, they go straight to dark or light surfaces; when older, they behave like the Oxytricha fallax, so that they end where they would have begun if they had really obeyed Jennings's law.

Possible adaptation of differential sensitiveness. If it is not necessary to see in the actual phenomena of differential sensitiveness a series of trials which rectify the errors, and if one considers the stops, turnings, and recoils which characterize 
these phenomena as primitive and automatic reactions, under the same title as those of tropisms, we do not believe that these phenomena can be adapted to the variations which they provoke.

In fact, on the contrary, tropic reactions which are always well determined, the responses of differential sensitiveness, lend themselves to different modalities, and these modalities may be tributaries of experience.

We have seen (page 74) the bedbug direct itself toward the light which it ordinarily flees, at the simple approach of a lamp interposed from behind, and the Spirostomum ambiguum recoil from a noxious drop placed behind its body. These two responses seem false, they place the animal in peril, which perfectly conforms to the law of differential sensitiveness. But in both cases the organism finds itself in the presence of experimental variations which never occur in the environment in which it normally passes its existence. In cases where several modalities are possible, the insect seems to react by chance and often to adopt the wrong modality. This is the case in the following experiment, carried on by Bohn (1906): When the bedbug starts away from the bright window, a black or white screen is placed in its path, which produces a sudden variation in the intensity of the light; the animal 


\section{THE PSYCHIC LIFE OF INSECTS}

hesitates, and then, combining the rotation of differential sensitiveness with the acquired impulse, goes in an oblique direction, either to the side opposite the screen, or toward the screen itself. It pursues its march in the same direction if it meets the screen on the left side. Its adaptation is null; between the two modalities (direction to the right or to the left) which differential sensitiveness permits, the animal has no choice.

Quite different is the habit of these animals under natural conditions in moving in an environment where light and shade coexist. The animals are accustomed to screens and in the presence of these invariably choose one direction, always the same for each screen. One might say that they have learned to choose. This has been very well shown by the experiments of Bohn on the little gasteropods of the genus Littorina, and those of the same biologists upon the caterpillar of Tyria jacobare (see page 70). With these animals, and surely with all those whose organization has at least reached a certain point, the responses of differential sensitiveness to normal variations have been adapted and consequently are the result of a natural apprenticeship. This apprenticeship has been served by all the actual individuals who possess differential sensitiveness from birth, it "can have taken place," says Bohn, "only in a far 
distant past" in the course "of many fruitless trials," made already by the species under conditions of environment in which it has accomplished its evolution. When it cannot take place, as with the bugs and the Spirostomas presented with abnormal conditions, the phenomena of differential sensitiveness are produced by chance, without following a precise modality, without adaptation.

Species memory. The trials of apprenticeship! Here we are, it seems, brought to Jennings's theory, which we have immediately judged to be untenable, at least in the cases and in the form in which it has been presented. But this contradiction is purely apparent. In this theory all the reactions to stimuli, from those of tropisms to the recoils and rotations of differential sensitiveness, represent a series of motor phenomena which are actually tried before adaptation; the animal is still an apprentice, trying to adapt itself. But it is not any more so with the relatively higher animals which we have chosen for example; the Littorinas and the caterpillar of the dunes show all the phenomena of tropisms and of differential sensitiveness, but the latter manifests itself by a precise directive modality, which leads immediately to the end and without trials; the animal is no longer undergoing an apprenticeship, it is ben- 
efiting by a remote experience acquired by the species in the course of its history in normal ethological conditions.

With most of the articulates, if not with all, the manifestations of differential sensitiveness in the normal conditions of its environment seem perfectly adapted. It is the same with the mollusks studied by Bohn. They are hardly so with the lower organisms upon which" the delicate researches of Jennings were made. In Oxytricha fallax, for example, the infusorian executes its recoils and its rotations a number of times before reaching the favoring cold zone, but each time it comes nearer the latter, which indicates, perhaps, a beginning of adaptation and perhaps also gave birth to Jennings's theory.

But the articulates and the mollusks have a well-differentiated nervous system, a brain represented by a pair of ganglia, and sense organs connected with the brain; while the Infusoria are reduced to a protoplasmic mass, complex, it is true, but in which the sensitiveness is diffused, without any nervous localization. If it is true, as the most precise experiments show, that sensations choose the brains as a center, and can produce there these durable impressions which characterize memory, we are led to see in the adaptations of differential sensibility one of the results 
(and perhaps also one of the causes) of the concentration of the nervous substance in a distinct system, a response by which the determined stimulating variations provoke determined movements, and not by others. It is the work of memory, not an individual memory, but a species memory, which has progressively developed from the origin of the species, and which, by heredity, manifests itself to-day in all representatives of the species.

Thus, species memory with the adaptation which it carries, presents a real development with the more or less superior animals, and remains in a rudimentary state with the more simple animals. But between these two extremes one sees all the intermediate steps in. the concentration of the nervous system, and one should wait to observe all the degrees in the phenomena of differential adaptation and of species memory. This is why we refuse to see in these phenomena what we have seen in tropisms,-manifestations to which physiological selections seem strange. Natural selection has been working on all these beings, but it has collaborated here with an active adaptation by physiological selection (see page 42 ).

Before going further, it will be useful to cast a glance over the path so far pursued. Tropisms have shown us primitive phenomena by which the responses of living matter to stimuli manifest 
themselves. These responses are automatic, but not without suppleness, for they always combine more or less with the manifold activities which have their seat in all organisms, even the most simple. With the vital rhythms, we find ourselves in the presence of primitive and automatic phenomena, but by reason of their periodicity these phenomena have left a trace on the living matter, and they can be produced aside from the excitation which gave them birth. The living being has become the seat of an organic memory, which liberates it somewhat from the exterior environment and puts it on the path toward higher activities. With the species memory, we take the first steps on this path and penetrate into the domain of psychism, where the animal draws into the impressions of its nervous substance the power to act in one way rather than in another, the power of choice. It is true, we are still in full automatism, for this memory is bequeathed to the representatives of a species by remote ancestors in which it was born, and to-day shows itself in the individual by simple acts; but it was in the beginning progressively acquired in the course of often fruitless experiments, and it represents the first beginnings of psychism. The lower organisms manifest their activity by tropisms, by rhythms, by the phenomena of differential sensibility, and 


\section{DIFFERENTIAL SENSITIVENESS 91}

we can hardly see in them gleams of species memory,- that is to say, of psychism. With the articulates, on the contrary, species memory plays a part which is not less great than the other responses to external stimuli, and psychism appears under the form of a new element, individual memory, which tends to take the predominant part in the entire activity of the being.

But before entering upon this new domain, we should study the so-called "simulation of death," which appears to be one of the most singular manifestations of differential sensibility.

Simulation of Death. Among the reactions produced by differential sensibility which strike us first is the sudden immobilization, the abrupt stopping, of the insect experimented with. This inmobility is commonly short, rapidly followed by a flight or a movement of rotation; but in some cases it is more or less persistent and represents only a differential reaction. In it the animal is rigid and simulates death.

Fabre's experiments. Let us study this curious phenomenon more closely and let us first follow the experiments carried on at Serignan by J. H. Fabre.

There is a predatory beetle, nocturnal in its habits (Scarites gigas), which greatly interested. the illustrious entomologist. A shock, a pressure 
from the fingers, and behold the insect upon its back, lying inert "as if it had expired. The legs are folded against the belly, the antennæ crossed, the jaws open." It is not "to dupe an enemy" that "the war-like pirate, so well armored," takes this attitude, so that any insect can grasp it by the head. Left absolutely alone, even under a bell-glass, it remains rigid. This condition of torpor lasts on an average twenty minutes, but it lasts longer if one submits the beetle to subsequent shocks. It can reach fifty minutes, after which "the scarites refuses to play dead." A trembling of the feet, the palpi, and the antennæ announce the return to activity. One can provoke these movements and this return by shocks, by tickling it, and especially by sunlight. Cold, on the contrary, does not seem to act upon the animal.

Fabre made similar experiments with other insects. The results vary according to the species. The little Scarites lavigatus, although closely related to the former species, remained motionless only a few minutes. The big buprestid Capnodis tenebrionis sometimes presented an equally brief reaction, but sometimes remained motionless for an hour. This last insect is very sensitive to variations in temperature; in the sun it resumes its activity quickly, while under the action of cold it may simulate death for nearly five hours. Quite 
contrary to the giant Scarites, it loves the warmth and delights in the light. Buprestis rutilans, which has similar habits, rebels at experimentation. Each species has its own manner, and nothing can guide us in researches of this kind.

Characters which approach simulation with phenomena of differential sensitiveness. As Bohn has shown, the preceding phenomena seem tributary to differential sensitiveness. At first they manifest themselves identically under the influence of variations of a stimulant, whatever this stimulant may be. Fabre used shocks, pressures, but he reached the same result by submitting his insects for some seconds to vapors of ether. Holmes $(1903,1908)$ has stated that the waterbugs of the genus Ranatra do not react in the water, which is their normal habitat, but that they fall into rigidity when they are exposed to the air. Currant-worms are very sensitive to touch, and I have frequently seen them fall on the ground when I have thrown insecticidal liquids on them. This rigidity may be obtained by a sudden exposure to light or to shade, by sonorous vibrations, by an electric shock, even a light one. This may, and does, vary with one or the other species. In his interesting studies of these phenomena Rabaud has principally used pressure.

Like the responses of differential sensitiveness, 


\section{THE PSYCHIC LIFE OF INSECTS}

the phenomena of simulation appear in the most widely different organisms. Holmes states that he does not seem to be able to reproduce them with the lower invertebrates "such as Protozoa, colenterates, mollusks, and worms, although certain of these animals show reactions prophetic of this instinct." This observation is corroborated by Bohn, who notes phenomena which may be precursors of simulations with certain tube-inhabiting worms, with the amobas, and a contraction into a spherical mass with the rhizopods of the genus Pelomyxa. It is among the articulates that these phenomena are most often observed. The myriapods of the Julus group ordinarily roll up, and those of the Glomeris group into a perfect sphere. Among the Crustacea this rolling into a ball is noticed with certain isopods and amphipods above all with our species of Armadillidium, which then resemble Glomeris, the Talitres or sand-fleas curl themselves into an arc and bring their appendages to the sides of the body; it is noticeable that many spiders react to stimulating variations, and hold themselves motionless and press their legs against the wall of the cephalothorax-a phenomenon observed especially with the species which spin orb webs. Rabaud observes that most insects, if not all, are 
capable of taking on rigidity when a certain region of the body, variable according to species, is excited. But with many, this region is closely localized, difficult to reach, while with others, it is easily accessible to all stimuli, so that the animal readily takes on the characteristic rigidity. These latter insects, in which simulation of death is easily produced, belong to all orders, but they seem to be rather rare among the Lepidoptera, the Diptera, and the Hymenoptera; otherwise they do not seem to be related by any zoölogical affinity. Let us add, finally, that simulation is possible with certain vertebrates of all classes, as one notes even with the fox, and that similar phenomena are observed in sensitive plants, such as the Drosera, which responds by certain attitudes to various stimuli.

To end this parallel between simulation and differential sensitiveness, we must add that the agents capable of modifying the second (luminous rays, heat) act also upon the first, as the abovementioned experiments of Fabre show. The same experiments have shown us, also, that simulation may be provoked several times in succession with one individual, but that the subject ends by becoming temporarily insensible to the stimuli. It shows then a kind of fatigue which is noticed 


\section{THE PSYCHIC LIFE OF INSECTS}

also with animals successively submitted at close intervals to the productive variations of differential sensibility.

Mechanism and nature of the simulation. This parallel need not be pushed too far, because the mechanism and the physical nature of simulation present special characters.

Let us note first the muscular tetanus which gives to articulates in this condition the appearance of a dead body. "If a Ranatra," says Holmes, "is seized by one of its slender legs, one can hold it a long time horizontally without the legs bending in the least. This is as if a man were seized below the knee and held straight up without the knee bending, except that the legs of the Ranatra are incomparably more delicate than the leg of the thinnest man, and the muscular tension which holds the insect out must in consequence be intense." Rabaud has established the fact that this simulating rigidity is the result of a direct contact which differs from the ordinary physiological contraction in that it is produced instantly and not by steps, and also because the immobilized muscle, instead of being more excitable, is always infinitely less so.

Speaking in general of this tetanus, the simulating creatures are distinguished by a characteristic insensibility and by the very considerable lessen- 
ing or entire disappearance of the reflexes; one may try to excite them in many ways, mutilate them, cut off a leg; without the least reaction except sometimes a slight palpitation of the feet. The opinion of biologists is unanimous on this point, as on the preceding.

But these two phenomena, muscular tetanus and lessening of reflexes, are equally characteristic of catalepsy. We may, then, regard simulation as a cataleptic state. This was the opinion of Fabre, who has been followed by Holmes, by Bohn, and very recently by Rabaud.

May one say as much of the sudden inertia which is shown, before any movement, in the normal phenomena of differential sensitiveness? It is possible, but hardly probable. For want of experiments, we are ignorant if that state of inertia is produced by a muscular tetanus, but it is not impossible to show that it is accompanied by a considerable lessening of the excitability of the subject. From this point of view, the observations of Rabaud (1916) should be cited, for they will allow us, perhaps to reach the solution of the problem. This biologist distinguishes with our articulates two kinds of inertia, of which the praying Mantis and Dixippus morosus offer perfect examples. These two Orthoptera may be thrown into a condition of simulation and then, immobilized, ac- 


\section{THE PSYCHIC LIFE OF INSECTS}

quire the characteristic insensibility; but the second during the day and the first when it lies in the foliage, seem equally inert and are simply motionless, since they respond then to the least excitation. But Rabaud has shown that our freshwater sand-flea (Gammarus fluviatilis) takes on this last state by differential sensitiveness when it finds itself shaded from light rays, so that the inertia produced by this sensibility is of quite another nature than simulating rigidity. After observations upon the seashore beach-flea (Talorchestia), Holmes arrives at quite another conclusion, and thinks that the ordinary immobility may lead to immobilization. The problem is not yet solved, but the studies of Rabaud seem indeed to lead to its solution.

Other studies by the same author establish the fact that the simulating reflex with insects is provoked "by non-sensorial excitations directly upon certain points on the surface of the body" and that the antagonistic reflex, that which returns its mobility to the animal, has also for its seat a localized spot. Most often the excitable zone of the immobilizing reflex is found in a vein of the wing (among butterflies, dragon-flies, etc.), on the legs, on the sternal plate; and that of the mobilizing reflex at the end of the abdomen, at times also (in Lepidoptera) at the extremity of the antennæ. 
Rabaud has not always fixed the excitable points with sufficient precision, and we may believe that all are not narrowly localized. In any case, it does not seem exact to say that simulation is independent of sensorial organs, at least with the articulates. The action of the light rays and of ether shows that this is not always so, and the pressure exercised by Rabaud upon the excitable areas must certainly have some influence upon the ends of the tactile nerves. From this point of view, simulation does not seem to differ much from differential sensitiveness.

We can explain in the same way the simulation which is independently produced by the cervical ganglia. Holmes has stated that Ranatras, deprived of the head and prothorax, become rigid when they are excited by slight shocks, and he adds that he obtained the normal simulation with spiders whose brain had been destroyed. Evidently the eyes play no rôle in either case, but the provoking shock must certainly touch the terminal tactile nerves.

Biological significance. If it is not doubtful that the simulation is a phenomenon of differential sensitiveness, limited to cataleptic tetanus, and characterized by it, we must admit that its biological significance is still very obscure. Must we see in this phenomenon a special state, pre- 


\section{THE PSYCHIC LIFE OF INSECTS}

served by natural selection because it is advantageous to the species? This was for a long time the dominant opinion, some believing that the individual deceives its enemy by taking the attitude of a dead body, and others believing that the simple immobility deceives the enemy.

The first of these opinions was founded on vague appearances which do not support even a slightly attentive examination. Without doubt, many simulating species take a certain attitude, but this attitude is hardly that of a dead body. Darwin compares in this regard seventeen species of articulates (Julus, Cloportas, spiders, insects) and the result was "that in no case was the attitude exactly the same, and in certain ones the attitudes of the simulating individuals and the dead ones were as different as possible." Moreover, many insects take any attitude whatever at the moment of simulation; it suffices to take Ranatras from the water, says Holmes, "to put them into a state of immobility, which ordinarily lasts several minutes, and sometimes for more than an hour. The legs may be held against the body so that the insect resembles a stick, but they may also be stretched out at a right angle or bent in any direction whatever, this one one way and that one another, following the position in which they happen to be at the moment of simulation." One gets attitudes 


\section{DIFFERENTIAL SENSITIVENESS 101}

which are just as varied with the walking-stick of the laboratories, Dixippus morosus, which is not unlike the Ranatras in form. I have been able to convince myself that currant-worms do - not take a fixed position; often they roll themselves in a ball like many other larvæ, but often also they hold themselves straight, or bent, or regularly arched. This is not "simulation of death," and this term, unfortunately fixed by usage, gives a very inexact idea of the behavior of the animal.

But should we not regard this rigid immobility which characterizes simulating articulates as an artifice of protection? This is hardly probable, because this immobility is often produced by the enemy which cannot be duped in this way, and finds it advantageous in making its capture. It is possible that occasionally immobility plays a protecting rôle, says Rabaud, very justly, "but it cannot serve as a basis for a suggestion of natural selection, especially because the reflex of immobilization produces with certain animals, the Zygænas, for example, only an effect which is too fugitive to give it any real advantage. Moreover, I have collected precise facts which show that immobility deceives predatory insects very little. If for certain arthropods, such as Glomeris, the reflex immobilization is profitable, for others it is 


\section{THE PSYCHIC LIFE OF INSECTS}

rather harmful. . . M Moreover, the existence of the antagonistic reflex renders it liable to come into effect at the wrong time and do away with all the defensive value which immobility had given them."

In fact, we find ourselves in the presence of a nervous phenomenon which seems to play no part in the conservation of the species, which presents no relation to zoölogical affinities, and which appears to be a simple specific exaggeration of differential sensitiveness.

However it may be, the fact that decapitation does not prevent immobility from being produced is a proof that this phenomenon, with the articulates at least, should not be considered as tributary to psychism. But the cataleptic state can be provoked with a certain number of higher vertebrates, and the young herdsmen know how to produce it easily in the goats and the poultry which they are watching. Fabre tried this with a turkey when he was studying the hypnosis of insects. But travelers and biologists report that several birds (the sea swallow, according to Holm, the wild goose of Siberia, according to Wrangl) have recourse to this subterfuge when they find themselves in danger, and the fox is said to use the same artifice. If we can establish by a series of experiments the veracity of these statements, 


\section{DIFFERENTIAL SENSITIVENESS 103}

we shall have to admit that with higher animals this simulation may be voluntary and serve to protect them, but this is not the case with insects, where everything seems to show that it is purely automatic. 


\section{CHAPTER VI}

INDIVIDUAL OR ASSOCIATIVE MEMORY

The phenomena so far studied manifest themselves in the lowest animals, in many plants, even also in the highest representatives of the animal kingdom. They cannot be related closely to nervous differentation; they are, before all, reactions of the living matter, of protoplasm, to stimulating influences. The nervous system and the sensorial organs serve simply as agents to the reactions provoked by these influences; they are not primordial factors, for one observes identical reactions in a throng of organisms in which these organs show no trace of differentation. In these diverse cases the sensation, or nervous impression, must be absent or singularly reduced. The automatism seems perfect, even when it causes phenomena of periodicity which reveal an organic memory.

The preceding observations do not apply to phenomena arising from species memory. With these we leave the domain common to all organisms to enter into that of animals in which the nervous system plays a predominate rôle. Psy104 
chism appears in the form of a choice between the diverse modalities offered in response to variations of stimuli. It acts, therefore, as only a rudimentary psychism, rudimentary and very distant, limited to stimulating variations and to impressions which they have already produced in the species. In the course of ages these last have been graven on the brain centers and have left there a permanent trace; and to-day the same variations determine the responses belonging to these old survivals. The vague psychism at the beginning has become an automatism.

Let this change from psychism into automatism hold our attention, for it is not the exclusive appanage of species memory. One sees it more and more and more plainly in the other phenomena which constitute the relative life of the higher animals. But these phenomena are complex and varied, thanks to the development of nervous and sensorial systems which permit the individual to know his surroundings better, to be more susceptible to the influence of these surroundings, and to receive livelier impressions; more apt for the same reason to be graven on his brain and to leave there a persistent trace. From that comes an individual memory, more extended and more flexible than the species memory, whose narrow domain is limited to stimulating variations. 


\section{THE PSYCHIC LIFE OF INSECTS}

It is the brief study of these new phenomena which will be the object of our research. Leaving behind the lower animals and protoplasmic irritability, we will confine ourselves entirely to articulate animals, to follow then the development of individual memory, and to examine the change of the manifestations of this memory into automatic acts.

Manifestations of individual memory. Fabre tells us the story of the Languedoc sphex (Sphex occitana) a kind of wasp that hunts the grasshoppers of the genus Ephippigera for its progeny, stings them under the thorax and paralyzes them, and carries them to a prepared place where each victim is buried with an egg laid on its side. Usually the sphex places the grasshopper a short distance from the point where it is going to dig its nest, but it often meets obstacles on the journey. A wasp dragging its heavy burden arrived at the foot of a wall freshly plastered, where it could not find a favorable place for digging. Fabre saw it abandon its victim, fly to the top of the wall, where it sought, under the tiles, a gravelly place, then, having made its choice, returned to its victim, which it wished to hoist up. Twice the grasshopper fell to the ground and twice the wasp repeated the attempt. The third trial was crowned with success. In this unusual case the insect was 
helped by memory; it remembered the place where it had left its prey and after ten minutes passed in its investigations it readily went back to it. Moreover, the exercise of the memory is a necessity for a species which captures its prey before digging a burrow. While it is working at its digging the insect "does not fail from time to time to give a distant glance at the Ephippigera left on the route." A great beetle, the sacred scarab (Ateuchus sacer) does the same thing in making the underground burrow where it will store its ball of dung which is to serve it as food. It leaves the burrow, in course of excavation, says Fabre, to go fondle its dear ball and roll it a little nearer.

In the case of Sphex as in the case of the scarab, the obstacles are small and the distance is not great. I borrow from Turner (1912) an example where the difficulties were greater. It was again with a predatory wasp, not a sphex as Turner said, but a spider-hunting Sphegid. The insect captured its prey in a yard in front of a school and tried to carry it into the cellar of a house just opposite. But the burden was too heavy to be carried in flight and there was a barrier of planks midway between the school and the neighboring house. The insect came to the barrier and tried to climb over backward. A scantling was in the 


\section{THE PSYCHIC LIFE OF INSECTS}

way. It descended, dropped its spider, flew to the door of the cellar, then returned and took its victim again and carried it to the end of the barrier at a spot where a row of stakes began. Again a dropping of the prey and again a flight to the cellar, a flight at a direction of forty-five degrees from the former. On its return its prey was dragged quite to the door; there the wasp left for a momentary exploration. New attempts by the wasp and new climbings which encountered a scantling; three times the wasp tried to surmount this obstacle and the third time she descended to lay her burden on the ground. A last attempt was finally successful, the insect entering the cellar through a hole left by a knot. "The action of this wasp and the movements that characterized it," observes Turner, "cannot be explained by tropisms . . . and it seems neither to be the result of what Thorndike calls movements of trial and error. All the behavior of the animal is that of a creature struggling against obstacles to reach a certain known spot in a known place"; and who does not see that in this struggle the insect is aided by memory?

The mechanism of individual memory with insects is the subject of fine and very suggestive researches made by Ferton on the solitary bees of the genus Osmia. The bees of this genus nest in 


\section{INDIVIDUAL OR ASSOCIATIVE 109}

more or less tubular cavities, where they prepare their cells of triturable materials. Each cell receives a paté of honey and pollen and an egg from which comes a young larva that is to consume this nourishment, after which the cavity is closed with a mortar like that forming the cells.

Let us study with the author (1905) the behavior of two species, Osmia rufohirta and O. ferruginea, which make their nests in the empty shells of land

\section{$\mathrm{C} \cap \mathrm{B}$}

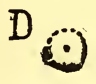

\section{$M *$}

Fig. 4.-Movements of the shell of an Osmia rufohirta which is hunting at $M$-The distance $A$ to $B$ is $12 \mathrm{~cm}$. (After Ferton.)

snails. The first has the habit of rolling the chosen shell to a favorite spot and, after closing it, putting it in a hiding-place. The second, less particular, leaves the shell where she finds it.

An Osmia rufohirita (Figure 4) closes its shell, situated at A, by means of a mastic made of leaves gathered at M. She pushes the shell to $B$ and then returns to $\mathrm{M}$ to make the mastic. After ten minutes she returns, describes a course toward A, then goes to B. She continues this for a quarter 


\section{THE PSYCHIC LIFE OF INSECTS}

of an hour, but, during her absence the shell is removed to $C$. On her return the bee flies to $A$, then to $\mathrm{B}$, and, finding nothing at either spot, begins to hunt around, which finally brings her to the shell, where she deposits her mastic. Before going away again she takes several reconnaissance flights (just as Turner's Sphegid did in a new situation) and at the moment of return she follows the route $\mathrm{A}, \mathrm{B}, \mathrm{C}$. An absence of a halfhour. The insect has brought her shell back to $\mathrm{A}$, but she follows the route $\mathrm{A}, \mathrm{B}, \mathrm{C}, \mathrm{A}$, sometimes neglecting $B$, where the shell stayed only a short time. The nest is then carried to $D$. The bee follows the route $\mathrm{A}, \mathrm{C}, \mathrm{D}$, but afterward goes by C, D, "appearing to have forgotten the point A." "Little by little the image of the former places of her nest are effaced in the memory of the insect." In fact, the bee obeys impulses of mnemonic origin.

Osmia ferruginea is less skilful in her manœuvers, perhaps because she is not accustomed to place her nest. When one carries the latter fifty centimeters away, it takes her a long time to find it, and, although she takes reconnaissance flights before leaving it, it is not without difficulty that she directs herself in the course of her first journeyings. But, little by little, the impressions become stamped on her memory, and when the shell 
has been moved several times one sees the wasp fly to the different points where she has been, after the manner of Osmia rufohirta. Like the latter, $O$. ferruginea very quickly neglects the spots where the shell has rested for only a short time.

From these experiments we may deduce with the author "that memory of places plays a great rôle in the return ... of the Osmias," that it is quick, tenacious, that its tenacity increases with the multiplicity and the duration of the impressions, and, finally, that it diminishes very quickly to the point of disappearing when the impressions are rare and brief. Here we are very far from tropisms, from differential sensitiveness,-indeed, even from species memory. Thanks to the impressions they receive and so easily keep, the sphex and the dung-beetle of Fabre, the Sphegid of Turner, and the Osmias of Ferton know how to manage things and to meet the most unexpected situations. They do not act as automata; the memory that guides them in these circumstances seems, indeed, from its essential characteristics, to belong to the same degree of psychism as the human memory.

Apprenticeship. The experiments of Ferton show us that the memory of the Osmias is facile, but, that it is not of the same degree in all species. A single exploration suffices Osmia rufohirta to learn to know well the new position of its shell; 


\section{THE PSYCHIC LIFE OF INSECTS}

but several journeys are necessary for Osmia ferruginea to arrive at the same result.

The apprenticeship is rapid in the first species, slower in the second, but it is truly an apprenticeship. But the ability to learn plays a great part with the articulates and we must study it a little closer.

Let us consider first species which are lower in the entomological scale and for this purpose choose the orthopterous group Blattide (cockroaches). These insects are known to shun the light and to seek the darkest places. However, despite the very obvious repulsion which they show to lightirays, one can teach cockroaches to endure them. It suffices to inflict on these insects when they wish to enter dark places a treatment which drives them away; an electric shock, for example. Szymanski (1912) and Turner (1912) have tried this method with the common cockroach (Blatta orientalis), which they submitted to shocks from an electric platform every time the insect wanted to go from the light chamber to the dark chamber of its cage. Each of these authors states that the common cockroach is very quick to learn, but different individuals are not equally apt. According to Szymanski, in order to make a blatta refuse ten times in succession to enter the light compartment, the number of shocks 
necessary varies from sixteen to one hundred and eighteen. Turner observes, moreover, that the males learn more quickly and remember better than the females, the young, or the aged individuals, and states that the habit may persist even after a molt. But is it really an acquired habit and not a phototropic reversal produced by the electricity? Turner has settled the question by trying apprenticeship of the blattas in a cage in which the two compartments (light and dark) had as a common partition, a curtain which did not quite reach the floor of the cage. Once the apprenticeship was completed, the same cockroaches were put into another cage where the common, partition had a door. In this new lodging the insects went immediately to the dark compartment. They associated in this memory the sensations of shock with a certain place, but their repulsion from the light remained perfect.

Certain Coleoptera are equally teachable, among others the margined Dytiscus, which is a large fresh-water beetle. Forel says (1900):

A Dytiscus marginalis which I had in a bowl, and which I was accustomed to feed, ended by learning a little. Instead of retreating to the bottom of the bowl when I entered, it jumped almost out of the water and immediately seized what I gave it, even from my finger. Quiet before, it put itself in motion as soon as it saw 


\section{THE PSYCHIC LIFE OF INSECTS}

me enter. It remembered then that it was I ( $I$ don't believe that it could distinguish me from another person) who brought it food.

Labitte has also noticed an apprenticeship with the same insect.

The yellow-winged sphex (Sphex flavipennis) is a hunter of crickets, which digs its nest, a nest with several cells, before leaving on a provisioning expedition. When it returns with its burden, it drops it near the entrance of the burrow, makes a domiciliary visit, then comes out to seize its benumbed victim, which it drags in by the antennæ. This wasp forms little colonies of from ten to twelve individuals in sandy soil. Fabre tried the following experiment on a wasp of one of these colonies: While one of them was making its domiciliary visit, he removed the victim to some distance, which caused a search by the wasp on issuing. Once in possession of its prey, the sphex dragged it to the edge of the burrow and again left it, to explore the hole again. More than twenty successive times Fabre repeated the process. The wasp never failed to bring the cricket back to the nest and to leave it there, to make its visit. All the wasps of the colony behaved in the same way, and not only these but those which nested in the same place the next year and which were the descendants of the first. But the wasps 
of another colony were not so foolish: after two or three times they learned to avoid the trick and, without any visit, they dragged the cricket into the burrow. "Thus," concludes Fabre, "the knowledge of the trick is transmitted; there are tribes that are more clever and those that are more simple, apparently according to the faculties of their fathers." The insect does not always obey "a fatal inclination which circumstances cannot modify," its acts are not "invariable," and it is wrong to believe it incapable "of acquiring" the least experience at its own expense."

According to Nicolas, Pompilus viaticus is no less wise. Like all the Pompilide, it is a hunter of spiders; but instead of storing its victim immediately, after the manner of the other species of the same genus, it leaves it near the burrow, to make a domiciliary visit. If the spider is removed a little way during the visit, it does not fail to bring it back and to enter its burrow immediately; but it does not act this way long, for if the same trick is tried several times, it enters direct with its victim.

The social Hymenoptera,-wasps, bees, and ants,-learn and retain with more facility. We shall see in other parts of this book with what facility Lubbock, Forel, and many others knew how to accustom them to come to take honey from fixed 


\section{THE PSYCHIC LIFE OF INSECTS}

places, and how they came to those places even when the honey was no longer there. François Huber $^{1}$ cites a characteristic observation on this subject:

Some honey had been placed on a window ledge in the autumn, and the bees came in crowds. The honey was taken away and the window was closed all winter. The following spring when the window was opened the bees returned, although there was no longer any honey there.... An interval of several months had not effaced the impression.

Lovell (1909) reports a similar observation and all bee-keepers know that bees retain for a long time the memory of places where they have found honey.

Articulates other than insects also are capable of changing their habits by apprenticeship. Placing American crawfish in a boat with two gangways, the one covered with glass and the other open, Yerkes and Huggins (1902) accustomed the animals to avoid the former and to use the latter. It took a month and sixty trials to attain this result. Progress was slow but continuous and the habit persisted fifteen days after the education. It took an equal amount of patience for Drzewina (1910) to accustom a Gulf of

1 F. Huber, Nouvelles observations sur les Abeilles, 1814. 


\section{INDIVIDUAL OR ASSOCIATIVE 117}

Biscay crab (Grapsus varius) to use a side door made in the glass partition which divided its boat into two compartments. The crabs of this species wish to go in a straight line toward the sources of light. Drzewina's crab was attracted toward the empty compartment by the light of a candle; on the way it met the glass partition and, in its effort to find a way through, finally found the door; and the many trials taught it finally to go straight to the door.

Individual or associative memory. Experimentation has not so far played a sufficient part in the biological study of the invertebrates and it will not be easy to bring together many examples similar to the preceding, nor as good ones. But these suffice to place the rôle of memory of articulates, and especially of insects, in the full light. Most of these animals, if not all, are capable of receiving sensations, of graving them for a longer or shorter time on their nervous systems, and keeping them there, so much the better if they have been strong and repeated several times. By the association of these sensations, they can modify their habits, acquire new ones, and show themselves capable of apprenticeship. The cockroaches of Turner learned to remain in a lighted room by associating the notion of shock with that of darkness. The Pompilus of Nicolas immedi- 


\section{THE PSYCHIC LIFE OF INSECTS}

ately stored its spider, because its memory associated the recollection of the search with that of its capture, and, in the experiment of Drzewina on the crabs, visual sensation surely intervened,the sensations of places and muscular sensations, perhaps still others.

Whether the sensations remain isolated or are associated in the memory, they do not impress themselves equally on all articulates. The examples just cited show us that from this point of view a very great diversity exists not only among the species but between the different individuals of the same species. What differences there were in the remembrance of impressions and facility in apprenticeship between the two species of Osmia studied by Ferton, between the individuals of the common Blatta submitted to the electric shock by Szymanski and Turner, between the different kinds of the yellow-winged sphex which Fabre studied! The faculty of retaining, of learning by experiment, in association, shows in each individual a particular development, and merits, for this reason, the name individual memory. From the fact that the sensorial nervous organs of the representatives of the same species are very nearly alike, they ought to show a great similarity in their manner of receiving and holding sensations, but this similitude does not reach identity, and 
just as each individual has certain structural traits that distinguish it, each one is distinguished also by the development of its psychic faculties.

How these especial aptitudes of individuals separate us from species memory, where the response to stimulating variations is an adapted movement, always the same, variable simply in its amplitude, and the same way with all individuals! Moreover, between the individual memory and the species memory one can see other differences still more striking and all as profound. The domain of the first involves all the influences of the environment; that of the second is restricted to the variations of the external agents. The first may be extended and actually modified; the second is an immutable legacy of the past; with the first the association of the sensations and, consequently, apprenticeship are possible, in the second the vague original psychism has been transformed into a pure automatism.

In spite of the differences the individual memory and the species memory are not without contact. Both, in fact, are the result of nervous impressions; both enter into the psychic domain, because at a given moment, more or less, they are manifest by choice; finally, both have led to habits which have quickly turned to automatism.

Passage to automatism. This last point deserves 


\section{THE PSYCHIC LIFE OF INSECTS}

our attention, for it is one of the dominant characters of the psychology of insects. With these animals, in fact, certain sensations rapidly impress themselves on the nerve centers and give rise to motor reactions which very quickly take on an automatic character. Let us recall the way the two species of Osmias acted in response to the artifices of Ferton. Their shell, situated at A, was successively moved to $\mathrm{B}, \mathrm{C}$, and $\mathrm{D}$, and when the bees returned with their harvest they flew to points A, B, C, before finding the shell at D. They went automatically to point $\mathrm{A}$, where the shell was first situated; at $\mathrm{A}$ was aroused the memory of point $B$, and at $B$ that of point $C$, and at $C$ that of the removal to $D$. The recollection of a place unleashed the recollection of the next place; the individual memory, in other words, was combined with automatism.

Even with man the acquiring of habits by apprenticeship is a step toward automatism. But all the cases just cited give us the proof that arthropods, insects, or others, can acquire new habits more or less quickly. And, if this is the result obtained by a short experimental apprenticeship, one is quite right in thinking that natural apprenticeship leads more surely still to automatic habits, for there is the fact of the con- 
ditions of the animals' environment, conditions which act on him and his posterity.

Rules of individual memory. Certain sensations may be so acute that for the moment they destroy all others. This phenomenon is not rare in man,as witness "absorbed persons." It is commoner still with the arthropods and plays a very great part in the life of these animals, as numerous biologists have noted. One cannot easily distract a digger-wasp when she is paralyzing her victim, a dung-beetle when it is rolling its ball, a fly when it is drinking milk. Entirely absorbed in her work, the foraging bee, says Pérez, ${ }^{1}$ seems oblivious of everything that is not the immediate object of her activity; whether she is returning or starting out, she seems to see nothing that goes on about her. Pillagers try to force the door (of the hive); she brushes past them without recognizing them; honey is spread on the table, she takes no care at all not to fall into it and become entangled in it. We know that ants recognize one another with their antennæ, that they get along beautifully with the individuals of their formicary, while they engage in pitiless battle with those of another nest or with another species. In the last case everything else is forgotten in the

1 J. Pérez, Notes zoologiques, 1894. (Actes Soc. Linn. Bordeaux. v. 47 . pp. 231-331). 


\section{THE PSYCHIC LIFE OF INSECTS}

ardor of the belligerents. "One can," says Forel, "cut off several of their legs, or even cut them in two in the middle of the body and they will continue to fight and kill one another as if nothing had happened to them."

As to the invasion of automatism into habits, it is subject to an essential rule which may be called "the rule of predominance," for this term expresses the fact that a single sensation or a small number of predominant sensations suffice automatically to release an act which opposes a more numerous group of sensations. An example taken from the observations of Ferton will help us to render very tangible the exact meaning of this rule. Ammophila holosericea is a predatory wasp like sphex and Pompilus, but, instead of paralyzing Orthoptera and spiders for its young, it attacks measuring-worms. It is necessary to collect four or five of these caterpillars before closing its nest, which it has dug in the sand. One of these wasps had just closed its filled nest and Ferton offered it a caterpillar already paralyzed by one of its congeners. The insect found this one excellent, carried it near its burrow, and began to remove the material which closed the latter. But finding the burrow already full, the wasp forgot the caterpillar and hastened to close the burrow and flew away. Then she saw the caterpillar 


\section{INDIVIDUAL OR ASSOCIATIVE 123}

again and resumed manœuvers. It is not doubtful, that, under normal conditions, the insect associates at least three different sensations before storing her prey: consciousness of the paralyzed caterpillar, of the proximity of the nest, and of the incompletely provisioned nest. But, in the experiment, a single sensation seems to control the actions of the insect; the sight of the paralyzed insect automatically provoked the storing manœuver, and the sight of the open burrow the manœuver of closing.

It is especially from old sensations more or less strongly impressed, that the memory of articulates is made, and it is the recall of old sensations by new ones to which is due, in large part, the activity of these animals. But one can know the sensations of animals only by the external manifestations of which they are the cause, and, as Bohn justly observes: "All sensations do not manifest themselves externally" immediately; many remain latent in the memory and are recalled to manifestation by the occurrence of new associative sensations. A wasp has taken some honey treated with alum; she immediately draws away and begins carefully to clean her mouth parts. That is the external manifestation of a disagreeable gustatory sensation. But what sensations has a bee when it makes many visits to 


\section{THE PSYCHIC LIFE OF INSECTS}

nectar placed upon a plate of uniform coloration? To know this it is necessary to move the plate a little and, in its place, to put a second, also provided with nectar but differently colored. Lubbock $^{1}$ has tried this experiment, employing very different colors and, despite the substitution he has always found that the insect returns to the first plate, to which it has formed the habit of going for honey. Lubbock's bee associated the sensation of color with the sensation of taste: both were fixed in its memory, but while the second showed itself by journeys and meals, the second remained hidden, and, in order to make it evident, it was necessary to try the indirect method of moving the plate.

1 J, Lubbock, Ants, Bees and Wasps, 1882. 


\section{CHAPTER VII}

SPONTANEOUS MODIFICATIONS OF HABITS

Here we find ourselves in the presence of two kinds of activities which at first seem very dissimilar,-those which all the representatives of a species produce without actual apprenticeship, and those which are acquired by each individual in the course of its own life. The first include all those actions which are the result of tropisms, of organic and of species memory. They are not due to any intention of the animal and present themselves as reflexes, but as reflexes which are coördinated so as to put the whole organism into action. They belong in the domain of instincts. The second appear very different, since they imply choice and presuppose a certain individual intention; but we have seen that these very quickly take on the character of habits, and even turn into automatic actions. If these individual habits can be transmitted by heredity they will become similar to the first, and we shall find ourselves prepared to comprehend the problem of the psychology of insects, to know the mechanism by which 


\section{THE PSYCHIC LIFE OF INSECTS}

these often extremely complex instincts were acquired, have evolved, and still continue to evolve. The question is highly important, and we will try to solve it in the light of facts, but before beginning we should know whether or not insects are capable of modifying their habits.

Can insects. spontaneously modify their habits? Animal psychology is a very delicate science, because more than any other it risks the confounding of the objective with the subjective. The intimate phenomena of animal behavior escape direct observation, and it is only from the manner in which they manifest themselves that we are able to understand them. Then comes in the personal judgment of the observer, and two things present themselves: on the one hand, reasoning by analogy it gives the animals human faculties (anthropocentrism); on the other it shows an excessive tendency to follow from the bottom to the top the stair of living beings and to reduce all the animal activities of the lower organisms to purely mechanical manifestations.

What shipwrecks have been caused by these rocks, even among the most highly esteemed biologists! Against the first most of the biologists have struck, from Réaumur to Lubbock; among others, a disciple of Darwin, Romanes, who has popularized anthropocentrism in his remarkable 
work on "The Intelligence of Animals." Against the second rock the savants of the German mechanistic school have dashed themselves, -Wundt, who denies all psychic faculty in animals, even in the most advanced; Uexhull, who declares that "For the biologist, animal psychology cannot exist"'; Bethe, who accords, however, certain psychic aptitudes to vertebrate animals. In his book on "Vision," Nuel ranges himself among the most advanced of the scholars of this school who have revived under a new scientific aspect, although with strange scientific terms, the animal mechanism of Descartes.

Shall we give some examples of the diametrically opposite tendencies of these two schools? We have only to choose from the works in which Lubbock and Bethe have accumulated their observations upon and their experiences with the social Hymenoptera, notably the ants and the bees. Lubbock observes that "the anthropoid apes, in their structure, evidently approach man more nearly than any other animal," while the ants can "justly pretend" to the same rank "by the degree of their intelligence." Such, however, is not the opinion of Bethe (1898). "Should we attribute psychic qualities to the ants and to the bees?" asks the Strasburg professor, who, after having experimented and observed, replies to this 


\section{THE PSYCHIC LIFE OF INSECTS}

question in the following manner: "It seems that the whole group of invertebrate animals lead a purely reflex life. . . and that these animals perform as simple machines all the acts which appear so intelligent."

So the two methods of reasoning (the one descending from man to the inferior animals, the other mounting toward man, starting with the simplest organisms) bring diametrically opposed conclusions. "That was to be foreseen," say's Claparède ${ }^{1}$; "the descending method, as a matter of fact, speaks only in terms of consciousness; the ascending method knows only the mechanophysiological tongue." Our embarrassment would be great if we were bound to follow the one school or the other, but this is not the case, and we will wisely stay in the domain of observation and experiment. But it is not to be doubted that an animal can show proof of psychic aptitudes, of understanding, when it is "in condition to learn and to modify its comportment," its hereditary habits. That is the decision of Bethe. It was equally, I think, that of Loeb and of Bohn when they coined the expression "associative memory," although this memory becomes very quickly, at least with the insects, automatism.

1 E. Claparède, Les Animaux, sont-ils conscients? 1901. (Rev. Phil., Paris. v. 26. pp. 481-498.) 
We are here in the presence of a method which promises to recognize psychic actions without rising or descending in the animal scale. It suffices to follow it in making an abstract theory, leaving to the facts the signification which belongs to them. To speak strictly, in studying the variation of habits of the Osmia bees, of the Pompilus wasps, the cockroaches, the crawfish, and the crabs, we have already concluded that these animals are capable of modifying their habits and of learning to take on new ones. But this was under experimental conditions which were more or less different from those which are normal to the organism. To avoid this criticism, let us examine the insect left to itself in the surroundings among which it passes its life.

Observations of Fabre. I will first invoke testimony which cannot be impugned,-that of Fabre, an intense believer in the changelessness of instincts. The venerable biologist says:

Pure instinct, if it existed alone, would leave the insect unarmed in the perpetual conflict of circumstances. ... A guide is necessary. ... This guide the insect possesses to a very evident degree. It is the second domain of its psychology. In this domain it is conscious and can improve by experience. Not daring to call this aptitude rudimentary intelligence, which is too advanced a title, I will call it discernment. 


\section{THE PSYCHIC LIFE OF INSECTS}

Of this aptitude the "Souvenirs Entomologiques" show us many examples.

Many predatory Hymenoptera capture and paralyze for their young different kinds of prey, choosing, however, species of the same group. With certain forms this taste is extremely localized, and this is notably observed with the wasps of the genus Sphex, notably with our old acquaintance the yellow-winged sphex. This species captures only crickets, and would it be capable of changing its habit in case of emergency and taking prey of another kind? "To prove such facts," says Fabre, "would be of prime importance, for it would teach us whether the inspirations of instinct are absolutely immovable or vary within certain limits." But the indefatigable biologist of Serignan has had the "good fortune to note a case of this kind." Upon the banks of the Rhône he saw this sphex "attack, not a cricket, but a common grasshopper." This observation has been doubted by Kohl after an examination of Fabre's figures, and he attributes the observation to another species of wasp,-Sphex maxillosus. I think, however, that Fabre had studied the yellow-winged sphex too often to be deceived in this instance; but if Kohl is really right, it is Sphex maxillosus which can modify its customary habits, because, according to Ferton and Kohl, it is not 


\section{MODIFICATIONS OF HABITS}

accustomed to hunt crickets, and Picard has often seen it attack victims of this kind.

We have known for centuries that the sacred scarab makes little balls of the excrement of the horse or of the mule and that it rolls these little balls to a hole where it buries itself with them. But what we did not know, and what Fabre himself did not know for a long time, is the relation of this practice to the conservation of the species. This relation is, in fact, indirect. The excrement of the little ball serves exclusively for the nourishment of the female; but where is the egg? And what will nourish the larva when it is born? After a long" career of biological research of the most careful kind, Fabre solved this problem. For its progeny the beetle chooses sheep dung, finer and more oily than that of the horse, and makes a round ball of it. Then it makes a little hole in this ball and places there its large, ovoid egg, resembling a bead of amber, and covers the hole carefuly, modeling the ball into the shape of a pear and transforming its narrow end into an egg chamber. Upon the stony plateaus where this insect almost always works it is very difficult to dig a hole and make a comfortable nest. Therefore the round ball is made on the surface and rolled to the spot where the beetle is going to bury itself with it to watch over the hatching of the young. 


\section{THE PSYCHIC LIFE OF INSECTS}

In the cages where Fabre raised the insect in soil which he brought in, and when, very rarely, the free beetle found a soft soil, the method was quite different. The beetle dug its hole, gathered its sheep dung, and then enclosed itself in order to prepare the little ball into its pear-shaped form. Thus the ball-roller modified its instinctive habit under fortuitous conditions when it found itself near soft earth in which it could make its nest rapidly. In other words, it discerned the favorable character of the soil and adapted itself to these conditions. ${ }^{1}$

Observations of Ferton. Of all the biologists who have devoted themselves to the habits of insects, Ferton is surely one of the most precise. Sagacious and penetrating, he submits his observed facts to a very severe analysis and reports them in conservative terms. $\mathrm{He}$ is a sure and perspicacious guide. "After more than a quarter of a century of observations on Hymenoptera," he writes in his most recent work, "I have only very rarely seen acts of intellect, and yet all did not act with only a modification of instinct." One would think that he agreed with Fabre, but the latter believed in the immobility of instincts,

1 Monsieur Labitte has shown me that Ateuchus does not always do this, but this is no contradiction of Fabre. 
while Ferton concludes from his studies that they are modified slowly, very slowly, "this variability coming to be of the same kind as the structure of the insect."

It is in the solitary bees of the genus Osmia that he noted the most numerous and the greatest variations in habit. It is known that the group including Osmia papaveris have the habit of lining their cells with the petals of certain flowers, each species choosing for this purpose a preferred plant. Osmia lanosa and $O$. papaveris confine themselves to the red petals of the corn poppy, so far as possible. In Corsica, Ferton has seen the first-named species take the yellow petals of Glaucium luteum and of Sisymbrium officinale and the blue petals of Matthiola tricuspidata and the white corolla of Convolvulus sepium when a drought deprived it of the poppy; and at Montlouis, where this latter flower is lacking, he has noted that Osmia papaveris uses the musky mallow. Ferton adds, after Buttel-Reepen, that in Pomerania the same species gathers the petals of the corn-flower. He notes in another place that Osmia perezi substitutes mallow for the morning-glory, and that Osmia cristata substitutes the tree mallow for the common mallow.

Raphiglossa zethoides of the family Eumenida 


\section{THE PSYCHIC LIFE OF INSECTS}

is a solitary wasp which nests in broken twigs, in which it encloses paralyzed beetle larvæ with an earthy or sandy cement. Ferton says :

At La Calle one of these wasps collected grains of sand and carried them to a vertical stem of Arundo [a reed], a clump of which grew a few steps away. The stem chosen was broken about fifty centimeters above the ground, and the break, being very near the first node, left above it a canal only one centimeter long. So the wasp pierced a hole in the reed four centimeters below the node to effect her entry into the stem between the nodes, and in there she made her nest.

The free end of a broken stem is the spot usually chosen for the nest by Hymenoptera which work in this way, but the free end in this instance being too short, the wasp departed from its usual custom and chose the cavity of the following internode and pierced it from the outside.

Pérez and the Osmias. The lamented Professor Pérez was the teacher of Ferton. He had the same ideas and his biological observations were of the same thorough character. His observations on the variability of the instincts of the Osmias are of the greatest interest. He shows ${ }^{1}$ that Osmia rufa nests in any convenient cavity. It likes to repair old nests, but cut reeds, holes in

1 J. Pérez, Leș Abeilles, 1889. 
boards, empty snail-shells, keyholes, appear to it to be excellent places to make its masonry cells. Fabre induced the Osmias to work in glass tubes. Pérez says :

They utilize the place to best advantage; the bee knows whether to arrange her cells in line in order to give them an exact cylindrical form when a narrow tube is used, or to place them without order when there is plenty of space. This total absence of exclusivism, this flexibility of architectural genius, surely does not conform to the theory of an unchangeable and blind instinct. To depart from its customary habit so easily, or, more, not to have any habit and to adapt itself without effort to the thousand conditions which chance offers, it is surely necessary to have a modicum of intelligence.

The Philanthus wasps. In investigations of this kind it is necessary to know how to concentrate one's effort and to follow the actions of a species in their slightest details. No discipline is less harsh, for the life of these animals is full of captivating incidents and certain of these incidents have a scientific bearing. I followed in 1900, at Luc-sur-Mer, the goings and comings of a predatory wasp, Philanthus triangulum, which hunts bees and stores them in cells at the bottom of its long burrow. At that time the sand-dunes of Luc extended up the breaches in the cliffs, and 


\section{THE PSYCHIC LIFE OF INSECTS}

the Philanthus wasps nested there by the thousands, to the great injury of the bee-keepers of the neighborhood. Every Philanthus which returned to the nest carrying a bee, first opened its closed burrow, then penetrated it to place its prey, then some minutes later returned to the orifice to scratch the sand together and close the burrow again. This cleaning up done, the insect rests for a longer or shorter time in the interior of its home, after which it reappears at the entrance, which it opens and where it shows its yellow face before taking flight. In every case, before starting out on another hunt, it comes out of the burrow and completely closes the orifice with sand, which it moves about with its hind legs. This is always done by the Philanthi of the sand-dunes, but on the other hand some of the Philanthus wasps nest in the vertical walls of the breach, and these never close the holes. It is not incapacity which causes them to neglect this work, for they know just as well as the others how to close their burrows every evening, or even during the day when a robber wasp tries to get in. It is necessary to attribute the striking differences which exist between the Philanthi of the dunes and their brothers of the breach to the difference in the places of nesting. The soil of the one being argillaceous and compact, the insect in penetrating the 


\section{MODIFICATIONS OF HABITS}

burrow with its large victims does not injure the walls of its home like the Philanthus of the sand, and therefore has no need of repairing the walls, nor the door, in the way that the other does. On the other hand, the walls of the breach being vertical, the Philanthus would not be able without great difficulty to close its gallery at the moment of leaving, and it abstains from this task which is always performed with great punctuality by its neighbors of the dune. From all of this evidence, our bee-hunter can modify its customary habits and adapt itself to the conditions of the place where it lives.

The urn-making Ammophila. In the course of the long and very able studies which they devoted to the biological investigations of the solitary wasps, George and Elizabeth Peckham ${ }^{1}$ have shown numerous individual variations in the habits of these insects. I will content myself with recalling one of the most striking. Ammophila urnaria examines its nest carefully before provisioning it, and closes it each time that it carries a caterpillar to it. This closing is rapidly done, but after the last journey, when all of the victims have been put into place, the wasp closes its nest with much more care, each individual working ac-

$1 \mathrm{G}$. W. and Elizabeth Peckham, Instincts and Habits of the Solitary Wasps, 1898. (Wisconsin Geol. \& Nat. Hist. Surv. Bul. 2, sci. ser. 1.) 


\section{THE PSYCHIC LIFE OF INSECTS}

cording to his whim and the character of the place. This one contents itself with closing the orifice with a little sand which it rapidly collects, doing the whole job in five minutes; another spends more than an hour in the work, carefully selecting its sand, which it mixes with fragments of leaves, covering the nest with a fine layer which it spreads out equally over the surface. These authors say:

When at last the filling was level with the ground, she brought a quantity of fine grains of dirt to the spot and, picking up a small pebble in her mandibles, used it as a hammer, pounding them down with rapid strokes, thus making this spot as hard and firm as the surrounding surface. Before we could recover from our astonishment at this performance she had dropped her stone and was bringing more earth. We then threw ourselves down on the ground, that not a motion might be lost, and in a moment we saw her pick up the pebble and again pound the earth into place with it, hammering now here and now there until all was level. Once more the whole process was repeated, and then the little creature, all unconscious of the commotion that she had aroused in our minds ... and intent only on doing her work and doing it well, gave one final comprehensive glance around, and flew away.

To smooth the earth which closes the nest is an instinctive habit of the species, but to employ in 


\section{MODIFICATIONS OF HABITS}

this operation a pebble which serves as a tool is no longer instinct; it is a reasoning act, of which we find very few examples among animals. The Peckhams are exact and minute observers, confining themselves to facts, and quite opposed to anthropocentrism, which they ardently attack in their work. One can imagine the emotion which seized them when they found themselves in the presence of such a surprising case of individual variation. What adds to the interest of their observation is that it is not an isolated one. Several years before, Dr. S. W. Williston of Kansas had observed a variation of habit identical with this, with another species of Ammophila, namely $A m$ mophila yarrowi. Dr. Williston's observation was published in 1892 in "Entomological News," and the Peckhams rightfully believed it their duty to republish it in their book, the latter observation also relating to a single individual. 


\section{CHAPTER VIII}

\section{EVOLUTION OF INSTINCTS}

Modification of instincts by the inheritance of acquired habits. From the facts which we have just recited we may conclude that insects are individually capable of modifying their habits, and the experiments cited in the preceding chapter prove that they can acquire new ones. This is what Bethe demands, and since the German author calls himself "a man of good intent, open to proof," I suppose that he will cease to see in insects simply reflex machines.

Observation has not established that in a state of nature, without the help of man, insects are capable of acquiring new habits, but we cannot doubt that this is the case. We have seen that certain females of Sphex flavipennis know how to overcome the artifice which consists in taking away their prey while they are making a visit to the burrow. After this surprise has been repeated two or three times they omit the visit and immediately store away their captures. But the 
wind may play the same part as the experimenter, and then the insect responds with a change of habit. In the beginning the new habit will be transitory, but, repeated at intervals, it may become definitive. It would be very interesting to know if the two Ammophilas observed by the Peckhams and by Williston would use a stone to perfect another burrow; but these wasps rebel at captivity, and the experiment was not tried,without doubt, because it was very difficult.

We know that new habits change very quickly to automatism with the articulates. If they pass on to progeny, if they are born in the young of the parents which have acquired them, they will have changed in character and will have become instincts. But can acquired characters become truly hereditary? That is the question which we must consider.

Arnold Pictet, an eminent Swiss biologist, in 1905 raised caterpillars of different species, offering them plants which differed as much as possible from those which they naturally eat. The caterpillars of the diurnal butterflies almost all rebelled at these attempts, but those of several night-flying moths took the new food, though not without some difficulty. With these last "the acquaintance with a new food was often transmitted by heredity, and individuals whose parents had 


\section{THE PSYCHIC LIFE OF INSECTS}

become habituated to a strange diet ate the same leaves, after hatching, with much greater facility." Of all the rearings carried on by Pictet, the most significant were with the caterpillars of Ocneria dispar, popularly known in our country under the name of the zigzag and in America under that of the gipsy moth. The caterpillars of this insect have a bad reputation because they despoil trees of their foliage, especially oaks and birches. Pictet offered them the leaves of the walnut, which have a very special flavor, and they naturally disdained them. It was with the greatest difficulty that he brought the young caterpillars to feed upon them. When older they always were able to accustom themselves to them, but the moths which issued from this rearing were less highly colored and smaller, and the generation to which they gave birth and which was given the same food could not be raised to the egg-laying point. To render this second generation fertile Pictet nourished the caterpillars with oak leaves at first, after which the rearing was carried on with walnut leaves. In a rearing conducted to the fourth generation (first walnut, second oak, third walnut, fourth walnut) they had become so accustomed to the new diet that the moths had resumed the form and the size of the insects which had normal food. The experiment was not car- 
ried further, but it is probable that the caterpillars produced by the fourth generation would have remained faithful to their new diet.

An experiment by Paul Marchal (1908) led to definite results of even more importance. This distinguished biologist induced a scale insect of the peach (Lacanium corni) to live on the honeylocust, or false acacia. This was not done without trouble, and only certain larvæ issuing from the laying of the Lecianium were able to adapt themselves to the new food; but with these there was complete success, beyond all expectation. Becoming adult the following year, the scale insects reproduced upon the locust, and their young had so entirely accepted this host plant that it was impossible to rear to sexual maturity those which he transplanted to the original host (peach). Very quickly the new habit became hereditary and hereditary to the point where the insect could not return to its primitive habit.

In the two preceding examples there is the inheritance of becoming accustomed to a new diet. Here are others in which heredity takes a new turn. The larvæ of the willow chrysomelid (Phratora vitellina) feed normally on the leaves of a willow (Salix fragitis) which has leaves whose lower surface is smooth. They attach themselves to this lower surface, attacking the 


\section{THE PSYCHIC LIFE OF INSECTS}

epidermis to reach the parenchyma, and skeletonize the leaves. Some young larvæ were established by Schroeder (1903) upon a willow with downy leaves,-Salix viminalis. They adapted themselves without difficulty, cutting and pushing aside with their heads the long pilose clothing of the lower face of the leaves and forming with it and with the skin of this surface a sort of blanket which covered them completely. These larvæ devoured the tissue of the leaves, and one of them made a mine three centimeters long. The adults coming from these larvæ deposited 127 layings on viminalis and 219 on fragilis. In the course of successive generations, all raised on viminalis, the number of layings placed upon this species increased progressively while those laid on fragilis diminished. In the fourth generation Schroeder obtained fifteen layings all upon viminalis, and the larvæ coming from these layings adopted the mining type of life. It is evident, adds the author, that similar modifications are produced in nature, especially when the normal food plant is lacking.

Still more astonishing is the hereditary transformation of habits obtained recently by Arnold Pictet in 1911 with Lasiocampa quercus. The caterpillars of this moth attack deciduous trees and bushes, notably the oak, and eat the leaves at 


\section{EVOLUTION OF INSTINCTS}

their edges. When placed upon pine they try to feed, but their mandibles cannot open widely enough. Many die, but certain individuals succeed in existing by attacking the ends of the pine needles, where they dig into the parenchyma. In the second generation the caterpillars had become adapted to the new diet, but they were adapted beyond return, for they perished when placed upon a tree with flat leaves, or they attacked the leaves at the tip and hollowed out the interior as the caterpillars of the preceding generation had learned to do in the pine needles.

As Darwin has noted, a striking example of the heredity of acquired habits is shown by the mulberry silkworm. It is not to be doubted that this insect formerly lived in a wild state and that it could then live under conditions which would be fatal to it now. What has happened to these insects under the influence of long domestication? Pérez says :

Life on the trees has become impossible, at least in our climate; they cannot resist the wind, which would blow them to the ground; they cannot sustain the rays of the sun, which the wild caterpillars could avoid by going around to the lower face of the leaves. If high temperature and free air give silkworms a remarkable appetite, one notices on the other hand that whether they are sleeping or are in the state of repose preceding the 


\section{THE PSYCHIC LIFE OF INSECTS}

molt, they are placed in the least favorable circumstances upon the upper surface of the leaves, exposed to the rain. A long domestication has evidently made them lose a host of instinctive habits whose loss [before domestication] would have led infallibly to their total destruction even before the end of the caterpillar stage.

The Lamarckian law of heredity. The experiments which we have just described are almost all very recent, and they will have to be added to somewhat, but they establish the fact that insects acquire new habits very quickly and that these acquired habits become hereditary and that they take the form of instincts. "For a long time," wrote Lamarck," "we have had in this respect a feeling of what is the case, since it has come to be a proverb that Habits become second nature."

I do not believe, as a matter of fact, that we can literally apply to these phenomena the law of heredity of acquired characters according to the formula of the illustrious zoölogist.

All that nature has made individuals or their race acquire or lose by the influence of circumstances has been long in achievement; for example, by the influence of the predominant employment of such an organ or by the constant lack of use of such a part. This is passed on by a generation to new individuals provided these acquired changes are common to the two sexes or to those which have produced these new individuals.

1 Lamarck, Philosophie zoologique, 1809. 
This law appears to me to lend itself to two objections, the one relating to habits and the other a very general character.

The first is of slight importance, since to cause its disappearance it suffices to modify very slightly the Lamarck text. As to habits at least, the hereditary transmission of acquired variations does not necessitate always a very long "influence of circumstances" upon the race. This action has been exercised, no doubt, for a long time with the silkworm, but in the experiments of Schroeder and Pictet the inheritance was acquired at the end of a very few generations, and in that of Marchal on the scale insects it was complete with the second generation.

The second objection appears to me to be much more serious, and that is why I have italicized the clause. If it is true that one of the necessary conditions of heredity is the coëxistence of the same acquired character in the two procreators, how is it possible to explain with the Lamarckian theory the acquisition of morphological characters which distinguish the male from the female animal? and, to confine ourselves to the subject which we are discussing, how can the evolution of instincts in most insects be explained? With the latter, as a matter of fact, it is the female almost always which occupies herself with breeding, 


\section{THE PSYCHIC LIFE OF INSECTS}

which hunts, collects, makes nests ; and it is consequently with the individuals of this sex that we observe the most interesting instinctive habits. With a good number of dung-beetles and certain other forms where both sexes work conjointly in the same labor, the male lives only for himself and often even perishes soon after coupling; and his instincts are infinitely less complex and quite different, for the most part, from those of the female. If, then, we accept the principle established by Lamarck, we must renounce the Lamarckian explanation of the very curious instincts which we observe with the sacred dung-beetle and with the solitary wasps, just as we cannot comprehend the adaptive modification of the organs which the females of these insects show. If it is true that, in order to be transmissible by heredity, the acquired changes must be common to both sexes, the Lamarckian law completely destroys the Lamarckian evolutionary theory. In his interesting work upon the "Crisis of Evolution," LeDantec insists at length upon this Lamarckian law and stresses the importance of his final restriction, but his opinion was certainly not shared by the lamented Giard, for, in his "General Principles of Biology,"' published in 1876, and his "Evolutionary Controversies," appearing in 1904, the eminent zoölogist modifies the law of Lamarck and 


\section{EVOLUTION OF INSTINCTS}

does not mention the restriction which I have italicized above. For the rest, if acquired characters are hereditary they should be governed by the Mendelian law, and this law specifically shows that two procreators marked with different characters bear in the first generation individuals with mixed characters (heterozygotes), in the second a certain number of similar individuals with others which are quite pure (homozygotes), some of the male character and others of the female character.

In fact, there has not been tried, down to the present time, any experiment to settle the question whether or not, with species having very different males and females, acquired characters are hereditary, and I have remarked how desirable it is that experiments should be made in this way with such forms as Ferton's pompilids, the Sphex flavipennis of Fabre, and the Ammophila urnaria of the Peckhams; but aside from what I have just said I believe that it will be necessary in the meantime to follow the example of Giard and remove the final restriction from the Lamarckian law. We will admit that acquired characters are hereditary, not only in species where the two sexes have the same habit, as is established by the experiments of Marchal, Schroeder, and Pictet, but also with those in which the two sexes are from 


\section{THE PSYCHIC LIFE OF INSECTS}

this point of view profoundly different; in fact, we need only conform to the law of Mendel.

It is clear, moreover, that natural selection in the course of generations causes all the individuals to disappear which do not present the acquired character in a pure state, since this latter is really advantageous to the race. For example, the employment of a tool is advantageous in making the nest: the females of Ammophila urnaria which have acquired this habit, in pairing with males in whom naturally the habit cannot exist, will give female individuals of mixed characters, others with pure characters, some of the male type and others of the female type, in everything concerning habits.

Lamarck seems to have foreseen the objection just formulated, for in the commentary on his law he expressed himself in the following way: "In reproductive reunions, the mixtures among the individuals which have different qualities or forms are necessarily opposed to the constant propagation of these qualities and these forms." I have italicized the word constant because it shows that Lamarck did not ignore that in the progeny of two individuals with dissimilar characters certain individuals show the characters of the male and certain others of the female. But the illustrious 
zoölogist had not foreseen natural selection, the efficacious rôle of which was put in evidence by Darwin, and therefore he could arrive only at the conclusion that the characters advantageous to one of the sexes would finish by belonging to all of the descendants in the course of successive generations. Indeed, Lamarck expressed a fact of experience when he affirmed that acquired characters, particularly of one of the sexes, are not fixed with all the descendants of a caterpillar; but it must be added to it that these characters, when they are advantageous, end in the long run by becoming constant, thanks to the law of natural selection. It was this, without doubt, which warned Giard when he discarded from the Lamarckian law its final restriction.

How can we explain the hereditary transmission of acquired characters? In regard to the caterpillars raised by Pictet, Bohn (1913) observed that a change of the nourishment often results in a diminution of the activity of the organism. He says:

If it is a caterpillar, the adult which comes from it is smaller and paler and less energetic; it has a lessened vitality, a lessened muscular energy,- that is to say, a lessened chemical activity. It is precisely this which it transmits to the next generation. The heredity of the new habit would be only an illusion. What it inherits 


\section{THE PSYCHIC LIFE OF INSECTS}

would be simply an enfeebling of the chemical activity of the organism, and there is nothing mysterious about that. One inherits especially predispositions.

It is well also, as a matter of fact, that one should understand in these days the theory of Lamarck; but in the example cited by Bohn the heredity of the new habit is not an "illusion," since the chemical diathesis transmitted by heredity is the consequence of this habit which it will provoke anew in its descendants.

Is it necessary to believe with the same author that modifications of the chemical condition can also be produced by "causes foreign to the functioning," that is to say, independent of the Lamarckian explanation? That is not our opinion. For Lamarck the influence of the environment controls the predominant use or lack of use "of such organ" or "of such part," and by organ or part we should understand not only the external mechanisms of the animal but the tissues or groups of tissues which work and secrete in the interior of the body. We believe with Bohn that the atrophy of the wings of many insects is not the result of the non-use of these organs, and we do not ignore the obvious fact that the extraordinary ornaments of certain articulates (the mandibles of the stagbeetles, the frontal or thoracic horns of some scarabs, the spines of the Gasteracanth spiders) 
are not the result of predominant usage. These characters come, without doubt, from chemical modifications and, without doubt also, from internal functionings which depend upon environment and circumstances.

Modifications of instincts by mutations. The chemical modifications of the organism are due principally to the exercise of the muscles, of the digestive tube, of the nervous system,-in a word, the different tissues which one qualifies as somatic in distinction from the germinative cells which are specially intended for use in reproduction of the individual. In order that the acquired modifications should pass to the descendants it is necessary, evidently, that they should have affected the reproductive cells, but this action of the soma on the germ is absolutely denied by Weismann ${ }^{1}$ and by the neo-Darwinians who constitute his school. For these biologists "all changes come from primary modifications of the germ," modifications which bear upon "the molecular arrangement" of the germs or upon "the chemical composition of the molecules" or "upon both at the same time. ... Variations in the molecular structure of the germinative cells are always present in each species and may be increased and fixed if their

1 A. Weismann, Essays on Heredity and Natural Selection, 1892. Translated by $\mathrm{H}$. de Varigny. 


\section{THE PSYCHIC LIFE OF INSECTS}

results are useful." Thus Weismann rejects the inheritance of acquired characters, accepted by Darwin and by Lamarck, and of the Darwinian theory accepts only natural selection, limiting the conception which belongs to it to changes occurring in the germinative cells.

The school of Weismann contests the observations and experiments which tend to establish the heredity of acquired characters (for example, the cases observed by Brown-Séquard following the lesions occurring with guinea-pigs are due perhaps to an infection) or explains them by primitive modification of the germ cells. They explain also notably the inheritance of habits, for, according to Weismann, it is "totally erroneous" to believe "that the origin and the variations of instincts depend upon the usage of certain groups of muscles and of nerves in the course of the life of the individual."' 1 However, the celebrated biologist avows that his theory of the primitive modifications of the germ appears insufficient to account for "changes which present themselves as direct consequences of a change in external conditions." This is a considerable gap, because the influences of the surroundings have been able

1 In his beautiful work on The Genesis of Species, Monsieur Cuénot is less positive: "Many authors have thought, what I can hardly believe, that the instincts of insects are intelligent fixed and inherited characters." 
to play the essential rôle in the evolution of animals, and these primary factors of evolution, as Giard says, are just the agents pointed out by Lamarck. Do we not have, then, the influence of the soma on the germ? Weismann recognizes that a well-nourished plant will give larger seeds, richer in nutriment, and that these will increase more and more if the plant follows the same regimen during the generations. "But," he says, "this will not in any way be an example of the hereditary transmission of acquired characters; it would be only the direct influence of the better food, during growth, on the germinative cells." The distinction is subtle, for one cannot see how a better food can act upon the germs without the help of the somatic cells ; there is no other way of accomplishing this. If this be so, the exchanges between the soma and the germ are no longer, as Weismann characterizes them, a simple transformation. of "the molecules of a foreign body" into the molecules of the germ cells. The first transform themselves, without doubt, but they have also transformed the second.

In a penetrating study, published in his "Transformist Controversies," Giard has victoriously combated the neo-Darwinian theory and has cited numerous examples which appear to establish beyond doubt the heredity of acquired characters. 


\section{THE PSYCHIC LIFE OF INSECTS}

Undoubtedly the Weismann school will not be at all embarrassed for a reply that these cases involved direct action on the germ cells and not changes in these cells by the action of the cells of the soma; and surely they will give the same explanation to the hereditary phenomena which we have cited, since they absolutely deny the inheritance of acquired characters. Let us confine ourselves to the facts, that animals-insects in the present consideration-have modified their actual habits and that they have transmitted these changed habits to their descendants. These facts are incontestable, while one can justly dispute the contention that they are the direct and specific product formerly acquired "by selection, and that they have their basis, not in any change in the individual life, but in variations in the germ,"variations which cannot be verified, since they originated so far back.

If it is true that an animal can modify its habits and acquire new ones, it is no less certain that these habits can become hereditary only when they have provoked permanent modifications in the germ cells. The same observation may be applied to structural changes, and it was easy for Weismann to establish in opposition to Detmer that the modifications undergone by the dorso-ventral shoots of Thuja occidentalis offer no proof of the 
heredity of acquired characters, since they are entirely changed when one turns the shoots the other way. The individual can acquire new habits, but all these new habits are not transmitted to posterity, because they manifest themselves in the form of somatic reactions and because somatic reactions do not necessarily modify the germinative cells.

On the other hand, it is certain that there are variations which appear suddenly in the course of species evolution which are fixed by heredity, and which natural selection has maintained when they have proved to be advantageous. A propitious field for these mutations is offered by the social insects,- that is to say by the termites, the ants, the wasps, and the bees. We know that these social insects form families, sometimes extraordinarily numerous, in which the fertile individuals confine themselves to reproductive functions, while the work of the society is accomplished by sterile neuters, which at times, however, give birth to males. It is with the neuter individuals that we observe the highest instincts and the most perfect industry, and, as these individuals are generally incapable of reproduction and consequently not able to transmit the new qualities which they have acquired by experience, it must be admitted that the evolution of social instincts is produced by muta- 


\section{THE PSYCHIC LIFE OF INSECTS}

tion,- that is to say, by modifications which the germinative cells of the females have undergone and which have reacted suddenly upon a progeny subject to natural selection. Darwin has cited before any other this topical example to which many biologists have returned. Aside from the fact that in certain cases the neuters can transmit their characters through the males which they produce, one can argue against this that the females capable of establishing a colony are reduced to their own labor and fulfil all the social functions until the time when the neuters are sufficiently numerous, and that during this period they can acquire new habits transmissible to their progeny. The objection is not without value, and probably certain kinds of instincts may be involved in this way, but it must be observed that the females almost always are confined to various simple occupations during the short period in which they play the part of colony-founders; and that it is only afterward, when the neuters have appeared, that the colony functions in its full complexity. It is, then, with the neuters that the principal changes of habit must be noted, and these changes, since the neuters are sterile, cannot be anything but mutations. These last come from the differences which always exist between the male cells and the female cells, from the combination of these two 


\section{EVOLUTION OF INSTINCTS}

elements; also, without doubt, from a slow, direct or indirect, action of external agencies upon the egg and upon the germinative cells of the parents.

To give an example of very important mutation, and to show how the curious forms which are often observed in the neuters of certain social insects come about, we may consider for a moment the phenomena of abrupt variations which I discovered (1905) with the fresh-water crustaceans of the family 'Atyida. The two higher types of this family are Ortmannia and Atya. In the genus Ortmannia (Figure 5) the claws of the first two pairs of legs terminate in a bundle of moderately long hairs which show upon one of their sides an armature of comb-like hairs. In other respects they are

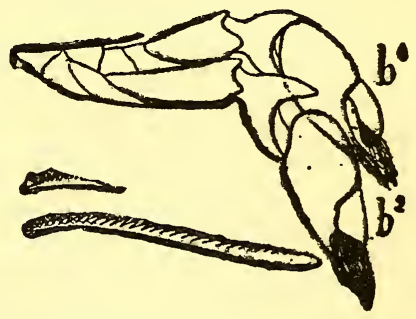

Fig. 5. - The two front legs $b 1, b^{2}$, of Ortmannia allu. audi with one of the hairs and the enlarged extremity of a hair from the finger. Ortmannian form. constructed on the same type as the craw-fish,that is to say, with a palm-like portion at the end of which are fingers. In the genus Atya (Figure 6), on the contrary, the claws are split to the base, reduced to two fingers almost identical and carrying on their distal end a bundle of verý 


\section{THE PSYCHIC LIFE OF INSECTS}

long flexible hairs with fine barbules arranged in no especial order. There is, therefore, a large hiatus between the two types. But it is not doubtful that Atya was derived by mutation from Ortmannia. If the American species of the latter genus appear to-day completely fixed, it is quite otherwise with the two Indo-Pacific species, Ortmannia alluaudi and Ortmannia henshawi. In both species, as a matter of fact, a single female gives birth to individuals of both types. The in-

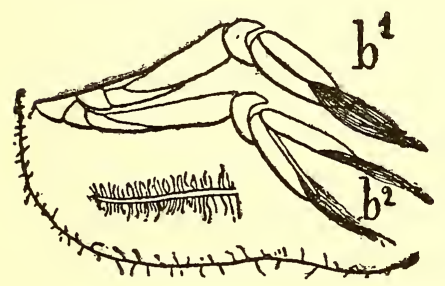

Fig. 6. -The two front right legs of Atya serrata with one of the hairs and a greatly enlarged extremity of a hair from the finger. Atyaian form.

dividuals like Atya issuing from Ortmannia alluaudi were described by Spence Bate under the name Atya serrata, and Randall gave the name of Atya bisulcata to those from Ortmannia henshawi. It was after a comparatively close study that I was led to believe that Atya serrata and A. bisulcata were the products of mutations, and Bordage (1909) confirmed this conclusion by rearing in an aquarium ovigerous females of Ortmannia alluaudi. I can only repeat to-day what I wrote formerly about this discovery: "Can we not explain in this way the mysterious presence 


\section{EVOLUTION OF INSTINCTS}

of polymorphic individuals in the colonies of ants and termites And the point of departure of polymorphism of these forms, may it not be a mutation similar to that of Atya?" In citing this example I am quite in the domain of the present work, since variations in structure and variations in habits are frequently correlated, although not always. We have not yet studied the habits of the Atyida, but it is doubtful that, with their claws so profoundly different, the Ortmannias take their nourishment in the same manner as the Atyas.

Atavism. From the preceding facts we can concliude, contrary to the disciples of Weismann or the neo-Darwinians, that instincts may be modified by the hereditary transmission of slowly acquired habits, and, contrary to the pure neoLamarckians, that new instincts may appear suddenly by mutation. Darwin arrived at the same conclusions. "It would be one of the gravest errors," he wrote in his treatise on "The Origin of Species," "to believe that most instincts have been acquired by habit in a generation and transmitted by heredity to following generations." And he added, "I believe that the effects of habit are of a quite secondary importance if we compare them to natural selection upon what we can call accidental variations of instinct,- that is to say, variations produced by the same unknown 


\section{THE PSYCHIC LIFE OF INSECTS}

causes which bring about slight variations in the structure of the body." These accidental variations are nothing but mutations. Darwin believed them always very feeble, which seems to be contradicted in the case of Ortmannia, and he thinks that they are accentuated by the action of natural selection. He believes, also, that they play a greater part in the evolution of instincts than the inheritance of habits, but that is a point which it is impossible to confirm in our present state of knowledge.

However it may be, the two schools agree in attributing the evolution of instincts to heredity,that is, to modifications in the intimate nature of the germ cell, brought about by different influences, which can maintain themselves as long as other influences do not modify them in turn.

These intimate modifications of the germinative cells do not always manifest themselves in the structure or the instincts of the descendants. Some of them remain latent for a longer or shorter time; then suddenly their presence is noted with certain individuals having the ancestral characters. This is the phenomenon to which the name atavism has been given. It is frequently noted with man, where it is seen especially when the children resemble their parents much less than their direct or collateral ancestors. 
The experiments of Schroeder (1908) upon the larvæ of a small moth, Gracillaria stigmatella, furnish a beautiful example of atavism and of rapidity in the acquiring of habits. These caterpillars have the habit of enclosing themselves in a case which they make from the end of the pointed leaves of a species of willow (Salix alba, variety vitellina) and line with silken threads. They do the same on the black poplar, the leaves of which are drawn out into a point. But their instinct does not lack flexibility. Schroeder observed that, taken out of the case, which has used up much silk, they can make another, or simply roll up the edge of a leaf or even draw together by threads two or three contiguous leaves, and he notes that in doing this sort of thing they show instincts which are found with other Microlepidoptera whose work is more primitive. Analogous variations are again observed, although of a greater intensity, when one places a caterpillar with leaves of which it is impossible to make a typical case. Thus with the rather obtuse leaves of Salix aurita there is a simple fold of the edge just as with the leaves of Salix viminalis when the tips have been cut off. After placing ninetyfour caterpillars on such leaves Schroeder found that eighty-four formed a shelter by folding the edges, the others trying with varying success to 


\section{THE PSYCHIC LIFE OF INSECTS}

roll the cut ends of the leaves into cones. The second generation, to the number of forty-three, all appeared to have acquired the instinct of folding the edges of the leaves. But nineteen caterpillars of the third generation having been placed upon normal leaves, fifteen of them made cones and four continued to fold the leaf edges. Schroeder considered this a double example of atavism: the first fifteen had undoubtedly gone back to the instinct of their grandparents, but the four others had shown rejuvenated primitive habits of ancestors much farther back. Let us say in passing, with Schroeder, that it is very difficult to explain these facts as variations in the germ cells, that there is a reciprocity in the relations of the germ plasm to the soma, and that, according to circumstances, the variations of both can be hereditarily efficacious.

Attavistic manifestations show the variability of instincts and the hereditary power as to the variations of instincts, but, from the fact that they revive ancient habits often acquired a long time past, they cannot be confused with actual variations. Wheeler (1905) has reviewed many phenomena which he considers related to atavism, notably the faculty which the domestic honey-bee has of sometimes nesting in the open air, and the Polistes of temperate regions of storing honey 


\section{EVOLUTION OF INSTINCTS}

like the wasps of the same genus which live in the tropics. In these two cases atavism does not seem doubtful, but examples may be cited where the embarrassment is greater. Ammophila hirsuta, variety mervensis, is a predatory wasp which chooses for its victims cutworms of the genus Argotis and which has an especial agility in relation to the quick movements and struggles of its prey. As Ferton has noted, after Fabre, this wasp has a firmly fixed instinct. But Ferton has seen the same species capture a large, aboveground caterpillar, Cucullia chamomilloe, and in another case the hairy caterpillar of Epinephele jurtina which lives on grasses, and we know very well that the Ammophilas avoid hairy caterpillars. Ferton says :

In these two cases, has the Ammophila, not being able to find the cutworm which she is looking for, abandoned her usual hunting-method to develop another? I do not think so, and to admit it would be to give the creature too much intelligence. . . . In my opinion it is atavism which has led my two specimens to paralyze these other caterpillars. The instinct of $A$. hirsuta is not yet sufficiently fixed, and it happens that the female in hunting found herself near a larva which was not her normal prey, but nevertheless stung it and paralyzed it in order to give it to her larvæ, just as her ancestors had done. 


\section{THE PSYCHIC LIFE OF INSECTS}

This explanation is a convenient one, but without any proof, like most of the explanations founded on atavism. It is easy to invoke the past, but you cannot always have a response; or, rather, as Emery has shown (1902), we reply subjectively by means of comparisons which allow us to confound simple homologies with real atavistic phenomena. However this may be, this story of Ammophila hirsuta is of interest because it shows that this wasp is capable of profoundly modifying its predatory habits when necessary.

A retrospective glance. Whether they are the result of acquired characters or come from mutations, the innate and automatic acts which we have just studied are characterized by the fact that they are always supposed to have a psychic origin. This rule applies to mutations with not less force than to the acquired characters, for the sudden appearance of a new habit carries with it some fumbling or groping, soon rectified, and the sudden appearance of a new organ brings fumblings or gropings and analogous rectifications. When an Atya is born from an Ortmannia it is ignorant of the functioning of the claws armed to the base and the long plumy hairs which terminate them, and it is necessary to acquire habits which were not those of her progenitors; and however short 
the apprentice stage may be, it nevertheless demands some gleams of intellect.

It is to acts of this kind that many authors confine the term instinct, usually without considering their psychic origin. Thus defined, instinctive acts, according to Cuénot, differ from tropisms, from differential reactions, and without doubt from rhythms, "in that they are more complicated and dependent to a lesser degree upon external stimuli, being above all determined by internal stimuli." These differences are real, but it will not be difficult to cite acts of this kind as simple and as dependent upon external stimuli as the reactions due to a species memory. And if one considers that these last come from an undeniable psychism, although far back, the barrier totally disappears which separates instinctive acts, thus understood, from phenomena of differential sensibility.

In fact, we believe it is preferable to designate as instincts all the innate and automatic acts of an organism which is sound and whole: the tropisms and the rhythms which are simple reactions of living matter, without apparent trace of choice, - that is to say of psychism-even when they imply, like rhythms, an organic memory; the manifestations adapted to a differential sensibility 


\section{THE PSYCHIC LIFE OF INSECTS}

which presuppose a species memory and consequently a very ancient psychism; finally, the acts which come from an individual or associative memory which are the automatic expressions of a higher grade of psychism. Thus instincts group themselves into different categories and are far from having, all of them, the same origin. That is why we believe it illogical to see in them the manifestations of a faculty which one opposes to intelligence, under the name instinct. This latter term is frequently employed, but it should not be forgotten that it expresses phenomena of a very different kind.

Automatic and innate, like reflexes, instincts are closely related to reflexes, and the sole character which permits us to distinguish them is that they demand the integrity of the organism, while reflexes can be very well produced in portions of organisms immediately after their separation from the body. For a definition, we cannot have true reflexes with beings where the nervous system is not differentiated; and therefore we do not know how to join to reflexes the tropisms of the lower organisms. But it is not so with the articulates, and it may be said that with these animals instincts require the condition of age and the help of the cerebral ganglia, while re- 
flexes are often produced in decapitated or sleeping individuals.

However, even this difference is not absolute, as is shown by hypnotized subjects, and even better by the phenomena of dreams and somnambulism. In the hypnotized subjects there is still a will which commands, that of the hypnotizer; in the somnambulist and in the subject who is dreaming, reflexes govern the activity, either according to chance, which makes one or the other act on the nervous system, or in a well-determined sense which gives the acts accomplished an appearance of reason, as one often observes with sleep-walkers. How, then, can we distinguish instincts from reflexes?

In our opinion, in these extreme cases distinction is not possible, and the articulates give us a manifest proof. There are cases, in fact, where these animals are totally absorbed by the reflex life without any regard to contingencies. Who has not seen groups of ants excite themselves over a twig which they were trying to bend, vainly,because they were all pulling against one another! Certain crabs have the habit of gluing to their backs all sorts of objects, and this habit gives them the advantage of concealing themselves in the places where they live, but they stick on also 


\section{THE PSYCHIC LIFE OF INSECTS}

strikingly noticeable objects foreign to the environment. The spiders of the genus Pardosa attach to their spinnerets the silk cocoon which contains their eggs, and carry it, but they accept with indifference any foreign body of the same form and to this inert object they devote the same care as they give their precious treasure.

We know how, after having paralyzed their victim, certain predatory Hymenoptera grasp it by the neck and squeeze it with the mandibles in order to make it disgorge drops which they absorb. Ordinarily this is done carefully, in order not to kill the paralyzed victim, but it is often also very brutal and causes wounds from which the victim does not recover, so that it is a dead body, and not an inert but living prey, which the wasp puts into her cell to nourish her future larvæ. Marchal has noted an instance of this sort with Cerceris ornata, which hunts for its young the solitary bees of the genus Halictus. Fabre has noted still more suggestive facts. A certain Pelopaus is a paralyzing wasp which stores up in masonry cells the spiders that are necessary for food for its larvæ. Let us take a cell to which the insect has carried its first spider, upon which it has laid an egg. How will the wasp act if you take away this victim? "It acts absurdly," says Fabre. A second victim was brought, which dis- 
appeared also, to be replaced by a third, and so on. The experiment continued for two days. "At the twentieth victim, tired out by these repeated expeditions, the wasp judged that the cell was sufficiently filled, and very conscientiously closed it up containing nothing at all." The same wasp made its nest of several cells attached longitudinally, which it covered afterward with a uniform rough coating. One of these structures, which had just been completed, was entirely removed, leaving only a faint trace on the wall where it had been. On its return, without hesitation the Pelopaus alighted on the place where the nest had been and deposited there its clay pill, and it continued to make the rough coating over the absent nest. "Two days afterward," says Fabre, "I visited the hidden place, and it did not differ in appearance from a completed nest."

The mason bee is not less inept in changing her work while this is under way. If she is engaged in building, one can give her in exchange an entirely completed cell filled with food, but she will keep on building and adding material to the already completed cell. If she is in the act of collecting food, she does not try to finish an incomplete cell which has been given her, but seeks rather a strange cell in the proper condition in which to store her honey. Fabre says: 


\section{THE PSYCHIC LIFE OF INSECTS}

The bee that is building, and to whom I offer a cell already built, full of honey, does not renounce her mortar for that; she is making masonry, and having started on that task, guided by an unconscious impulse, she must continue to make masonry, although her task will be useless, superfluous, contrary to her interests.

If the insect is engaged in provisioning, "she will never decide to abandon the pollen brush for the trowel."'

Studying similar phenomena with a predatory wasp in Réunion, Bordage (1912) supposes that the four successive acts of these insects-construction, provisioning, egg-laying, and the closing of the cell-are reflexes caused by the passage of the egg to different points in the oviduct, each region being the seat of a definite reflex which the insect must obey. This is very possible and perfectly rational, but, however it may be with this theory, one is obliged to admit that in the cases cited our insects have acted as pure automata by a simple play of reflexes which hold them, as is the case with somnambulists.

With their tropisms, their rhythms, the adaptive manifestations of their differential sensibility,-above all, with their power of transforming habits into automatic actions,-the articulates are essentially animals of instinct whose activities consist principally of automatisms, but automa- 
tisms dominated by cerebral power. One can hardly see in them "simple reflex machines," for they know how to bend to circumstances, to acquire new habits, to learn and to retain, to show discernment. They are, one can say, somnambulists whose minds awaken and give proof of intellect when there is need for it. This takes us a long distance from the mechanism of which Bethe has made himself the protagonist.

Two essential peculiarities characterize the activity of insects: on the one hand the presence of multiple appendages which are more or less perfectly adapted; on the other, the power very quickly to transform acts which are intelligent at first into automatic acts. The second is, without doubt, a consequence of the first, for the appendages are tools scarcely fixed in their forms and in their functions, and at any rate this is undeniably the principal factor in the evolution of the articulates. Thanks to it, as a matter of fact, the automatic activity of the animal is able to enrich itself with new elements borrowed from intelligence and therefore adapted to new necessities. A substratum of activity is produced and developed which permits intelligence, as Bergson says, to push out on the wings of instinct. But it does not push out very far or very high, because its impulses are quickly fixed in an automatic form, 


\section{THE PSYCHIC LIFE OF INSECTS}

but each time the instinctive substratum is increased so as to give the animal a larger field of activity. Thus one reaches the higher articulates, where the most complex automatic actions, touched with intelligence, control them, and lead to an end where they seem ruled by reason. And that is why we repeat here what we said at the beginning of the present work: Never are the articulates so far from us as when they appear to resemble us most. 


\title{
CHAPTER IX
}

\begin{abstract}
COMPARATIVE PSYCHOLOGY. HISTORY OF THE POMPILIDS
\end{abstract}

The present is really a continuation of the preceding chapter. If it is true that instincts are modified nowadays by the hereditary adding of new habits, it must be admitted that they were modified in this way formerly during the long periods in which the history of each species was being unfolded. But what has this evolution been? The problem appears unsolvable, for each species has its history, and, in the domain of instincts still more than in that of structure, the past lends itself but little to observation. It is not impossible, however, to arrive at an approximate solution. Each group, as a matter of fact, however big it may be, has followed an evolution of its own, and in each group all the species are not actually in the same stage of this evolution. Some have rested at certain stages of the journey; others have advanced more or less. So by comparing these species, the ones with the others, it is possible approximately to reconstitute the evo- 


\section{THE PSYCHIC LIFE OF INSECTS}

lutionary phenomena which have been produced in a group in the course of its history.

This is what we are going to try to do for the predatory Hymenoptera of the family Pompilida.

The pompilids are hunters of spiders. Active and enterprising, they know how to escape the venomous fangs of their redoubtable adversaries, which they chase and paralyze before carrying them to their place of nesting. This having been done, they drag their victim in, lay an egg on its side, then close the hole and depart forever. "The egg produces a larva which sucks the juices of its victim, devours it, and leaves only its appendages untouched. It encloses itself immediately in a cocoon and transforms there to a nymph. When its evolution is finished, the adult pompilid throws off its nymphal skin, opens the cocoon, and leaves the nest.

Such is, in brief, the history of the pompilids. Some of them do not hunt, and simply lay their egg upon victims paralyzed by other individuals. After the custom of the cuckoo, they make their offspring benefit by the food which an unfortunate congener has collected for its own. These are, in fact, veritable parasites.

The prey captured. On this subject we should first listen to Ferton, who more than any one else has studied the habits of the pompilids. After 
having observed that the size of the victims captured by each species cannot exceed certain limits, sometimes very large, the distinguished observer adds:

It is not only necessary that the pompilid should hunt for a spider which fills certain conditions of size, but it is necessary also that it should have a special kind of life which adapts it to the wasp's method of chase. The pompilid which takes customarily earth-inhabiting spiders will not attack those which build webs . . . and, reciprocally, one which chases spiders living in the free air will neglect those which live under the earth.

Let us give some examples of this. Let us take the above-ground spiders. Evagetes laboriosus hunts exclusively the wandering Lycosas, the jumpers (wolf-spiders), and does not always succeed in following them, because it is short-sighted. The six-spotted Pompilus catches the thomisid spiders which lie in wait among the flowers. The thick-headed Pompilus attacks the epeirid spiders in their orb-webs, and the apical Pompilus, studied by Fabre, knows how to extract the segestrid spider from its silken funnel. The same specialization exists with the earth-inhabiting spiders. The ringed Calicurgus, the banded Pompilus, and the somber Pompilus pursue the burrowing lycosid spiders. The first makes the spi- 


\section{THE PSYCHIC LIFE OF INSECTS}

der issue from its burrow, and Fabre supposes that "in the walls of a narrow burrow the wasp cannot direct its sting with the necessary precision," but, more audacious or more expert, the two other species do not hesitate to attack the victim in the depths of its burrow. Not less brave and still wiser are the pompilids which hunt the Mygales, for the burrow of these spiders is closed with a door and the spider within often grasps this, so that it is necessary to use some ruse to force it. The wandering Pompilus and the yellow-bellied Planiceps, which hunt the species of the genus Memesia, have no other tool than their appendages with which to do this, while to reach the Corsican Mygale the plicate Pompilus has an especial adaptation. "Its flat head, armed with an elongated hood, is," says Ferton, "a powerful lever which gives support to the mandibles when they have succeeded in getting under the edge of the door of the spider."

In order to hunt successfully, the pompilids have been obliged to conform in details to the habits of their adversaries. With certain species studied by Ferton these adaptive habits are of the greatest interest. The acrobatic Pompilus chases a very nimble theridiid spider, namely $L i$ thyphantus corollatus, which joins together tufts 
of grass with silken threads over which it darts away in flight with an acrobatic quickness, but the Pompilus is not less accomplished in this exercise. With rapidity it follows the frail threads, and when, as a stratagem, the spider lets itself fall on the soil, the Pompilus jumps after it. Here is something still better: When the wandering Pompilus chases Nemesia badia in the spring, it paralyzes the creature at the bottom of its hole, which is a simple shaft, but in the autumn it must manœuver a bit, for the shaft is then flanked with a lateral branch in which it can hide, and is fortified with a door. Then the Pompilus, says Ferton, carries away the doors "which cover the two orifices" and seeks to make the spider come out to repair the damage. It sticks its abdomen into one of the holes, but scarcely has it done so when it draws it out quickly and rests on the ground with its eyes turned toward the second orifice, its wings raised and vibrating, ready to dart upon the spider. Then it goes to the second door and does the same thing, and then begins again at the first. At other times it contents itself by giving certain knocks at one of the orifices, stopping and watching the second opening of the nest. Finally the spider jumps quickly out of the hole, and flees with all its agility, but the hunter is quicker still 


\section{THE PSYCHIC LIFE OF INSECTS}

and captures it within a few centimeters, and stings it. The yellow-bellied Planiceps has not yet arrived at this perfection, and enters one of the branches and loses the spider, which escapes by the other. All of the pompilids are not equally crafty, and some, although very few, hunt all kinds of spiders indifferently, and remain in the primitive condition in which, without doubt, all of the members of the family once lived. This is the case, according to Ferton, with Vachal's Pompilus, and in the United States, according to the Peckhams, with Pompilus marginatus.

Treatment of the victims. As soon as captured the victim receives the poisonous sting of the hunter. With the pompilids, as with the other paralyzing Hymenoptera, the employment of the sting, according to Fabre, cannot be accomplished with half-knowledge; it should be perfect from the start, for an incomplete inertia would be dangerous for the egg or the young larva fixed upon the victim, and death following the sting would not be less so. The victim must remain living but inert for as long a period as the larval life.

Among other examples in support of this statement we may cite the observations of Fabre upon a spider-hunter, the buffoon Pompilus (Calicurgus scurra). After many struggles

"the Epeira lies turned over on its back. The Pompilus 
is on top. . . . With its legs it controls the legs of the spider; with its mandibles it holds the cephalo-thorax. ... The dart of the wasp, directed from behind forward, is plunged into the mouth of the spider with minute precautions and with great persistence. Almost instantly the venomous fangs are rendered inert and the formidable prey is defenseless. The abdomen of the wasp then extends its are and the sting is plunged in behind the fourth pair of legs, on the rnedian line near the juncture of the abdomen and the cephalo-thorax. At this point the skin is finer and more penetrable than elsewhere. . . The nervous centers controlling the movement of the legs are situated a little higher than the point of the wound, but the direction of the sting, from behind forward, allows it to reach them. From this last sting the eight legs are at once paralyzed." The spider is from that moment inert. Its lethargy must last six or seven weeks, and then only "comes true death and its accompanying decomposition." Less time than this is necessary for the larva of the pompilid to devour its victim.

Many pompilids employ this method of the Calicurgus, but certain others depart from it, as the observations of Ferton have shown. While the banded Pompilus contents itself with stinging the mouth of its Lycosa, the eight-spotted Pompilus renews the puncture under the thorax of its already inert victim, and when we take from 


\section{THE PSYCHIC LIFE OF INSECTS}

Pompilus pulcher the lycosid which it carries, paralyzed, to its nest, it does not regain possession of its victim without stinging it again. One would say that it has the idea that the work is incomplete and that it is necessary to finish it.

Is it in obedience to a similar fear that certain pompilids nibble off or break off the legs of their paralyzed victims? This removal of the legs has been observed by Ferton; and by the Peckhams with numerous species ( $P$. vagans, $P$. scelestus, etc.), and with these the complete or partial removal of the legs results. This last phenomenon was noticed in 1839 by Colonel Goureau. It is common with Pseudagenia, as Ferton and Rabaud have shown (1909). Ferton noticed it also with Salius bisdecoratus, and the Peckhams with Pompilus fuscipennis and Agenia bombycina. Having observed that the palpi and fangs are always respected, and that the removal of the legs is accomplished at the moment when the prey is going to be put into the burrow, the Peckhams supposed that this habit is for the purpose of rendering easier the placing in the burrow; but I think, with Ferton, that it acts only to render the inertia more complete, for Pompilus vagans lodges its victim in the hole which the latter has dug. Rabaud argues against this interpretation, which presupposes with the Pompilus a rather extraordinary 
degree of intellect, and he brings forward in support the fact that the victim is rendered inert before the mutilation, but he forgets that the inertia produced by the sting is often fugitive. In any case, if the manœuver of the Pompilus has not for its end a perfect inertia, it surely accomplishes this result. Is this result really necessary? Fabre is convinced of it; but observation shows that, aside from the buffoon Calicurgus and some other pompilids, the inertia is more or less fugitive and incomplete. Ferton tells of an epeirid (Meta segmentata) captured by the hyaline Pompilus (Salius hyalinatus) that remained inert several days, then revived little by little, and completely recovered on the twenty-fifth day. A wandering Pompilus had just stung the large Nemesia badia. The same biologist observes:

At the end of some minutes the paralysis ceased, and almost to the end of the feeding of the larva the Nemesia remained living. . . . I have found several half eaten by the Pompilus which were capable of running in the box in which they were enclosed.

In other instances the victims of the same Pompilus have not been completely paralyzed. Of eleven Epeira strix noticed by the Peckhams with Pompilus quinquenotatus, three had been immediately killed, two lived four days, and five others 


\section{THE PSYCHIC LIFE OF INSECTS}

from five to forty days. It is then right to think, contrary to Fabre's opinion, that the inertia of the victim is not a necessary condition to the perfect development of the larvæ of the pompilids, that the females of this group of insects often show a very imperfect knowledge in the art of killing, and that in the course of time they have undergone an evolution in this art.

How does this evolution proceed? The primitive manœuvers, without doubt, were much like those which Ferton observed with a pompilid closely allied to Salius opacus, where the stings "were given by chance in all parts of the body, from the mouth to the extremity of the abdomen." These multiple stings exhausted the reservoir of venom without always paralyzing the victim. The author adds:

One thinks, then, that it is of advantage to a species to acquire more precision in the use of the sting, since the dangers which it runs in the struggle will be diminished in this way. It would not be astonishing if time and natural selection had brought eertain species to the efficiency of Calicurgus scurra.

Between these two extremes, other pompilids show all the intermediary stages, and as to the nibbling off or amputation of the legs, it is necessary to regard this as a return to the ancestral 
method, a return which has as its effect, if not for its object, to bring about a more perfect inertia.

But, since the more or less rapid revival of the spiders does not have an injurious influence on the development of the larvæ of the pompilids, one can understand how certain species have been able to abandon some of these practices. The mining Pompilus ( $P$. effodiens) seems to have arrived at the stage where this practice is on the point of disappearing. In Corsica, Ferton has seen it strike the Nemesias with two thrusts of the sting, like Calicurgus, but in Algeria, where the same species hunts lycosids, the egg is fixed without a sting upon the spider, which remains perfectly active. In the course of his. studies Ferton caught one of these pompilids just as it was coming out of a burrow. He exhumed the lycosid, which carried its side the egg of the wasp, and left it near the entrance of the burrow.

When touched by the wasp, which returned to finish its work, it fled rapidly, but the Pompilus had seen it, and pursued it and threw itself upon it. I distinctly saw the abdomen of the wasp turn around the spider as if to sting it. The spider stopped, on being assaulted by the wasp, and remained motionless, its legs folded, while the wasp carried and dropped upon it some bits of earth. A few minutes afterward the spider jumped up as lively as before, and ran to hide itself in the grass. 


\section{THE PSYCHIC LIFE OF INSECTS}

It was captured, put in the post-office, crossed the Mediterranean, and came to Bordeaux, where Professor Pérez received it alive with the egg attached. "It had not been stung," concluded Ferton, "and I willingly give the explanation of atavism to the act of the wasp which curved its abdomen under the body of the spider."

We are thus led to pompilids which seem to have lost completely the habit of stinging. In 1872 the zoölogist Karsch found a very active lycosid (Tarantula inquilina) which carried an egrg on the right side of the abdomen. He watched it and soon saw a legless larva coming from the egg and fixing itself at that point. Placed in a glass filled with earth, the spider dug a cylindrical hole, covered the orifice with silk, and stayed there. Soon there remained only fragments of the legs of the spider, and the larva transformed to a nymph from which four weeks later a Salius fuscus emerged triumphantly. In 1870 Lichtenstein did the same thing with Salius affinis, and spiders carrying an egg of this kind are not rare. Although the pompilid has not been observed at the moment of egg-laying, it seems true that certain species of the family lay their eggs without stinging their prey.

So the art of paralyzing, with the pompilids, will have begun with punctures made by chance, 
and will have continued with these Hymenoptera up to the wise use of two stings, but, paralysis not being necessary for the development of their larvæ, this habit has disappeared, and reappears only as an act of racial memory (an atavism).

The possibility of this evolution and the differences in the inertia of the victims is explained by the fact that the stings can produce a permanent injury by destroying the nerve centers or a transitory action by means of the secreted poison. The observations of the Peckhams upon a lycosid stung by Pompilus scelestus throws a light on these two kinds of phenomena. The victim seemed dead at first, then revived somewhat, but always with a noticeable lethargy, but it could not see, and when flies were given to it it was necessary for it to touch them; the cervical ganglia had without doubt been seriously injured. The Peckhams kept this spider for three months. It ran about its cage, but until the end remained perfectly blind.

Relations of the egg and the larva with the host. The egg of the pompilid is always attached to the abdomen, on the back or on the sides, and when the victim is caught upside down, which is rare (Agenia), on the ventral side. As to the larva which comes out of it and which attaches itself exactly at the same point, it is protected by the host, 


\section{THE PSYCHIC LIFE OF INSECTS}

which folds its legs and avoids any movement capable of wounding it. The same observation applies also to all ectoparasites.

I believe that Ferton has caught an inkling of the reason for this singular arrangement. Returning to Nemesia badia, the victim of the wandering Pompilus, "Never," he says, "is the egg or the larva touched. The spider avoids it with its spiny leg as though it were a painful wound." Whatever be the impression produced by it, it seems that the spider avoids rendering this impression more acute by touching the organism fixed to its side. He acts like a wounded person who refrains from touching his wounds, in order not to make them sorer. It is a phenomenon of differential sensibility.

Rabaud also attributes to differential sensibility the instinctive fear which spiders show in regard to their aggressors. But here there are two phenomena of different kinds: the flight or the defense of the spider on which the predator shapes his attack, and the complete inertia of the victim when it is just going to be captured. The first of these phenomena seems to have its origin in experience and the acquirement of heredity, but the eataleptic state which characterizes the second is a consequence of differential sensibility. I add that this state singularly facilitates the task of the 
pompilid, which can sting its victim with certainty and even place its egg upon it when it has lost the instinctive habit of stinging.

The arrangement of the nest. Certain pompilids make no nest. Aporus bicolor deposits its prey in a crevice, and Evagetes laboriosus in a shell or in a cleft in the ground; others, like the buffoon Calicurgus, scratch some bits of mortar out of old walls to make their hiding-places, or, like the banded Pompilus, dig only slightly; but most of them are adroit miners which dig a hole at the bottom of which they arrange a chamber for the victim.

Having been acquired progressively, the mining art can be lost the same way. It is notably lost with those pompilids which chase the earth-inhabiting spiders, and who use as a nest the burrow of the victim. This is the habit of the wandering Pompilus, hunter of the Nemesias, and which, when one offers it a free-living spider, paralyzes it, digs a hole, but no longer knows how to arrange it, and abandons the job. Ferton says :

Thus, $P$. vagans, accustomed to nest in the burrow of its victim, has become incapable of digging a nest when she wants one. She is, however, still a digger, since she knows how to dig ... . and it is not the tools nor even the habit of digging which are lacking. Just as an organ becomes atrophied from want of use, an unused in- 


\section{THE PSYCHIC LIFE OF INSECTS}

stinct becomes atrophied after a while even when the tools which it used have not become modified.

There are also among the pompilids mason species which construct the nest with bits of plastered earth. Our Pseudagenia punctum builds in this way a nice cellule in the form of a little tunnel, and the Peckhams state that the nest of Pseudagenia bombycina is composed of sixteen contiguous cells. To understand the origin and development of this new industry, we must study the manner in which other pompilids arrange for the closing of their nests. Most of them content themselves with sweeping sand over it and scratching it about with their legs. Some, like Pompilus quadripunctatus studied by Ferton, puddle the closure with the end of the abdomen. Evagetes laboriosus closes the entrance "with a thick barricade of little stones, with bits of earth, and with debris of twigs and leaves," and Agenia variegata with balls of spider-web which it compresses into a compact tissue. Agenia structor comes nearer the mason species, nesting in a shell, says Ferton; she closes the orifice "with a stopper of finely plastered earth" which she fortifies with a barricade of stones and bits of earth. Sometimes she makes several cells, like the preceding species, but instead of separating them 
with grains of quartz or limestone she employs materials similar to those of the stopper.

Pompilus scelestus is one of the rare burrowing species which prepare the burrow before leaving: for the chase. Most of the others capture their victim first, place it on a tuft or in a hollow, sometimes even hiding it under a layer of sand, and then devote themselves to the preparation of the nesting-hole. The transition between these two very different methods is shown us by species which make no nest, which leave their prey in the hole of the victim, and by diggers like Pompilus viaticus and $P$. cingulatus, which build two cells in the same nest or put two victims in each cell. The momentary abandonment of the prey is not without inconvenience, for it leaves a chance for robbers. Nicolas (1888) reports that certain Pompilus viaticus will themselves be deceived indefinitely when they leave their victims while they make their burrows, while others very quickly become alive to the situation, like the yellow-winged sphex in Fabre's experiments. Pompilus pulcher employs another method. Ferton has seen it hide its prey under a light layer of earth and proceed immediately to hunt for a convenient spot in which to dig its hole. When this is half dug the Pompilus returns to its victim, carries it to the hole, and enters the hole with it. It has not, how- 


\section{THE PSYCHIC LIFE OF INSECTS}

ever, finished the digging. "I have seen it," says Ferton, "come out from time to time to push away the debris. ... The wasp is thus enclosed with its spider while finishing its task, which may last half an hour." For the Pompilus, the fear of the robber is the beginning of wisdom.

The parasitic pompilids. There are, as a matter of fact, some pompilids which, instead of hunting, lay their eggs upon the victim which their congeners carry to the nest. The first observations concerning this change of habit are due to $\mathrm{J}$. Pérez. Having seen a Ceropales maculata trying to lay its egg on a spider which a Pompilus rufipes was carrying, the lamented professor suspected a new phenomenon and was happy enough soon to find an egg upon the victim of a certain pompilid which had been laid by a Ceropales. This was almost a confirmation of views advanced from Dahlbom to :Taschenberg. "The Ceropales he concludes, are parasites of the pompilids."

Ferton had the good fortune, which he merited more than any one else, of following this little entomological drama to its last act. His first two observations resemble the two observations of Pérez, but in the second he was able to follow the egg on the spider and obtained a Ceropales maculata. The third is still more interesting and should be quoted: 
A Pompilus chalybeatus, watched by a little Ceropales cribrata, was carrying to its nest a large Lycosa. At the moment when the spider disappeared in the hole, the Ceropales arrived, entered into the nest after the load, and remained there a few seconds. I collected the wasp and the victim, the latter bearing the eggs of the Pompilus. Six days later the egg ... shriveled, and the embryo already formed, did not reach the hatchingpoint, but I found two days after the larva of the Ceropales which was attached under the abdomen of the spider. The latter had revived, and lived during the whole repast of the larva.

.Most of the Ceropales, if not at all, have similar habits. In the United States the Peckhams found two individuals of this genus harassing a Pompilus scelestus which was carrying an enormous lycosid. They captured it instead of noting the subsequent events, which was unfortunate, since Adlerz has' stated that the Ceropales hides its egg in the narrow lung-chamber of the spider.

The origin of parasitism with the pompilids. It is, then, certain that some pompilids do not hunt, do not paralyze, do not nest, and yet assure the fiuture of their progeny by ravaging others of the benefit of their work. How can such an inversion in the ordinary habits of the family be brought about?.

Beginning with 1890, Ferton observed that 


\section{THE PSYCHIC LIFE OF INSECTS}

Pompilus pulcher and $P$. viaticus carry the paralyzed victim to the nest which they make, and in 1901 that Salius vachali enters sometimes in an effort to rob them of their prey; and these struggles and the thefts which follow appear to occur more frequently still with Pompilus rufipes which lives in colonies in the warm sand-pits. Ferton notes:

They are a colony of crafty rogues, always in motion. rummaging about, often hunting for the spiders of the neighborhood, entering the holes which they find in their desire to hunt the proprietor. If they succeed in stealing a victim, they bury it, if a new thief does not interpose and oviposit on it. Sometimes these thefts are the cause of very lively fights.

However, this species is not frankly a parasite, but is only inclined to robbery. Every day Ferton saw it hunt and oviposit honestly in the same locality.

What is accident with $P$. rufipes becomes the rule in a related species, $P$. pectinipes. From the numerous and patient observations carried on at Bonifacio by Ferton, it seems that this species examines the ground with its antennæ in order to discover the nests of other pompilids, and opens a discovered burrow, penetrates it, detaches the egg fixed upon the victim, substitutes its own, and then closes the violated burrow. This Pompilus 


\section{COMPARATIVE PSYCHOLOGY 195}

is closely related to $P$. rufipes and $P$. argyrolepis whose nests it exploits. This is, says Ferton, a $P$. rufipes which has taken on the habit of theft, and has therefore lost the habit of nesting.

And so by successive steps we are led to the habits which characterize Ceropales. We cannot do better than to approve the opinion of J. Pérez upon the origin of parasitism with the pompilids and the parasitic bees: "Instinct in general is like an organ, subject to variation; it is even more variable than an organ. The cessation of laborious habits," once acquired by heredity, is ordinarily "followed secondarily by the atrophy of the working structures," for all change of habits modifies more or less the physiological condition and reacts, therefore, upon the organism. Bordage (1912) does not believe "that it suffices that a female predatory Hymenopter should proclaim ... her right to idleness" in borrowing a neighboring nest, in order that this habit should become hereditary, and he invokes an internal modification at the same time physiological and organic. This modification surely exists, but it has been produced by the change of habit. One cannot admit, on the other hand, with Marchal (1890) that the parasitism of our Hymenoptera results primitively from a modification of structure of the organs, for Pompilus pectinipes dif- 


\section{THE PSYCHIC LIFE OF INSECTS}

fers in no respect from related non-parasitic species, and the oviscapt of Ceropales seems, indeed, to be the product, not the cause, of parasitism. Here is verified the truth of the old biological adage, "Function creates the organ, but the organ lends itself to functions."

It appears from this long exposition that in all or in part of their instincts certain species of the family do not yet present any perfect specialization. These ambiguous forms are evidently more malleable than the others in the psychological domain, and one conceives that analogous forms by apprenticeship and heredity have been able to produce new psychic types by orientating their actions in different ways.

Thus the comparative psychology of the pompilids appears to us full of instruction, for it makes evident the possible ways which they have probably followed in their psychic evolution. We have noted in these direction many stages, not always sufficiently to give an exact view of the different possibilities, but do not forget that the family includes almost a thousand species and that fifty at most of these have been the object of biological research. What rich and suggestive fields are reserved to the zoölogist in studies of the pompilids of the tropics! And how fertile should this comparative method prove to clear up the past in the light of the present! 


\section{SPECIAL PART}

We have limited ourselves so far to the study of the essential phenomena by which the activity of the entomological world manifests itself to the observer, and our study has brought us to rules which permit us to establish the variety of these phenomena, to speculate as to their origin, and to follow their connections. This will be the fundamental part of the present work, since it will put us-indeed, has put us, I think-in the possession of a working method.

But entomological activity in general presents the greatest complexity, and it is on account of the need of further study that we have been able simply to separate the principal phenomena. It remains now to envisage what we have seen manifest itself under natural conditions,- that is to say in its normal development,- -with the multiplicity and the subordination of the phenomena which constitute it. This will be our object in the second part of this work.

Moreover, we cannot pretend to discuss in a small number of pages all the forms in which the activity of the entomological world is exhibited. A special volume will be necessary to do this, and 


\section{THE PSYCHIC LIFE OF INSECTS}

this we will present later. For the present it will suffice to study some of these forms, chosen from among the most suggestive and the most striking,-not only those which seem to defy all explanation, for it is necessary first to face the difficult problems, but even those which appear actually insolvable.

Therefore we are going to pass in review, in a series of chapters, the relations of insects to flowers, the mechanism of far-away orientation, the division of the sexes with the Hymenoptera, and the origin of the social life of these insects.

Before beginning this study, it will be useful to note that insects and other arthropods are furnished with sensorial organs whose peripheral cells, impressed by excitants, are relayed to cerebral cells where these impressions are transformed into sensations. Most of the sensorial impressions of articulates are received by means of hairs connected with nerve cells. Tactile hairs may be distributed over the whole body, but are principally found on the antennæ and the palpi of the mouth apparatus. These two organs, the first especially, carry also the olfactory nerve terminals, ordinarily situated at the bottom of little crypts. It is really with the hairs situated on the antennæ that the articulates perceive sound vibrations, for they are deprived of any auditory vesi- 
cle, with the exception of certain Crustacea. As to taste, that has its seat in the mouth, where it operates without doubt also through nerve termini. The organs of sight are quite different and much more complicated. They are composed of a corneal lens, of a hyaline vitreous body, and of retinal cells which receive the images. With most adult insects and with the Crustaceans the t.wo visual organs are composed of numerous elementary eyes juxtaposed, which function independently of one another and, by the juxtaposition of the luminous spots which they produce upon the retinas, give a direct image of the object. With the other articulates and with the larvæ of insects the eyes are variable in number and are reduced to simple ocelli. The ocelli, which are simple eyes, coexist, with many insects, with composite eyes. They seem especially to give a luminous impression, while the composite eyes take advantage of the vision of forms, and better appreciate movements. The bees are blind for red, and its complimentary color, blue-green. Ants are sensitive to ultra-violet. 


\section{CHAPTER $\mathrm{X}$}

\section{INSECTS AND FLOWERS}

Anthophilous insects. We have become accustomed to call insects which are attracted to flowers anthophilous.

Almost all of the anthophilous insects belong to the highest groups of the entomological fauna,to those whose metamorphoses are complete. The more primitive orders appeared in the world in an epoch when flowering plants did not yet exist, and therefore they did not have to adapt themselves to flowers. Aside from Neuroptera of the family Thripsida and the true bugs of the genus Anthocoris, insects whose metamorphoses are incomplete do not rob flowers. With some rare exceptions, we can say the same thing about larvæ of all the orders. Even in the order Coleoptera, where, however, the metamorphoses are complete, the frequenting of flowers is exceptional. With the Cetonians which browse on petals and pollen, with Saprinus which visits vile-smelling flowers, and with the little Meligethes which swarm in 
corollas, the grinding-apparatus of the mouth is not modified, although it becomes elongated and already presents an adaptation to flowers with certain longicorns, notably with the genus Strangalia.

When it elongates into a beak, as in the beeflies and the mosquitos, or when it spreads out into spongy lobes as in the house fly, the buccal apparatus of the Diptera is wonderfully adapted to collecting liquids. Indeed, the Diptera are almost all flower-frequenters. Certain of them, such as the bee-flies, collect the nectar while flying; others, like the Syrphide, feed at rest, collecting at the same time nectar and pollen.

This adaptation to flowers is closer still with the Lepidoptera. Aside from the moths of the genus Micropteryx, which have preserved the mouth parts of the Neuroptera, they have a long tube-like beak which permits them to suck up liquids and consequently also the nectar of flowers. The beak is commonly so long that it is rolled into a spiral when the insect is at rest. It reaches its maximum with the Sphingida, which drink during flight in the same way as the beeflies. It is also a very plastic organ, capable of playing other rôles. As Künckel d'Herculais has shown (1916), it becomes an inflexible stylet with Acherontia, or the death's-head moth, which em- 


\section{THE PSYCHIC LIFE OF INSECTS}

ploys it to reach the honey in cells, and with the exotic noctuids of the genus Ophideres, by which it is used to puncture fruit.

All the Hymenoptera are fond of nectar, but certain of them not only collect the floral products for their own use, but gather them also for their larvæ, so that the whole existence of the insects is bound up with flowers. So it is with the solitary wasps of the Masarian tribe and in the vast group of Mellifers, or bees. The progressive adaptation of the collecting-apparatus is very striking in this last group. With the solitary bees of the genus Prosopis the mouth parts do not differ from those of other Hymenoptera, and it is with their lower lip, short and bilobed, that these insects collect nectar and pollen which they disgorge afterward to their larvæ in the form of a paste. With Colletes the skin is covered with hairs to which pollen attaches itself and is afterward brushed off and mingled with the nectar to make porridge for the larvæ. With the Halycti and the Andrenas there is a double progression. The hind legs possess a tuft of long hairs for the collection of pollen, and the lower lip is elongated into a beak for the collection of nectar. It is elongated still more with other Mellifera, in which, combined with the jaws, it becomes a capillary tube that folds into a $\mathrm{Z}$ when the creature is 
at rest. And, further, the pollen apparatus becomes a ventral brush with the solitary bees of the genera Osmia and Chalicodoma. It is also similar in the Halycti, in the Xylocopas and the Anthophoras, while it acquires a high degree of perfection with the social bees, namely the bumblebees, the Melliponas, and the true bees properly so called. Unlike the solitary forms, these insects moisten the pollen with their mouth at the moment of collection, and make cakes of it which they attach to a depression or comb situated on the external face of the tibiæ of their hind legs. And to facilitate the agglomeration of the pollen dust, the following segment is much enlarged and on its internal face is a brush with short hairs and ridges in parallel series. The adaptation to the anthophilous regimen is perfect.

Whatever its beginning may have been, or however completely realized it has become, the adaptation of the Mellifera to flowers is sufficient and is necessary. Without doubt these insects are fond of all sugary material, even the honey-dew from the leaves or the honey-dew of plant-lice; but with the bees that is an accessory resource, and we may well say, with Pérez, that "all the species of bees would dislappear without exception if fflowers ceased to exist or if they ceased to produce nectar and pollen." 


\section{THE PSYCHIC LIFE OF INSECTS}

The choice of flowers. The anthophilous insects do not visit all flowers indifferently. In the course of an entomological excursion in which I had as a companion the very learned Professor Giard, we made a large collection of Micropteryx calthella in the suburbs of l'Isle Adam. The resplendent country offered to the honey-collectors the most diverse corollas, but the graceful little moth had chosen for its exclusive use the yellow cupule of the buttercup (bouton d'or), Ranunculus acris. This was not an accidental phenomenon. In his treatise on "Floral Biology," which is a compendium of the relations noted between insects and flowers, Paul Knuth noticed our Micropteryx upon another Ranunculus (R. repens), but the list is not complete, for the species frequents also the great Ranunculus of the marshes (Caltha palustris), which really has given it its name. In fact, $M i$ cropteryx calthella frequents the flowers of several Ranunculaceæ with yellow flowers, and it is probably by mistake that Stainton has recorded it upon flowers of Carex.

We have here, then, a species which limits itself to a very small number of flowers,-indeed, to flowers of the same coloration and of the same type. Insects of this kind are rather rare. According to Kerner (1891), Bombus gerstaeckeri 
devotes its attention to the aconites, Andrena florea to the bryonias, Osmia adunca and O. loti to the viperines. This exclusivism is not, however, without elasticity. Osmia papaveris lines its nest always with the red petals of the poppy, but in Cerdagne, where this flower is entirely lacking, Ferton has seen the insect choose the petals of another flower, the musk mallow. Analogous variations will, without doubt, be observed with many insects which have a choice of flowers without being narrowly adapted to them. When, on the other hand, a species has suffered a great disaster through its adaptation to special plants, it can no longer frequent others. So it is that the Hymenoptera of the genus Blastophaga exclusively frequent figs whose fertilization they assure. It is so, also according to Riley, that the American moths of the genus Pronuba are closely adapted to the yuccas and can fertilize the flowers of these plants only. But in general anthophilous insects are strongly eclectic and get their nourishment from the most diverse plants. With the nocturnal Sphingida, which limit themselves to a small number of flowers, and the day sphinx (Macroglossa stellatarum), which has no especial choice among the corollas, the species of Micropteryx, and our charming noctuids of the genus Plusia, with the 


\section{THE PSYCHIC LIFE OF INSECTS}

bumblebees and with our honey-bee, we cannot perceive any great specialization from this point of view.

However, it is not by chance that we can collect these very eclectic species. In their exclellent treatise on apiculture, Gaston Bonnier and G. de Layens observed that the collecting-flight of the honey-bees is always appropriate to the weather and the place. Each morning the colony sends out into the country scouts which explore the neighborhood to find out the best plants and the proper places for collecting honey. On the return of this advance-guard the workers go out in clouds, some charged with the collection of pollen, the others to sip the honey, as Aristotle has already pointed out. The principle of the division of labor is perfectly observed, each collector gathering exclusively the one or the other product, and almost always, at least in each journey, limiting its visits to a single kind of flower. The harvest varies according to the seasons, and in each season certain flowers are the object of their preference, among others sainfoin, honey-locust, clover, which furnish an abundance of preferred nectar. The beekeepers know this faculty of choice very well, and have profited by the knowledge by growing near the colonies an American plant, the Phacelia of 
California, which flowers luxuriantly for a long time.

Even with the most eclectic flower-loving insects the choice of flowers is always limited, for most of them are primarily fond of nectar and many of them possess no organ which will enable them to reach into all corollas. Gaston Bonnier ${ }^{1}$ has justly said that the true anthophiles "go in the greatest number where the nectar is ... the easiest to collect." And when, in his memorable study upon the Alpenblümen (Alpine flowers), Herman Müller divided the flowers into nine groups according to the relation which they bear to anthophilous insects, he had only to arrange the preceding observation in systematic form. His system has been held in great favor. It serves as a basis for the great "Treatise on Floral Biology" by Paul Knuth and has recently been popularized by Kirchner (1911). However, if it is beyond criticism in its principles, it bares its flank by its complexity and above all by the ambiguous delimitation of its groups. So if flowers are especially frequented, some by Lepidoptera, others by Hymenoptera, certain others by Diptera, it does not follow that they are suitable for little insects, and most of the anthophiles go to the flowers in

a Les nectaires, 1879. (Ann. Sci. Nat. Botanique, ser. 6. v. 8.) 


\section{THE PSYCHIC LIFE OF INSECTS}

which the pollen is largely exposed, upon those where the nectar is half hidden (Ranunculacea) and upon the Scabiosa and the composites in which the nectar occupies the bottom of the corollary tube. The conclusion from this study is that the length of the beak forces the insects to a selection of flowers for the collection of nectar. With their beak seven or eight millimeters long, our particular little Lycænas are not able to reach down as deeply as Papilio machaon, with which the organ may reach a length of fifteen millimeters. These differences are still greater with the Sphingida. In Smerinthus tilice the beak measures no more than three millimeters, but with the Macroglossa which frequents the honeysuckle it reaches twentyeight millimeters, and in the sphinx of the morning-glory eighty millimeters. Müller states that with a certain American species, Macrosilia cluentius, it may reach a quarter of a meter.

These observations become especially interesting when they are applied to the social bees. Our honey-bee, for example, is incapable of getting the nectar from narrow flower tubes whose depth exceeds six or seven millimeters, for its beak does not measure more; also, it can utilize certain clovers and not others. The workers of the common bumblebee (Bombus terrestris) are hardly better fixed, but the garden bumblebee (B. hor- 


\section{INSECTS AND FLOWERS}

torum) and especially Gerstaecker's Bombus ( $B$. gerstaeckeri) are well equipped, for the beak of the workers measures fourteen to sixteen millimeters in the first and eighteen to twenty-one millimeters in the second, according to Knuth. We know that the beak of the male bumblebee is a little shorter than that of the workers, while that of the female is the longest. We know, also, that these insects have an especial liking for the aconites, but the nectar of our yellow-flowered aconite is much more deeply situated than that of the blueflowered aconite, and so the observations of Dalla Torre on Gerstaecker's bumblebee are explained. With their elongated beaks, the females of this species suck the yellow-flowered aconites, while the males and workers content themselves with the blue flowers.

But very often the bumblebees do not allow themselves to be baffled by the depth of the corollas. With their mandibles they gnaw a hole in the wall of the tube which is in the way, and thus easily reach the nectar. Having the habit of gnawing the cells in their nests, these insects employ the same method when they find themselves in the presence of coveted flowers which are inaccessible without being cut open. The solitary bees of the genus Xylocopa (carpenter bees), which gnaw into wood in order to place their cells 


\section{THE PSYCHIC LIFE OF INSECTS}

there, are still more prompt than the bumblebees to perforate floral organs, although they are of greater size and furnished with a long beak. I have seen (1903) our Xylocopa violacea make long slits in the nectar spur of the garden balsam and the monkshood without ever trying to introduce the beak directly into the orifice of the corolla. In a clump of cultivated verbena, the insect "darted upon the flower, turned the especial stem under its venter and, turning the corolla tube, made a slit or long wound in its lower part.' This was a brutal bee, which made play of mutilation. According to $H$. von Ihering (1903), a Brazilian social bee, Trigona ruficrus, does the same thing with orange flowers.

Our domestic honey-bees do not ordinarily make holes, but they know how to profit by those made by other honey-seekers, as I have seen with the monkshood flowers visited by our carpenter bee. Like the carpenter bee, they dart upon the flower spur.

But when this was intact they appeared to disdain the flower and made only a short stop; the conditions were not favorable to the honey harvest. The visit to the already mutilated corollas was of an entirely different character. The bee felt of the surface of the spur with the point of its jaws; having recognized the existence of 
an opening, it seized the spur with its legs, plunged its beak into the tube, and sucked up the nectar. . . . The beak of the bee being shorter than that of the Xylocopa, it became evident in many flowers that the busy gatherer did not reach the liquid, but many times it overcame this difficulty by prolonging the cut to a proper point. How did it do this work? It is not easy for me to describe the precise manner. . . . As to the act itself, it was undoubtedly performed. When the bee abandoned a flower I immediately examined the spur, and the presence of a fresh wound almost bleeding (if one may so express oneself) gave me manifest proof of a recent mutilation.

Bees often profit in this way by the slits made by the Xylocopa in the spurs of balsams, but they do it very seldom with the Verbenas the tube of which is too long or has been destroyed by the carpenter bees. In all the cases observed the work was done by workers in search of nectar. Those which collect pollen have another method, and force themselves directly into the corollas. Thus, in paying her visit to the flower spurs when searching for nectar, the bee gave proof of observation and of memory, and acted not as an automaton, as Bethe pretends, but as an intelligent being. According to Herman. Müller, she always makes use of a hole in the corollas.

How are insects guided toward flowers? This is one of the most disputed questions in entomo- 


\section{THE PSYCHIC LIFE OF INSECTS}

logical biology, -at least one of those which were so, for to-day it seems rather clear. Anthophilous insects visit flowers to seek their nourishment but what is the guide which leads them there? Is it sight? Is it odor? Or both senses together? It is the vision of colors, said Conrad Sprengel (1793) after numerous observations. It is above all the vision of colors and of forms, reply Lubbock and Forel, who place little importance in the sense of smell of the Mellifera. Again, Herman Müller, Knuth, Pérez, Buttel-Reepen, etc., equally give predominance to the visual sensations, but recognize the important rôle of the olfactory sensations. "Aside from color," says Paul Knuth, "the perfume is the most powerful means of attraction; in many cases, even, it is not easy to distinguish which of the two means is the more efficacious." The conclusions of Plateau (1907) are diametrically opposed. "The sense of smell, so highly developed with most insects," says he, "far from being an accessory factor, is really the principal sense which leads them to discover flowers enclosing pollen and nectar." Without being as explicit on the subject of the rôle of the olfactory senses, Gaston Bonnier approaches Plateau in that he regards the part played by colors as very subordinate. Without doubt, he observes, bees can recognize colors, but 
that is not the question; "it is necessary to know whether or not brilliant colors attract the insects in preference to less visible colors, all other conditions being equal." To this he replies in the negative after researches to which we will refer later.

Bonnier has had the merit of proposing the problem and, alone with Plateau, of braving all criticisms, sometimes hardly kind, of the numerous partisans of the opposite thesis. Before taking part in this controversy, it will be well to examine the facts which serve it as food.

(I) Attraction to colors. The Peckhams relate that, having placed some red nasturtiums upon a yellow background near a wasps' nest, they saw that the insects flew to the flowers before their return to the nest, while they passed by indifferently when clear yellow nasturtiums were substitued for the red ones. "And, since the odor was equally strong in both cases, it seems indeed that the color was the sole agent of attraction." Plateau himself recognized the demonstrative value of this experiment.

The bees in search of dainties visit equally gaudy colors. This Lovell (1912) observed with some workers which had become accustomed to take honey from a gray carton; the appetite once appeased, they left on their expedition, entered 


\section{THE PSYCHIC LIFE OF INSECTS}

flower gardens in the neighborhood, and always chose the most brilliantly colored flowers.

The horminelle sage is a large, decorative labiate, which carries at its tip a splendid bouquet of blue or rose bracts and, below, whorls of apparently small flowers. Having observed that the honey-seeking insects went customarily to the flowers and not to the terminal bunch, Plateau (1898) concluded that the lively coloration did not serve as a guide to the honey-collectors. However, certain of them went first to the conspicuous blooms, and those were surely apprentices. The insects should have been followed from the instant they began to frequent the sage. With similar inflorescences isolated in the field, we reach quite different results. Ferton saw Andrena vetula visiting the feather hyacinth (Muscari à toupet) whose sword-like inflorescence is composed of little fertile flowers of a pale violet and terminates in a group of sterile flowers whose violet hue is magnificent. The bee collects from the fertile flowers, which alone contain nectar; but how does it comport itself in the presence of plants from which all of these flowers have been taken away? "When Andrena vetula came to one of these mutilated inflorescences," says Ferton, "it flew toward the plume, but when it was some centimeters away it descended to the place where the 
fertile flowers belonged and, not finding them, it went to another plant." The same biologist has seen other Andrenas visit the white mucous patches (frog spittle) produced by a little cicadellid. From this the fair conclusion is that in a richly beflowered space the bees are "better guided by sight than by perfumes which are being given out at the same time by all the plants."

The experiments of Josephine Wery (1904) are no less demonstrative. They were carried on in a bare field where, five-hundred centimeters from a bee-hive, were placed bouquets or food to which the bees came, not by chance, for no other flower could distract them, but by the sole attraction of the colors or of the perfume. I repeat here some of the results obtained by this observer:

(1) Natural flowers, uncovered (balsam, coreopsis, etc.), 32 visitors.

The same, hidden by leaves, 7 visitors.

(2) Flowers with slight odor but highly colored (dahlia, etc.), 35 visitors.

Very odoriferous flowers but slightly colored (Reseda), 6 visitors.

(3) Whole flowers and, at six yards, honey in a beaker :

Whole, free flowers, 32 visitors; honey, none. Whole flowers under glass, 12 visitors; honey, none. 


\section{THE PSYCHIC LIFE OF INSECTS}

(4) At intervals of six yards exposed natural flowers, the same hidden under leaves, honey, and artificial flowers :

Natural, exposed flowers, 25 visitors.

Hidden flowers, 7 visitors.

Honey, 1 visitor.

Artificial flowers, 20 visitors.

Carried on with innumerable extraordinary precautions, these experiments led, as we see, always to the same result.

Plateau (1876) has denied the vexillary rôle of artificial flowers. In a garden filled with different flowers, where Arabis alpina was "nearly the only one visited by insects," he introduced very vivid artificial flowers and found that they received no visits. The contrary would have been surprising, since apparently the insects neglected all the natural flowers with the exception of the Arabis, and from this experiment together with several other similar ones Plateau could not but conclude that artificial flowers do not attract insects.

The same author describes also an observation by Vallete, who saw a day sphinx (Macroglossa stellatarum) try its beak upon flowers painted on tapestry. Although J. Wery, in her memoir, reports several similar facts mentioned by different biologists, and although Pérez confirms this ob- 
servation with another very similar one, the subject surely needs more careful study.

But, if we except this special case, it is quite correct to say that anthophilous insects are guided to flowers by the coloration which the latter present, and that, all things being equal, they visit those which stand out by their colors against the green foliage of the plants.

(2) Influences combined with color and with form. Here is a herbage-covered slope where here and there shine out the white flowers of the bindweed of the fields. A butterfly of the genus Pieris flits among these flowers, and with undulating flight moves from one to another, neglecting none. The flowers of the plant have a penetrating perfume, but this perfume cannot act as a giuide to the insect, for the distance which separates the flowers is too great. Evidently the color and the form of the flowers are the attractive agents.

In fact, when one destroyed the visible parts of the flowers, without touching the nectaries, once at least the insect was not attracted. This is what Darwin ${ }^{1}$ observed removing the blue-colored floral parts in a spray of Lobelia erinus assiduously frequented by the workers of the honey-bee. The same observation was made by Lovell (1909) on

1 Charles Darwin. The effects of cross and self Fertilization in the Vegetable Kingdom, 1876. 


\section{THE PSYCHIC LIFE OF INSECTS}

the flowers of pear, borage, and pumpkin, and by Josephine Wery with bouquets of natural or artificial flowers. Working with the monkshood and with Digitalis, Gaston Bonnier reached an opposite conclusion, but this learned botanist himself notes a similar occurrence. It is necessary "to observe after a certain time has elapsed," because " the bees are accustomed to flowers" and "find themselves for an instant unsettled before having. to take on a new habit." And this observation very justly proves that flowers from which the petals have been removed remain unvisited until the moment when certain bees, hunting for food, discover the nectar. Following numerous experiments with Lobelias, primroses, bindweeds, Digitalis, and so on, Plateau (1896) observes with Bonnier that anthophilous insects (Hymenoptera, butterflies, Eristalis) visit flowers without corollas; but, differing from the French botanist, he does not tell us whether they come immediately or after a longer or shorter period. However, just as in the former case, the experiment lacks the necessary completeness, for the petals were cut off with scissors and there always remained a visible portion.

Thus the visual sensations of color and form surely play a rôle of the first order in directing anthophilous insects toward flowers. 
(3) Influence of floral odors. It is well known that bees and many other flower-visiting insects are accustomed to visit a certain kind of flower at certain times and at those times to neglect other kinds. This habit places before us a problem which Darwin has raised. "Bumblebees and the honey-bees are good botanists," wrote the illustrious observer, "because they know that varieties can present great differences in the color of the flower while belonging to the same species. I have frequently seen," he adds, "bumblebees fly directly to a plant of common Dictamnus fraxinella; and all went to a white variety, to a purple variety of Viola tricolor, and to another of golden yellow." Gaston Bonnier made similar observations upon the varieties of hollyhocks, and Plateau upon a certain number of plants frequented by different insects, both concluding from their observations that honey-visiting species are indifferent to colors.

But we know that this is not so, and that is why we are going to try to solve the problem proposed by Darwin. If anthophilous insects are "good botanists" which distinguish the corollas of a given species whatever its color may be, it is evident that they have as guides the two elements of the flower which vary only slightly, the form and the perfume. What part in this attraction the one 


\section{THE PSYCHIC LIFE OF INSECTS}

or the other takes, we cannot say, but we must acknowledge with Bonnier that floral perfumes are of two very different kinds, the one produced by the essential oils which have their principal seat in the whole extent of the corolla, and the other by the nectar, which has a particular aroma. Insects come to the flowers for nectar, biut the experiments of Lubbock (1875) have shown that they strongly sense the essential oils, and we must have to agree that the odor of these oils must play a part in the complex sensations which permits insects to be "good botanists."

There are flowers which exhale a fetid odor and which are distasteful from that fact to most insects (flowers with the nauseous, idiopathic odor of Delpino, the indoloid perfumes of Kerner). Aristolochia sipho smells like urine, Aristolochia labiosa like spoiled fish, Arum dracunculus like a decomposed cadaver. But these flowers are visited by insects, and some even have the habit of visiting excrement and putrefying flesh. Paul Knuth reports that upon five flowers of Arum dracunculus he found 463 Coleoptera of which 377 belonged to a species (Saprinus nitidulus), which feeds on cadavers, and that Walker at Gibraltar saw in the same flowers Calliphora vomitoria, Scatophagus, Dermestes, and three species of Saprinus. We know that these sarcophagic and 
stercophagic insects perceive odors from afar, and for them it is undoubtedly odor which is the principal attraction. On the other hand, flowers with agreeable perfumes (the sympathetic odors of Delpino, the benzoloid and terpinoid perfumes of Kerner) may attract from afar certain very sensitive anthophilous species. Has not Kerner seen the convolvulous sphinx proceed directly to the invisible flowers of honeysuckle situated a hundred meters away?

It is impossible to apply a general rule to anthophilous insects. Without doubt they depend on both sight and smell to direct them toward flowers, but with some it is sight which plays the principal part and with others it is the olfactory sense. In general, we may say with Pérez that "for distances at which sight cannot be any help, the bees, and without doubt most insects, are guided in their search for flowers by odors transported by the currents of air. ... When the distance is short enough for the sense of sight to intervene, the insect flies straight to the flower whose appearance attracts him, but this appearance is enough in the absence of any probable perception of perfume when the accidents of flight bring it near a flower. It alights then if the perfume is one which pleases it; if not, it leaves.

Rôle of the psychic faculties in the search for 


\section{THE PSYCHIC LIFE OF INSECTS}

flowers. Forel has justly observed that if insects are guided by "a principal directive sense" the rule is always that they associate the impressions of several senses. Capable of attention, endowed with memory, and very apt in learning, they do not act as pure automata, but, "all ready to put their instincts into play (hereditary automatism), these work with precision when sensations" arise to evoke them.

They know above all how to profit by acquired experience. When, in the course of their work, they have been conducted by chance or by their senses either to sugared baits which they covet or to deceptive flowers, they are assisted by the memory of places and of appearances to return to the first and to avoid the second. This explains the assiduity of the Mellifera among the greenish flowers of ivy, of currant, and of the willows, the decided predilection of Andrena florea for the greenish flowers of bryonia which seem odorless to us, and the disdain of the honey-seekens for the false Melissa though its beautiful big flowers are agreeably perfumed. If it is true that it is at least doubtful that anthophilous insects have the preference, which Herman Müller attributed to them, for flowers of certain colors, one can be assured that this results from a sensorial association and from experience. Kerner contends that the 
color scarlet is disagreeable to bees, and he offers as proof the fact that they never visit the splendid red flowers of Pelargonium zonale. But P'érez has shown that if a little honey is introduced into the corolla of this plant the bees will visit it with perseverence when they once discover the precious food. So they associate the sensations of. form and color with the sense of taste, and, ordinarily neglecting the white and red varieties of this species, continue for a time to visit the scarlet flowers even when these no longer contain honey.

It is because he had not studied the faculties of insects that Plateau was led to deny the vexillary rôle of floral colorations. In a row of simple dahlias, he covered four heads with squares of different colors in which the perforated middle allowed the yellow flowers to be perceived. Then he hid the perforation with a disk of another color. And finally he tried the two experiments with the green leaflets of the wild creeper [vignevierge]. Before the operation the flower heads were very frequently visited by different insects (bumblebees, carpenter bees, Vanessas, etc.). They were also visited afterward, but not withaut hesitation on the part of the visitors.

Forel repeated the same experiment in a basket in which were blooming forty-three differently colored flower heads. With vine leaves, folded, 


\section{THE PSYCHIC LIFE OF INSECTS}

he covered completely twenty-eight of these flower heads, leaving thre others intact. Not without trouble the bees abandoned these, but one of them after two hours recognized the stratagem and reached the flower head by following the lower part of the vine leaf. Others followed her example, and soon the covered flower heads were visited as much as the others. Forel says:

Plateau, then, has experimented badly and concluded falsely. The bees still saw his dahlias at first incompletely covered. When he afterward entirely covered them, but only from above, the bees had already recognized the strategem and still went to the dahlias from sight. Plateau had not counted upon the memory and the attention of the bees.

Associative memory, as a matter of fact, has reached a remarkable development with certain anthophilous insects. I have observed (1904) the workers of our honey-bee in a field where the common brunelle, the cornicled lotus, plantain, and different species of clover showed some colored spots. Although the flora was scant, the honeyseekers frequented only the brunelle and could recognize its upright clusters in which the unflowered calyces formed a base of reddish brown and the violet corollas a terminal crown. The insect examined all the clusters, whether they were or 
were not terminated by flowers. The coloration of the calyces sufficed to attract it, but it took its flight as soon as it recognized the hopelessness of its search. It associated the notion of color with the idea of harvest, and the color of the inflorescences acted solely as its guide in its journeys. More demonstrative still is the following observation. There grow side by side in America an indigenous cotton and its Asiatic varieties. The former has accessory nectar glands on the green leaflets of its involucre, while the latter have none. But the biologist Allard (1911) has stated that the bees "always visited the involucral nectaries," whichever cotton plant they came to, but once upon the Asiatic varieties, they "soon recognized their mistake after having alighted upon a flower, and hastened to abandon it."

Thanks to their associative memory, the bees very soon acquire habits. Buttel-Reepen ${ }^{1}$ says:

When the hives are in the neighborhood of buckwheat, flight is very active only from the beginning of the morning up to ten o'clock, after which they rest for almost the remainder of the day; then begin again actively the following morning. We know that buckwheat produces nectar only in the early hours of the morning. When the honey sources stop, the bees go around a little longer

$1 \mathrm{H}$. von Buttel-Reepen, Sind die Bienen Reflexmaschinen? 1900. (Biol. Centralblatt, v. 20.) 


\section{THE PSYCHIC LIFE OF INSECTS}

and then suspend their useless flight. In spite of the sea of brilliant flowers and its strong perfume, one finds ordinarily during the day after ten o'clock only a very small number of bees in the buckwheat fields.

The insect has regulated its habits according to the rhythm of the nectaries.

On reciprocal adaptation. We know now that flowers are indispensable to the greater number of anthophilous insects, and we know on the other hand, from the researches of Darwin, that insects are necessary to a great number of flowers, whose fertilization they assure,-particularly cross-fertilization, which is especially advantageous. Has this reciprocity of services a consequent reciprocal adaptation between the insects and the flowers which they frequent? The adaptation of anthophilous insects to flowers is denied by no one. It is progressive, as we have shown in the beginning of this chapter, and reaches its maximum with the bee-flies, the butterflies, and the social bees.

The adaptation of flowers to the insect is more debated, and, indeed, more debatable. While Bonnier and Plateau give it no weight, or very little weight, it seemed plain to Darwin, to Herman Müller, to Pérez, and above all to Lubbock, ${ }^{1}$ who has singularly exaggerated it. He says:

$1 \mathrm{~J}$. Lubbock, On the British Wild Flower Considered in Relation to Insects, 1875 . 
Not only the form and the actual colors, the brilliant tints, the sweet perfume, and the honey of flowers have been developed little by little following an unconscious selection exercised by the insects, but even the arrangement of colors. . . . The form, the size, the position of the petals, the relative situation of the stamens and the pistil are disposed in relation to the visits of insects and in order to assure the great object (fertilization) which these visits are destined to produce.

This is not the place to press this question, and I will only say that it is possible that the emission of the nectar, the perfumes, and the floral colors result from an adaptation of the flowers to insects, but we can bring forward no proof. And I will add that, on the contrary, many of the floral structures seem to have this origin. Thus it is, for example, with the atrophy of the lower pollen sac in the Labiates with two stamens. To convince oneself of this, it suffices to watch a Mellifer visiting sage. With its head the insect pushes the little arm of the long connective stamen and submits it to violent friction. This friction acts upon the staminous tissues, and, as this has been done probably since the sages have existed, one can see that it has resulted in the gradual modulating of the pollen sacs on the little connective arm. In fact, the extremity of this arm presents often some traces of a polliniferous formation, and indeed in 
Salvia cretica these staminal vestiges are still well developed and fertile.

Trap plants. We have for a long time given the name trap plants to a certain number of Asclepiads and $Z$ ingiberacea whose flowers are so made

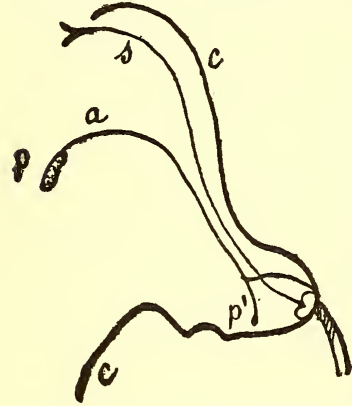

Fig. 7.-Vertical section of the flower of sage. In introducing itself into the corolla $c$ to reach the nectaries situated at the bottom, the bee pushes aside the little arm $p^{\prime}$ from the connection with the stamen $a$ and receives on its back the contents of the pollen sac $p$ situated at the end of the large arm; when it afterwards penetrates a flower it scrapes with the back the bifid stigma of the style $s$ which charges it with pollen. that they often hold in fatal captivity the insects that visit them. Künckel d'Herculais (1909) has studied the mechanism of this capture in an Argentine Asclepiad, Araujia sericofera, and in a magnificent Zingiber of the genus Hedychium. In the first the beak is wedged at the summit of the narrow angular space which leave between them the hardened expansions of the two contiguous stamens. In the second it remains held to the tissues of the narrow corollary tube by an "action comparable to that which results from the introduction of the moistened finger into a tube, or, better, into the mouth of a bottle." The first can hold bees as well as Lepidoptera, and the second catches only the 
great sphinx moths whose beak is long and bulky. In both cases the insects often escape. The victims of the Asclepiads die of inanition without causing any damage to the flower. The large sphinx moths, however, thresh around before dying, and mutilate or tear off the flowers of the Hedychium.

Traps of another sort have been described by H. Müller in the butterwort of the Alps, and by Sprengel in the Aristolochias. In these last plants the hairs which transform the long floral tube into a net do not stay rigid for a long time; they wither at the moment when the pollen sacs in the chamber which terminates the tube open, and the insects captured in this chamber can then go out, carrying with them the grains of pollen which will fertilize other flowers.

From the fact that certain trap plants hold and kill some of the insects which visit them, we may conclude that the reciprocal adaptation is a lure. These plants show us simply that the best adaptation cannot fit every case; all flowers are not adapted to all insects, and reciprocally; but there are enough hospitable flowers to save the race of insects which may take themselves to the trap flowers, and enough insects to bring about without injury the fertilization of the latter. I add that it is natural that the victims of the trap plants 


\section{THE PSYCHIC LIFE OF INSECTS}

are not adapted to play with the trap, for adaptation presupposes heredity and these insects will not leave any descendants.

In reciprocal adaptation each adapted one works for its own benefit without regard to the other, and if the plant has only indifference for the insect, the latter also is indifferent to the fate of the plant. Osmia pérezi decorates its nest with strips torn from the petals of Convolvulus cantabrica and $C$. altheoides, but the flowers torn by the insect are ruined and are destined to be sterile if they are not fertilized in advance. "I marked fifteen flowers torn by the bee," says Ferton, "and . . . six hours later I found certainly eight more, of which only one had pollen grains; the other seven were dried, sterile, victims of their beauty."

It is necessary to apply to reciprocal adaptation the aphorism of Claude Bernard, "The law of physiological finality is in each being, and not outside; the living organism . . . works for itself and not for others." 


\section{CHAPTER XI}

\section{THE FACULTY OF ORIENTATION}

How do insects orient themselves when proceeding to a place which is more or less distant? Are they simply reflex machines, as Bethe says? Or are they guided by a special directive sense, as Fabre believed? Or are they not simply served, like all of us, by the ordinary senses and by a memory of places? Here again we are in the open field of controversy.

In the course of an excellent study devoted to this question, Claparède ${ }^{1}$ observes " that the most fundamental point which needs elucidation is whether the objective, the spot toward which an animal directs itself, can be a goal unknown to it, one which it has never visited, never explored; and further, whether or not this goal is directly perceptible (by sight, smell, hearing), and in the latter case, whether the path followed does or does not include landmarks. . . . Each one of these cases, in fact, authorizes a different hypothesis.

1 Ed. Claparède, La faculté d'orientation lointaine, 1903. (Arch. de psychol, Geneve, v. 2. pp. 132-180.) 


\section{THE PSYCHIC LIFE OF INSECTS}

We see, then, the importance," adds Claparède, "which should be placed upon them. in a preliminary way."

This is absolutely our opinion, and in first considering flying insects we will follow the plan outlined by Claparède.

Perceptible objective point. Chance plays a predominant rôle in the two essential activities of insects, the search for nourishment and the sexual approach. It leads the animal to places in which the objective becomes capable of exciting the organs and of producing a directive action.

In the search for nourishment, chance is nearly always lacking with the very numerous larvæ which are born at the very spot where they find their food, and therefore, so to speak, quite in the dining-room. With others it is aided by tropisms which very often lead the insect to the feast. The young caterpillars of the gipsy moth on the end of twigs (positive phototropism), and those of the milkweed butterfly on asclepias (negative geotropism) are examples. As to adults, it is very often by the play of chance, in fact almost always, that they are led to points from which they can be guided toward food. And mosquitos are directed by odor, bees by the sight of flowers and the perfume of fields covered with flowers, stercophagous and sarcophagous insects by the odorous 


\section{THE FACULTY OF ORIENTATION 233}

emanations from excrement or from cadavers.

It is also chance which aids sexual approach, by placing the males on the odorous track produced by the emanations of their future mates. With the great peacock moth and with many other nocturnal Lepidoptera these emanations may be perceived at a great distance. In all these cases they exercise an automatic irresistible attraction on the males, and from this fact provoke tropisms rather than true sensations. We are here facing a situation where it is not easy to distinguish between these two kinds of phenomena. However it may be, both serve as aids to chance in conducting the insect to an unknown end, which is the female.

Non-perceptible objective; migrations. There are cases where the insect reaches an unknown objective guided by a series of intermediary excitants. As Claparède observes, these cases approach the preceding ones, because each intermediary "determines the direction" and plays "in some sort the rôle of the unknown but appreciable end." The processionary caterpillars of the pine, studied by Fabre, offer us a perfect example of one of these cases. They are born upon the needles of the lower branches where the moth has deposited her batch of three hundred eggs. After having browsed upon the neighbor- 


\section{THE PSYCHIC LIFE OF INSECTS}

ing needles-first the two needles where they were born-they direct themselves through the foliage, pressed by the need of nourishment and surely also by tropisms. But it is by stages that they go, eating at each stop the needles which they meet. These needles are the intermediary excitants which lead them to an unknown objective, to the top of the tree. There they build a large common nest in which they hide during the winter. When the month of March arrives they finally leave this nest and descend to the ground to transform into chrysalids. Their objective is unknown to them, and no intermediary excitant directs them; they are led by their geotropism, which has become positive after the physiological modifications which they have undergone. Indeed, whatever their geotropism at the time of their birth, all larvæ of insects that transform in the soil present at the time of their maturity a more or less evident positive geotropism.

The history of the migratory grasshoppers gives rise to much more difficult problems. We can give a resumé of them from information which Künckel d'Herculais, the indefatigable student of these voracious creatures, has been good enough to furnish. The migratory locust of northern Africa (Schistocerca peregrina) is a native of the Sahara Desert region. It passes all of 


\section{THE FACULTY OF ORIENTATION 235}

its life there ordinarily, but in certain years, when spring arrives, the adult grasshoppers assemble in swarms and fly by stages toward the north, using their stops to feed, to couple, and to lay eggs. They thus arrive at the Atlas frontier and invade the plain of Algeria quite to the Mediterranean littoral. The journey brings about changes of color, and, from the red which distinguished them at the start, they change little by little to chestnut and then lemon-yellow. The invasion stops in May to June, the period that ends their existence, which is rather long and punctuated by a dozen egg-layings. The young coming from these eggs have a series of molts and travel in considerable armies which devour everything on their way. When they have acquired the wings characteristic of the adult they group together in swarms, and by nocturnal flights direct themselves toward the south to gain the Sahara regions. Rose-colored at first, they pass to gray and then to yellow. Their sexual maturity is then perfect: they couple, lay, and thus produce the hibernating generation. The same species makes similar migrations in Arabia and in India. In the Argentine Republic, the migrations of Schistocerca americana are made in the opposite way.

Here we have migrations similar to those of birds, but more difficult to interpret because the 


\section{THE PSYCHIC LIFE OF INSECTS}

grasshoppers never have as guides older individuals of the same species. Without doubt they start out to find food, and the unknown objective toward which they go is indicated by the plants which serve them as intermediary excitants. But why is the return always the opposite from the going? And why are the two journeys always in the meridian direction? Can it be said that the grasshoppers are guided by the sun? By the winds? By a magnetic sense? By an hereditary memory? These hypotheses will have to be supported by proof. Climatic conditions must certainly play a great part in these movements, but we are far from knowing in a satisfactory way what they are. The problem is still almost wholly a problem.

The objective is known: return ta the nest. When the processionary caterpillars enter their nest after a meal they are guided toward this known end by a conducting thread of silk which they have spun out in going and which they use in returning. All the caterpillars of a colony behave the same, and return to their nest without appearing to manifest any psychic aptitude.

But how is the return of adult insects effected when biological exigencies lead them to a determined spot,-beetles of the genus Cicindela which have the habit of returning to the natal burrow, 


\section{THE FACULTY OF ORIENTATION 237}

the scarabs which make provisionments of dung, and the numerous nest-making Hymenoptera whether they are predators or honey-gatherers?

Before taking up this problem we must establish a distinction between aërial, or flying, insects and terrestrial species which move without leaving the ground. As Forel says, the former "have a knowledge of places very different from that of non-winged forms,-much more comprehensive and much broader. The terrestrial beings have their horizon continually obstructed, which renders their direction by means of sight much more difficult." The behavior cannot be the same in the two cases, and Ferton has given a striking proof. When the predatory wasp, Ammophila heydeni, carries to its burrow the numerous victims intended to nourish its larvæ, it arrives by flight and alights exactly at the orifice of the nest when it has captured the little measuring-worms which ordinarily form its prey; but when necessity obliges it to take other and much larger caterpillars, it has to return on foot and finds its nest only after a rather long search.

Aërial, or flying, insects. This observation by the clever entomologist seems surely to show that sight and a memory of places play a large part in the orientation of flying insects. We know, moreover, that these insects are incapable of directing 


\section{THE PSYCHIC LIFE OF INSECTS}

themselves when their eyes are covered with opaque varnish, and Buttel-Reepen observes that bees, when twilight comes, fall to the ground instead of reëntering the nest.

The same biologist adds that some bees lose forever their memory of places and have to begin a new apprenticeship after they have been given certain narcotics (ether, chloroform, etc.); that they undergo a progressive enfeebling of the memory under the influence of cold, of baths, and after five or six weeks the memory of the place of the nest is lost. Finally, their memory of places is less tenacious in summer than in winter, because "new impressions come to replace the old ones." This last fact is corroborated by the observations of François Huber and of Lovell, who saw bees return to a window where the preceding autumn they had found honey (see page 116), associating the memory of an especial place with the gustatory sensations which they had experienced at that spot. But a psychic process such as this cannot take place without observation, and observation, because of too great a similarity, may be at fault in the visual sensations. Forel says:

“'A bumblebees' nest which I had put on a window ledge, showed me what trouble the bumblebees which returned from their excursions had in distinguishing this window from other windows in the same façade. The 


\section{THE FACULTY OF ORIENTATION 239}

first few times especially, they flew a long time around the other windows before finding the right one."

Lubbock with the 'wasps and Buttel-Reepen with the bees have recorded errors of this kind.

These facts have already cleared up a question which we are considering, but before concluding it is necessary to follow the problem a little further and study the return to a known place with or without indicating points.

The end is perceptible. Whatever may be the manner in which insects direct their journeys, there comes a time when the place which they are seeking becomes perceptible. How is it, then, that they get to this point?

It is, says Fabre, by a special faculty, a sort of topographic feeling, of which it is impossible for us to form an idea, having ourselves nothing analagous, and, to show how "subtile and precise" this faculty is, the ingenious entomologist turned his attention to the predatory Bembex which carries flies to its closed burrow. He scraped off the spot where the opening of the nest was found, hid the orifice under a stone, under a sheet of dung, and the insect always alighted at the precise point. That was proof to him that neither sight nor odor nor the memory of places plays any part in this phenomenon. 


\section{THE PSYCHIC LIFE OF INSECTS}

:To support his thesis of orientation with a force or sense which is unknown to us, Bethe made numerous experiments. He took a hive from its base, and put in its place an empty hive to which the bees on return made numerous visits before going to the familiar hive. He slowly turned this one on its side, and the arriving bees could not find the door when the rotation passed forty-five degrees. He moved the hive one or two meters, and the bees formed a swarm at the spot where the door had been. Then, following a method well known to bee-keepers, he placed an empty hive at this spot, into which the swarm immediately precipitated itself. From this he concludes that sight and odor do not serve the bees, and that an unknown force guides these insects, not to the hive, but to the point where they have been accustomed to go.

But since the bees as well as the Bembex come to the customary end of their journeys, the "unknown force" of Bethe and the "topographic feeling" of Fabre seem to be nothing but memory. That is what Forel and Buttel-Reepen have observed, and it is, in fact, what experience shows. If the topography of the place is but slightly modified the insects are disturbed when they return. I placed a little flat stone on the closed nest in 


\section{THE FACULTY OF ORIENTATION 241}

which a Bembex rostrata was shut up for the night. ${ }^{1}$

The next morning I found that the wasp had opened an orifice at the edge of the stone. The day after that, during the absence of the Bembex, I raised the stone and put it twenty centimeters from the orifice. The insect soon returned, carrying a fly, and went without hesitation to the border of the stone,- - that is to say, twenty centimeters from the entrance to its burrow,-where it began to dig as if it had found a good place. I chased it away twice, and twice it came back to the same spot. Finally I put the stone where it was at first, and the Bembex immediately found the entrance to its lodging. It had fixed in its memory very exactly the topography of the place, and had associated the visual sensation of a little flat stone with that of the entrance to the nest. Marchand (1900) has made a similar experiment with the same insect, and Turner (1908) with the Anthophoras. Bordage relates that he disoriented a spider-hunter, Pison argentatum, by simply displacing the furniture of the room in which this wasp had built its mud nest. The Pelopæus wasps have the same habit as the pre-

1 E. L. Bouvier, Les habitudes des Bembex, 1901. (L'Anneé psychol. 1900.) 


\section{THE PSYCHIC LIFE OF INSECTS}

ceding species, and are no less easily disoriented. Turner has stated that they found their nest with difficulty when he varied the play of light and shade in the locality where they were domiciled. Often the points on the way which strike the insect produce no impression on our senses. The Peckhams tried this with Bembex spinole whose nest was found in the middle of a clear space quite uniform in appearance. They smoothed over the surface of the ground during the absence of the insect, which upon its return flew all around before finding the spot and then dug for some time before reopening the nest. It is clear that to these little creatures the least objects have a guiding value which larger bodies do not have, for it is necessary to fix the exact place where the very narrow entrance of the nest is to be opened. After he felled a sycamore in the immediate neighborhood of his hives, Bethe noticed that the bees were not at all troubled by the disappearance of the tree and entered their hives without hesitation. He wrongly concluded that the memory of places plays no part in the return to the nest, forgetting, without doubt, that while a large tree may serve as a guiding point from a great stretch of country it would not be a guide for the insect to the narrow door of its hive.

How is it possible for insects to mark the exact 
point to which they ought to return? It is a fact well known to bee-keepers that the young bees when they leave the hive for the first time, and the old ones when they first leave a hive which has been moved, make a reconnaissance flight before their home. The bee, says Pérez, begins in this flight to study "the door, the surroundings, and successively, farther and farther, the neighborhood," looking always toward the nest. Then, "when it has fixed in its memory the topography of the region which it inhabits," it turns its head away and "learns to know and to fix in its memory the objects farther and farther from its house." This is not a simple hypothesis. The young bees, observes Buttel-Reepen, do not find their nest again when one takes them even a short distance, and the old ones are confused when one has carried their habitation very far from the places which they are accustomed to frequent.

Most of the flying Hymenoptera, if not all, make these reconnaissance flights when they establish their nests, and many of them every time that they leave on a collecting-trip. The Peckhams have made some interesting observations on this subject. They have even put down graphically the flight which the insect makes before quitting its stamping-ground. It is a spiral, the turns of which depart more and more from the orifice, 


\section{THE PSYCHIC LIFE OF INSECTS}

but these turns are simply sinuous in Sphex ichneumonea (Figure 8) while they are ordinarily complicated with numerous rings with Astata $b i$ color. Sometimes the reconnaissance takes another character. When it leaves its nest, Ammophila urnaria sometimes hunts several days before finding its first caterpillar, which obliges it to go

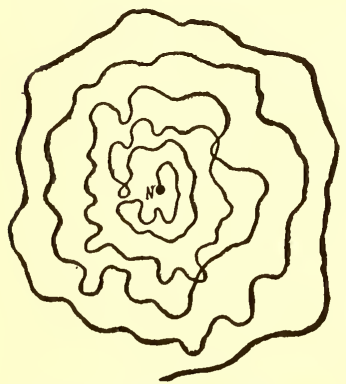

Fig. 8.-Reconnaissance route of Sphex ichneumonea when she leaves her nest N. (After the Peckhams.) back to visit the place at intervals in order to keep the recollection of the locality fresh in its memory. When, on the journey, the wasp has to drop her victim, she starts on a flight of reconnaissance around it, which will permit her to find it again. This characteristic manœuver has been noticed by all biologists. It is often very short, but rarely insufficient. Evidently, aërial insects have an excellent and rapid topographic memory, to which, without doubt, the mosaic vision of their composite eyes contributes.

In support of this I will relate the following observation, which is one of the most suggestive among those which Bembex offers: A stone, P (Figure 9), flat and white, had been left several 


\section{THE FACULTY OF ORIENTATION 245}

days about one decimeter from the opening, $\mathrm{A}$, of a burrow. One morning (during the absence of the Bembex) I covered under a uniform coat of sand, for a space of six or seven square decimeters, the poor blackish vegetation which surrounded the nest, and replaced the stone at the

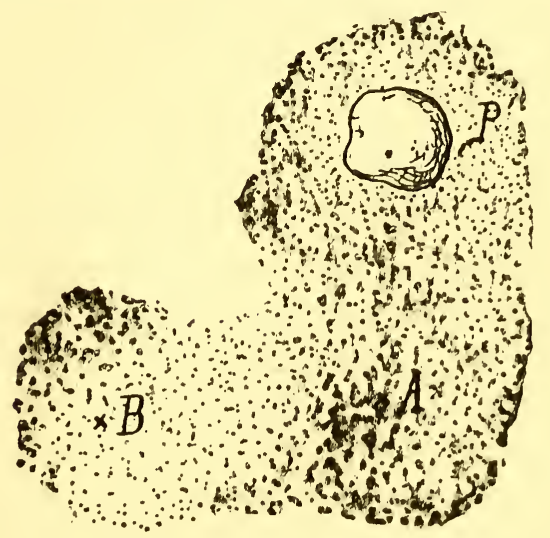

Fig. 9.-Zone explored by two specimens of Bembex whose nests, situated at $A$ and $B$ in the neighborhood of a flat stone, $P$, have been covered with sand before $(B)$ and after $(A)$ the issuance of the insect.

point $\mathrm{P}$. Some minutes after this operation I saw a burrow, B, which I had not noticed, open, and out came a Bembex, which closed it immediately, made some reconnaissance flights, and went away toward the fields. Its absence was short. It returned two minutes afterward without any 


\section{THE PSYCHIC LIFE OF INSECTS}

prey, but, not having exactly taken its bearings on departure, it wandered in all directions for a quarter of an hour around the point B (the dotted space), scratching, digging, waving its antennæ, after which it finished by finding the right point, and reëntered. Meanwhile the Bembex of burrow A had returned, carrying a large Eristalis. Disconcerted by what had been done in her absence, she flew undecidedly for some instants over my artificial cover and then ended by bumping into the side of the stone (that is to say a decimeter away from the orifice) and beginning to dig. But she soon flew away, explored the country within a range of some meters, returned to dig near the stone, left again, finished by leaving her Eristalis, to begin digging again, explored the space marked with dots around $\mathrm{A}$ and $\mathrm{P}$. This lasted forty-five minutes, and it would have lasted much longer. I came to the rescue of the poor creature, by showing her the orifice of her nest. What a difference in the return of the two wasps, and how important does the reconnaissance flight appear which permits the former to alight in the exact vicinity of her nest!

Non-perceptible end with or without intermediary guiding points. We know now that flying insects, once in sight of the spot where their nest is established, find the orifice of the latter by means 
of visual sensations fixed in their memory. It now remains to know the manner in which they have been led to the point where this spot becomes perceptible.

Bethe enclosed some bees in a box, and set them at liberty at least three or four kilometers from their hive. All returned to the domicile except two, which flew to the box placed upon a stone. It is an "unknown force" which guided them, says Bethe, but Buttel-Reepen and Forel observe that the bees had foraged over a wide range, that they recognized guiding points, and that the two which remained in the box were young ones which had not yet gone a-foraging. Fabre carried some Chalicodomas far from their masonry nest, and liberated them at distances which varied from one to two kilometers. Of the 144 individuals, 47 returned to the nest after intervals of from five minutes to several hours, and Fabre concluded that these bees are guided by a special sense of orientation. It is very clear, however, that some insects erred; that the greater number were lost, and that the others, more lucky, had noticed guiding points. I have made a calculation, in fact, that the number of bees which returned to the nest is reduced in proportion as the distance is increased: at two kilometers, five out of ten; at three kilometers, from three to four; and at four kilometers 


\section{THE PSYCHIC LIFE OF INSECTS}

a little less than two. The influence of the memory of places is plain.

To avoid criticism, Bethe and Fabre carried their insects to places which they had never visited. The hives of the former were situated not far from Strasburg. The bees were liberated in the city itself, at 350,400 , and 650 meters from the hives, to which they returned after a time which varied from one minute and a half to ten and a half minutes. The insects of the second were mining-wasps of the genus Cerceris, which, liberated in the middle of the city of Carpentras at three kilometers from their nests, returned there in the proportion of five out of ten. But it is very certain that bees frequent cities, where they know marvelously well how to discover sweet things, and the long time which they took to return shows that they knew the streets of Strasburg, for they fly at five-hundred meters a minute in the open country. As to Fabre's Cerceris, perhaps they did not know Carpentras, but they knew the neighborhood, where some of them reached known places which guided them to their nests.

Set at liberty in a place which they have never reached in the course of their journeys, insects seek vainly for their route. Buttel-Reepen carried a closed hive seven kilometers and took 


\section{THE FACULTY OF ORIENTATION 249}

from it some bees, which he kept in a box and set free forty and eighty meters from the new place. They did not know how to return to the place where their nest had been, and Bethe explained this phenomenon by saying that the "unknown force" acts only from three to four kilometers. But this is a mistake, for they did not return to the displaced hive however near it was. Is it necessary further to establish the fact that the memory of places is confused with the "unknown force" of Bethe and the "topographic feeling" of Fabre? 'Romanes established a hive in the second story of a house which was separated from the sea by a lawn and which had at the right and at the left beds of flowers. When the bees had formed the habit of entering and going out by the window of the apartment, Romanes took advantage of their nocturnal sleep by closing the door of the hive, and next day captured a certain number which he used in his experiments. Some were liberated at sea not far from the coast, others upon the shore two hundred yards from the house, others in the flower beds. The last all returned to the hive; but none of the others returned, because they had not explored the lawn and the sea. Yung made a similar experiment on Lake Geneva, and concludes with Romanes that bees are 


\section{THE PSYCHIC LIFE OF INSECTS}

incapable of reaching a point which is known but not perceptible when they have not explored the region which separates them from it.

To the memory of visual sensations must be added the memory of olfactory sensations. Ferton gives some curious examples in his studies of the shell-inhabiting Osmias. Displaced for some centimeters, the shell in which the bee nests is found on the sand even when it is crushed; it is also found when it is hidden in a tuft of herbage; and when it is replaced by another shell of the same species the insect notices the fact, disdains the substitute, and leaves in search of the shell which belongs to it. 


\section{CHAPTER XII}

THE FACULTY OF ORIENTATION WITH TERRESTRIAL ARTICULATES

Different articulates. Aside from insects, we know only a little about orientation with terrestrial articulates. That is why it will be interesting to report the following observation concerning Agelena labyrinthica, a very common spider which wanders about during the summer, while in the autumn it constructs funnel-shaped nests upon hillside herbs. On a beautiful day in the month of August, I noticed (1909) an Agelena carrying a grasshopper which was mutilated but still fresh. I teased the creature in order to make it leave its prey, and I chased it a little distance away,some centimeters at first, then ten centimeters, then twice that distance. Each time it made a half-turn and came back to the grasshopper. I drove the spider forty centimeters away, and it returned again in its footsteps, and, crossing the short turf, where it stopped, several times moving its palpi, finished by directing itself straight and 


\section{THE PSYCHIC LIFE OF INSECTS}

seizing the grasshopper once more. The animal was, then, capable of orienting itself toward a known point which it could not see. I believe that the spider remembered the direction taken in its chase and followed back the same route, but I also think that it was helped by the sense of smell and that this sense has its seat in the palpi which it feverishly waved. The nest spiders are known from their tactile sensitiveness, but their olfactory power is still mysterious and must soon be studied.

Orientation to a point is better known with the terrestrial insects. "By scent and by sight," says Fabre, the sacred scarab very quickly finds its ball which an accident has caused to roll away from it. The predatory wasps, which return heavily laden, are not equally apt in returning to the nest. Sphex subfuscatus, which captures the large Italian grasshopper, is one of the species best endowed in this regard because it carries on a minute scouting. "When it leaves the burrow which it has dug, to go and search for its grasshopper," says Ferton, "the Sphex pivots on itself without leaving the ground, probably to examine the aspect of the place, . . . several times, and at different points in the journey the wasp repeats this evolution."

There are even differences of aptitude with the predators which store their victim. Pompilus fus- 
cipennis appears the most maladroit. While it is digging its burrow, the insect returns often to examine the inert prey, and although this is always in fact at a distance of only twenty or thirty centimeters, she does not find it easily. At times she draws it nearer the nest, in which case she can find it quickly. The Peckhams have given a diagram of the marches and countermarches executed by an individual of this species. What cleverness, on the contrary, is shown by a pompilid studied by Fabre! This one interrupts her mining work to visit the spider, but she goes in a straight line, and when the victim is removed a short distance she finds it very quickly, for she remembers the place where she left it. Fabre says :

The insect comes always to the last spot, without bothering about the others. I marvel at the memory of this myrmidon. It was enough for her to have seen once, in haste, a spot which did not differ in any respect from a number of others, to recall it very well in spite of her preoccupation as a miner excited by her underground work.

It is, indeed, sight which gauided her, not odor, for she passed over the spider without noticing it when it was covered with a delicate leaf. She had a surprising memory for places. 


\section{THE PSYCHIC LIFE OF INSECTS}

Orientation with the ants. Not less surprising is this conclusion of Fabre, who admits the faculty of scouting to walking insects whose horizon is necessarily restricted, while he refuses it to Chalicoderma and to Cerceris, - that is to say, to flying insects which embrace a vast space with their eyes. The entomologist of Serignan has observed correctly with the pompilids, but an insufficient analysis of his experiments has made him err with Cerceris and Chalicoderma. Both orient themselves in the same way,-by their eyes, which are large and fortified with numerous facets.

Is it the same with the worker ants? In contrast to the pompilids, they are obliged to walk exclusively, and though we know them to be endowed with sense of touch and smell, we also know that their sight is very imperfect. However, Fabre attributes to them, as to the pompilids, the faculty of scouting and a memory of places. Having seen the Amazon ant (Polyergus rufescens) leave in a compact troop to destroy a colony of another species and make slaves of them, he observes that the road of return is exactly that of going, that its route is the same after an interval of several days, that nothing stops the colony on this march, neither sweepings nor a thread of water nor very odorous leaves; in fact, that an individ- 
ual isolated from the column rejoins it very quickly if it departs a little into the explored territory, while it wanders by chance when one places it on the other side of the nest. From all these facts Fabre concludes that the Amazons do not possess the "directive faculty" and that they are guided by "sight helped by a memory of places," not by odor as many biologists think.

May we be kept from believing the truth of the solution proposed by Fabre! Of all the problems which the behavior of insects presents, this appears to us one of the most subtile and the most controverted. Following the example of Cornetz, who has tried to resolve it by many experiments, we will study first the mechanism of the orientation of exploring ants which start singly on a search for provender; and it is only after that that we shall observe the workers in collective expeditions on the ant roads. According to the very just remark of Cornetz", we shall see, in fact, "that the collective traject is only a consecutive and complex phenomenon having for its beginning the first path of an ant departing to a distance on a journey of discovery and having succeeded in finding either a place of provender or a propitious spot for the establishment of a new colony."

Exploring ants. (I) Rules of their march. Let

1 V. Cornetz, Les explorations et voyages des Fourmis. 1914. 


\section{THE PSYCHIC LIFE OF INSECTS}

us offer an appetizing bit to a worker looking for provender; she takes it and, often without turning, she marches, says Cornetz, in a certain direction which she holds, with or without angles, quite to the place where she will find her nest or a colony.

Is this return road familiar to her, or is the in-

s sect guided to her home by her

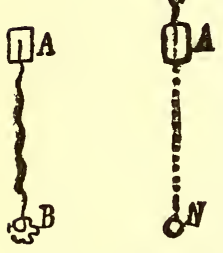
senses, or by a special instinct, a homing instinct? Piéron (1904) has shown us by experiment that Cornetz has given a good name to this phenomenon. A worker of Messor is returning to her nest (Figure 10,

Fig. 10.-Route followed by an N) and, meeting a movable support which comes $(A)$, prepares to proceed: "displaced back to its nest with the support, without which $N$ when this her journey would be confused, and upon a support placed in a similar situation at $\left(\mathrm{A}^{\prime}\right)$ This route is known or unknown," she, "directs parallel to that herself toward a point (B) correswould have foi- ponding to the position of her nest, lowed, but, ar- so that, if it had not been moved,"
riving at $B$ at so the distance of she would have gone exactly to it.
the nest, she turns around to In other words, she follows a path Pearch. (After parallel to her first direction and to a distance equal to that which would have led her 


\section{WITH TERRESTRIAL ARTICULATES 257}

to the nest; but, on account of her removal, she does not reach the nest.

Before Piéron, Lubbock had tried, in ignorance, a similar experiment. Some yellow ants (Lasius flavus) in an artificial nest (Figure 11, N) went by a narrow bridge, $p$, to larvæ placed in a beaker (C) on a table, and proceeded back and forth be-

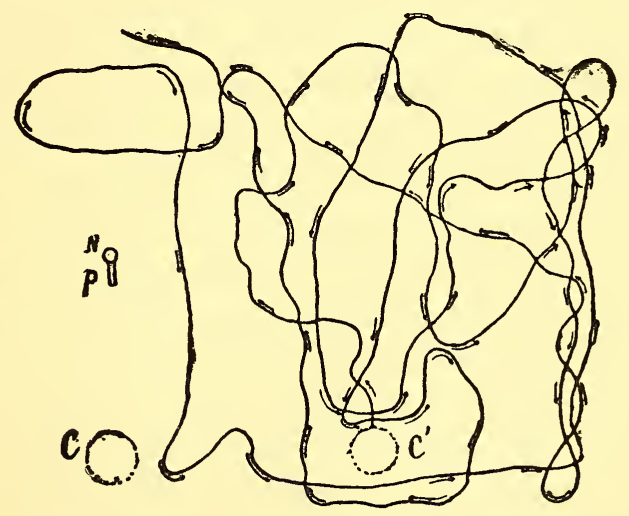

Fig. 11.-Route taken by a Lasius flavus which wandered between its nest $N$ and the larvæ in a cup $C^{\prime}$ when the last were removed to $C$. (After Lubbock.)

tween the beaker and the nest. The beaker was moved three inches (to $\mathrm{C}^{\prime}$ ) while the ant was busy with the larvæ. Its work finished, the insect took the return road, but, instead of directing itself toward its nest, it followed a direction nearly parallel to this road, continued still, and always in a 


\section{THE PSYCHIC LIFE OF INSECTS}

nearly parallel direction which did not lead it to its nest. The ant retained the orientation of its early journeys. This important result did not strike Lubbock at all, and it is to Cornetz that the honor is due of having shown that it confirmed in advance Piéron's rule.

Cornetz repeated the experiment of Piéron, not only when the ant followed the direction of its nest but when it was hunting. He offered it a bit of food on a support, and, while it was busy in choosing a particle, he gently turned the support without disturbing the insect. This ant was not at all disoriented. As soon as it took its morsel it directed itself in a certain way, always parallel to that which it would have taken to reach its nest. And this happened whatever rotations were made or in spite of the disturbance which occurred on its journey. When the ant was carried to the other side of the nest it marched away from it, a phenomenon which Fabre has noticed with the Amazon ants, but $\cdot$ which he attributed to their faulty knowledge of places.

Quite different is the behavior of the exploring worker when one takes it on its issuance from the nest to place it at a considerable distance. Once in possession of its food, it is completely disoriented; turns on the support, leaves it, makes circles more and more extended through the neigh- 


\section{WITH TERRESTRIAL ARTICULATES 259}

borhood, and often abandons its morsel of food. At two meters it was necessary for Cataglyphis (Myrmecocysts) to make a long march to find its nest; at two-hundred meters, it searched for a day without success. However, ants are among the best travelers and, rapid on the march, extend their hunts well beyond two-hundred meters. So the return is the function of going, which it follows in an inverse sense. An exploring ant, moved on leaving the nest, is incapable of returning to it; but a single journey out is enough to enable it to orient its return.

(2) Interpretation of these rules. Such are the important rules established by Piéron and Cornetz. It remains now to interpret them.

What determines the direction of the explorer is the object of going; but how can an explorer preserve this direction in the course of a journey which cannot be regular, on account of obstacles and the necessity of searching? How, especially, is it capable, on going from the nest, to keep the same direction every time it starts toward a definite point?

The sense of angles permits it to preserve its direction. Let us note first that in leaving the nest an explorer always goes in a straight line. Experience taught it that it can find very little in the neighborhood of the nest and that its 


\section{THE PSYCHIC LIFE OF INSECTS}

search, to be fruitful, must extend farther. This straight line gives a general direction to the journey. If the insect is going to a known spot it will only have to preserve the direction, oscillating more or less, according to custom. We can, ourselves, up to a certain point, keep a direction without knowing the surrounding objects.

The phenomena are ordinarily more complex. The going path is not always direct; it often takes

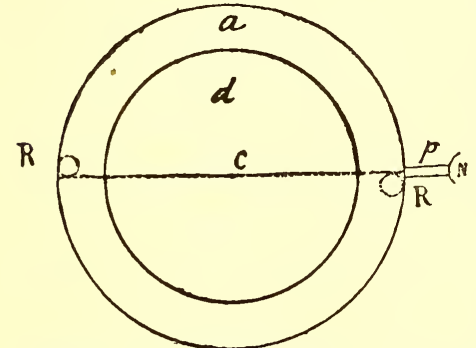

Fig. 12.-Experiment of Lubbock. (See text.)

the form of a broken line whose angles approach more or less a right angle. Some experiments of Lubbock teach us what happens then. A large horizontal disk (Figure 12, d), turned on a pivot in its center, was prepared. It was contiguous to a ring, $a$, situated in the same plane, and which also turned, but independently. The whole formed a circular table. At the end of the diameter of the table was a narrow bridge, $p$, which led to an artificial formicary, $\mathrm{N}$, of Lasius niger; at the other diameter was a reservoir, $\mathrm{R}$, which contained the larvæ of this species. The ants followed the diameter in order to go to the larvæ. If 


\section{WITH TERRESTRIAL ARTICULATES 261}

one turned the disk while they were busy, they turned themselves at an equal angle, but in the contrary sense if they were to preserve their direction and reach the reservoir. And it was not the attraction of the larvæ which guided them, for, if the table was turned 180 degrees, they turned as much, which led them to the end of the diameter but not to the reservoir, which brought them now to the bridge at $R^{\prime}$. So the ant noticed the angular deviations. It had what Cornetz calls the sense of angles, and P. Bonnier the sense of attitudes, which permits it to correct deviations and to march parallel to its original direction. What is the nature of that sense? We do not know. With the vertebrates it has for its seat the labyrinth of the ear; but the ants are deprived of this organ, the rôle of which is perhaps filled, we think, by the faceted eyes, which are very sensitive to displacements.

Cornetz does not deny to the ants the sense of angles, but he thinks that these insects can preserve their direction, when it is interrupted, just as well through a succession of angular sensations, and he offers as proof of this fact that a Messor "appeared insensible" to the slight rotations which he gave a specimen while it was absorbed in choosing its food. It did not rectify the angles, and left for home in the right direction when it 


\section{THE PSYCHIC LIFE OF INSECTS}

had grasped its morsel. But is it very certain that the ant had not noticed the rotary movement, and was this not perceived in spite of the care which it was devoting to the choice of its food? Evidently it acted automatically, but was this automatism greater than that of the Lasius of Lubbock upon its disk? And the Saharan guide, of whom Cornetz (1910) speaks-did he not automatically preserve his direction in the desert although absorbed in his chase of gazelles? We believe that the ants are capable of noticing and retaining their angular displacements without any interruption, and consequently are capable after each angle to take a direction parallel to the preceding. This is not the idea of Cornetz, who concludes from his experiments that "the ant can maintain a special direction without need of associating it with a previous position.

How is the direction taken on issuing from the nest? Cornetz arrives at the same conclusion, which appears to him to be the essential result of his researches, when he studies the capital phenomenon of orientation to learn the direction which an exploring ant takes on starting out from its nest toward an unknown point, a place of provender, or an old nest. And he bases his thesis on the following observation. A colony of Cataglyphis had abandoned its home for another one sit- 
uated forty meters to the north. The new nest having been broken up some days after, Cornetz observed that "from the heap of rubbish there issued some large workers which set out without hesitation toward the south, carrying larvæ toward their old nest." These ants "retain, then," he adds, "for several days, the direction of the old nest, and that, independently of the position of the sun at the moment of the disturbance, as well as a visual, olfactive, or tactile sense of the ground between the two nests." An observation of Wasmann ${ }^{1}$ seems to confirm Cornetz's views. Some sanguinary ants, Formica sangui$n e a$, had established themselves in a new nest from which the top turf was removed after some days, and a certain number of workers, seizing the larvæ, fled singly toward the old nest across plants and other obstacles which separated them from it to a distance of eighteen meters. Odor could have played no part in this migration, for rain had completely washed the soil, and Wasmann thinks that the ants were guided to their ancient nest by the visual memory of places.

Wasmann's conclusion seems better justified than that of Cornetz, but the visual images of the topographic memory should not be confounded with sensations. One can distinguish between two

1 E. Wasmann, Die psychischen Fähigkeiten der Ameisen, 1899. 


\section{THE PSYCHIC LIFE OF INSECTS}

lights of different intensities without perceiving the image of the objects made clear by these lights. But there is no doubt that these differences of light play a part in the orientation of ants. Lubbock has observed that his Lasius niger oriented itself by the light of a candelabrum placed near the table. Those accustomed to this light behaved like those we have mentioned (page 260), but they did not reëstablish the angles any longer, and walked in the opposite way, with or without

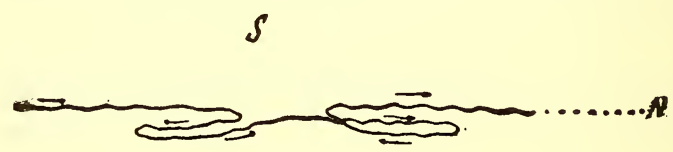

Fig. 13.-Two deviations made by an explorer of Messor when, crossing a shaded spot to return to the nest $N$, she receives from the right the sun's rays reflected by a mirror. (After Santschi.)

the rotation of the disk, when the candelabrum was placed at another point on the border of the table. They oriented themselves toward the light. The following experience of Santschi (1911) is still more significant. An explorer of Messor came back to its nest (Figure 13, N) toward evening, lighted at the left by the sun. On arriving at a shaded place where it continued its journey directly, the insect received the sun's rays reflected by a large mirror situated at the right. It immediately changed its direction, and walked in 
such a way that the rays from the mirror struck it from the left. It oriented itself by the rays from the mirror just as it had done by the direct rays of the sun.

Viehmeyer on the one hand and Turner on the other have arrived at the same result by different methods. Viehmeyer (1900) reared Leptothorax unifasciatus which had established their nest in earth in the middle of a transparent bottle. Having carried the bottle near to a window, he saw the insects dig another nest on the opposite side and carry their larvæ to it. While they were moving, going from the light to the dark side, he turned the bottle 180 degrees, which had the result of placing the new nest toward the window, but did not prevent the ants from continuing their moving toward the opposite side. The experiment of Turner (1907) more nearly recalls that of Lubbock. Upon a horizontal platform communicating by several bridges with an artificial nest, the ants were thrown with their eggs. When their fright passed, the creatures thought of their precious progeny, which they carried to the nest, using one of the bridges. The route once established, the lamp, which lighted this scene from the side, was carried to an opposite point, which caused new trouble. Soon, however, the ants again began their regular march, but, oriented by the lamp, 


\section{THE PSYCHIC LIFE OF INSECTS}

they went the reverse way and reached the nest by the opposite bridge.

Contrary to Santschi, Cornetz thinks that the ant directs itself "independently of the position of the sun," that it preserves in its sensorium a "pure direction" without any modification, and he advances as a proof the fact that it directs itself in the shade as well as in the sunlight. To this we may reply, with Santschi, that even on a shady journey the side toward the sun is lighter, the ants are more sensitive than we are to differences of radiation, since they react to the ultraviolet, and that, even in the night, it is very possible that they orient themselves by the stars in a spot covered by zones of shade and light. These hypotheses have in them nothing of the improbable, although it will be necessary to justify them by experiment. On the other hand, it is not to be doubted that ants can orient themselves, not only by the sun, but by all the large objects which surround them. We do not ignore the observation of Forel upon the Lasius, which followed him in his movements and confused him with a tree. Santschi reports several similar facts,-a worker of Messor correcting its orientation by the presence of a great heap of sheaves when disturbed in the experiment of the mirror, Camponotus orienting itself by a date-tree, Aphonogaster taking a 
wall for a point of guidance. Thus to the guidance from the sun, which is certainly of prime importance, may be added, and is added in many cases, the guidance from different more or less lighted zones, and it is by means of these multiple things that the insect orients itself. "If one of these zones rapidly disappears from the visual field (passage of the sun into shadow)," observes Santschi, "the insect continues to use the remaining zones, but if there is a sudden transposition from these zones (experiment of the mirror) the insect, taking a new direction corresponding to the change, only maintains its orientation in relation to the guides of an habitual preponderance."

How can we explain the orientation of the insect when some catastrophe has destroyed all of the guiding points in the vicinity of the nest, on the theory of resting zones?

In the experiment of Cornetz upon Cataglyphis, and in that of Wasmann on the sanguinary ants, certain individuals returned to the old nest, but they did not know whether or not the individuals had retained the habit of visiting this nest, and it would not have been surprising if all had returned. We may, in fact, believe that, upon the destruction of their nest, the workers fled in all directions, and that certain ones, finding themselves on an unknown route, recognized the guid- 


\section{THE PSYCHIC LIFE OF INSECTS}

ing points which led them to the old nest. In fact, it is useless to discuss experiments of which the details are not all known, since these details may have a fundamental importance. If it were established that our insects can orient themselves solely by the light of the sun, we should be "led far," observes Cornetz,- that is to say to the conception that ants know how to estimate its height at different times of the day. Evidently this supposition cannot be admitted without a rigorous experimental examination. Although it appears strange and improbable, it does not perhaps exceed the faculty of apprenticeship of these animals, to whom orientation is a vital necessity. In admitting "that the ant can preserve a direction independent of environment," Cornetz departs still more from the truth. We cannot too highly esteem the patient researches of this experimenter and the progress he has made in the difficult problem which we are considering, but we think we ought to say, with Santschi, "as far as the new and inexplicable facts concerning guiding points are not registered and verified, so far shall we not have demonstrated the seat and the nature of the sense of pure direction." To admit a sense of this kind "will remain a useless hypothesis and an explanation which should be reserved as a last resource." 
To sum up, ants orient themselves essentially like flying insects, - that is to say, by the visualized aid of near or distant bodies, utilizing their memory of places and the recollection of impressions which they have received through other senses, especially that of smell. There are many degrees between the eyes of a wasp or of a bee and those of the most poorly endowed ants, and it would be at least surprising if a mysterious sense of orientation had come to the latter and not to the former. Incapable of leaving the ground, and provided with eyes having commonly less numerous facets, the workers of the ants have a narrower horizon,--and that is all.

According to the condition of their eyes, and the conditions under which they live, ants employ in their orientation the eyes or the antennæ. Forel has stated that Formica pratensis, after their eyes had been varnished, "had trouble in finding their way while outside; while they "directed themselves earily in their rearing-boxes" filled with odors. If the insect is completely blind like Eciton carolinse, then it guides itself exclusively by smell and by touch. Forel says (1900):

Throw a handful of Eciton with their larvæ upon an absolutely strange ground. . . . In such circumstancesin which other ants spread out in disorder and take an hour or more (sometimes less) to reach order again, to 


\section{THE PSYCHIC LIFE OF INSECTS}

bring their nymphs together, and especially to remember the surroundings- the Ecitons organize themselves without losing a minute. In five minutes they have formed distinct files of workers which do not leave one another, tapping the earth with their antennæ, exploring all the holes and cracks until they find a convenient cavity. Then their arrangements are executed with an astonishing order and rapidity. The workers follow and understand one another, as if at a password, and in a very short time everything is all right.

(3) Turner's "circling." During the second part of their journey, that of their return, the workers march in perfect order toward the nest, in a straight line or one parallel to the line of ooming out (Figure 14), without the circuits necessitated by the search for food, but, arrived near the nest, the insect changes its attitude; it hesitates, searches, describes circles or sinuous arcs of a circle which finally lead it to the orifice. This is what Cornetz called Turner's circling, using the name of the learned American who has best studied this phenomenon.

Although well oriented during its return, it is rare that the explorer goes straight to the orifice of the nest. The first orientation cannot be perfect, and also the road of return is not superimposed on that of going. It is more or less parallel, so that it will be to one side as it approaches 


\section{WITH TERRESTRIAL ARTICULATES 271}

the nest. But arriving in this region, the insect recognizes familiar objects and familiar odors; it can perceive the odor and perhaps the noise of the nest. Thus its memory comes into play and

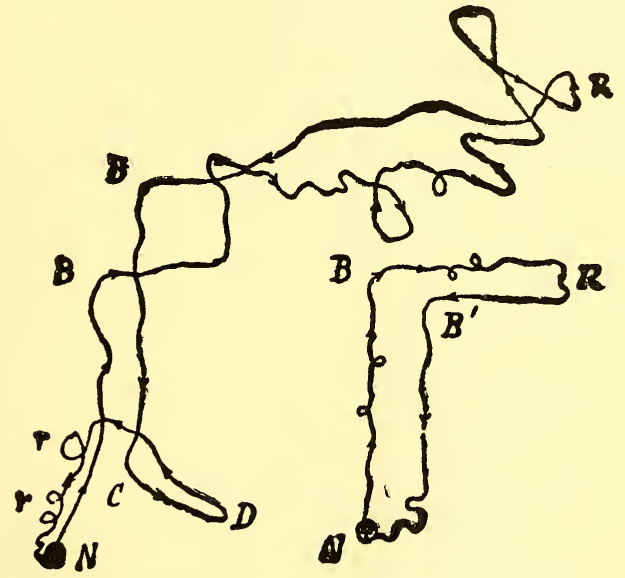

Fig. 14.-The going and returning of an exploring ant. At the right, a scheme of going and returning in the opposite direction. At the left, the real path of an exploring Messor which, leaving its nest $N$, made from $B$ to $R$ a side exploration, coming straight to $B^{\prime}$, where she made an angle equal to $B$, but, having taken this angle a little too soon, wandered from $C, D$ through $r, r$, and finally found her nest again. The distance from $C$ to $D$ was about 1 meter. (After Cornetz.)

chooses the proper guides to lead it to the nest, which it finds by its circlings (Figure 14, C, D, $r, r$ ).

Sometimes one of the guiding points seems to be sufficient, and then the insect makes a sharp 


\section{THE PSYCHIC LIFE OF INSECTS}

turn to march directly to the orifice. This is the way with Cataglyphis. Cornetz followed one of these running ants during its return journey. Its march was rather sinuous, but at a point situated some meters from the nest it started straight toward it. It turned before the orifice and stopped at a distance of one or two meters, and resumed the sinuous method to another point, where it suddenly turned straight toward the nest. Cornetz tried this over and over again, and found that the ant recognized, from having doubtless visited them already, a certain number of guiding points fixed in its visual memory. According to Cornetz, a single one of these points was enough to give it "the pure direction" which led it to the orifice. But these points were numerous. There were not less than thirty of them in a space of eighteen meters where Cornetz made his experiments. Thirty, without counting those which he did not discover! That is a good many "pure directions" to be kept in the memory of an ant! Is it not more logical to believe that the insect simultaneously sees. several points of near-by guides, a small local topography, and that it utilizes these to establish the direction of its nest? The Cataglyphis ants have a distinct sight. According to Cornetz, they can distinguish the form of the smallest objects at five or six centimeters, and 


\section{WITH TERRESTRIAL ARTICULATES 273}

many guiding points are at a lesser distance in the plane which the author studied in the course of his interesting experiment.

This circling is always carried on when the ant seeks its nest, even when it is far away. Having gathered some Cataglyphis at the moment they were starting out, Cornetz placed them several meters away. Completely upset, they described larger and larger circles,- - which permitted them, without doubt, to find guiding points and to gain their nest.

Estimation of distance. The experiment of Piéron (page 256) shows that the sensorial excitants are not the direct cause of the circling. Transported to a distance, the insect follows a path parallel to the first direction, and begins to circle at a point from which, if it had not been moved, it would have quite certainly reached its nest. It circled to seek a guiding point; and it had, then, an idea of the distance to be covered.

Piéron explains this phenomenon by attributing to the ants a "muscular memory, the memory of the different motions made to go from one point to another, a reverse memory, allowing return to the original place." It is clear that this faculty plays no part in orientation, for, as Cornetz justly says, "a pedometer is not a compass." Moreover, if we observe that the explorer does not on 


\section{THE PSYCHIC LIFE OF INSECTS}

the return follow the path of going, that it meets other obstacles and ordinarily returns with a burden, we cannot accept such an hypothesis as Piéron's. But we may happily modify this hypothesis by supposing with Santschi that the insect can to a certain degree estimate the sum of the effort made during the outward journey and estimate the time of the return by taking into account the additional effort required by the burden. We must not forget, also, that this estimate of distance is only approximate.

There is also the estimate of the distance the ant must travel in returning compared with that in going, when that was an angled line. In the rare cases where the two routes are very close, it is possible that the guiding points indicate to the insect the apex of each angle. But, contrary to Santschi, we do not believe that this rule is general. It seems more reasonable to admit that the ants have a notion of the distance between the apices of each angle, and that the changes of direction, are perhaps due to memory of angles (usually nearly right angles) or a more or less distant guiding point. Here again we must note that these estimates are always approximate.

As we have seen, our ignorance of these phenomena is still very great, especially if we add 


\section{WITH TERRESTRLAL ARTICULATES 275}

the fact that we do not know why the circuits for search made in going do not enter into the esti-mate of the effort to be produced on the return journey (Figure 14).

In the course of experiments carried on with Formica rufa, Szymansky has noticed that if one places an obstacle transversely upon the scent which the ants follow, the insects join the route diagonally when they have reached the extremity of a long obstacle. Working in the same way with Messor, Santschi observed that the individuals behaved differently; some continued their march in the direction of the obstacle, others took a direction parallel to the scent, and certain others rejoined the line of march diagonally like Formica rufa. It seems that these insects were urged by two "force ideas,"-the one which led them to return to the scent, the other which preserved the original orientation, and that from the conflict of these two ideas came the behavior of each individual.

Whatever may be the value of this interpretation proposed by the Swiss biologist, it is established that our insects are capable of taking the diagonal, but they do not do this when they are following a scent, an ant road. If the explorers do not behave the same and take on return the reverse of the outward route, it is perhaps be- 


\section{THE PSYCHIC LIFE OF INSECTS}

cause such a method would defeat the end which they are pursuing. They return to the nest and are guided to it by their memory of distances, of angles, and the orientations of the journey. By taking the diagonal at each angle they profoundly upset their recollections, for the road which they are following is not a scent, and after they have followed a diagonal nothing allows them to recognize where and how they ought to change their direction.

Upon the ant roads. To reach the exploitation field where they find food, many ants follow visible and well-traced routes which radiate around their nest. These routes are commonly rather broad near the orifice, sometimes several centimeters in breadth, but they become progressively narrower, sometimes branching, then ending in uncharted ground where the ants act as explorers. The Messors, most of our species of Lasius, Formica pratensis, and Formica rufa, the Tapinomas, the Pheidoles, etc., make routes of this sort. The species of Cataglyphis, on the contrary, travel individually. Aside from these permanent roads which may be abandoned after exploration, ants often follow temporary roads which are made in great number during a limited period. It is almost always when they are moving the colony that the ants which have permanent roads establish 
temporary roads, but this is also done when exploration is in view, as has been noticed with Atta in tropical America, which climbs trees to cut bits of leaves destined for its fungus gardens. Several species in our country make only temporary roads. The sanguinary Formica and its near relative, the ash-colored Formica, make very few others, and only at the time when they are moving the colony. Roads of this sort are followed by the Amazon ant when it is going to neighboring nests of Formicas to capture the brood which will give it slaves. Each expedition comprises a whole phalanx of workers, and the path remains until the pillage is completed.

The establishment of a road. According to Forel, this is how the Amazons (Polyergus rufescens) go to the "nest of Formica rufa, situated often from forty to sixty meters away and quite hidden. In the springtime and in the summer days the Polyergus workers individually leave their nest and explore the vicinity for great distances, thus discovering the nests of the species which they pillage. It can be stated with certainty that these are scouts, which later become guides." Thanks to the memory of the places which they have scouted, they serve as guides to the phalanx, and this memory is not purely visual, as Fabre believed, but also olfactory and tactile, 


\section{THE PSYCHIC LIFE OF INSECTS}

since, "deprived of its antennæ, a Polyergus cannot orient itself."

It is always with the path of an explorer that the establishment of a temporary or a permanent road begins. When the ants are blind they follow the road of the explorer solely by the antennary sense, as we have seen in the experiment of Forel with Eciton carolinense. Certain ants with sight indicate the route to their sisters, and leave on it a slight scent from the end of the abdomen. Thus it is with our little Tapinoma erraticum, according to Forel and the experiments of Santschi; and also with Lasius niger, according to Lubbock.

We owe to Cornetz exact experiments upon the way Messor establishes its permanent roads. A nest of these mining ants is found in a poor plare without herbage or graminaceous plants in the neighborhood. A worker leaves for exploration, and is offered a package of small seeds. The insect profits by the prize, and makes many journeys between the nest and this provender. Other workers go out in turn. Guided, without doubt, by the scent trace of the explorer, they follow the scent of their sister for a certain distance from the nest; then they spread out fan-shaped, and only part of them reach the seeds. In proportion as the number of seekers multiplies the common 
WITH TERRESTRIAL ARTICULATES 279

scent increases. It is not to be doubted, Cornetz justly observed, that the putting out of provender brought about a slow change from a hunting country into a road; then later, in following days, a progressive transformation of the road into a permanent route visible through frequent use.

Behavior of ants on their roads. The antennal senses (tactile, and especially olfactory) play a predominant part in guiding ants on their roads. We already know that the Amazons are incapable of following. when the antennæ have been cut off. Forel has shown that Formica pratensis wanders in all directions and finishes by remaining motionless, when it has been submitted to the same operation; while it makes turns and detours but nevertheless arrives at the correct objective when the eyes have been varnished. Pieron reached the same result with Messor. These ants depend greatly on tactile impressions, for they are disquieted and tap their antennæ in all directions when some familiar object is removed or when one places an obstacle on their route. Lasius fuliginosus, whase sense of smell is much more acute, does not seem to hesitate when traps of this kind are prepared. With Formica cinerea the eyes and the antennæ seem to play an equal part.

An old experiment of Bonnet (1745), often repeated since, emphasizes the rôle of smell. It con- 


\section{THE PSYCHIC LIFE OF INSECTS}

sists in passing a finger across the road used by ants. There is then a great disturbance. The travelers pause, hesitate, disoriented by the disappearance of the familiar scent and by the sensation of a new odor. Sometimes a simple sweeping suffices, as is the case with the Tapinomas. With others, like the Messors studied by Piéron, vegetable odors, washing with water, or the displacing of dust do not interrupt the march. Like the Tapinomas, the Amazon ants, stopped by this means, end nevertheless by again taking up the march. One of them experiments in crossing the barrage, others follow, and soon the entire phalanx emerges on the refound scent. This shows, says Forel, that the sense of smell rather than sight guides the insect on its route. As we shall see later, "the ant on her return knows and feels by her scent from which side she went, and necessarily deduces from this that to return she ought to direct herself in the opposite way. Should a barrier appear (nature produces one sometimes) she hesitates, then learning what the matter is, since the scent which she has behind her she brought from the pillaged nest and not from her own, and since there are no others, she does not hesitate any longer to cross the barrier."

To conclude this section I will cite some experiments of Santschi, who shows very well the rôle 


\section{WITH TERRESTRIAL ARTICULATES 281}

of the different senses in the orientation of ants by scent. A stick is laid across a road followed by Messor; this is a normal obstacle which the passengers cross going and coming, but when it is raised and placed out of the road, ants remain attached to it or go away a little to return to it, for it is their only point of guidance, a point especially odorous. Light rays reflected by a mirror simply produce an eddy in a band of Messor which is following a scent; they do not prevent these insects from continuing their journey. If the scent is interrupted, on the contrary, the ants are disoriented and direct themselves in all sorts of ways. They were guided by the odorous trace which has disappeared, and the light rays, far from serving them as a guide, have only increased their perplexity.

Direction followed upon a scent. Not only do ants know how to direct themselves by scent, but they distinguish it in the sense of going and coming. Upon a scent which had served at their colony-moving, Formica pratensis went back and forth between their nest and a tree where they were caring for plant-lice. Forel says:

Several times I seized the workers which were returning from the tree to their nest, their abdomens filled with honey, and I placed them each time again upon the line of the colony-moving, but about a yard from the place 


\section{THE PSYCHIC LIFE OF INSECTS}

whence I took them. Recovering from their first astonishment, and after having made several short circuits, they placed themselves each time, without being deceived en route, in the right direction leading to their formicary, never the opposite.

And Forel asks how they have been able to recognize by the scent the direction which they followed. Since "ants see badly," one is led to suggest the following explanation: With their mobile antennæ, in which the olfactory organs are varied and very numerous, these insects can explore by contact the odor fields following the three dimensions of space and form in their memory "a kind of chemical topography from the odors as elements of special energy." Much more, they perceive at a distance odorous emanations which increase in the air their "chemical geography of space, but in a more confused way." Thus, provided with this "topochemical sense which enables them to recognize forms and the relations of forms, they are capable of distinguishing in their odorous fields the differences which the traces of going and coming show on a scent, the right side and the left side of this, and consequently the direction which they should take. Not without embarrassment, the workers of Forel found the right way when their eyes had received an opaque varnish. With the antennæ cut off, they were 


\section{WITH TERRESTRIAL ARTICULATES 283}

completely incapacitated. Odor plays a much more important part than sight in this phenomenon.

This was equally shown in the pretty experinents made in 1882 by Lubbock. The eminent biologist had habituated Lasius niger to cross a little wooden bridge to reach their provender. When they were on the bridge, he turned it 180 degrees. The travelers usually executed the inverse rotation which is known to us, but in addition-and this is the interesting fact-they did not know enough to take the scent which they found before them when they arrived at the end of the bridge. On the contrary, when three similar bridges were placed in their way they crossed without the least embarrassment the two bridges at either end when they had been transposed without rotation (Figure 15, $b$ ).

Bethe (1908) has repeated with some modifications the experiments of Lubbock upon Lasius niger. These led to the same results, and he concludes properly that ants leave directive traces on their journey, but, considering insects as automata which act simply by reflexes, he supposes that the odorous traces represent a polarization and that, by reason of the contrary polarities going and coming, they are directive, in a reflex way, on the route. When the bridges are turned at 180 de- 


\section{THE PSYCHIC LIFE OF INSECTS}

grees (Figure 15, c) the travelers lose their orientation because they find themselves in the presence of inverted polarities. But Wasmann has had no trouble in proving that this deduction lacks foundation. Ant roads are covered with traces of both kinds, and if it is true that these traces are of contrary polarities, they should reciprocally neutralize one another. Even if it is not so, the
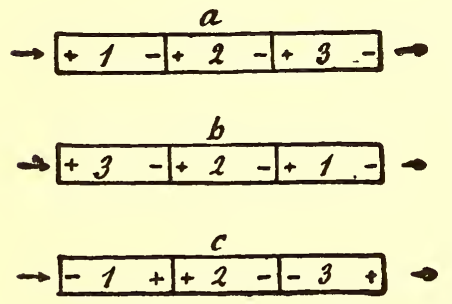

Fig. 15.-Experiment of Lubbock modified by Bethe. The Lasius ants pass over three contiguous little blocks 1, 2, 3, to return (a) to their nest. When the position of the end blocks is inverted without being turned (b) the ants continue their journey as at $a$, but if the blocks 1 and 3 are turned at 180 degrees they refuse to proceed on them when they themselves are on 2. If block No. 2 is turned at 180 degrees when the ants are on it, they also refuse to go on to the two neighboring blocks. rotation of a bridge on the route could not fail to disorient them, for the travelers would always meet before them traces of perfectly usable polarities. It would be difficult to deny the justness of these criticisms; and, moreover, Bethe has modified his hypothesis (1902) by saying that the term polarization expresses simply the idea that the odorous traces must be qualitatively or quantitatively different going and coming.

This is nearly the interpretation of Wasmann, for this biologist admits that the odorous traces 


\section{WITH TERRESTRLAL ARTICULATES 285}

differ in character according as the insect is going from its nest or returning, but, as Escherich ${ }^{1}$ remarks, in spite of this agreement the two biologists differ profoundly in their manner of interpreting the orientation of our insects upon their route. "According to the reflex theory of Bethe, the different traces are nothing but physiological excitants adequate to provoke the reflex of going and coming ...., while according to Wasmann, the ants really perceive the kind and quality of the odors. They can, according to circumstances, use or not use these perceptions, which they elaborate in new associations and preserve in the memory" to find and follow the right direction on their scent. Forel does not think differently, and the interpretation of Wasmann is nothing but the general placing together of the ideas of Forel on the topochemical sense. Assuredly this is to grant much to the ants, but it is not outside the domain of possibility and of experiment. Forel says:

Just think an instant: We have in the skin a sense giving us an exact knowledge of a thousand odors and shades of odors of all the bodies which surround us, not only when they touch us but even in the form of the most subtle emanations from a certain distance. Let us

1 K. Escherich, Die Ameise, 1906. 


\section{THE PSYCHIC LIFE OF INSECTS}

think of these hands in the shape of a rounded tube placed at the end of two long mobile whip lashes which we can move and tap with each step. Note that if the emanations of different objects ... are mingled at a little distance, the chemical nature of the surfaces of these organs are very closely localized by limited special surfaces. ... If we were endowed with such a sense the world would be transformed for us. Odor would become a sense of forms.

But in its antennæ the ant possesses a pair of organs of this nature, and this is why Wasmann is able to range himself on the side of Forel. No one knows the habits of ants better than these eminent biologists, and no one appreciates as well the difficulties of their hypothesis, but it is not necessary to invent a new sense, for their topochemical sense is nothing more than a tactile odoriferous sense, and it thus remains in the experimental field.

With Wheeler, Escherich, and most of the biologists, we believe that ants orient themselves like other Hymenoptera-that is to say, by means of their senses and by associating their senses according to the case; visual orientation predominates with many exploring forms, olfactory with some others, while smell joined to touch serves them very well when they are following a scent. 


\section{CHAPTER XIII}

THE DIVISION OF SEXES WITH NEST-MAKING HYMENOPTERA

The females of certain insects may be fertile without coupling, and then produce eggis which have not been subjected to spermatozoal fecundation. When this phenomenon' is accidental, as happens sometimes with the mulberry silkworm moth, the eggs develop only rarely and with difficulty, but when it becomes normal the result is quite different. Note, for example, the Adoxus vitis of the vine, where the males are almost unknown and seem to play no part, and the insect then gives birth to a series of generations in which the non-fecundated females produce only females until a final generation which contains both females and males.

Whatever form it may take, reproduction without spermatozoa is called agamic, or parthenogenetic. It is quite different from the sexual reproduction characterized by the fusion of the egg with the spermatic cell, which is the rule with al- 


\section{THE PSYCHIC LIFE OF INSECTS}

most all animals. In such forms as the phylloxeras, the Chermes, the plant-lice (and certain phytophagic Hymenoptera of the family Cynipidce, and of the sawflies), where the last of the agamic generations produces individuals of both sexes, these individual's couple and their fertilized eggs produce females exclusively. Thus we have a cycle, or a sexual generation intercalated regularly between one or more agamic generations.

Division of sexes with the social hymenoptera. The preceding rules do not apply to the social Hymenoptera,-bees, wasps, and ants. With these insects each colony is a numerous family in which all the individuals are common offspring procreated by a fertile female to which is ordinarily given the name of queen. Certain members of the family are males which couple with the future queens and perish soon afterward; the others, infinitely more numerous, are females incapable of coupling, neuters, which devote themselves exclusively to the work of the colony, from which fact the name workers is derived. With some species of ants certain neuters have an especial armature and play the defensive rôle of soldiers.

Occasional fertility of the neuters. The neuter females are incapable of coupling; provided with 


\section{THE DIVISION OF SEXES}

reduced genital organs, they can reproduce, in certain cases, but then lay male eggs exclusively.

Although disputed by Pérez, this phenomenon. has for a long time been known with the honeybee; and in fact was pointed out by Aristotle. All bee-keepers know that hives deprived of their queen are filled with males or false drones (ruches bourdonneuses,-buzzing hives), and Marchal (1904) when experimenting with colonies of this kind has shown that males are produced by workers. Should not this exceptional phenomenon be attributed to the absorption by the workers of food intended for the larvæ? This was at first Marchal's opinion, and becomes the expression of the truth following the researches made by the distinguished biologist with the German wasp (Vespa germanica). ${ }^{1}$ It appears, in fact, from these researches that the recently issued worker wasps become egg-layers when the cells of the nest are emptied and especially when they are deprived of the queen. Then, says Marchal, "the workers, no longer having a young brood to nourish, consume the liquids which they would have given to the larvæ," which induces the development of their ovaries and gives them fertility. So that the normal sterility of the workers is due

$1 \mathrm{P}$. Marchal, La reproduction et l'évolution des Guêpes sociales, Archives de $Z_{0 o l}$., 1896. Exp. (3), v. iv. pp. 1-100, (1896). 


\section{THE PSYCHIC LIFE OF INSECTS}

to a reduced feeding, which the author justly calls "a nutritial castration."

It is to a cause of the same kind, to a "food castration," that Emery (1895) attributes the production of neuters with the ants. We know, as a matter of fact, according to Forel, ${ }^{1}$ that worker ants may become fertile, and according to Reichenbach (1902) this fertility may be induced by suppressing their queen. Wasmann (1895) also explains by the alimentary regimen the polymorphism which he has observed in colonies of Leptothorax acervorum, and without doubt it is necessary to attribute to the same cause the multiple intermediaries which Holliday (1903) has noticed between the winged queen and the wingless individuals in Leptothorax emersoni. But it does not seem too much to admit that the workers, slightly different from the females, are capable of coupling, which would explain the experiments of Reichenbach and of Wheeler (1909), who have obtained males and workers in orphan formicaries. But the phenomenon must be infrequent, for from the eggs coming from workers Forel, Viehmeyer, Wasmann, and Fielde always obtained males only.

So, just as bees in their hives obtain queen larvæ at will by feeding the very young worker

1 A. Forel, Les Fourmis de la Suisse, 1874. (Soc. helvet. des Sci. Nat. Nouv. Mém. 26.) 
larvæ with the royal jelly, the workers of social Hymenoptera may become fertile by feeding on the food intended for the brood, and in all cases, except perhaps with the ants, the fecund workers lay exclusively male eggs.

Division of the sexes among the bees. But in a hive in good condition, male eggs do not come from the workers; they are laid by the queen, who places them in appropriate cells longer and larger than the others. And this suggests the question as to whether or not these male egg's are parthenogenetic like those of the fecund workers.

This was, in 1835, the idea of a Silesian beekeeper, Father Dzierzon, who afterward advanced it in his "Theory and Practice of the New Friend of the Bees." He writes:

The queen is fertilized once for all on her nuptial flight. Once returned into the hive with a quantity of spermatoza which fills her seminal receptacle, she occupies herself with her function as an egg-layer, fertilizing the eggs from which come the females (workers and queens), giving out parthenogenetic eggs when she wishes to produce males. And as the cells of the females are quite different from the cells of the males, and as she lays in each kind an egg of the appropriate sex, it is necessary to admit that she has a power of choice which permits her to lay the eggs of one or the other sex at will.

Such is Dzierzon's theory. It has a bearing 


\section{THE PSYCHIC LIFE OF INSECTS}

which extends quite beyond the limits of bee-keeping, and we must examine a little more closely its two essential points.

(I) The male eggs are not fertilized. The theory clears up perfectly phenomena which had hitherto seemed inexplicable. It was already

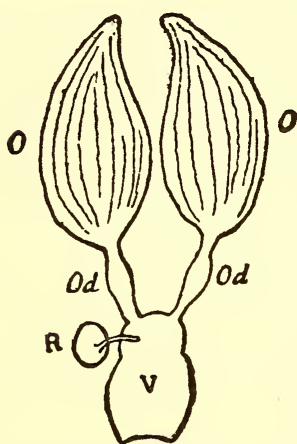

Fig. 16. Diagram of the genital organs of a wasp or a female bee: $O$, ovarian tubes; $O d$, oviducts through which the eggs pass to gain the gerital vestibule $V ; R$, seminal receptacle in which the male spermatozoa accumulate at the instant of coupling; they enter or leave it by a narrow canal.

tacle (Figure 16, R) of a bumble-bee, and by Seibold (1856), who found no spermatozoa in the recontained male eggrs and female eggs. Having realized that the queen lays only male eggs when her fecundation is delayed, also when her nuptial flight has been prevented by cutting off her wings, or again, when she was born at a time when the males had perished, the illustrious François Huber sought in vain for an explanation of these phenomena, and in despair cried, "It is an abyss in which I am lost!" But these facts are easily interpreted in the light of this theory. They have been further corroborated by Dzierzon himself; who found a simple clear liquid in the female recepbelieved that the ovarian tubes 
ceptacle of a queen of this kind. The experiments of Berlepsch (1860) are no less favorable to this theory. When a queen has been subjected to an especial pinching of the abdomen, or has been exposed to a sufficiently intense cold, she lays male eggs continuously. In the first case it is probable that a lesion of the abdominal nerve centers prevents the seminal vesicle from opening and throwing the spermatozoa on the eggs. In the second, the spermatozoa contained in the vesicle are probably benumbed. In both the eggrs deposited are parthenogenetic.

Direct observation proves also that male eggs are not fertilized. Seibold examined microscopically fifty-two eggs collected in worker cells and twenty-seven collected in male cells. The last never showed a trace of spermatic impregnation, while thirty of the former showed spermatozoa; he did not see them in the other twenty-two because his preparation was poor. The significant results were obtained by Paulcke (1899) and by Petrunkievitch (1901). These biologists examined under the microscope different kinds of eggs which had been sent them by Dickel, and they confirmed Seibold's observations in all points. Petrunkievitch could even recognize the original of each egg, although the labels had been changed. In spite of all this, the biologist Dickel (1903) 


\section{THE PSYCHIC LIFE OF INSECTS}

remains one of the adversaries of the Dzierzon theory. He contends that the sex of the eggs is determined in the cell by a saliva peculiar to the workers. I have read Dickel's memoir with care, and I confess that he has not convinced me, so vague and improbable are his experiments.

The following criticisms, on the other hand, merit attention. We know that in Europe there exist two quite distinct races of bees: the Italian bee which is yellow in color, and the [to France] indigenous bee, which is rather black. If it is true, as the theory suggests, that the male eggs are not fertilized, the effects of hybridization between the two races should be noticed only with the females, workers or queens. But this is not always so, as Dzierzon himself has noticed and as different biologists have proved; J. Pérez, for example, who, having introduced into a hive of the pure native race deprived of all males a pure Italian female fertilized by an equally pure native male, afterward found in this hive 151 pure Italian males, 83 pure natives, and 66 with mixed characters, making in all 149 males having more or less the traits of the native male fertilizer.

,These experiments cannot be cited against the theory, because they offer almost insurmountable difficulties which make them subject to criticism. Could not the males found by Pérez have come 
from egg-laying workers? And could not the native males have found their way into the hive? Who can say, moreover, that a queen is surely of pure race, and that the two races are not both the issue of a wild black bee long domesticated? According to this, the results observed by Pérez would be simply due to atavism. One of the most distinguished American bee-keepers, E. R. Root (cited by Phillips.1) has stated some profound truths on this point. He says:

We have many times received from Italy queens supposed to be as pure as possible, but the males from these queens were of varied coloration. Some had a large amount of yellow, while others were completely black. If Pérez had seen these males he would have concluded that certain ones were French, others German, and some Italian. ... The pure Italian queens show all degrees of coloration, from bright yellow to jet-black. We obtained a very black daughter from an imported Italian queen, but the workers coming from this queen were of a uniform coloration, with all the characters of pure Italians. Some of the queens, daughters of the imported mother, are completely yellow and others completely black. . . .

The variations of color observed by Pérez do not upset a theory which everything else confirms, at least in its essential principle, that it is the par-

1 E. F. Phillips, A Review of Parthenogenesis, 1903. (Proc. Amer. Philos. Soc., v. 42, pp. 275-345.) 


\section{THE PSYCHIC LIFE OF INSECTS}

thenogenetic nature of the eggs which produce males.

(2) Selective power of the queen in the division of the sexes. We arrive now at the second principle. Is it true, as Wasmann contends, that the queen lays at will eggs of one or the other sex, that she voluntarily fertilizes certain eggs, and that she places the eggs, fertilized or not, in the appropriate cells?

At first glance the examination of the facts seems to justify the theory, for it is true that egglaying workers, non-fertilized queens, and queens which have used their stock of spermatozoa, place their drone eggrs by chance in the cells; it is equally established that normal queens lay eggs of either sex in the proper cells.

But it is not always the same. Dadant and Drory have shown that very fertile queens may in certain cases place eggs of males or workers in all kinds of cells. Drory (1875) states, moreover, that the queen places her male eggs in little cells when all the large cells have been taken away. Finally, the same Drory, and also Root and Dadant, have noted that worker eggs are laid in the large cells when all the little ones have been destroyed. From these facts we must conclude that there comes a time when the queen is obliged to lay either worker eggs or male eggs, and that, 
contrary to the theory, fecundation is not a voluntary act with her.

What is the cause of these abnormal deposits, and even the usual deposits which are almost always made in a series, the queen laying methodically male eggs in all the large contiguous cells and behaving the same with the little ones for the worker eggs? Since it is in the spring-time, before swarming, that the principal depositing of male eggs occurs, we may believe with Dadant that there comes a time when the seminal receptacle, fatigued by multiple contractions, enters into a condition of inertia which keeps it from emitting spermatozoa. But this muscular inertia appears to us to be independent of the high temperature of the hive, and, as we shall see, it is better to attribute it to a rhythm acquired by the bees in the course of the many generations which form the woof of their history.

However it may be, we must admit that the queens normally have the power of laying their male eggs in large cells and the worker eggs in the small ones. This is a very strange power,involuntary, since it is subject to the desire to lay, and closely bound to the reflex mechanism of the seminal vesicle. This reflex has been attributed to the dimension of the cells, which, according to their size, do or do not compress the abdominal 


\section{THE PSYCHIC LIFE OF INSECTS}

walls (Wagner) in forcing the queen to spread her legs or bring them together; but the history of the social wasps and, still more, that of the solitary bees lead us to think that the reflex originates in a psychic stimulation provoked by the sight of the dimensions and the form of the cells.

And to finish this critical study of Dzierzon's theory, we may say with Pérez:

It is sufficient to recognize in the bee, not knowledge as to the sex of the egg it is about to lay, which one cannot reasonably admit, but the instinct to deposit in each kind of cell eggs of the appropriate sex. Selective faculty goes just that far and no farther.

Division of sexes with the social wasps. We know that the social wasps differ from the honeybee in that their large cells are reserved for the true females, while the little ones are intended for the rearing of the males and of the sterile females called workers.

But it appears from the beautiful observations of Marchal on the German wasp: first, that the queen lays "in a continuous manner until the end of July or the beginning of August" worker eggs in the little cells; secondly, that then the big cells are built which "thus give the choice to the queen between the two distinct kinds of cell"; thirdly, 
that afterward the large cells receive exclusively female eggs, while the little ones are provided by chance with the eggs of males or workers.

Marchal very happily explains these facts by a variation in the contractility of the seminal receptacle by a kind of muscular fatigue already suggested by Dadant for the bees. After the long uninterrupted laying of workers, which lasts until the beginning of August, "the reflex which brings the contraction of the seminal receptacle to the moment of the laying of each egg is no longer produced with the same regularity and ... then the eggs can be laid without being fertilized. Therefore," says Marchal, "the almost sudden appearance of males is due to the relatively inert condition of the receptacle. Thus the queen does not lay male and female eggs at volition, but a moment arrives when her laying perforce contains males because of the relative inertia of her receptacle, and her active rôle consists in distributing the eggs according to the sex," in a very precise manner in the large cells which receive only the eggs of fertilizable females or by chance in the little ones where are ordinarily placed the worker eggs or the male eggs.

Why does the queen place fertilized eggs exclusively in the large cells? One cannot suggest mechanical hypotheses, for it is hardly probable 


\section{THE PSYCHIC LIFE OF INSECTS}

that the large size of these cells causes the closing of the seminal receptacle with the bees and its opening with the wasps. As we have done with the bees, Marchal attributes the reflex opening to a psychical phenomenon. The large cells, he says, "have the faculty of stimulating the queen, who seems in certain cases to have a marked preference for them. It must be admitted that upon these large cells she concentrates all her energy and that on this account she will lay in them only fertilized eggs.'" Here, as with the bees, the laying of male eggrs seems to be the manifestation of an annual rhythm, but in this case it does not reach the same precision. With the bees, in fact, the laying of these eggs seems to be continuous during a short period in the spring-time, while with the wasps it begins in the middle of summer, to continue during the autumn, alternating with the laying of worker eggs. This is a lower stage in the division of sexes.

Solitary Hymenoptera. We know very little about the division of sexes in the other social $\mathrm{Hy}$ menoptera, the Meliponas, the bumblebees, and the ants. On the other hand, this subject has been admirably studied by Fabre with numerous solitary nest-making Hymenoptera, especially those which provision their cells with honey and pollen and which constitute the group of solitary bees 
(Osmia, Chalicodoma and Anthidium), aside from the predatory species which give their progeny paralyzed victims (such as the bee-eating Philanthus, Sphex, Solenius, etc.). With all these insects, whether they are honey-bearers or predators, the cell is closed after the egg-laying and the provisioning. With all of them, in addition, the male is smaller than the female, except with Anthidium septendentatum and $A$. bellicosum, where it is larger.

The female determines the sex of the egg. Fabre has stated that with the species in which the female is larger than the male the cells are of two kinds, some spacious and well filled, which give out females exclusively; the others smaller and less well provisioned, which always give out males.

Is it to the food, richer or poorer, that we must attribute this exact distribution of the sexes? Experiments will teach us. The large cells of Osmia tricorna are three times as large and as fully provisioned as the others. In a reed in which a row of cells of this bee was found, Fabre took away the large cells and added to the small ones a portion of the provision, and he found that on issuing the large cells still gave out females and the smaller ones males, the former of small size and the latter larger than usual. "This suffices," ob- 


\section{THE PSYCHIC LIFE OF INSECTS}

serves Fabre, "to do away with the very improbable supposition that the determination of the sex depends upon the quantity of food." We shall see later, in another way, that it is no more dependent upon the dimension of the cells. And from this it is proper to conclude that the egg at the moment of being laid has a determined sex, ${ }^{1}$ and that the rôle of the female consists in placing it in a proper cell.

The eggs have their sex at the moment of the laying, but are they equally sexed when they leave the ovarian tube to enter the oviduct (Figure 16, $\mathrm{O}, d)$ ? If this were so, the female should place her large and small cells in the order of the laying and would not be able to change, but it is just the contrary, as experiment shows. Fabre gave to his Osmia tricorna a composite glass tube of which one half was small and the other large, and the bee made in the first part little male cells and in the second large female cells. To another egglayer he gave the mason cell abandoned by a Chalicodoma, contracting certain cells and leaving the others intact, and the latter received female eggrs and the former male eggs. What would be the laying if the insect could find only narrow cells? He offered to his Osmias a snail "whose shell,

1 The observation also shows that the larvæ of insects on issuing from the egg are already males or females and this sex can be recognized by certain characters. 


\section{THE DIVISION OF SEXES}

looking like a little ammonite, enlarged by slow degrees and had at its mouth, in the usable part, a diameter hardly greater than that occupied by a male cell." In order to make its full laying, a female occupied successively seven shells and put in them fourteen cells of which twelve were for males and two only for females. Another used eleven shells, and, being very fertile, placed in them twenty-six cells. "In this exceptional case twenty-five males were found, and one female,-one only, and occupying shell No. 17," which happened to be a slightly larger shell.

Thus the female, aware of the sex of the egg, can, on account of the diameter of the cells, produce only eggs of males. Surely, says Fabre, "when it comes from the ovary the egg has not a determined sex. It is at the moment of laying, or a little before, that it has received the final touch which settles the sex."

Mechanism of the phenomena. But is it true, as Fabre thinks, that "to be able to give to each larva the space and the nourishment which belong to it, whether it is male or female . . the female should know the sex of the egg which she is going to lay"?

Let us first note that the solitary nest-builders must instinctively build or choose large cells and small ones, that they have acquired this instinct 


\section{THE PSYCHIC LIFE OF INSECTS}

after long experience or through mutations, and that the species which manifest it from the first have been able to benefit largely from natural selection because this greatly reduced the architectural needs.

Given this instinct, it suffices, as Marchal observes, "from a simple psychic adaptation" of the female, "for the seminal receptacle to contract for one of the two kinds of cells and to remain inactive for the other." At the sight of a large cell the female will contract her receptacle in a reflex way, the spermatozoa will fertilize the egg situated in the oviduct, and the fertilized egg will produce a female; with no reflex before the little cells there will be no fertilization and the egg will develop into a male.

This is the same explanation which we have adopted, following Marchal, for the social bees and wasps. It avoids the idea of the will of the female, but supposes that the male eggs are parthenogenetic. But if it is true that this is the case with the social species, it is far from enabling us to affirm that the same rule is obeyed with the solitary species. This is, I believe, the sentiment of Cuénot (1899) and perhaps also that of Bugnion (1910), but upon this point research has been insufficient. I know of no other except that of Verhoeff (1891), who attributes a constant partheno- 
genetic origin to the males of two solitary wasps (Odynerus spinipes and $O$. parietum), although those of $O$. reniformis result sometimes from a fertilization. We should not underestimate the importance of this gap, and it is to be hoped that serious study will soon make it disappear. If, as we may believe, research establishes the fact that the males of the solitary nesting bees have a parthenogenetic origin, it will completely justify the hypothesis proposed by Marchal. In a contrary case, the explanation of the mechanism of the division of the sexes will be very delicate. The fact is established that with non-parthenogenetic species the sex of the egg is determined by the spermatozoa, which are of two kinds from the point of view of their power and, sometimes, from the point of view of structure. It is necessary, then, to admit that the psychic reflex of origin provokes the issuance of spermatozoa of the one or the other kind. We do not know of any such mechanism, and we must pass over this difficulty, which will, without doubt, vanish after badly needed studies have been made, as we have suggested above.

The rhythm in the laying. To ascertain whether or not the division of the sexes with the solitary nesting species is effected according to a rhythm, it is necessary to observe the insect in full liberty. 


\section{THE PSYCHIC LIFE OF INSECTS}

This is what Fabre has not failed to do, and his observations are none the less interesting because he made them with another object. But he has stated that the Osmias, when they find a place where they can effectively make their entire laying (about fifteen eggrs), first construct female cells, then afterward, nearer the opening, all their male cells. A sphegid which works in dry twigs, Solenius vagus, does just this thing. So also does the Chalicodoma of the walls, which first prepares its female cells and then, after them, its male cells. Verhoeff (1892) has made identical statements in regard to a large number of wasps, some honeybearers, and others predators.

When the female, for lack of sufficient space, must divide her laying among different lodgings, she applies the same rule, first establishing the female cells and then afterward, near the orifice, the male cells. Fabre on this point made numerous observations, of which only a few can be mentioned here. Osmia tricorna uses all sorts of places. In the bellied-out cell of the Anthophoras the dilated bottom is used to make a female cell and the narrower upper part is used for one or two male cells. A very fecund female which laid twenty-five eggrs placed its laying in five fragments of reed in which she established her cells in the following manner: 


$\begin{array}{lccccc}\text { First reed } & 7 \text { females } & 1 & \text { male } \\ \text { Second } & , & 3 & , & 3 & , \\ \text { Third }, & 3 & , & 2 & , \\ \text { Fourth }, & 1 & , & 2 & , \\ \text { Fifth }, & 2 & , & 3 & ,\end{array}$

Similar observations in very great number have been made by Verhoeff, who gives to this habit of the solitary nesting species the name of proterothesis. The same rule applies to those rare species in which the male is much larger than the female and needs in consequence larger and better-provisioned cells. Anthidium septemdentatum and $A$. bellicosum, for example, first establish a female cell in the little turns of their snail shells, then, near the orifice of the shell, a great male cell.

The division of the sexes in partial layings explains what we observe in completely finished layings in the same place. Like Fabre, Verhoeff states that the males issue before the females and that in both sexes the issuing is effected in an inverse order to that of laying. This is, without doubt, a habit acquired long ago, which became quickly fixed by natural selection, since its advantages are many. It is eminently favorable to increased reproduction and unfavorable to the overthrowing of the nidification. Issuing before the 


\section{THE PSYCHIC LIFE OF INSECTS}

females, the males cannot couple with them, and, visiting flowers, can accommodate the females of another colony which are in a hurry to build nests; and, on the other hand, the issuing of the young individuals in an order reverse to that of the laying saves the progeny from disaster.

As to whether this precious instinct has been acquired and as to whether it has sexual polymorphism for its origin, I wish to call attention to the difference in size between the males and females to explain the distribution of the layings with the rare species, such as Osmia tridentata, where this polymorphism does not exist. According to Fabre's observations, this species distributes its eggs in identical cells, mixing the sexes,-with, however, a vague tendency to lay the male eggs nearer the orifice, and this in the complete layings as well as in the partial layings, as is shown in the following series:

Complete laying: F F M F M M F F F F M Fractional $\left\{\begin{array}{l}\mathrm{M} M \mathrm{M} M \mathrm{M} M \mathrm{M} \\ \text { F M F F M M } \\ \text { F M }\end{array}\right.$

These observations were made in Provence, but at Bonn in the Rhine provinces the same species has the instinct of distributing the sexes advantageously. Here are, in fact, two complete lay- 
ings noted by Verhoeff in a reed inhabited by Osmia tridentata:

First series: F F F M M

Second series: F F F F M M M

Even supposing that Verhoeff and Fabre misidentified the species which they used in their observations, it must be admitted that Osmia tridentata shows all the stages between the irregular division and the advantageous division of the sexes; and, even admitting a confusion of species, the observations of the two biologists show that advantageous distribution was progressively acquired with the Osmias. Once acquired, the instinct of advantageous distribution of the sexes must surely turn to a rhythm. Because of the labor of their nest-making the females of solitary species are not very fertile and ordinarily complete their laying in one place. They first build large cells and deposit in them all their female eggs, then devote themselves exclusively to the building of small cells and the laying of male eggs.

General conclusions. If it be true, as we cannot doubt, that the social Hymenoptera are derived from solitary species, we can imagine that the evolution of the curious instincts which are shown in the two groups in the division of sexes follows.

In the beginning males and females were of 


\section{THE PSYCHIC LIFE OF INSECTS}

about the same size, with the solitary species and the nesting species, so that the cells built by these insects were equally spacious, provisioned in the same way, and divided by chance. But, on account of the proterandry (early appearance of the males), which is of very ancient date with most articulates, this division of the cells had the fault of exposing species either to the disarrangement of the cells by reason of the premature issuing of the males or to the disadvantage of direct fecundation, since the males would have to await the issuing of the females nearer the orifice. So that selection should favor the nesting Hymenoptera with which the male eggs were laid after the female eggs.

But this rhythm in the laying could be established regularly only with forms in which sexual dimorphism appeared, doubtless by mutation. Sexual dimorphism is advantageous for nestmakers. It should extend under the influence of natural selection, and it is found, in fact, in almost all species of the group. It brought about as a consequence the building of two kinds of cells, the larger ones for the larger sex, and the others smaller and easier to construct. On account of proterandry and to avoid a mixing up in the architecture, the female cells were constructed before the male cells, and it is probably due to a psychic 


\section{THE DIVISION OF SEXES}

reflex produced by the sight of the cells that the mother acts upon her seminal receptacle so as to place in each one of the latter an egg of the appropriate sex.

Without doubt, social wasps came from predatory nesting species in which this rhythm was not yet well established, for after the middle of the summer they lay by chance male eggs and neuter egg's in the ordinary cells. With the honey-bee, on the contrary, the rhythm shows a remarkable regularity, and it is only in the especial cells that the queen lays male eggs a little while before swarming.

In any case, with the honey-bee as with the social wasps, the female eggs are fertilized, while the male eggs are not. It is perhaps the same with ants and with the solitary bees. If future investigations justify this hypothesis, we may believe that the social Hymenoptera have inherited this curious habit from their solitary nesting ancestors, who have at the same time bequeathed to them the rhythm in the laying of the male eggs. As to the abnormal laying of the workers, this seems to be a return to the functions of the solitary species, and, rather than otherwise, vain, for these forms seem incapable of being fertilized, and consequently produce only males. 


\section{CHAPTER XIV}

THE SOCIAL LIFE OF THE ARTICULATES

Like most animals, the articulates are, above all, individualists: they work for themselves without aid from their brothers, and their existence seems to have no other end than self-protection. Some, however, establish family societies which practice the most perfect communism. Then there is established among the members of each society a division of labor which renders the individuals collectively responsible. A fertile female or a royal couple are given the reproductive functions, the others are neuters, ordinarily sterile, which provide for the needs of the entire society, and their functions are divided according to their age and their special aptitudes. Thus, each individual depends closely upon the others in order to preserve its life. Communism is substituted for individualism with such strength that it becomes a vital need.

How has this substitution taken place? That is the problem which we are going to try to solve. 


\section{SOCIAL LIFE OF ARTICULATES 313}

This presents two aspects; the one historical and evolutional, upon which comparative biology sheds light; the other psycho-physiological, belonging to the domain of observation and experiment.

Individual societies. When the animals find a place favorable to their vital needs, they establish themselves there in small colonies and live side by side without bothering about their neighbors. Thus do the Ocypodes, the Gelasimas, and certain other crabs which live in the shore sand, the Coleoptera of the genus Cicindela, which dig their burrows in clay soils. Thus also do the nesting Hymenoptera: Bembex and Philanthus among the predatory species, Andrena, Halictus, Chalicodoma, and Anthophora among the solitary bees. Even in these groups all species are not equally sociable: thus our Chalicodoma of the walls constructs its mass of cells solitarily, while Chalicodoma pyrenoica likes to have its nest near others. Fabre says:

I have seen some of these nests (colonies) which, under the tiles of a shed, occupied a surface of five or six square meters. . . . It is necessary to see the active bee at work. ... Between the farmyard where they were building, and the road where they were preparing the mortar, the sound of the murmur of the arriving and the departing bees increased without interruption. The air seemed 


\section{THE PSYCHIC LIFE OF INSECTS}

traversed by continual streaks of smoke, so direct and rapid is the trail of the travelers.

Having the same habits as their progenitors, the young find it profitable to establish themselves in the place where their parents nested. They nest there in their turn and so give birth to a society where all the individuals are attached to a common locality; strangers having the same habits also come to make their nests in the same place, and the colony is composed of several juxtaposed families. The same thing occurs with the Chalicodoma of the Pyrenees, studied by Fabre, and with the African solitary wasp of the genus Synagris, studied by Roubaud; ${ }^{1}$ in fact, individualist societies are almost always the beginnings of family groups. Different circumstances, moreover, favor groups of this sort, among others the habit that certain young have of remaining at the maternal nest until the moment when it becomes necessary for them to work in their turn. I have described (1916) this habit in our Philanthus triangulum, and the Peckhams have made similar observations with an American species, Philanthus punctatus. What favors still more the formation of these family individualist groups is the laying of a large number of eggs at the same point of the

$1 \mathrm{E}$. Roubaud, Recherches bioligiques sur les Guêpes sociales et solitaires d'Afrique. (Ann. Sc. Nat., Zool. ser. 10. v., pp. 1-160, 1916.) 


\section{SOCIAL LIFE OF ARTICULATES 315}

nutritive subtratum. When the young issuing from these eggs have not the usual industry, they content themselves with remaining in the neighborhood upon the substratum, as is observed with the caterpillar of the cabbage butterfly (Pieris brassica). But if they have in addition the power of spinning a silken thread, they can associate their talents and together make a protective web which they leave at certain hours individually to satisfy their needs. This is done by an American Pierid, Eucheira socialis, which constructs a very spacious web, remarkable for the resistance and close webbing of its walls. This is also done by many caterpillars of nocturnal moths, among others the processionaries and several Bombycids and the Hypomomeutas.

Spiders are known for their sanguinary instincts and for the cannibalism which they practise either at ordinary times when they are kept in the same cage, or at the rutting period, when certain females have no scruples about devouring their lovers. But these murderous instincts develop only with age; on leaving the cocoon the young of the same hatching live in perfect harmony and associate their talents as spinners to make a common nest. This pacific humor persists with certain species,--rare, it is true,-and they continue the building of common webs in which 


\section{THE PSYCHIC LIFE OF INSECTS}

they live and bring forth numerous individuals. Eugene Simon ${ }^{1}$ has mentioned several of these sociable spiders, among others an American Theridiid, Anelosimus socialis, whose common web sometimes covers an entire coffee tree. "The spiders walk about there freely," observes the author, "meeting one another and tapping with their palpi as the ants do with their antennæ, and more often devouring a smaller prey.' Semichon (1909) has mentioned the same fraternal dwelling together of a social Mexican spider, Canothele gregalis, brought to the Museum by Leon Diguet (1909). This species makes upon trees vast social webs which it develops concentrically with spun threads which are to capture insects. Thousands of individuals live in perfect harmony in this immense pocketed sack, and never go out except after the rainy season, when they emigrate,-I was about to say swarm,- to leave room for the young. These nests divided and, suspended to the ceiling, act as traps for flies in certain parts of Mexico. One of them, exposed in the galleries of the museum [in Paris], reached the length of several meters.

Between the individualist groups of Gelasimas,

1 E. Simon, Voyage au Venezuela: les Araignées sociables, 1891. (Ann. Soc. Ent. France. v. 60, pp. 5-14.) 


\section{SOCIAL LIFE OF ARTICULATES 317}

Ocypods, and Cicindelids, where each one hunts on his own account, and those of the preceding social spiders, which spin a common web, and often divide their captures, there are a quantity of steps of which caterpillars and Hymenoptera offer examples. Even in the simple individualist colonies of Hymenoptera one observes a kind of espirit de corps when it is necessary to struggle for the common defense. In such a case, the Anthophora of the walls become singularly aggressive; established in sandy argillaceous soil which it perforates with tubular galleries, this bee comes out in war-like swarms every time one approaches the colonies; Buttel-Reepen (1903) relates the misadventure of an entomologist who was pursued a long time by one of these swarms after a badly executed swing of his net; and Friese reports that he himself was attacked for having tried to collect on the walls of a barn where thousands of Anthophoras had established their nests. It is a crowd reflex, Buttel-Reepen justly remarks, a reflex which is never produced when one attacks isolated individuals or small groups.

Communistic societies. The communistic societies obey the same laws as the preceding, but they are more rigorous in the family groupings, for they presuppose the young to be born by the side 


\section{THE PSYCHIC LIFE OF INSECTS}

of their parents. When these young are neuters simply charged with working, the social solidarity becomes complete. We must establish, however, the fact that such solidarity does not appear immediately in the different groups of insects which form communistic societies.

Societies of termites. Indeed, we do not know the primitive stages of the social life with those Pseudo-Neuroptera which are known by the wrong name of white ants, and which constitute the great family of Termitida. All the species of this family form communistic societies of a high type, with a permanent royal couple and with neuters. The royal couple establishes the nest and devotes itself thereafter to reproductive functions. It gives out first male or female neuters, always wingless, then at certain times sexual and winged forms, which swarm to couple and establish new colonies. A special treatment permits them, when it is necessary, to transform the neuters of one or the other sex into fertile individuals which replace the royal couple.

By their structure, the termites are closely related to the cockroaches, and we know that our common cockroach, that one which ranges in the bakeries and the kitchens, is distinguished by a great sociability. Lameere has established the fact that the termites became separated from the 
cockroach family in the course of the tertiary epoch.

Societies of ants. With the ants, as with all the communistic Hymenoptera, there is a fertile female or queen (sometimes several) upon which devolves the reproductive functions; the males die after coupling, leaving to the queen their spermatozoids, which it distributes according to the needs at the time of laying.

All the species of the immense group of ants form societies in which a variable number of femalle neuters fill the functions of workers. Those of the tribe of Ponerines approach the predatory Hymenoptera by their low stage of evolution. They establish, says Wheeler, feebly populated colonies where the females are slightly fertile and little different from the workers, which give them no care and frequently lay male eggrs. Like the solitary predators, they feed on all terrestrial articulates, which they dissect after the manner of certain wasps and serve in small bits to their larvæ. Finally, these low ants have preserved the habit of spinning a cocoon, which distinguishes them again from most of the higher ants and affiliates them with the solitary predators of the order Hymenoptera. We should then consider the Ponerines, and through them the other ants, as predatory Hymenoptera adapted to the social 


\section{THE PSYCHIC LIFE OF INSECTS}

life; as probably Scoliids and not as Mutillids, for the males and females of ants are winged, at least at the beginning of their existence.

For the rest, whatever may be the degree of evolution, many ants preserve the traits of a primitive social state, or return toward that state, by secondary adaptations. Fertile workers are frequent in the formicaries, and we know through Miss Holliday that Leptothorax emersoni presents not less than eleven forms between the queen and the workers. Certain ants' nests contain substitute queens, - that is to say, workers which perform the functions of queens. Finally, we know through Forel $^{1}$ that fertile females are numerous in the formicaries of Tapinoma erratica, and I have it from Bondroit that one can find as many as fifty in the nests of Myrmica.

Societies of Mellifera. It seems that an abyss, from the social point of view, separates the solitary bees from our domestic honey-bee, with which the division of work is so perfect; but comparative biology permits us to bridge that abyss.

We note first that certain solitary bees capable of living in small colonies are also capable of work in common. The females of Halictus frequently have the habit of digging a burrow, in which they

1 A. Forel, Les Fourmis de la Suisse, 1874. (Soc. helvet. des sci. nat. Nouv. Mém. 26.) 


\section{SOCIAL LIFE OF ARTICULATES 321}

hide away for the winter, but Verhoeff has found hibernating under a stone sixteen females of Halictus morio distributed here and there in branching galleries. We believe with ButtelReepen that a first female had established herself under the stone and that others, finding the place favorable, had continued the work of excavation. Certain Halicti studied by Nicolas (1887) offer the curious particularity "that a single door gave access to several habitations; one door opened upon several galleries where certain females were isolated. Such a disposition demands a special surveillance"; at the entry of the common gallery an individual was placed who acted as porter, chased away the intruders, and took care in the vestibule to keep a passage for the members of the colony. Aurivillius (1896) observed the same habit with the Hungarian species, Halictus longulus. The Halicti conduct us a little further on the way to communism. Most bees of this genus establish their cells isolated on the sides of the gallery, but Verhoeff (1891) has observed that the cells are a little nearer together in $H$. sexcinctus and that in $H$. quadrimaculatus their ensemble forms a sort of a ray everywhere isolated from the neighboring earth except in the lower part. There were found in these nests empty cells, without provisions, while others were inhabited by nymphs on 


\section{THE PSYCHIC LIFE OF INSECTS}

the point of issuing, so that it is possible that the first nests were always in contact with their mother; so it is, says Verhoff, "colonization is ready," and will be realized if the children aid their mother in her work.

This realization does not seem to be attained with Halictus, but it becomes almost absolutely the rule with the bumblebees, large, velvety bees, concerning which Buttel-Reepen (1903) has conducted a study rich in achievement. When she starts her nest in the first warm days, the queen provisions it before laying, like the solitary bees, but the food is insufficient, for the insect lays several eggs in the rearing-cell and she must open and close this cell several times to give her larvæ supplementary food, and that is the method followed by the bees. This mode is employed from the beginning until the first females have issued and replace the queen in her work. Poorly nourished by their mother, who assumed all the work, these females are small, undersized; but as more and more are born, their vivacity increases and also the size of the new-born, which in the end reach the dimensions of the queen. These female workers do not lay, but they may not be regarded as neuters, for they have the same structure as the queen, and may be distinguished only by the feeble development of their ovaries. At the end of the 


\section{SOCIAL LIFE OF ARTICULATES 323}

season, when the males appear, the largest are fertilized and hunt refuge for the winter. All the other individuals perish. It is not the same in the tropics, at least in Brazil, where Rodolphe von Ihering (1904) has found that the colonies of Bombus are perennial and multiply by swarming. Then the fertile females remain at home, and the nest can count numerous queens in addition to the workers. On the contrary, in the Northern countries, where the summer is short, certain species of bumblebees return to isolated work; Friese (1901) reports, in fact, that Sparre Schneider, in the course of long studies carried on at Tromsö, has never found worker females in the nests of Bombus kirbyellus, and that their rarity is extreme in those of B. hyperboreus. I may add that by the ovoid form and the irregular arrangement of their cells, by the employment of little twigs and moss in making the nest, the bumblebees recall certain solitary bees of the genus Osmia; without doubt they store up honey and secrete wax, but it is hardly possible that $B$. kirbyellus can accumulate provisions, and we know that certain solitary bees (Centris, some Anthophoras) already produce a waxy secretion.

The tropical bees of the family Meliponida, the American Meliponas and Trigonas of the two continents, build with wax ovoid cells similar to those 


\section{THE PSYCHIC LIFE OF INSECTS}

of bumblebees, but these cells are used only for provisions and are included in the nest which they build of clay and resin. What especially distinguishes the constructions of these bees is the presence of horizontal or oblique rearing floors formed by a single row of hexagonal cells which open upward, and are provisioned before the laying, like those of the solitary bees. The societies of these bees are formed of a queen and a number of neuter females which possess only collecting organs. We know from Hermann von Ihering ${ }^{1}$ that the young queens are of almost the same size as the workers, that those of Melipona are born in the ordinary cells and remain some time in the nest until their organs harden, while those of the Trigonas grow in large royal cells and are fully hardened before their issuance. In the two cases, however, the societies are perennial and multiply by swarming; and since the queen mothers become very obese and incapable of taking flight, it must be admitted that the swarms are formed by the young queens and by a crowd of workers.

The societies of Apis, or true bees, so-called, are also composed of a single queen, of neuter females, and males; they are also perennial and multiply by swarming, but they occupy a much

$1 \mathrm{H}$. von Ihering, Biologie der stachellosen Honingbienen Brasiliens, 1903. (Zool. Jahrh. Syst., v. 19. pp. 179-287.) 
higher place in the social hierarchy. Their combs are always vertical and formed of two layers of hexagonal cellules, which are connected at the bottom; these cells serve at the same time for provisions and for rearing, while the larvæ which they enclose are provisioned from day to day. The queen mother is obese but capable of flight; she does not allow the young queens near her, and after they issue, swarms with a party of workers. All the species are not, however, in the same evolutional stage. Apis dorsata makes only one comb, in which all the cells are alike; the little $A$ pis florea also constructs a single comb, but the cells are of two kinds, small ones for the workers, larger ones for the males, and according to Buttel-Reepen, it seems, indeed, that the royal cells are constructed at the expense of the latter. In the Apis indica and in our honey-bee (Apis mellifica) the combs are multiplied, more or less parallel, with cells of three kinds, of which the royal cells are constructed of several of the others, or at the expense of the worker cells. This is the highest social type in the group of Mellifera.

One would think that the higher bees are related to the solitary bees through the bumblebees, the Meliponas, and the Trigonas, but this is not true, as we see it, and it seems rather that these types have diverged on leaving their solitary sources. 


\section{THE PSYCHIC LIFE OF INSECTS}

In fact, we conclude with Emery (1894), "we know no precursor stage" to the kind of social form of our honey-bee, "but only stages which resemble these precursor stages, and which we may utilize to understand the biological phylogeny of the societies" of the Mellifera. The same is true, moreover, of wasps.

Wasp societies. With the social wasps as with the higher bees, the egg is laid singly in the still empty cell, and the food of the larvæ is given them day by day. But this food is composed of fragments of fresh prey more or less masticated and mixed with honey, and, except for their reproductive organs, the queens differ very little from the workers.

With $H$. von Ihering and Ferton, we had thought that the social wasps were near the solitary sphegids, more or less closely related to Bembex, because Monedula punctata studied by Hudson, Bembex mediterraneus, Stizus tridens, and $S$. errans, studied by Ferton, lay their egg in an empty cell and nourish their larvæ from day to day with killed or partially paralyzed prey. But the recent studies of Roubaud ${ }^{\mathbf{1}}$ have shown that, aside from this primitive method, the sphegids have evolved in the sense of causing more or less

1 E. Roubaud, Recherches biologiques sur les Guêpes sociales et solitaires d'Afrique. (Ann. Sci. Nat. Zool., ser. 10 v. 1. pp. 1$160,1916)$. 
perfect paralysis, which allows them to accumulate in their cells all the prey necessary for the food of their progeny; also, that they have not passed this stage, and that the social wasps are directly related to the solitary wasps of the family Eumenida.

As a matter of fact the Eumenida have become detached from the sphegid group, but their biological evolution has been brought about in a different way. The Odynerus and the Eumenes of our country are excellent paralyzers which lay their egg and afterward make a provisioning in mass like the sphegids. The African species studied by Roubaud, Synagris calida, S. sicheliana, Eumenes tinctor, Odynerus bellatulus, do the same in the wet season, since then there is an abundance of caterpillars, but in the dry season, when this food is much rarer, they await the hatching of the egg, furnish the larva "with more than enough food to last through the day," and before closing the cell complete the provisioning "with a sufficiently large supplementary supply of caterpillars." It is the delayed provisioning in bulk which leads us to the daily provisioning practised by Synagris cornuta. Roubaud has stated, indeed, that this species feeds its larvæ from day to day with fragments of caterpillars. After a detour which leads them to perfect paralysis and provisioning in bulk, 


\section{THE PSYCHIC LIFE OF INSECTS}

Synagris returns to the brutal habit of the Bembecids and to the mode of provisioning which is its consequence. This method is followed by all social wasps, notably by one of the African species, Belonogaster junceus, studied by Roubaud. With this wasp the habits resemble those of Synagris cornuta, but the young live in the nest by the side of the parents which built it, and the work which they do retards somewhat the maturation of their ovarian glands. In fact, these young become sooner or later fertile, and as the nests may be founded by several queens, we see that the societies of this species are polygenous at an approximate time. Having no workers, these very primitive societies dissolve by emigration when bad weather comes. Then it is not rare to see a queen raise a single larva at a time and behave exactly like Synagris cornuta. Without doubt Belonogaster builds paper nests like most of the social wasps, but certain of the latter also know how to build masonry nests, like Eumenes and Synagris, or to dig readily in the soil like Odynerus.

From Belonogaster we pass to Icaria and to Polistes marginalis, social African wasps in which Roubaud has noted the presence of numerous queens and of a lesser number of true workers. Polygeny is also frequent with the American social wasps, among which it was discovered by Her- 


\section{SOCIAL LIFE OF ARTICULATES 329}

mann von Ihering (1896) with Polybia scutellaris. In this species the number of queens may reach fifteen per cent. of the population, which is principally composed of neuter females. Extending the researches of his father on other species, Rodolphe von Ihering (1905) has divided the social wasps into polygamous forms (polygynes) and monogamous forms (monogynes) according as their societies include several queens or one only. This classification has been systematized by Ducke in a recent work, ${ }^{1}$ but it would hardly seem natural when we consider that certain genera, such as Polybia and Polistes, include at the same time monogamous and polygamous species. However this may be, we cannot doubt that Chatergus, Nectarina, and the most of the Polybias are polygamous; while the Vespidæ, the true wasps, are monogamous in all countries. It is to be noted that the polygamous American societies are perennial and that they multiply by swarming, that many store up honey, and that their cells are all alike, which is a primitive character. According to $\mathrm{H}$. von Ihering, Polybia scutellaris gives its larvæ mutilated prey, and not bits of flesh.

Our Polistes gallicus is an annual species whose pedunculate nest is made of cells of the same size. It forms monogamous societies, but Ferton has

1 A. Ducke, Revision des Guêpes sociales polygames d'Amérique: 1910. (Ann. Mus. Nat. Hungar. Budapest, v. pp. 499-544.) 


\section{THE PSYCHIC LIFE OF INSECTS}

seen females of this species (sisters, to all appearances) living in perfect amity and associating together in the work of the nest. As to the true wasps of the genus Vespa, they also are monogamous, but their nests are composed of many shelves in which are found cells of two kinds, little ones for the workers, larger ones for the true females, the eggs of the males being placed in those of either size, but preferably in the smaller ones. This is the maximum of the division of work and of castes in the group of social wasps. This division is not pushed as far as with the bees. When she is definitely held in the nest by the need of laying, the original queen, says Robert du Buysson, "' still continues to work; she gives slight retouches here and there to the covering and to the cells; she distributes to the larvæ morsels which are furnished to her by the workers," and this recalls a little the very primitive habits of Belonogaster.

Factors common to all the social groups. It appears from what precedes that the social life is found in very different groups and with groups which are very diverse from the psychic point of view. This form of life is, then, equally independent of heredity and of intelligence. As La-

1 R. du Buysson, Monographie des Guêpes ou Vespa, 1903. (Ann. Soc. Ent. France, v. 72, pp. 260-882.) 


\section{SOCIAL LIFE OF ARTICULÃTES 331}

meere ${ }^{1}$ judiciously observes, the origin of these societies "results from ethological factors which bring organisms of the same species together in the same locality, leading up to the establishment of social ties." "The ethological factors, the conditions of the environment favorable to the parents, are equally favorable to their descendants, who, because of the law of least effort, do not fail to profit by it provided the space is sufficient and that the habits of the animal are such that an individual permits or desires the neighborhood of its kin. And that shows us that combinations or groups of individuals are already family groups; also, that strangers of the same species can profit by the conditions of the favorable environment to join themselves to these groups and to enlarge them. From this a colony will develop which to a certain degree will differ from an adjoining one in its habits, from the fact that it represents a different family grouping. It is in this way that Fabre has interpreted his curious observations upon the ineptness which is characteristic of the yellow-winged sphex in certain of its colonies and upon the cleverness with which it meets emergencies in certain others (see page 114).

The factors of the communistic social life. Al-

1 A. Lameere, L'Origine des Sociétés d' Insectes, 1915. (Rev. gén. des sci. pures et appliv. v. 26, pp. 459-464.) 


\section{THE PSYCHIC LIFE OF INSECTS}

though we observe all intergrades between individualistic societies and communistic societies, the primordial trait of the latter is the association of the young with their parents in a manner which is profitable to both. In order that such a group shall be possible, it is necessary that the young, at least the first young, see the day while their parents are still working on the nest; but this condition is not enough; besides this, it is necessary that the young should belong to a species which is more or less sociable.

We know from Fabre that the female of Copris hispanicus remains in the burrow near its egg and even helps the young in hatching, but the latter when once out do not associate with their mother, for Copris prefers to work alone. It is probably not the same with Halictus quadrimaculatus studied by Verhoeff and with the Synagris studied by Roubaud, for the first young of these social Hymenoptera remain in contact with their parents. But the phenomenon is rare, if it occurs, and it is not known in any communistic society among these insects. With these, however, we are on the point of beginning the evolution of the social life. When, with species possessing similar instincts, the hatchings are such that normally there is contact between the parents and their young, the latter do not migrate. And if they re- 
main in the nest in which they were born, "it is probably," as Lameere says, "by virtue of the law of the least effort:- they profit by the work begun by their parents or by their mother," and that is, in fact, what we see in all communistic societies.

Other factors contribute to hold these new-born to the nest. Roubaud observed that the young females of Belonogaster remain in the nest for eight days and during this time receive the nutritive morsels which they chew and distribute among the larvæ "after having eaten a certain portion of it." In exchange for this privilege, which allows time for their ovaries to ripen, they devote themselves to the care of the nest and await for the coming day of coupling. Once fertilized, they become in their turn egg-layers, and then are attached to the nest by new bonds, - the gratification which egg-laying gives them by satisfying the ovarian apparatus, and their liking for a liquid rejected by the mouth of the larvæ which they know wonderfully well how to collect. It is an individual interest which keeps them in the nest and which makes them work in the common interest, that is to say to assure better the preservation of the species. Aside from the egg-laying, which is an accident with the workers, the same factors of colonization apply to the whole group 


\section{THE PSYCHIC LIFE OF INSECTS}

of social wasps. The larvæ of our Vespa, observes Robert du Buysson, "have the faculty of secreting an abundant liquid from the mouth. When they are touched, there suddenly appears a large transparent drop which covers the larger part of the face. The queen, the workers, and the males are fond of this secretion and they know how to excite the larvæ to furnish them this beverage." Between the larvæ and the adults a food exchange is established, a trophobiosis. Roubaud says:

Wasp societies are trophobiotic societies, dependent on the exploitation of the larvæ. They tend toward maximum production, in an individualistic way, of the larvæ. The maternal love of the wasps, which is shown in the perfect care which they take of their young in feeding them from the beak like birds, does not differ at bottom from the feelings which ants have for plant-lice and scale-insects, which they cultivate for their secretions.

We also believe, with Roubaud, that individual interest is not without weight in the societies of ants and termites. Forel observes, in fact, that the eggs of ants as soon as laid receive the attention of the workers, which, "are constantly occupied in licking them." Bugnion has stated, on the other hand, that the eggs of the termites of Ceylon are "bathed in a covering liquid 


\section{SOCIAL LIFE OF ARTICULATES 335}

at the moment of laying," that they "are submitted first to the operation of licking," and that without this operation they cannot develop. Is this not then again a phenomenon of trophobiosis?

We cannot extend this to the bees, for the worker bees can gain no advantage from the eggs nor from the larvæ, especially with the Meliponas, where the provisionment is great. But the young of all the Mellifera have the advantage of being born in an already prepared nest, and all without doubt enjoy to a certain extent the privileges which the young honey-bees have. We know, indeed, that at the moment of their birth the young bees are cared for and brushed by the older workers, that afterward these stay in the nest to act as nurses, and that they as well as the larvæ benefit from the provisions collected by the others. They do not leave a lodging where the hospitality is so great!

Founding of communistic societies. If it be true, as we cannot doubt, that social insects have developed from solitary ancestors, there is reason to believe that communistic societies were originally monogamous, that is to say established by a single female. That is what we see normally with the wasps and the bees of our country, with Vespa and most of the Polistes and some of the Polybias 


\section{THE PSYCHIC LIFE OF INSECTS}

of tropical regions. It is the same with the termites, where one rarely finds several royal couples in a nest. This is the belief of Buttel-Reepen, of Lameere, and also mine, as well as of Von Ihering and his son Rodolph's, supporting the idea that polygamy is a primitive character of communistic societies, that it originated in an epoch of perennial summer in which the social life developed under the influence of the warm climate, that it persists to-day in regions which have preserved that climate, while it has given place to monogamy in localities where the climate has become colder.

These biologists apply this thesis to the consideration that in our country insect colonies are all monogamous, but, on the contrary, very often polygamous in tropical regions. But from the fact that we find several queens in one society we cannot conclude that this has a polygamous foundation. In reality climatic influences act on the constitution and the duration of communistic groups in the measure in which they favor the provisioning of the nest. When they permit a continuous and more or less abundant harvest the society can become perennial, and one can conceive that then the young queens can remain in the nest with its founder until the period of swarming. When, on the contrary, the harvest 


\section{SOCIAL LIFE OF ARTICULATES 337}

is limited to a single season this perennial form cannot become possible except with those species (termites and true bees) which store up sufficient reserve food for hard times; otherwise the colony dissolves when food begins to be scarce. Thus a favorable climate may produce a perennial colony, and this favors in its turn the association of females, but these possibilities are not always realized and their realization depends on the habits of the species, as is shown by the true wasps, or Vespida, which in all countries form annual monogamous societies. Therefore, to know whether polygamous societies are established by several queens we must know about their beginnings, and so far this has been so only with Belonogaster junceus.

But it appears from the observations of Roubaud that the colonies of this very primitive social wasp are ordinarily monogamous at the time of their fecundation. "Customarily," says the author, "it is an isolated female which lays the first base for the nest, but very often, also, two or more females associate together to found a new nest."

We know that ants' nests very often contain several queens, but it is probable that they were established by a single queen. I have told before how Jacob Huber was able to follow the estab- 


\section{THE PSYCHIC LIFE OF INSECTS}

lishment of a colony of fungus-cultivating ants from the original queen, and on the other hand Bondroit had the good fortune to find a nest of Lasius in which the queen was still alone with a small number of larvæ coming from her first eggs. It will be interesting to know whether or not the formicaries of Lasius and those of Atta, which cultivate fungi, usually contain several queens at the period of their complete development.

Origin of castes in communistic societies. However it may be, the nests of termites, of bumblebees, of ants, and of most of the wasps are always established by royal couples which at the start must satisfy all the needs of the budding society. The need is great, but it quickly grows less, since there soon hatch young individuals of the same sex, which join their efforts to those of their parents. In Belonogaster, where communism is at its dawn, the young resemble the stem-mothers and have the same functions. Their ovaries are not yet ripe, and before becoming egg-layers they remain in the colony and act there as workers.

But the experiments of Marchal have shown that the sterility of the worker wasps is the result of functions which they perform in the society. Worn out with intense labor and giving much to the larvæ, they are ordinarily incapable of forming eggs and have therefore subjected themselves 


\section{SOCIAL LIFE OF ARTICULATES 339}

to a nutritial castration. From that comes the very long retardation in the laying, which Roubaud has observed with certain young females of Belonogaster, and from it also comes the peculiar constitution of the bumblebee societies, which are monogamous in our country and in which the workers are well-formed but sterile females, but which in America are polygamous, many females filling the rôle of egg-layers while others are true non-fertile workers. It is also a nutritial castration of the same origin to which we must attribute the existence of pure workers in the swarming colonies of Polybia and other polygamous wasps, the Meliponas and other true bees. With the latter and perhaps with other swarming species the nest is not established by the queen, but by the workers, which emigrate with her and do all the work except egg-laying.

In many cases, but not in all, the castration of the workers comes from insufficient larval food. This phenomenon is very evident with the insects whose nest is begun by the original couple or the original female. The first larvæ are scantily fed because of the intensive work of the mother which has to provide for all needs. So the first-born are always neuters or immature and are always of smaller size. But when the food of the larvæ becomes more copious, when the young take a part 


\section{THE PSYCHIC LIFE OF INSECTS}

in the work and set the founder free for her normal functions, then the size increases and there comes a moment when certain young develop into queens and males (royalties). This can easily be noted with the bumblebees and the wasps of our country. Termites do not seem to lend themselves to observation of this kind; however, with them also the castration is of alimentary origin, for their young larvæ can be made royal when they are better nourished.

The influence of the nourishment of the larvæ upon fecundity is much more evident still with the Meliponide of the genus Trigona and with the true bees generally, with the exception of Apis dorsata. These bees make their royal cells much more spacious than the others and provision them much more richly. With the Trigonas, where the cells are provisioned all at the same time and closed with the egg inside, the royal food seems to be of the same nature as that of the workers. With the bees whose larvæ are nourished with the beak, this food is not only more copious but of a peculiar quality (royal jelly), and it is so effective that it is necessary for the bees to transform ordinary cells into royal cells for the use of the young larvæ to which they will give the royal food in order to make of them future royalties. 


\section{SOCIAL LIFE OF ARTICULATES 341}

These phenomena are much more obscure with the ants. According to the observations of Wheeler on the Ponerines, the nourishment is served by chance and it seems impossible to distinguish from the food alone between the worker larvæ and the queen larvæ; but this is perhaps only apparently so, for there are other species in which the lack of nourishment makes the females retrograde into workers. It is thus, according to Wasmann, with the sanguinary ants, which take into their nests the Staphylynid parasites of the genus Lomechusa which they lick on account of the cutaneous secretion. Lameere says:

When these parasites become very numerous the ants become crowded. It is said that then the larvæ which would have given birth to winged females, being badly cared for, produce only degenerate wingless females (pseudogynes) having transitional characters which brings them near the workers. This is the opposite of the transformation of a worker into a queen of the honeybee.

Before drawing any conclusion from the preceding facts, we must stop to consider two kinds of bees, namely the Meliponas and Apis dorsata, which differ from related forms in the mode of rearing their queens. Like the Trigonas, the Meliponas enclose their egg in a provisioned cell, but they do not build royal cells, and all are alike. 


\section{THE PSYCHIC LIFE OF INSECTS}

It is, then, not the nourishment which produces the differentiation of females into workers and queens with these forms. With Apis dorsata, as with all true bees, the larvæ are nourished at the beak, but the queen larvæ do not seem to receive a special food, and in any case are reared in the same cells as the workers. Here again the differentiation of the female individuals appears to be independent of the nourishment, and this differentiation is inherent in the protoplasm of the egg. This potential differentiation is still more evident in the eggs of termites whch produce soldiers armed with a frontal horn. Bonnier (1914) has shown, in fact, that the embryos of these soldiers already possess this horn and that the young leaves its egg-envelop with its definite characters. These facts are bothersome at first, since they seem to show that the female eggs of Melipona and of Apis dorsata and the soldier eggs of certain termites possess properties which are entirely lacking in the analogous case of other communistic insects. These last are called trophogenic because they produce individuals whose sexual development depends on the food; the others are called blastogenic because they are already functionally differentiated.

But it seems difficult to admit that the female eggs of Apis dorsata and of the Meliponas and 
the eggs of the nasute soldiers of termites differ so profoundly from those of related forms. We believe it more rational to suppose that all eggs are more or less blastogenic,- that is to say capable of producing young of a determined kind,but that this power is rarely so great as to resist the effects of a later feeding. With this very important restriction, we may apply to all communistic insects the explanation which Lameere applies only to the soldiers of the termites: "We find ourselves here in the presence of a phenomenon comparable to that which is offered to us by those Papilios which give in one egg-mass two or three varieties of females."

We need not delude ourselves, however, with this explanation, which is, rather, a comparison; it is far from clearing up a mystery which rests without doubt in the intimate constitution of the eggs and in the manner in which a female can make in her body eggs of different kinds other than of one sex. But the cause of this diversity is not, perhaps, so mysterious. Contrary to Lameere, who really followed the ideas of Weismann, we attribute it in part to properties ao quired in the course of social evolution. Wheeler (1910) attributed the differentiation of castes in communistic societies to a philoprogenitive instinct which led the members of the colony to de- 


\section{THE PSYCHIC LIFE OF INSECTS}

prive themselves for their young and which already showed with the solitary ancestors of the social insects. We do not deny that that instinct might be necessary, just as a certain sociability is necessary, to the installation of the communistic life. But how has it been able to develop to the point of producing castes and of reacting on the constitution of the eggs? That is the gist of the problem.

But Belonogaster and Bombus have shown us that the castration of the females has been progressively brought about from the influence of work which will not allow the ovaries to become sufficiently nourished. This castration has resulted in the annihilation of the tendency to couple, to reduce the ovipositions or to make them disappear, and in addition to concentrate all the activity of the individual upon work,-that is to say to increase its philoprogenitive instincts. That such changes in the constitution of the reproductive glands and in the habits have been able to affect the somatic cells of the body and through them the eggrs or germinative cells, is what we believe possible, in spite of the contrary assertions of Weismann (see page 154); and from this the habits and characters acquired by the neuters may be transmitted to the progeny by the 


\section{SOCIAL LIFE OF ARTICULATES 345}

means of males coming from non-fecundated eggrs which usually produce workers.

To this Lamarckian explanation it cannot fail to be objected that worker eggs are rare and accidental, but they are much commoner than is believed, as the most recent investigations show, and many biologists think that with communistic insects they play an important rôle in the production of the males. In any case, it is enough that some egg-layings, even very scarce, should exist in order that the characters acquired by the neuters may be transmitted.

There is, then, reason to believe that the fertile female hands down to the neuters born to her, aside from mutation characters, those acquired progressively by their caste. What is not yet explained is the faculty of laying eggs of two kinds, some predestined to sexual functions and others to the life of neuters, but a mystery of the same kind exists concerning all females that have polymorphlic progeny. We have seen, moreover, that this predestination is not absolute, and that with most communistic insects proper food and proper care can modify it.

The characters acquired by the royal individuals are a consequence of the specialization of the neuters. In so far as they take a more or less im- 


\section{THE PSYCHIC LIFE OF INSECTS}

portant part in the cares of the society, the royal individuals devote themselves more and more to sexual functions, and in the most perfect societies they know no others. Here again the characters and the habits are progressively acquired. With most social insects the royal individuals have preserved from their birth, and preserve sometimes all their lives, the characters of their solitary ancestors, especially the instruments of work which permit them to establish a new colony by themselves. Later, when their activity confines itself to the filling of the reproductive functions, they may become modified, and the females may acquire a considerable size in relation to the development of their ovaries. With the higher bees, Meliponas and true bees, the workers alone have to preserve the normal characters and the instruments for work. Exclusively occupied with egglaying functions, the queens are extremely obese and do not possess these instruments. That they have lost them because of the specialization which belongs to them, is shown with the bumblebees, where the queens are not less well tooled than the female workers.

Communistic societies are super-organisms. It is the presence of workers which gives communistic societies their highest degree of perfection, 
for it is that which allows the greatest division of labor and which establishes between the members of the colony the most complete solidarity. From this point of view we have established a parallel between communistic societies and differentiated cellular organisms. In the two cases one notes all the steps between the division of work at its beginning and its extreme form as seen with the higher animals. In the two cases, also, certain elements function to the end of assuring reproduction; others are devoted to the vitality of the organism. The differentiated cells of the soma, or body, of a living being correspond to the neuters of the societies and, like them, they function for the good of the organism and are sacrificed to preserve its life. The germinal or reproductive cells are represented by the royal individuals, and live, like them, with the active workers, and, like them also, they are immortal in the sense that they continue in their progeny. The sacrifice of numerous units for some is not less necessary to the progress of organisms than to that of the societies. As Lameere says, this sacrifice testifies "to the triumph of life through death," and, we may add, of the race over the individual.

In summing up we may apply to all societies of insects which are frankly communistic the same 


\section{THE PSYCHIC LIFE OF INSECTS}

character that Bergson ${ }^{1}$ attributes to the hives of the honey-bee. They are "really and not metaphorically a unique organism" in which each individual is united "to the others by invisible bonds." One may call them, with Lameere, "super-organisms." We scarcely know the steps by which the social bonds of these super-organisms have been established, the division of social work, and how an original alimental castration has produced the workers, and we are ignorant of the manner in which the members of one colony have been able to coördinate their actions, until they have reached that marvelous condition which makes the nest and the rearing a work which is singularly complex and always the same in spite of the obstacles and the various situations which the insect meets in its work. Isolated, the social individual is incapable of all useful endeavor; in company with its fellows, it knows how to solve the greatest difficulties. I have seen (1905-06) the honey-bee nest in the open air under very different conditions, but it has never failed to choose the best architectural method of protecting its combs or to give its cells their characteristic form. Georges Mæterlinck has spoken of the esprit of the hive. Is there, then, an esprit of communistic

$1 \mathrm{H}$. Bergson, L'Evolution créatrice, 1907. 


\section{SOCIAL LIFE OF ARTICULATES 349}

societies? And this esprit,-is it not somewhat analogous, by the reaction of individuals upon individuals, to what Dr. Gustav LaBon has called the esprit of crowds? It is easier to indicate this problem than to solve it. 


\section{CONCLUSION}

In current language the word "instinct" is used for all the hereditary and automatic manifestations of activity, from tropisms to the most complicated outward manifestations of individual memory. Instinctive acts are stereotyped, always the same when responding to stimuli of the same kind, and almost always adapted to their object, although not the result of the previous individual experience. It is impossible to define them more precisely, since they are varied and complex, overlapping one another and often becoming so confused that it is difficult to trace their limits.

We should not, however, put them all in the same category and attribute a common origin to all. Tropic reactions result from the properties of living matter, rhythms presuppose an organic memory, and therefore an ancient or recent apprenticeship; but this apprenticeship is purely mechanical and is dependent upon the stimuli that produce it.

Apprenticeship has also played a part in the 350 
manifestations of species memory which play so great a part in the behavior of articulates, although this has a distinctly higher oharacter, since it was created by the distant ancestors of the individual under the form of a choice between the different possible responses of differential sensitiveness. Choice means still more and has an intellectual character that is even more wonderful in the instinctive manifestations of the individual memory. Endowed with well-developed senses and a nervous system, the animal not only reacts to new necessities with new acts, but it preserves the memory of old sensations, associates the old with the new, and uses them to meet the new emergenoy. :Thus, in an intelligent way, new habits are established, which by heredity are added to the patrimony of instinct, modifying it and forming one of the essential elements of its evolution. It is these instincts, acquired by an intelligent apprenticeship, that Forel said were automatized reasoning, and it is to them particularly that we may apply the conception of certain biologists who define instincts as habits which have become hereditary and automatic. It is probable that all the higher instincts had originally this intellectual quality. This certainly is true of those which originated from more or less slowly acquired habits; but it is apparently also 


\section{THE PSYCHIC LIFE OF INSECTS}

the rule with those originating as mutations; for whether they result from sudden psychic change or follow a sudden organic modification, these instincts must alway's be preceded by some intelligent period of apprenticeship, during which they are perfected, to pass on to posterity and to take the instinctive character.

Here, then, we are confronted with several classes of instinctive acts, which differ not only in their origin but in intellectual characteristics. No doubt they are linked together by many intermediates, and in the animals which we are considering they often blend the one with the other or even with the reflexes, on account of the profound differentiation of nerve and sensorial centers. Nevertheless it is very difficult to see in them manifestations of a special faculty which under the name instinct we can place on the plane of intelligence. There are certain forms of activity which may justly be called instincts, since they are innate and automatic, but these forms proceeded in diverse ways from the vital energy which is the source of all organic activity; and the highest, which are at the same time the most striking ones in the animals we are studying, were originally acts which required more or less true intelligence on the part of species and of individuals. Intelligence never played any part in the 
development of that instinct which attracts nocturnal Lepidoptera toward the light, nor does it play any greater part with the rhythms by which organic memory manifests itself. But it is intelligence that rules by adaptive selection all manifestations of species memory; and it is intelligence, again, that puts together the most complicated mechanisms of instinct in the diverse forms of association and of individual memory.

Instincts are diverse. If we class under the name instinct not one special faculty' but the ensemble of all instincts, that is to say, innate automatism, whatever its origin may be, we may say with Bergson that instinct and intelligence "are not things of the same order," that they "diverge more and more in their development," but that "they never completely separate from each other." They are both "opposites and complements" and they assist each other.

On the one hand, indeed, the most perfect instinct of the insect is accompanied by certain gleams of intelligence, be it only in the choice of place, time, or material of construction. When, exceptionally, bees build in the open, they invent new and truly intelligent arrangements to meet the new conditions. But on the other hand, intelligence has still more need for instinct than instinct for intelligence, for the ability to work with raw material presupposes in the animal a superior grade of organi- 


\section{THE PSYCHIC LIFE OF INSECTS}

zation, to which it could have risen only on the wings of instinct.

Before such evidence Fabre was forced to modify his theory of immutable instinct. He says:

Pure instinct alone would leave the insect disarmed in the perpetual conflict of circumstances. . . . A guide is necessary in this confused mix-up. . . . The insect surely has this guide in high degree. This is the second domain of its psychic powers. Here it is conscious and perfectible by experience. Not daring to designate this rudimentary aptitude as intelligence, a title too high for it, I shall call it discernment.

But is not discernment in this sense really a form of intelligence?

Such is the measure in which instinct and intelligence are associated in animals. If, with Bergson, we regard consciousness "as proportional to the power of choice at the will of the animal," it will be evident that consciousness must be singularly obscure in all instinctive acts, but that on the contrary it must accompany' all intelligent acts. Bergson, however, regards consciousness in a peculiar light, since he considers it as life "projected through matter," as the common source from which have sprung in different directions both instinct and intelligence. This leads us away from the common concept which sees in consciousness the torch which enlightens our ac- 
tions. It is possible, even probable, that a consciousness of this kind exists to a greater or less extent in the animals. However, we cannot know anything about it, and we believe with Edmond Claparède ${ }^{1}$ that "animal psychology can and must scrutinize the problem of the greater or less intelligence of animals without being concerned with their consciousness."

In its simplest form intelligence reveals itself to us in a choice between the various alternatives offered by circumstances, and in one of its highest forms in the power of invention which, according to Bergson, enables the human race to "manufacture artificial objects, especially to make tools with which to make other tools and to vary their fabrication indefinitely." These two extreme forms are naturally connected by many intermediaries, and we know that both play a part in the behavior of articulates. The latter seems, however, to be rather exceptional in the group, and shows itself only in a primitive stage which consists of the use of foreign bodies as implements. With Ammophila urnaria the tool is a small stone with which the female rams and packs the dirt that closes her burrow. With certain ants of India (Ecophylla smaragdina) and of Brazil

1 Ed. Claparède, Les animaux sont-ils conscients?..1901. (Revue phil., v. 26, pp. 481-498.) 


\section{THE PSYCHIC LIFE OF INSECTS}

(Camponotus textor) the instrument consists of the larvæ of the same species which, held between the mandibles of the workers, glue and fasten the leaves of which the nest is constructed, edge to edge, with their thread. The implement of the crabs of the genus Melia, in the Indo-Pacific seas, is a delicate sea anemone which, held between the pincers of the animal, probably serves to paralyze its prey by its urticating exudations.

Facts of this kind are rare in the world of the articulates, but they have an important significance. The use of the stone is not yet a fixed habit with Ammophila urnaria; it belongs only to certain more highly endowed individuals with whom, perhaps, it is only an accident. Possibly it will finally pass into the instinctive habits of the species; for the present it remains in the class of individual and intelligent acts. The crabs of the genus Melia are already beyond this stage, since all the species carry anemones and all have a curious modification of the pincers, the fine teeth having become elongated into needles which give them a better hold on their guest-tool. The adaptation to the latter is evident, but it does not seem that the crab is likely to be in grave peril when it has not its Actinia. Many of the Melias brought back by explorers have no anemones, and we may believe that the presence of this living tool is not yet 
a vital necessity to the species of this curious genus. But this is not true of the ants which use their larvæ as needles. Here the singular habit is innate, specific. It was probably acquired through intelligent acts, but, with the species which practise it, it now belongs entirely to the domain of instinct. And so we always return to the fact which dominates the psychological history of the articulates, namely, the transformation of intelligent acts into instinctive acts. The following considerations formulated by Bergson admirably apply to this group:

Among animals, invention is never more than a variiation on the theme of routine. Locked up within the habits of the species, the animal succeeds, no doubt, in broadening these by its individual initiative; but it escapes from automatism only for an instant, just long enough to create a new automatism; the gates of its prison close as soon as opened; dragging on its chain, it merely succeeds in lengthening it. With man consciousness breaks the chain.

Man occupies the highest point in the vertebrate scale, for he breaks the chain of instincts and thus assures the complete expansion of his intellect. The insects, especially Hymenoptera, hold the same dominating position in the scale of the articulates, where they are the crowning point of instinctive life. These two groups represent the 


\section{THE PSYCHIC LIFE OF INSECTS}

actual extremes of the two paths followed by psychic evolution in the Animal Kingdom,- - the articulates toward instinct, the vertebrates toward intelligence. These two paths are quite divergent, but why have they diverged? At the beginning of their evolution, during that far distant epoch when they were differentiating along four main lines (Echinoderms, mollusks, articulates, and vertebrates), animals were threatened by a danger,-_"an obstacle," says Bergson, "that doubtless almost checked the progress of animal life. There is a peculiarity which we cannot help being struck with when we glance at the fauna of early times. The mollusks then were more universally provided with shells than those of to-day. The arthropods in general were provided with a carapace.... The oldest fishes had a bony covering of extreme hardness." But, "the animal which is shut up in a citadel or in a coat of mail is condemned to an existence of half-sleep. It is in this torpor that the Echinoderms and even the mollusks are living to-day." The arthropods and the vertebrates escaped from it, and to this happy circumstance we owe the present development of the highest forms of life.

In two directions, indeed, do we see the impulse of active life regaining the upper hand. The fishes exchanged their ganoid armor for scales. Long before them the 
insects had appeared, having also rid themselves of the armor that protected their ancestors. In both groups the inefficiency of the protective envelop was compensated for by an agility that enabled them to escape their enemies and also to take the offensive and to choose the place and time of the encounter.

These remarks are profoundly true, but they should be modified in one point which is essential to explain the structure and the special psychology of the articulates. These animals have never lost their chitinous armor that protected their primitive ancestors. They have preserved it in its entirety and with greater or less thickness, and the Coleoptera, the crabs, the scorpions, and the thousand-legs of our times yield nothing in this regard to the ancient forms from which they are descended.

In fact, to-day as formerly, they are covered with an external skeleton of chitin, and that is why Edmund Perrier, wishing to emphasize their dominant character, has called them by the name of Chitinophores. To escape imprisonment within their protective envelop, to acquire the flexibility and mobility necessary to their evolution, they became the object of certain superficial modifications. These consisted in the division of the armor into several pieces by means of articular lines, along which the chitin is less thick than else- 


\section{THE PSYCHIC LIFE OF INSECTS}

where, dividing their armor into pieces and permitting these pieces to move one upon another. Thus they became articulated, and at once acquired agility without losing their protective armor. Naturally, such joints were formed wherever the several segments, arranged in a row and constituting the body of the animal, came together, with the result of giving these segments a certain independence and yet preserving, to a large degree, their uniformity. Indeed, we see that many articulates possess a pair of appendages on each segment (myriapods and the majority of crustaceans) and that the insects most remote in this regard from the primitive types are still provided with seven pairs of appendages (one pair of antennæ, three pairs of mouth parts, and three pairs of legs), without counting the modified or rudimentary organs to be seen at different points on the abdomen. And the chitinous envelop of these appendages has broken into joints just as the body is divided into rings. Hence the name of arthropods, often given to articulate animals.

What a difference from the vertebrates, in which the skeleton becomes an internal framework which allows the organism to reach greater dimensions, the segments to fuse to a greater degree and to lose more or less their independence, 
all of which results in the reduction of the number of limbs to only two pairs!

Now, the relative independence of the segments and the multiplicity of the appendages have as a corollary a differentiation of these parts, each of which plays a special rôle in the organism. As Bergson observes, the various appendages of the articulates are a kind of natural tools, which differ from one another in structure as well as in function. Their specialization may even be carried so far that each part of an organ performs a special function. This is well seen in the bee, in which the first tarsal joint of the hind legs is transformed into a brush, the tibia into a pollen basket, while the two joints, by the contact of their edges, form pincers which seize the flake of wax secreted by the abdomen underneath. It is an admirable tool and wonderfully adapted to fill its particular functions. As a general rule, apart from the changes which they undergo in the course of specific evolution, the appendages of arthropods are nearly unchangeable in the individual and are narrowly adapted to certain purposes; they are the tools for instinctive work, in which they differ from the less specialized but more supple limbs that serve as implements to the vertebrates, at least to the higher vertebrates. With 


\section{THE PSYCHIC LIFE OF INSECTS}

these latter, as Bergson says, the two pairs of limbs "perform functions much less strictly dependent upon their form," acquiring complete independence in man, "whose hand can do any kind of work." Thus, the extraordinary preponderance of instinctive activity among the articulates seems to have as its essential point of dependence the differentiation and the multiplicity of the appendages,- - that is to say, the chitinization of the integument and the formation of articular lines which result from it. These animals from the beginning were doomed to use organic tools, and they made the best use of them. Their main psychical task was to grave upon their memory and to repeat instinctively the acts to which these organs were fitted. 


\section{INDEX}





\section{INDEX}

Activity, manifestation of, by lower organisms, 90

Adaptation, as evinced by tropisms, 41

in evolution of species memory, 89 possible, of differential sensitiveness, 84

reciprocal, 226

Adaptative selection; rôle of intelligence in, 353

Aërial insects, knowledge of orientation in, 237

sight in, 237, 238

African fly, vital rhythms of, 50

Agamic reproduction, definition of, 287

Agelena, orientation with, 251

Ammophila, urn-making habits of, 137,139

Amœbœ, in simulation, 94

Anemotropism, definition of, 29

diptera in, 29

fish in, 30

hemiptera in, 30

paludinas in, 30

Animal intelligence, 355

Ant roads, 276

behavior of ants on, 279, 280, 281 establishment of, $277,278,279$ use of antennary sense in, 278

Antennæ, seat of chemotropic reactions, 25

Antennal sense of ants, 279, 280, 281

Anthophilous insects, and associative memory in, 224, 225

definition of, 200

in flower selection, 204

rôle of color and form with, 218

Anthropocentrism, 126

Ants, in chemotropic reactions, 26 in thermotropism, 22

reproductivity in, 290

results of "food castration" among, 290

"Apprenticeship," of articulates, $112,113,114,115,116,118$

rôle of, in instincts, 350

in species memory, 350

Apiculture, 206

Aquatic bugs, manifestations of hydrotropism in, 24
Aristolochias, trap mechanism of, 229

Aristotle on fertility of neuters with bees, 289

Arthropods, name for articulates, 360

Articulates, "apprenticeship" among, 112,113

as individualists, 312

chitinous armor of, 359

development of, toward instinct, 357

development of communism among, 312

in simulation, 94, 95, 96, 97, 98, 99,100

invention among, 355

make-up of memory of, 123

name arthropods for, 360

proterandry among, 310

psychic life of, instinct in, 358

social life of, 312,348

psychology of special, 259

terrestrial, orientation with, 251

use of tools by, 355,356

Articulations, development of, 360

differentiation of, 361

Asclepiads, trap mechanism of, 228

Associative memory in anthophilous insects, 224

Asymmetry of lighting, relation of, to asymmetrical muscular activity, 12

Atavism, 161-166

as evidenced by moths, 163

Automacy of simulation, by insects, 103

Automatism, characteristic of tro pisms, 37

dominance of, 119, 120, 121

evolution of, from psychism, 105

of phototropic animals, 9, 10

Automatized reasoning, 351

Bacterium thermo, in manifestations of chemotropism, 25

Balanus, in manifestations of phototropism, 19

Bedbug, differential sensitiveness of, 74

in "trial and error," 85 
Bee fertilization, 290, 291, 292, $293,294,295$

Bees, buccal adaptation of, 203

in acts of individual memory, 121

in manifestations of individual memory, 108, 109

individual societies among, 313

male eggs of, Huber on, 292, 293, 294

selective power of the queen among, 296

sense of orientation in, 247

social, buecal apparatus of, 208

societies of, $320,321,322,323$, $324,325,326$

Beetles, in manifestations of individual memory, 106

in simulation of death phenomena, 91

"Behavior." 77

of ants, on ant roads, 279, 280, 281

of Tyria jacobcece, 77

of Vanessa antiopa, 78, 79

Bergson, definition of Consciousness, 354,355

on communistic societies, 348

on evolution of function, 362

on instinct, 173,353

on intelligence, 353

on invention, 355

on invention among animals, 357 on organic memory, 63

Berlepsch on male eggs of bees, 293

Bethe, on instincts, 173

on orientation in ants, 283, 284

on reflex lives of insects, 127

on topochemical sense among ants, 285

on orientation, 240,242

Bohn, observations on automatism of phototropic animals, 8

on acquired periodicity in insects from natural rhythms, 57

on law of differential sensitiveness, 71

and law of variation in excitant, 74

and possible adaptation, 86,87 , 88

and tropic combinations, 81

in relation to stimulus specificity, 73

on interrelation of tropisms and differential sensitiveness, 77

on phenomena of stimulation, 93, 94,97

on psychic aptitudes of animals, 128 on physico-chemical interpretation of phototropism, 16 on sensitiveness in negative phototropism, 68

on species memory, 88

on vital rhythms, 60

Bonnet on sense of smell of ants, 279

Bonnier, on apiculture, 206, 207

on castes in communistic societies, 342

on exploring ants, directive sense of, 261

on form attraction of flowers, 218

on influence of fiower odors, 219

on reciprocal adaptations, 226

Bordage, on experiments in orientation, 241

on instincts and reflexes, 172

Brown-tail moth, in manifestations of thermotropism, 22

Buccal apparatus, adaptation of, 20 in bees, 203

in diptera, 201

in hymenoptera, 201, 202, 203

in lepidoptera, 201

in social bees, 208

Bugnion, on evolution of social instincts, 334

on fertilization among solitary species, 304

Büttel-Reepen on associative memory in anthophilous insects, 225

on crowd reflex of hymenoptera, 317

on polygamy in communistic societies, 336

on sight among aërial insects, 238

on societies of bees, 320,321 , 322,325

Butterwort, trap mechanism of, 229

Cannibalism among spiders, 315

Castes in communistic societies, 338 origin of, 338

relation of Lamarckian theory to, 345

Castration, through food insufficieney, 339

Caterpillars, and known objective, 236

and inherited instincts, 141, 142

individual societies among, 314 , 315

processionary, migratory reaction of, 233

Chance, rôle of, in search for nourishment, 232

in sexual approach, 232, 233

Characteristics, acquired, Detmer on, 156 


\section{INDEX}

Giard on, 155

heredity of, 150-174

Neo-Darwinian theory on, 153, 154,155

Chemicals in their relation to tropisms, 24

Chemotropic reactions, seat of, 25

Chemotropism, definition of, 25 examples of, 25 oxygen experimentation in, 25 in ants, 26

in Drosophila ampelophila, 26

in mosquitoes, 27

in silkworm moths, 26

manifestations of, by Bacterium thermo, 25

negative, 26

Chitin, segmentation of, into joints, 360

Chitinophores, Perrier on, 359

Chœromyias, larvæ of, in fetal rhythms, 51, 52

"Circling," Cornetz on, 270, 271, 272,273

Claparède on animal intelligence, 355

on migrations, 233

on orientation, 231 on psychic aptitudes of animals,

Cockroaches, social evolution of, Lameere on, 318

Coleoptera, in diurnal periodicity, 53 in geotropism, 27

Color attraction for bees, Lovell on, 213

Color attraction for insects, 213, $214,215,216$

Color attraction of flowers, Pérez on, 217

Communism, development of, among articulates, 312

Communistic instinct, among bees, 313

among crabs, 313

among spiders, 316

among wasps, 314

Communistic social life, factors in, $331,332,333,334,335$

Communistic societies, as superorganisms, 346

Bergson on, 348

esprit in, Maeterlinck on, 348

growth of solidarity in, 318

Lameere on, 347

monogamy in, 337

origin of castes in, 338

polygamy in, 336

"Comportement," $7 \mathbf{7}$

Consciousness, Bergson on, 353, 354 definition of, 354
Contacts, effects of actions of insects on, 28

Convoluta, natural rhythms of, 57

Cornetz on "circling," $270,272,273$ on establishment of ant roads, 278,279

on exploring ants, 256, 258

directive sense of, 261,265 , 267,268

on orientation in ants, 255

Corolla mutilation, by bees, 209, 210

Cossus ligniperda, in manifestations of phototropism, 9

Crabs, individual societies among, 313

Crawfish, in manifestations of stereotropism, 31

Crowd reflex, among hymenoptera, 317

Crustaceans, mutations among, 159, 160

Cuénot on fertilization among solitary species, 304

Cuma rathkei, in manifestations of phototropism, 9

Currant-worms, differential sensitiveness of, 72

Dadane, on queen bee fecundation, 296,297

Danais archippus, in manifestations of combined tropisms, 33

Darwin on biological significance of simulations, 100

on flower odors, 219

on inherited instincts, 145

on reciprocal adaptation, 226

Davenport, on periodicity of excitability, 48

on tropic adaptations, 44

De Layens, on apiculture, 206

Dermatoptic sensations and differential sensitiveness, 75

Detmer, on acquired characteristics, 156

Dewitz, on rheotropism, 29, 30

on stereotropism, 30

Dickel, on male eggs of bees, 293

Differential response and tropisms, 67

Differential sensitiveness, and dermatoptic sensations, 75

and law of return, 73

and law of variation in excitant, Bohn on, 74

and light, 78 
and phenomena of simulation, 93 , 94,95

and points of stimulation, 76

and possible adaptation, 86,87 , 88

and species memory, $87,88,89$

and tropic combinations, 81

as outcome of "trial and error," 81

as shown in "simulation of death," 91

in relation to stimulus specificity, 73

to tropisms, 77

to variation of the excitant, 74

independence of stimulated points of, 76

law of, 71

in contradistinction to tropisms, $74,75,76,77$

modalities of, 86

of bedbugs, 74

of currant-worms, 72,74

of maggots, 69, 70, 74

of Starfish, 72

of Vanessa antiöpa, 67

of worms, 61

possible adaptation of, 84

rules of, $70,71,72$

Diguet on societies among spiders, 316

Diptera, buccal apparatus of, 201

in anemotropism, 29

in diurnal periodicity, 53

Directive orientation, manifestations of, by Volvox, 6

Directive sense of exploring ants, 259

Distance, estimation of, by exploring ants, 274

Diurnal butterflies, vital rhythms of, 48,49

Diurnal periodicity, acquisition of, 50

examples of, $51,52,53$

of coleoptera, 53

of diptera, 53

of hymenoptera, 53

of neuroptera, 53

of pseudo-neuroptera, 53

Diurnal variations in excitability, 46,47

Division of sexes in partial layings, $306,307,308$

Dixippus, in periodicity, 54

Dolichopodids, in geotropism, 28

Dolley on asymmetry of lighting, 12

Drory, on queen bee fecundation, 296

Drosophila ampelophila, in chemotropic reactions, 26 in manifestations of phototropism, 15

Drzewina, on acquired rhythms, 58 on apprenticeship, 116, 118

Dubois, Raphael, on periodicity of phosphoresence phenomena, 55

$\mathrm{Du}$ Buysson, on evolution of social instincts, 334

on wasp societies, 330

Ducke, on wasp societies, 328

Dung-beetle, individual memory of, 111

Dzierzon, on male eggs of bees, 292 on parthenogenesis of male bees, 291

Egg-laying, periodicity in,

Emery, on ant reproduction, 290 on atavism, 166

on societies of bees, 326

Englemann, on chemotropism, 25

Englenas, directive orientations of, 6 positive phototropisms of, 34,35

Escherich, on topochemical sense among ants, 285

Ethological factors, in group evolution, 331

Euproctis chrysorrhoea, in phototropism, 19

Excitability, variations in, diurnal, 46 periodicity of, 47

Excitant, variations in, and law of differential sensitiveness, $\mathbf{7 4}$

Exploring ants, 255

"circling" among, 270, 271

directive sense of, 260,261

estimation of distance by, 273, 274,275

independent sense of direction of, 262,263

rules of march of, 255

sense of direction in, 259

Eyes, relation of, to phototropic sensitiveness, 10

Fabre, on changelessness of instincts, 129

on division of sexes among solitary hymenoptera, 300, 301, 302

on establishment of ant roads, 278 on evolution of social instincts, 332

on fertilization among ants, 303, 304

on geotropism, 28

on immutability of instinct, 354

on individual memory, 111 
on individual societies among bees, 313

on instincts and reflexes, 170, 171,172

on manifestations of individual memory, 106

on migrations, 233

on orientation in articulates, 252 , 253

on pompilids, 180

on proterothesis among solitary nesting species, 306

on "simulation of death," 91

on simulation phenomena, 93, 94, 97

on social adaptation, 99,331

Fauvel, on acquired rhythms, 58

Fecund neuters, parthenogenetic reproduction among, 288, 289, 290

Fecundation by the queen bee, 295, 296,297

Fecundity, influence of nourishment on, 340

Fertilization among ants, 303, 304 among solitary species, 304,305 of bees, 290, 291, 292, 293, 294, 295

performance of, 227

Fertility, among neuter ants, causes of, 290

Ferton, observations on individual memory, 108, 112

on atavism, 165

on color attraction for insects, 214

on fiower preferences, 205

on habits of insects, 132, 133

on manifestations of individual memory, 108, 109

on pompilids, 176, 177, 178, 182 . $185,188,189,192,193$

on self-benefit in reciprocal adaptation, 230

on wasp societies, 326,329

Field, on ant reproduction, 290

Figs, selection of, by hymenoptera, 205,212

Flies, and phototropism, 7

Flower odors, attraction of, 221 influence of, 219

Flower selection, Kerner on, 204, 205,212

Flower selection, 212 psychic factors in, 222

Flowers, adaptations to, by mellifera, 203

and antliophilous insects, 207, 208

and bees, interrelation of, 204

interrelation of, 203 artificial, attraction of, for insects, 216

rolation of insects to, 200

Forel, on automatized reasoning, 351

on social grouping of ants, 320

on ant reproduction, 290

on evolution of social instincts, 334

on apprenticeship, 113

on orientation of aërial insects, 237

on psychic factors in flower selection, 222

on topochemical sense among ants, 285

on rôle of scent in and orientation, 281,282

on antennal sense of ants, 279

on establishment of ant roads, 278

Form attraction, Darwin on, 217

of flowers, for insects, 217,218

Friese, on crowd reflex of hymenoptera, 317

on societies of bees, 323

Functions, evolution of, 362

Galvanotropism, 42

manifestations of, by Palcemonetes, 42

Gamniarus pulex, in manifestations of phototropism, 15

Geometrids, "four-legged" appearance of, 4

Geotropism, in coleoptera, 27 definition of, 27

in dolichopodids, 28

Giard, on Lamarckian Law, 147 on Neo-Darwinian theory, 155

Grasshoppers, migratory reactions of, 234

Gravity, action of, on tropisms, 27

Habit, as shown by the urn-making Ammophila, 137

as typified by the Philanthus wasp, 135, 136, 137

transference of, into instinct, 357

Habits, of insects, 129, 130, 131, 132,133

of Osmias, 134

Hadley, on phototropic reaction of lobster larvæ, 11

Heat, in relation to tropisms, 22

Heliotropism, meaning of, 7

Hemiptera, in anémotropism, 30

Hereditary transmission of acquired characteristics, 151, 152

Heredity, 146, 147 of acquired characteristics, 153 
Higher animals, subordination of tropisms in, 36

Holliday, on ant reproduction, 290 on social grouping of ants, 320

Holmes, on biological significance of simulations, 100

on phenomena of simulation, 93, 94,97

Huber, on apprenticeship, 116

on male eggs of bees, 292

on monogamy in communistic societies, 337

Huggins, on apprenticeship, 116

Hydrometras, rheotropism, in, 30

Hydrotropism, definition of, 23

experiments in, 23

manifestations of, by aquatic bugs, 24

by tanning fungus, 23

Hymenoptera, buccal adaptation of, $201,202,203$

choice of figs by, 205

crowd reflex of, 317

esprit des corps among, 317

in diurnal periodicity, 53

reconnaissance flights of, 243,244

relation of, to flowers, 202

scale of, in instinctive life of insects, 357

Individual memory, evolution of, 105 from species, 105

manifestations of, 106, 107, 108, $109,110,112$

by bees, 109

by beetles, 107

by Osmia, 108, 109, 110

by wasps, 106

of bees, 121

of dung-beetle, 111

of Sphegia, 111

reasons for use of name, 118

rules of, 121

Individual societies, among bees, 313

among crabs, 313

among insects, 314

among spiders, 316

among wasps, 314

Individualism among articulates, 312

Instinct, and reflexes, 173

compared with intelligence, 353

definition of, 167

development of, through organic tools, 362

differentiation of, from reflexes, 168

due to habit, 357

immutability of, 354

importance of, in psychic life of articulates, 357,358

in insects, 125
Instincts, and reflexes, $170,171,172$ changelessness of, 129, 130, 131 definition of, 350

evolution of, 140,174

inheritance of, 141, 142, 143, 144 inherited, 144,145

of caterpillars, 141, 142

of silk worms, 145

modifications of, by inheritance, 140,141

by mutations, 153, 154

origin of, $350,351,352$

rôle of apprenticeship in, 350

tropic reactions among, 350

Intelligence, compared to instinct, 353

influence of adaptive selection, 353

Intention, in insects, 125, 126, 127

Invention, among articulates, 355

Irritability, protoplasmic, 1-105

Jennings on differential sensitiveness and tropic combinations, 82

on law of differential sensitiveness, 71

on pain, 83

on pleasure, 83

on species memory, 88

on tropic adaptation, 43

Kellogg on chemotropic reactions, 26

Kerner on flower odors, 220, 221 on flower preferences by insects, 204

Kruth, Paul, on interrelation of flowers and bees, 204, 208

Künckel d'Herculais, on buccal apparatus of lepidoptera, 201

on migrations of grasshoppers, 234,235

on trap plants, 228

Labitte, on apprenticeship, 114

Lamarckian law of heredity, 146, 147

Lamarckian theory on origin of caste, 345

commentaries, by Lamarck, 150 , 151

Giard on, 148

Le Dantec on, 148

Lameere on castes in communistic societies, 343

on communistic societies as superorganisms, 347

on evolution of social instincts, 333

on origin of social groups, 330 , 331 
on social evolution of cockroaches, 318

on polygamy in communistic societies, 336

Larvæ, of the Choromyias, in acquisition of rhythm, 51, 52

Le Dantec on Lamarckian Law, 148

Lepidoptera, buccal adaptation of, 201

vital rhythms of, 46,47

Light, and differential sensitiveness, 78,79

attraction of, for all insects, 5

directive action of, $2-20$

law of, on negative phototropic animals, 69

on positive phototropic animals, 69

Light production, rhythm of, 55

Light traps, use of, for destruction of Vive pyralis, 5

Lighting, asymmetry of, in relation to asymmetrical muscular activity, 12

Limulus polyphemus, in phototropism, 19

Littorina, in "trial and error," 86 natural rhythms of, 57

Living matter, protean character of, 41

Lobster larvæ, phototropic reaction of, 10,11

Locusts, in anémotropism, 29

Loeb, experiments of, in thermotropism, 22

on character of phototropism, 8

on chemotropic reactions, 26

on differential sensitiveness and light, 79

on galvanotropism, 42

on geotropism, 27

on law of tropisms, 6

on movement in relation to phototropism, 17

on periodicity of excitability, 48

on pnototropism and reproduction phenomena, 20

on phototropism and temperature, 17

on phototropic reaction of lobster larvæ, 11

on phototropism and nutritive phenomena, 20

on physical interpretation of, 11

on physicochemical interpretation of phototropism, 15, 39, 40

on positive phototropism of the Euglenas, 34

on psychic aptitudes of animals, 128

on pyralids, 4

on stereotropism, 31 on temperature and phototropism, 16, 17

on tropic adaptation, 43

on tropisms in relation to sensitiveness, 67

on variations in excitability, 46

Lovell, on apprenticeship, 116

on color attraction for bees, 213

Lubbock on exploring ants, 257

on flower odors, 220

on memory, 124

on negative chemotropism, 26

on orientatives in ants, 283,284

on phenomena of intention, 127

on reciprocal adaptation, 226

on visual images in orientation, 264

Luminous intensity, effect of, on negative phototropic animals, 69

Maeterlinck, on esprit in communistic societies, 348

Maggots, differential sensitiveness of, $69,70,74$

Marchal on castes in communistic societies, 338, 339

on division of sexes among wasps, 298

on fertility of neuters, 289

on fertilization among solitary species, 305

on inherited instincts, 143

on parasitism, 195

on reflexes and instincts, 170

Marchand, experiments of, in orientation, 241

Massari, on stereotropism, 30

Maxwell on galvanotropism, 42

Mayer, experiments on tropisms by, 33

Mechanical agitation and phototropism, 18

Mellifera, adaptation of, to flowers, 203

Memory, as topographic feeling, 240

individual, 90,104

evolution of, 105

manifestations of, 106, 107, $108,109,110$

loss of, among insects, 238

of articulates, make-up of, 123

of olfactory sensations, 250

of visual sensations, 248, 249

organic, 60,63

physiological, 63

species, 89

Mendelian Law, 149

Micropteryx calthella, choice of $R a$ nunculus acris, by, 204

Migrations, 233

with unknown objective, 232, 233, 234,235 
Misanthropic Pagurus, rhythms of 58,59

Modalities of differential sensitiveness, 85

Moisture in its relation to tropisms, 23

Monogamy in communistic societies, 337

Morgan on differential sensitiveness and tropic combinations, 82

Mosquitoes, in chemotropic reactions, 26

Moths and atavism, 163

Moths, night-fiying, "four-legged" appearance of, 4

Movement, and phototropism, 16, 17

Movement, rhythm of, 55

Muscular activity and, phototropism, 18

Mutations, amongst crustaceans, 159, 160

Mutations and the social insects, 157

Müller, H., on trap plants, 229

on reciprocal adaptation, 226

on flowers and anthophilous insects, 207, 208

on nectar sucking methods of bees, 211

Natural selection in insects with tropic reactions, 45

influence of, upon sexual dimorphism, 310

Nectar-sucking methods of bees, 209, 210,211

Negative chemotropism, 26, 27

Negative phototropic animals, effect on, of luminous intensity, 69 law of response to external stimuli, 70 law of response to light, 69

Negative phototropism, sensitiveness in, 68

Neo-Darwinian theory, on acquired characteristics, 153, 154, 155

Girard on, $\mathbf{1 5 5}$

Neuroptera, in diurnal periodicity, 53

Neuters, fertility of, among ants, 290 occasional fertility of, 288

Nicolas, on apprenticeship, 115 on pompilias, 191

on socicties of bees, 321

Noctuids, "four-legged," appearance of, 32

Noctuid moths, in stereotropism, 32 vital rhythms of, 49

Nourishment, search of, rôle of chance in, 232
Nutritive phenomena, effect of, upon phototropism, 19

Objective, known, caterpillars in relation to, 236

Objectivity of tropisms, 38

Olfactory sensations, memory of, 250

rôle of, in flower sclections, 212

Organ activity in flower selection, 211

Organic memory, 60

and vital rhythms, 40-64

Orientation, antennal senses in, among ants, 279, 280, 281, 283

in articulates, 252, 253

with Agelena, 251

with ants, 254, 255

with pompilids, 252, 253

with Terrestrial articulates, 251286

"circling" in, 270, 271

directive, away from light, 7 toward light, 5

experiments in, 240,241, 242

faculty of, $231-251$

knowledge of, in aërial insects, 237

perceptible, objective point in, 232,233

non-perceptible objective point in, 232,233

rôle of scene in, among ants, 281, 283

of ants, 269

use of antennæ in, 269

use of eyes in, 269,270

sense of, in bees, 246,247

of ants, conclusions concerning, 286

rôle of sight in, $283,284,285$ among ants, 283

through visual images, 263, 264, $265,266,268$

Osmia, and habits, Ferton on, 132, 133,134

flower selections of, 205

in individual memory, 108, 112

in manifestations of individual memory, 108, 109, 110

Osmia ferruginea, in individual memory, 110

Osmia rufohirta, in individual memory, 109

Oxygen experimentatives, as an example of chemotropism, 25

Oxytricha fallax, in "trial and error," $81,82,83-84,88$

Palomonetes, in galvanotropism, 42 


\section{INDEX}

Paludiuas, in animotropism, 30

Parasitism, origin of, amongst pompilids, 193, 195

Parker on asymmetry of lighting, 12 on differential response and tropisms, 67, 68

on law of differential sensitiveness 71

Parthenogenesis, among bees, 295 of male bees, 291

Parthenogenetic reproduction, definition of, 287

Paulcke, on male eggs of bees, 293

Peckhams, on color attractions for insects, 213

on individual societies among in. sects, 314

on orientation, experiments, 242 with articulates, 252

on pompilids, $180,182,184,185$, $187,190,193$

on reconnaissance flights of $\mathrm{Hy}$ menoptera, 243,244

on urn-making Ammophila, 137

Pelagic copepods, in phototropism, 17

Pérez on fertility of neuters, 289

on flower odors, 220

on habits of Osmias, 134

on individual memory, 121

on inherited instincts, 145

on interrelation between flowers and bees, 220

on male eggs of bees, 294

on orientation, 243

on parasitism, 195

on psychic factors in flower selection, 223

on queen bee fecundation, 298

on reciprocal adaptation, 226

Periodic phenomena, general occurrence of, 59

Periodicity, acquired, in insects, developed from natural rhythms, 57

acquisition of, 51

in egg-laying, 60

of Dixippus, 54

of excitability, 47

of phosphorescence phenomena, 54,55

phosphorescent insects in, 55, 56

thermic sensibility and, 50

Peripatus capensis, in manifestations of phototropism, 8

Perrier, on Chitinophores, 359

Perris on diurnal periodicity, 54

Petrunkievitch, on male eggs of bees, 293

Philanthus wasps, study of, in relation to habit, $135,136,137$
Phillips on parthenogenesis of bees, 295

Phosphorescence phenomena, periodicity of, 56

rhythm of, 55,56

Phosphorescent insects, and periodicity, 55, 56

Phototropic animals, automatism of, 9

positive, response to external stimuli in, 70 response to light in, 69

response to luminous intensity in, 69

Phatotropic sensitiveness, relation of eyes to, 10

Phototropism, 2-20

character of, 8

manifestations of, by Balaunus, 19 by Cossus ligniperda, 9

by Cuma rathkei, 9

by Drosophila ampelophita, 15

by Euproctis chrysorrhea, 19 by flies, 7

by Gammarus pulex, 15

by Limulus polyphemus, 19

by pelagic copepods, 17

by Peripatus capensis, 8

by Vanessa antiopa, 12

meaning of, 7

mechanical agitation and, 18

modifying factors in, 17

movement as modifying factor in, 17

muscular activity and, 18

negative, meaning of, 7

nutritive phenomena and effect of, 19

physical interpretation of, 11

physicochemical interpretation of, 13

positive, 5

meaning of, 7

sensitiveness in, 67,68

temperature and, 17

reproduction phenomena and, 20

Physicochemical explanation of tropisms, 39,40

Physicochemical interpretation of phototropism, $13,15,16$

Physiological finality, law of, 230

Physiological memory, 64

Piéron on antennal sense of ants, 279

on "circling," 273

on exploring ants. 255, 256, 258

on inheritance of instincts, 141 142,144

on organic memory, 63

on protean character of living matter, 41

on tropic adaptations, 44 
Plant life, directive orientation of, 6

Plateau, on color attraction of flowers, 216

on flower odors, 219

on form attraction of flowers, 218

on reciprocal adaptation, 226

Pleasure, 83

Ple urosigma, rhythms of, 61

Pliny, pyralids of, 2

Polygamy in communistic societies, 336

Pompilids, capture of prey by, 176, $177,178,179,180$

history of, 175,176

mason species amongst, 190

nest of, $189,190,191$

orientation with, 252,253

parasitic, 192

parasitism of, origin of, 193

relation of the egg and larvæ of, 187,188

treatment of victims with, 180 , $181,182,183,184,185,186$, 187

Pouchet, discoveries concerning negative phototropism by, 7

on phototropism and movement, 16

on phototropism and nutritive phenomena, 20

Protean character of living matter, 41

Proterandry among articulates, 310

Proterothesis among solitary nesting species, 306,307

Protoplasmic irritability, 1-105

Protoplasmic reactions, 104

rôle of nervous system in, 104 rôle of sensorial organs in, 104 to stimulating influences, 1-109

Psychic factors in flower selection, $221,222,223,224$

Psychic life, of articulates, importance of instinct in, 358

Psychic phenomena and tropisms, differentiation between, 38 independence of tropisms, 38

Psychism, appearance of, in lower animals, 105

evolution of, into automatism, 105

Pyralidae,

four-legged appearance of, 4

Pyralids of Pliny, 2

Pyralids, observations on, 5

Queen bee, fecundation by, 296 , 297, 298

Rabaud on biological significance of simulation, 101

on phenomena of simulation, 97

on pompilids, 188
Ranunculus acris, selection of, by Micropteryx calthella, 204

Réamur on periodicity of excitability, 47

on variations in excitability, 46

Reciprocal adaptation, 226

self-benefit in, 230

Reflex life of insects, 127

Reflexes, differentiation of, from instinct, 168

Reichenbach on ant reproduction, 290

Reproduction phenomena, effect of, upon phototropism, 20

Rheotropism, definition of, 30 manifestations of, by Hydrometras, 30

Rhythm, acquired, 52 et $s e q$

in laying, among solitary nesting species, 305

appearance of, 310,311

innate, 52

natural, development of periodicity in organisms in, 57

of Convoluta, 57, 61

of Littorina, 58, 61

of light production, 55

of Misanthropic pagurus, 58, 59

of Pleurosigma, 61

of movement, 54

sexual, of queen bees, 297

vital, 62

Romanes, on variations in excitability, 46

Root, on bee fertilization, 295

Root, on queen bee fecundation, 296

Roubaud, on acquisition of periodicity, 51

on castes, in communistic societies, 339

on diurnal periodicity, 50

on evolution of social instincts $332,333,334$

on monogamy in communistic societies, 337

on periodicity in egg-laying, 60

on wasp societies, $314,326,327$, 328

Santschi on estimation of distances by insects, 274,275

on rôle of senses in orientation of ants, 280, 281

on visual images in orientation, 264, 266

Scent, rôle of, in ant orientation, $281,282,283$

Schroeder on atavism, 163, 164 on inheritance of instincts, 144

Seibold on male eggs of bees, 293

Sensations, olfactory, in flower selections, 212 
Sensations, olfactory, memory of, 249,250

Sensations, visual, in flower selections, 213

Sensations, visual, memory of, 248, 249

Sensitiveness, differential, 65-103 tropisms and, 67

Sensitivity, in tropic animals, 35 property of living matter, 35

Sexual approach, rôle of chance in, 232,233

Sexual dimorphism, appearance of, 310

Sight, among aërial insects, 237

rôle of, in orientation, among ants, 283

Silkworm and inherited instincts, 145

Silkworm moths, in chemotropic reactions, 27

Simon, on social groups among spiders, 316

Simulation, amoebæ in, 94

articulates in, 94, 95, 96, 97, 98, 99,100

biological significance of, 99

by insects, automacy of, 102

differential sensitiveness and, 93, 94,95

mechanism of, 96

physical nature of, 96

water-bugs in, 91

"Simulation of death," 91

phenomena, beetles in 91

Social adaptation, 99, 331

Social groups, common factors in, 330,331

ethological factors in, 331

origin of, 330,331

Social Hymenoptera, derivation from solitary species, 309,310

division of sexes with, 288

members of colony of, 288 males, 288

neuters or workers, 288 queen, 288

Social insects and mutations, 157

Social instincts, evolution of, 332 , 333,334

Social wasps, division of sexes among, 298

Societies, of ants, 319,320

of bees, $320,321,322,323,324$, 325,326

of bees, building among, 323,324 , 325

of mellifera, $320,321,322,323$, $324,325,326$

of Termites, 318

Solidarity, growth of, in communistic societies, 318
Solitary Hymenoptera, division of soxes among, 300, 301, 302, 303

Solitary nesting species, proterothesis among, 306, 307

Soule, experiments on tropisms by, 33

Species memory, 87, 88, 89

adaptation in evolution of, 89

evolution of, into individual, 105

rôle of apprenticeship in, 351 rôle of nervous system in, 104

Sphegid, individual, memory of, 111

Spiders, cannibalism among, 315 sanguinary instincts of, 315 societies among, individual, 316

Sprengel on trap plants, 229

Stahl, experiments of, in hydrotropism, 23

Starfish, differential sensitiveness of, 72

Stereotropism, definition of, 31 manifestations of, by crawfish, 31 by noctuid moths, 32

psychic phenomena and, 38

Stimuli, external, and their relation to tropisms, $21-45$

law of response, positive phototropic animals and, 70 law of response, negative phototropic animals and, 70

Stimulated points in relation to differential sensitiveness, 76

Stimulus, specificity, in relation to differential sensitiveness, 72,73

Super-organisms, communistic societies as, 346

Szymanski, on apprenticeship, 112 on estimation of distances by insects, 274,275

Tannine fungus, in manifestations of hydrotropism, 23

Temperature and phototropism, 17

Thermic sensibility and periodicity, 50

Thermotropism, definition of, 21, 22 experiments on, 22

manifestations of, by ants, 23 by Brown-tail moth, 22

Tineids, "four-legged" appearance of, 4

Tools, organic, use of, in development of instinct, 362

used by articulates, 355,356

Topochemical sense, among ants, 285

Topographic feeling, among insects, 238,239

Topographic memory, visual images of, 263 
Tortricids, "four-legged" appearance of, 4

Trap plants, 228

"Trial and error," bedbug in, 85

in relation to differential sensitiveness, 81

littorina in, 86

Oxytricha fallax in, $81,82,83,84$ 88

theory of, 81,82

Tyria jacobaece in, 86

Tropic adaptation, 43,44

Tropic animals, apparentness of sensitivity in, 35

Tropic reactions and natural selection, 45

Tropisms, action of chemicals, 24

action of contact on, 28

action of gravity on, 27

action of heat on, 62

action of moisture on, 23

adaptation of, 42

anémotropism and, 29

association of, amongst themselves, 32

character of, 37

automatic, 37

characteristics of, adaptation, 41

injuriousness, 43

uselessness, 42

chemotropism, 24

combined, manifestations of, by Danais archippus, 33

discovery of law of, 7

effects of contacts on

anémotropism, 29

rheotropism, 30

stereotropism, 30

geotropism, 27

hydrotropism, 23

meaning of, 6

objective side of, 38

origin of, 40

psychic phenomena and, 38

psychic phenomena of, independence of, 38

physicochemical explanation of, by Loeb, 39, 40

relation of, to external stimuli, $21-45$

in relation to sensitiveness, 67

in relation to differential sensitiveness, 77

in contradistinction from differ. ential sensitiveness, $74,75,76$, 77

subordination of, in higher animals, 36 thermotropism, 21, 22

variations in, 44

Turner, on apprenticeship, 112

on "circling," 270,271

on individual memory of Sphegid, 111

on manifestations of individual memory, 107, 109, 110

on orientation experiments, 241

on visual images in orientation, 265

Tyria jacobcece, "behavior" of, 77

"trial and error," in, 86

Vanessa antiopa, differential sensitiveness of, 67

behavior of, 78,79

in manifestations of phototropism, 12

Variations in excitability, periodicity of, 47

in tropisms, 44

Verhoeff on fertilization among solitary species, 304

Vertebrates, development of, toward intelligence, 358

Viehmeyer on ant reproduction, 290

on visual images in orientation, 265

Vine Pyralis, destruction of, by light traps, 5

four-legged appearance of, 4

Visual images in orientation, 264, 266

Visual sensations, memory of, 248 , 249

rôle of, in flower selections, 212

rôle of, with anthophilous insects, 218

Vital rhythms and the organic memory, 40-64

and larva of Chœromyias, 51, 52

demonstrations of, by Lepidoptera, 46,47

of African fly, 50

of diurnal butterflies, 48,49

of noctural moths, 49

Volvox, in manifestations of directive orientation, 6

Von Ihering, on corolla mutilation, 210

on polygamy in communistic societies, 336

on societies of bees, 323

on wasp societies, 326,329

Wasmann on ant reproduction, 290 on castes in communistic societies, 341

on exploring ants, 262, 263, 268 
on orientation in ants, 284

on queen bee fecundation, 296 .

on topochemical sense among ants, 285

Wasp societies, 326, 327, 328, 329, 330

Wasps, in manifestations of individual memory, 106

individual societies among, 314

Water-bugs, in phenomena of simulation, 93

Weismann on castes in communistic societies, 343,344

on heredity of acquired characteristics, 153, 154, 155
Wery, on color attraction for insects, 215,216

on form attraction of flowers, 218

Wheeler, on ant reproduction, 290

on atavism, 164

on castes in communistic societies, 341

on chemotropism, negative, 27

on orientation among ants, 286

on social groupings of ants, 319

Williston, on habits of ammophilas, 139

Worms, differential sensitiveness of, 65

Yerkes, on apprenticeship, 116 








$\rightarrow$ (5)

int 5 . 